Final Report

FHWA/IN/JTRP-2002/13

\title{
DESIGN OF MSE WALLS FOR FULLY SATURATED CONDITIONS
}

\author{
by \\ Antonio Bobet \\ Assistant Professor \\ School of Civil Engineering \\ Purdue University \\ Joint Transportation Research Program \\ Project No. C-36-36FF \\ File No. 6-14-32 \\ SPR-2405 \\ Prepared in Cooperation with the \\ Indiana Department of Transportation and the \\ U.S. Department of Transportation \\ Federal Highway Administration
}

The contents of this report reflect the views of the author who is responsible for the facts and the accuracy of the data presented herein. The contents do not necessarily reflect the official views or policies of the Indiana Department of Transportation or the Federal Highway Administration at the time of publication. This report does not constitute a standard, specification, or regulation.

Purdue University

West Lafayette, Indiana 47907

August 2002 


\section{TECHNICAL Summary}

INDOT Research

Technology Transfer and Project Implementation Information

TRB Subject Code: 62-1 Foundation Soils

Publication No.: FHWA/IN/JTRP-2002/13, SPR-2405

August 2002

Final Report

\section{Design of MSE Walls for Fully Saturated Conditions}

\section{Introduction}

Over the past three decades, Mechanically Stabilized Earth (MSE) retaining walls have been increasingly used as design alternatives to traditional reinforced concrete retaining walls for supporting earth fills in civil infrastructure projects. MSE walls can retain earth fills of significant height and sustain surface applied loads at lower cost than reinforced concrete walls. Because they are flexible and mechanically redundant structures, MSE walls are particularly suitable for difficult foundation soil conditions where differential settlements are anticipated. In general, MSE retaining walls consist of structural fill reinforced with tensile-resistant inclusions that are connected to facing elements. The internal stability of the reinforced soil structure is provided by mechanical interactions of its three components, i.e. fill material, reinforcement, and facing.

MSE walls are much more economical than traditional cast-in-place concrete walls. Current design of MSE walls for drained conditions is based on limit state analyses in which the ultimate strength of the soil and the pullout capacity of the reinforcement are incorporated. This approach has been satisfactorily used for a large number of walls. However for fully saturated conditions there are no clear guidelines for the design of MSE walls.
INDOT design guidelines contain the following statement: "For fully saturated conditions, sitespecific field or laboratory pullout tests shall be performed". Performance of such tests is very timeconsuming and expensive. As a result, MSE walls are not specified for many projects.

The stability of MSE walls may be compromised in undrained conditions such as during a heavy rain or during a rapid drawdown. Excess pore pressures in low permeability soils may not dissipate quickly enough, and thus may reduce the effective stresses inside the soil, which in turn may cause a reduction of the shear strength at the interface between the soil and the reinforcement. The study of MSE walls in undrained conditions is needed to determine the behavior of saturated MSE walls where rapid changes in pore pressures are anticipated. For this purpose, a series of laboratory pullout tests are performed under drained and undrained conditions for different soil types ranging from clean sand to $35 \%$ silty sand and for overburden pressures of 30, 100 and $200 \mathrm{kPa}$. Numerical analyses are also conducted to determine scale and permeability effects for the dissipation of excess pore pressures.

\section{Findings}

Results from the experimental and numerical investigation of the drained and undrained pullout capacities of a steel reinforcement embedded into a silty sand soil matrix show that:

(1) Effect of silt: Drained and undrained pullout capacities decrease from clean sand to $5 \%$ silty sand, increase from $5 \%$ to $10 \%$, and then decrease from $10 \%$ to $15 \%$ and $35 \%$ silty sand. The pullout capacity changes as the internal friction angle of the soil changes because the pullout capacity increases as the internal friction angle of the soil increases.

(2) Effect of overburden pressure: The pullout capacity increases as the overburden pressure increases. Larger displacements are required to reach the maximum pullout 
capacity for higher overburden pressures. Higher soil stiffness is observed for higher overburden pressure.

(3) Effect of drainage: The undrained pullout capacity is always smaller than the drained pullout capacity except for clean sand, which is the same. The ratio of undrained to drained pullout capacity changes with silt content and with overburden pressure. For $100 \mathrm{kPa}$ and $200 \mathrm{kPa}$ overburden pressure the ratio is 1.0 for clean sand, decreases to $0.67 \sim 0.69$ for $5 \%$ silty sand, $0.77 \sim 0.78$ for $10 \%$ silt, $0.72 \sim 0.73$ for $15 \%$ and $0.57 \sim 0.59$ for $35 \%$ silt. For $30 \mathrm{kPa}$ overburden, the ratio is 1.0 for clean sand, 0.5 for $5 \%$ silt, 0.67 for $10 \%$ silt, 0.78 for $15 \%$ silt and 0.72 for $35 \%$ silt. Drained pullout tests usually show strain hardening, or at least no reduction in pullout load, after maximum pullout; in contrast, undrained pullout tests are generally strain softening. This is a particularly important finding since it indicates that failure in drained conditions will be progressive while in undrained conditions will be sudden and catastrophic.

(4) Effect of permeability: The dissipation of pore pressures inside the soil is very rapid for permeabilities larger than $10^{-2} \mathrm{~cm} / \mathrm{sec}$. For permeabilities smaller than $10^{-3} \mathrm{~cm} / \mathrm{sec}$, dissipation of pore pressures is very slow.

(5) Effect of scale: For permeabilities smaller than $10^{-3} \mathrm{~cm} / \mathrm{sec}$, scale effects are extremely important in that the larger the reinforcement, the longer the time for pore pressures to dissipate.

\section{Implementation}

Based on the findings from experiments and numerical analyses, the following is recommended for implementation:

(1) A small percentage of non-plastic fines in the backfill soil may have positive effects since the fines occupy the void space and decrease the void ratio, thus increasing the internal friction angle. Once the percentage of fines reaches a threshold value the addition of fines is detrimental and the internal friction angle and consequently the pullout capacity decrease. This may be caused by the fines preventing the particles to be in contact with each other, and thus reducing the shear stress required to mobilize the grains. For practical reasons, however, it is not recommended to use granular materials with fines content larger than 5 to $10 \%$ since segregation may become an issue and the material may be sensitive to changes in water content. As a general recommendation the fines should be nonplastic. For each project, the adequacy of a particular granular material as a backfill for a wall that will not experience undrained conditions can be evaluated by running triaxial tests on the material compacted to the required density.
(2) Granular materials with even a small percentage of fines are not recommended as backfill in walls where undrained conditions may occur. This is because of the large reduction of pullout capacity observed, which can be as much as $50 \%$. An additional detrimental effect of fines is that they can be washed out of the backfill as the water level behind the wall changes; this may produce internal erosion and damage the wall. However, submerged or partially submerged MSE walls can be safely used if a clean granular backfill is used. Indiana DOT stone \# 8 material is appropriate for this situation because of the low percentage of fines and large permeability.

(3) The findings from this research also show that field tests under drained conditions are not appropriate to evaluate the undrained pullout capacity under undrained conditions. If for a particular project, the undrained pullout capacity of a reinforcement embedded in a soil matrix needs to be evaluated, laboratory tests similar to the ones performed in this research are recommended. As a lower bound, the undrained shear strength of the soil could be used for stability calculations. 


\section{Contacts}

For more information:

Prof. Antonio Bobet

Principal Investigator

School of Civil Engineering

Purdue University

West Lafayette IN 47907

Phone: (765) 494-5033

Fax: (765) 496-1364
Indiana Department of Transportation

Division of Research

1205 Montgomery Street

P.O. Box 2279

West Lafayette, IN 47906

Phone: (765) 463-1521

Fax: (765) 497-1665

\section{Purdue University}

Joint Transportation Research Program

School of Civil Engineering

West Lafayette, IN 47907-1284

Phone: (765) 494-9310

Fax: (765) 496-1105 


\begin{tabular}{|c|c|c|}
\hline $\begin{array}{l}\text { 1. Report No. } \\
\text { FHWA/IN/JTRP-2002/13 }\end{array}$ & 2. Government Accession No. & 3. Recipient's Catalog No. \\
\hline \multirow{2}{*}{\multicolumn{2}{|c|}{$\begin{array}{l}\text { 4. Title and Subtitle } \\
\text { Design of MSE Walls for Fully Saturated Conditions }\end{array}$}} & $\begin{array}{l}\text { 5. Report Date } \\
\text { August } 2002\end{array}$ \\
\hline & & 6. Performing Organization Code \\
\hline \multicolumn{2}{|l|}{$\begin{array}{l}\text { 7. Author(s) } \\
\text { Antonio Bobet }\end{array}$} & $\begin{array}{l}\text { 8. Performing Organization Report No. } \\
\text { FHWA/IN/JTRP-2002/13 }\end{array}$ \\
\hline \multirow{2}{*}{\multicolumn{2}{|c|}{$\begin{array}{l}\text { 9. Performing Organization Name and Address } \\
\text { Joint Transportation Research Program } \\
1284 \text { Civil Engineering Building } \\
\text { Purdue University } \\
\text { West Lafayette, IN 47907-1284 }\end{array}$}} & 10. Work Unit No. \\
\hline & & $\begin{array}{l}\text { 11. Contract or Grant No. } \\
\text { SPR-2405 }\end{array}$ \\
\hline \multirow{2}{*}{\multicolumn{2}{|c|}{$\begin{array}{l}\text { 12. Sponsoring Agency Name and Address } \\
\text { Indiana Department of Transportation } \\
\text { State Office Building } \\
100 \text { North Senate Avenue } \\
\text { Indianapolis, IN } 46204\end{array}$}} & $\begin{array}{l}\text { 13. Type of Report and Period Covered } \\
\text { Final Report }\end{array}$ \\
\hline & & 14. Sponsoring Agency Code \\
\hline \multicolumn{3}{|l|}{ 15. Supplementary Notes } \\
\hline
\end{tabular}

The current design of MSE walls, which is based on limit state analysis, does not apply to undrained conditions. Laboratory and numerical pullout tests are performed to determine the relation between drained and undrained pullout capacities for different soil types (clean sand, 5, 10, 15 and $35 \%$ silty sand), overburden pressures (30, 100 and $200 \mathrm{kPa})$, and scale and permeability effects in the dissipation of excess pore pressures.

The results of the pullout tests show that both drained and undrained pullout capacities change as silt content changes since the pullout capacity increases as the internal friction angle of the soil increases. It is also observed that the pullout capacity increases as the overburden pressure increases. Undrained conditions significantly reduce the pullout capacity as much as $50 \%$. This is caused by the generation of excess pore pressures in the soil under rapid loading which decrease the effective stress at the soil-reinforcement interface. The magnitude of the pullout reduction is related to the permeability of the soil since for large permeabilities the dissipation of excess pore pressures is very rapid and no reduction in pullout is produced; in contrast for low permeabilities the dissipation of excess pore pressures is slower than the rate of pullout and thus a reduction occurs. This is confirmed by the experiments that show no reduction in pullout capacity for clean sand, and a large reduction for silty sands. The ratio of undrained to drained pullout capacity changes with silt content and overburden pressure; for 100 and $200 \mathrm{kPa}$ overburden pressure, the ratio is 1.0 for clean sand, $0.67 \sim 0.69$ for $5 \%$ silty sand, $0.77 \sim 0.78$ for $10 \%, 0.72 \sim 0.73$ for $15 \%$, and $0.57 \sim 0.59$ for $35 \%$ silty sand. For $30 \mathrm{kPa}$ overburden pressure, the ratio is 1.0 for clean sand, 0.5 for $5 \%$ silty sand, 0.67 for $10 \%, 0.78$ for $15 \%$, and 0.72 for $35 \%$ silty sand. It is observed in the numerical analyses that the dissipation of pore pressures is very rapid for permeabilities larger than $10^{-2} \mathrm{~cm} / \mathrm{sec}$, and significantly slow for permeabilities smaller than $10^{-3} \mathrm{~cm} / \mathrm{sec}$. Scale effects are extremely important since as the length of the reinforcement increases the time for pore pressures to dissipates increases.

\begin{tabular}{|c|c|c|c|c|}
\hline \multicolumn{2}{|c|}{$\begin{array}{l}\text { 17. Key Words } \\
\text { Mechanically Stabilized Earth, drained, pullout box, } \\
\text { pullout capacity, saturation, silty sand, soil reinforcement, } \\
\text { undrained. }\end{array}$} & \multicolumn{3}{|c|}{$\begin{array}{l}\text { 18. Distribution Statement } \\
\text { No restrictions. This document is available to the public through the } \\
\text { National Technical Information Service, Springfield, VA } 22161\end{array}$} \\
\hline 19. Security Classif. (of this report) & \multirow{2}{*}{\multicolumn{2}{|c|}{$\begin{array}{c}\text { 20. Security Classif. (of this page) } \\
\text { Unclassified }\end{array}$}} & 21. No. of Pages & 22. Price \\
\hline Unclassified & & & 163 & \\
\hline
\end{tabular}




\section{TABLE OF CONTENTS}

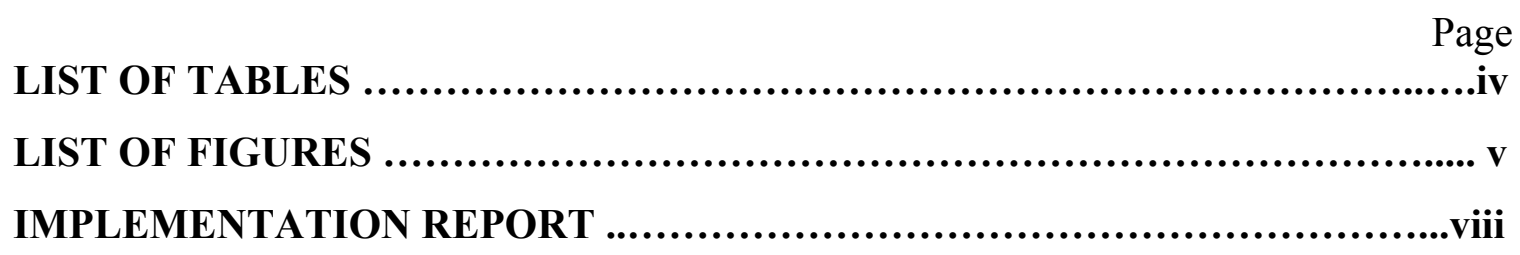

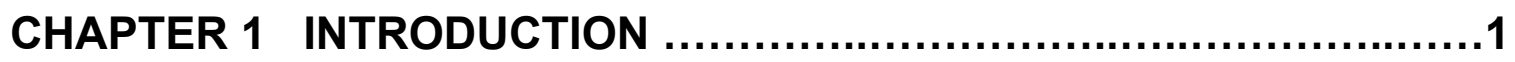

CHAPTER 2 LITERATURE REVIEW ............................................. 5

2.1 Introduction ...................................................................................................... 5

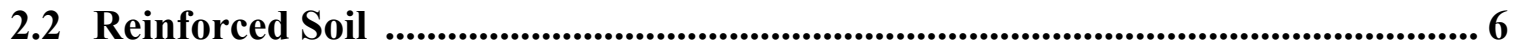

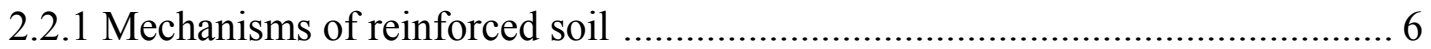

2.2.2 Concepts of reinforced soil …................................................................... 7

2.2.3 Design of mechanically stabilized earth retaining earth structures ................... 8

2.2.4 Soil behavior of MSE wall .................................................................... 12

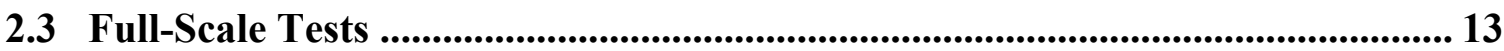

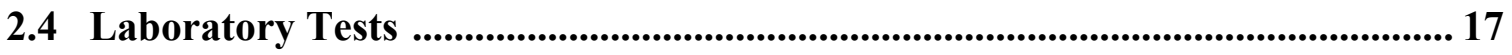

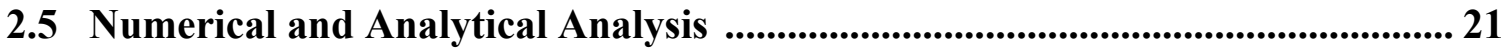

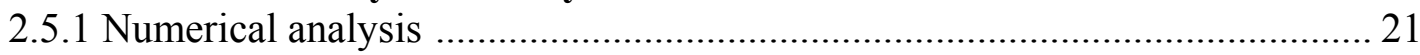

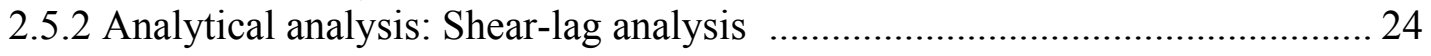

2.6 Case Studies : Failure of MSE Walls …...................................................... 27

2.6.1 Failure of a MSE wall in Glasgow, Kentucky ............................................... 27

2.6.2 Failure of a geogrid reinforced wall in Calgary, Alberta .............................. 30

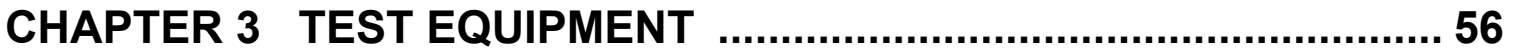

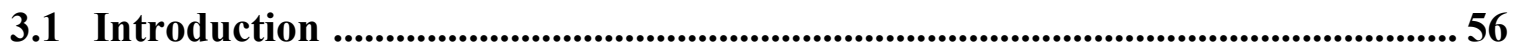

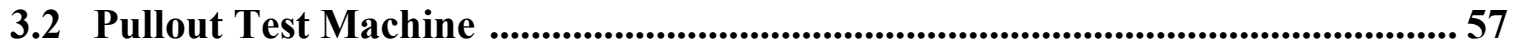


3.3 Measuring Devices .........................................................................................60

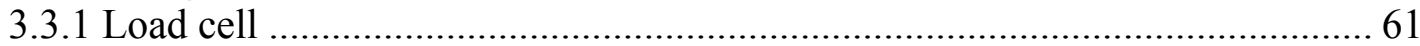

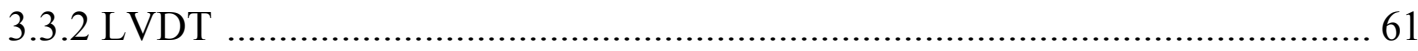

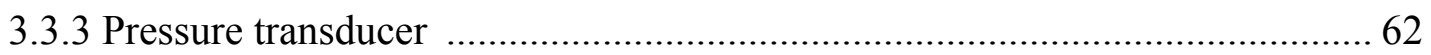

3.4 Test Procedure ……...................................................................................................... 63

3.5 Data Acquisition System ............................................................................................ 65

CHAPTER 4 LABORATORY TESTS AND RESULTS ….................... 73

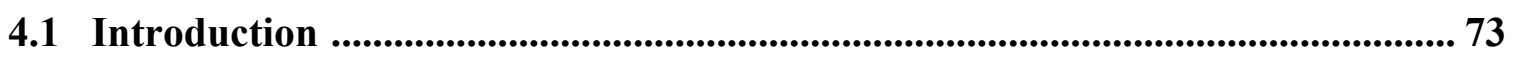

4.2 Material ....................................................................................................................... 74

4.3 Preliminary Tests ..................................................................................................... 75

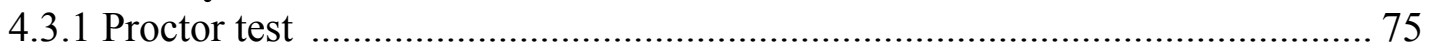

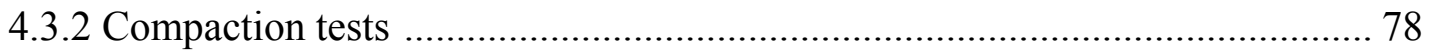

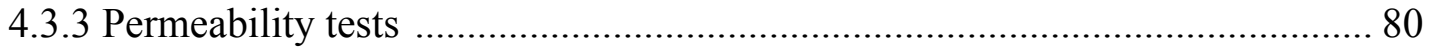

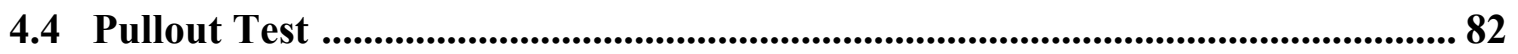

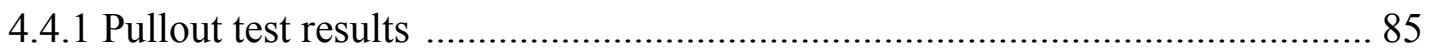

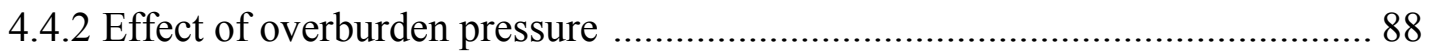

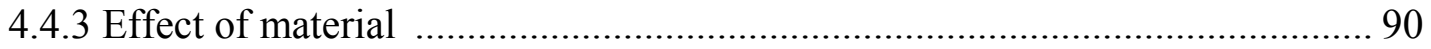

4.4.4 Effect of drainage condition ......................................................................... 97

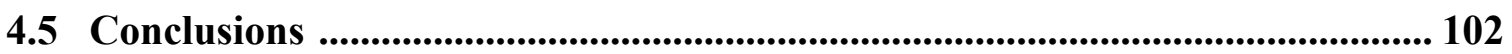

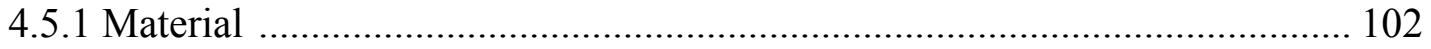

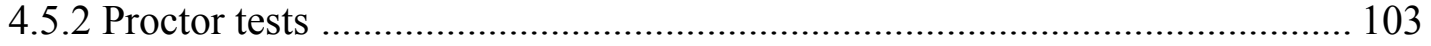

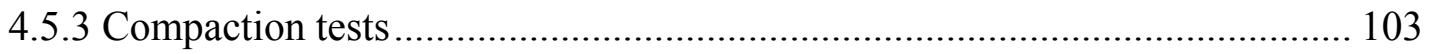

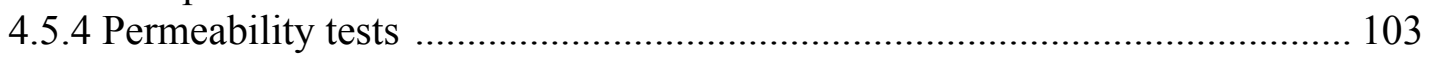

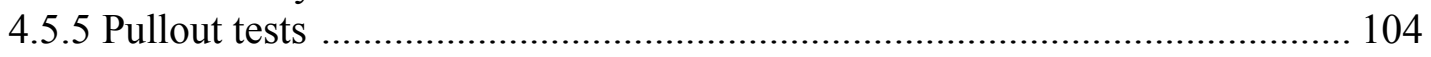

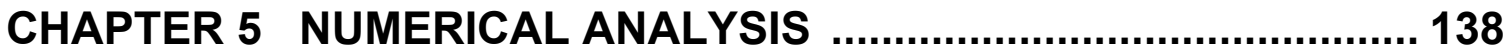

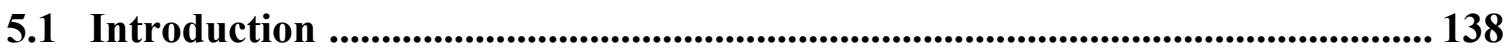

5.2 Finite Element Modeling …….............................................................................. 139

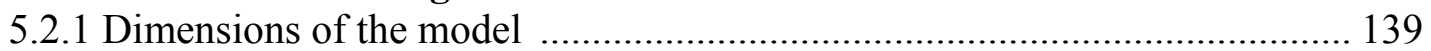

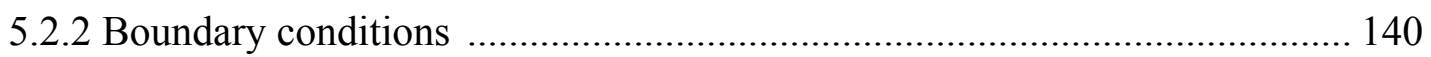

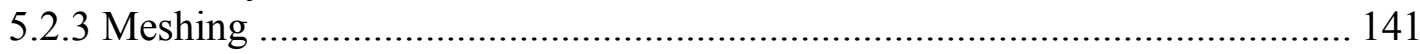

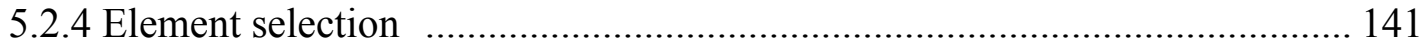

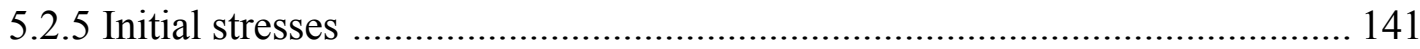

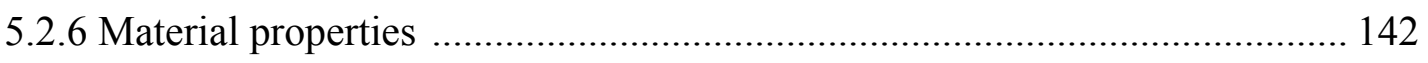


5.2.7 Factors investigated

5.4 Analysis of Consolidation Time ................................................................... 145

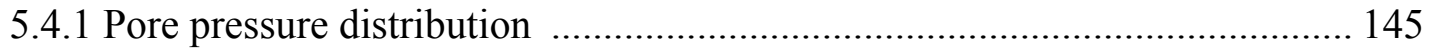

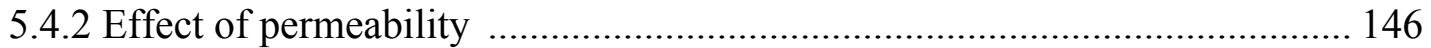

5.4.3 Effect of reinforcement length ............................................................. 147

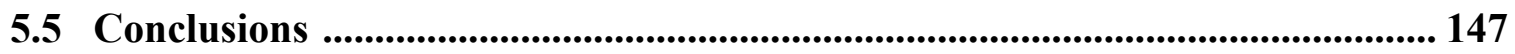

CHAPTER 6 CONCLUSIONS AND RECOMMENDATIONS ................ 155

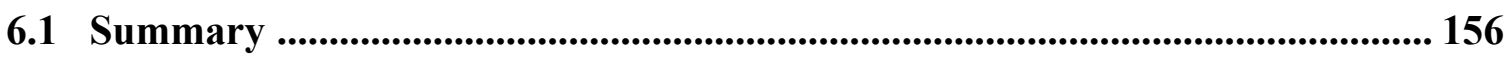

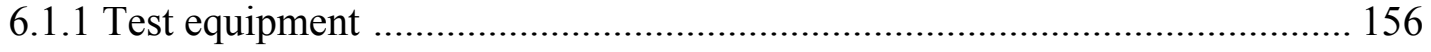

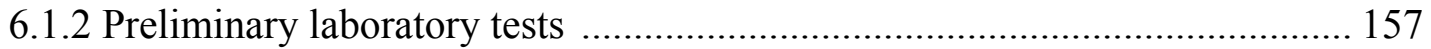

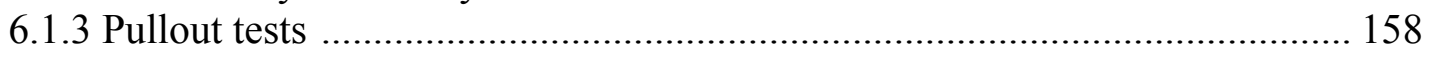

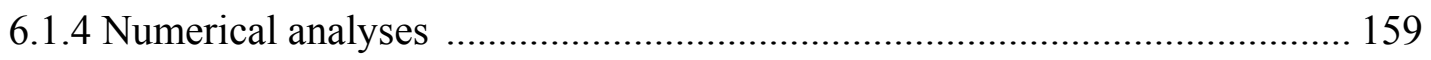

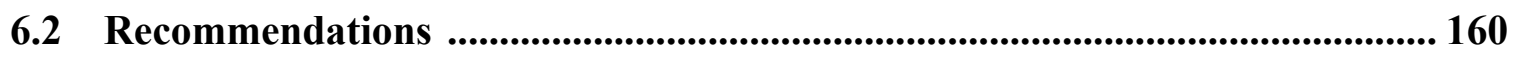

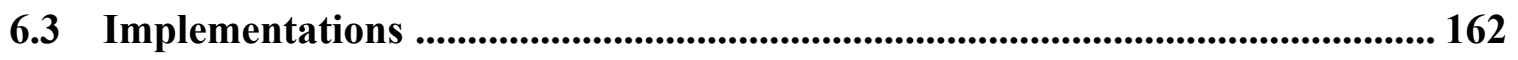

LIST OF REFERENCES........................................... 164 


\section{LIST OF TABLES}

Table $\quad$ Page

4-1 The Minimum and Maximum Void Ratios for Clean Sand and Silty Sand ............. 74

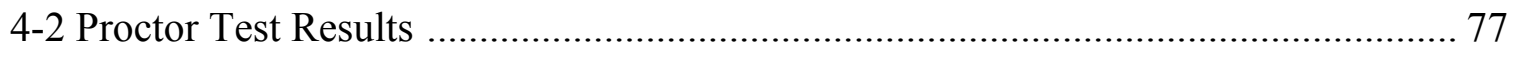

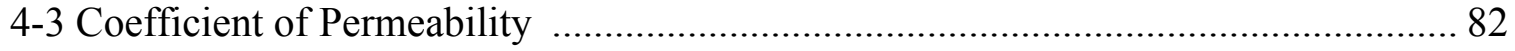

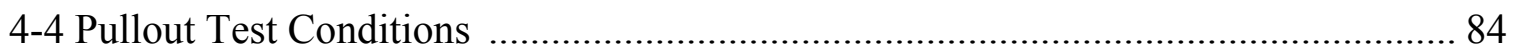

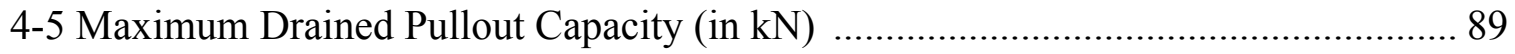

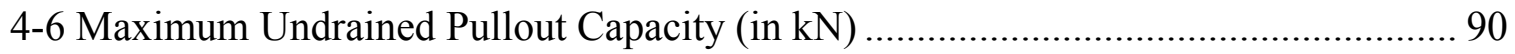

4-7 Relative Drained Pullout Capacity .................................................................... 91

4-8 Static Triaxial Test Results (After Salgado et. al., 2000) ....................................... 94

4-9 Correlation between Peak Friction Angle and Relative Drained Pullout Capacity.... 96

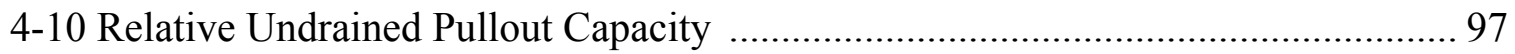

4-11 Undrained to Drained Pullout Capacity Ratio ................................................... 102

5-1 Material Properties of the Soil ............................................................................. 142

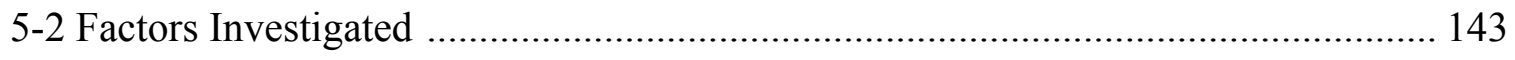




\section{LIST OF FIGURES}

Figure

Page

2-1 Mechanism of Reinforced Soil; (a) Anisotropic Cohesion Concept, and (b) Enhanced

Confining Stress Concept (After Ingold, 1982)................................33

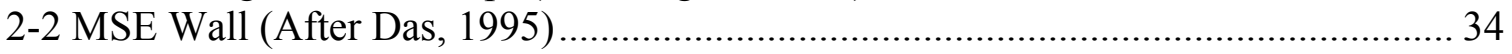

2-3 Location of the Failure Plane in MSE Wall with Steel Reinforcement

(After Schlosser et. al., 1974) .............................................................................. 35

2-4 Failure Mechanisms of MSE Wall with Steel Reinforcement (After Jones, 1996) ... 36

2-5 Analysis of a MSE Wall with Steel Reinforcement (After Das, 1995) ...................... 37

2-6 Coefficient of Friction for Steel Strip (After Bourdeau, 1999) ................................ 38

2-7 Load-Displacement Curves from Field Pullout Tests in Clayey Sand, Steel Grid

(After Bergado et. al. , 1993) .................................................................................... 39

2-8 Determination of Friction Coefficient between Soil and Reinforcement; (a) Direct

Shear Test, and (b) Pullout Test (After Palmeira et. al., 1989) .............................. 40

2-9 Effect of Top Boundary on Pullout Capacity, Steel Grid

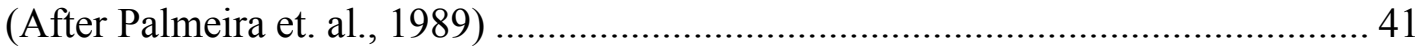

2-10 Effect of Roughness of Front Wall (After Palmeira et. al., 1989).......................... 41

2-11 Effect of Embedment Length of Reinforcement (After Palmeira et. al., 1989) ....... 42

2-12 Comparison between Tests with Reinforcement Close to and Far from Front Wall

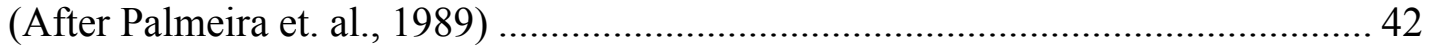

2-13 A Schematic Diagram of APSR Cell (After Abramento et. al., 1995).................... 43

2-14 Comparison of Total Pullout Capacity of Bamboo, Tensar, and Steel Grids at $25 \mathrm{~mm}$

Pullout Displacement (After Bergado et. al., 1993)............................................. 43

2-15 Modeling of Pullout Box; (a) Dimensions and Geometry, and (b) Boundary

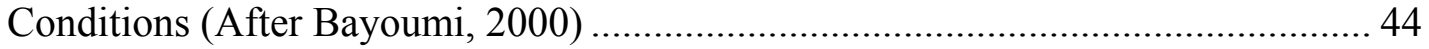

2-16 Effect of Silt Percentages $(\mu=0.1)$; (a) Drained, and (b) Undrained

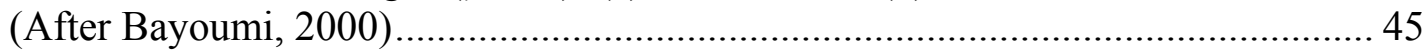

2-17 Effect of Interface Friction; (a) Drained, and (b) Undrained

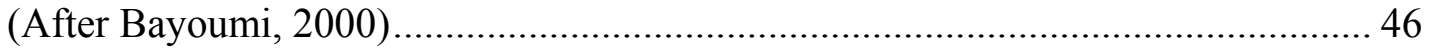

2-18 Effect of Vertical Stress; (a) Drained, and (b) Undrained (After Bayoumi, 2000) .. 47

2-19 Effect of Drainage Condition with Respect to Vertical Stress

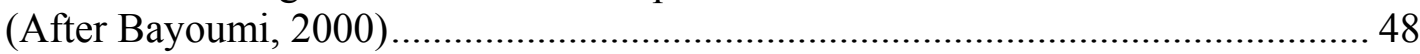

2-20 Effect of Lateral Pressure Coefficient for Undrained Condition

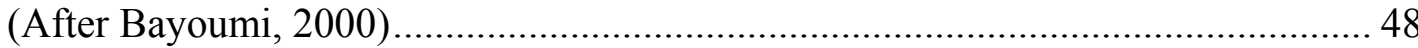

2-21 Modeling of Pullout Box for FE Analysis (After Bergado et. al., 1992) ................ 49

2-22 Comparison of Experimental and FEM Load-Displacement Curves

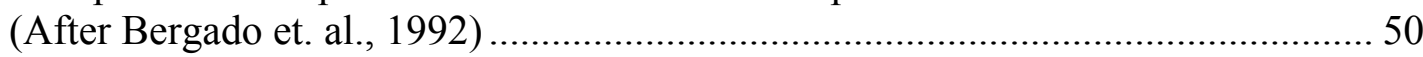

2-23 Geometry and Boundary Conditions of Pullout Tests for Planar Reinforcements

(After Abramento et. al., 1995) 
2-24 Comparison of Predicted and Measured Tensile Stress Distribution for Pullout Tests on Steel Sheet Inclusion (After Abramento et. al., 1995) ...................................... 52

2-25 Typical Section of As-Designed Retaining Structure, Geogrid Reinforcement (After Leonards et. al., 1994) ................................................................................ 53

2-26 Initial Period of Distress; (a) Deformation Rate, and (b) Rainfall (After Leonards et.

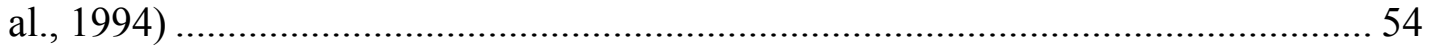

2-27 Typical Vertical Section and Design Details, Geogrid Reinforcement

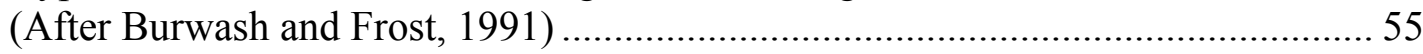

3-1 (a) A Schematic Diagram of the Longitudinal Section of the Pullout Box ............... 68

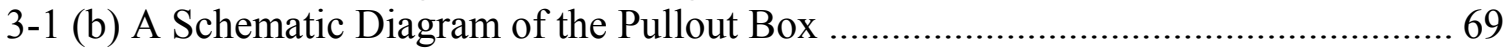

3-2 A Schematic Diagram of Pullout Test Setup ......................................................... 70

3-3 A Schematic Diagram of the Water Flow System at the Bottom of the Soil Chamber

3-4 Layout of Data Acquisition System (National Instruments Web page)

4-1 Grain Size Distribution (After Salgado et. al., 2000) ............................................ 106

4-2 Standard Proctor Test Results for Clean Sand and 2\% Silty Sand......................... 107

4-3 Standard Proctor Test Results for 5\% Silty Sand .................................................. 107

4-4 Standard Proctor Test Results for 10\% Silty Sand ............................................... 108

4-5 Standard Proctor Test Results for 15\% Silty Sand ............................................... 108

4-6 Standard Proctor Test Results for 35\% Silty Sand ................................................. 109

4-7 Location of Soil Sample Containers in Compaction Tests...................................... 110

4-8 Compaction Test Results for 5\% Silty Sand ..................................................... 111

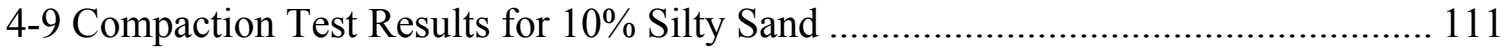

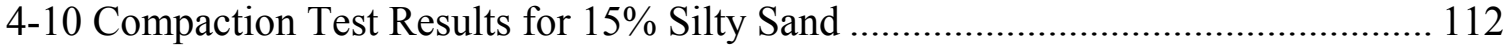

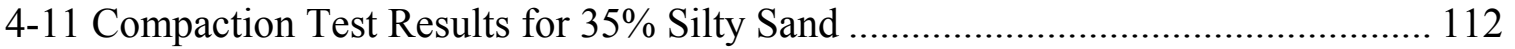

4-12 Coefficient of Permeability with Silt Content ..................................................... 113

4-13 Drained Pullout Test Results for Clean Sand ....................................................... 114

4-14 Undrained Pullout Test Results for Clean Sand ................................................. 115

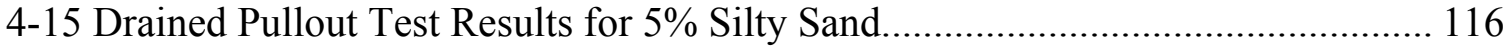

4-16 Undrained Pullout Test Results for 5\% Silty Sand............................................. 117

4-17 Drained Pullout Test Results for 10\% Silty Sand............................................... 118

4-18 Undrained Pullout Test Results for 10\% Silty Sand............................................ 119

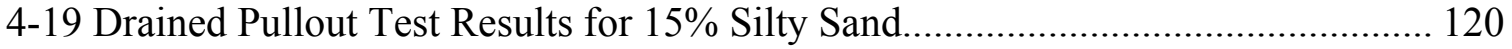

4-20 Undrained Pullout Test Results for 15\% Silty Sand........................................... 121

4-21 Drained Pullout Test Results for 35\% Silty Sand............................................. 122

4-22 Undrained Pullout Test Results for 35\% Silty Sand........................................... 123

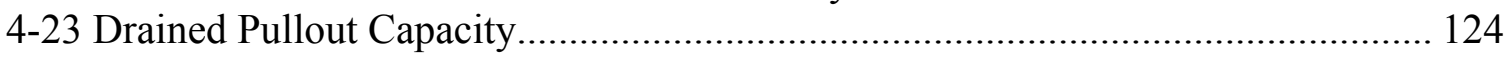

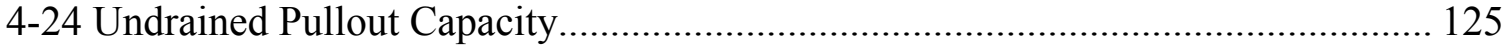

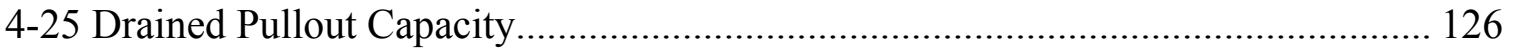

4-26 Relative Drained Pullout Capacity ................................................................... 127

4-27 Correlation between Peak Friction Angle and Relative Drained Pullout Capacity 128

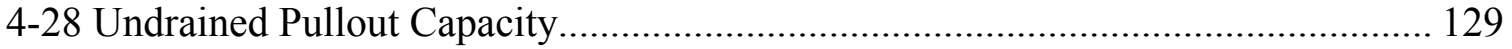

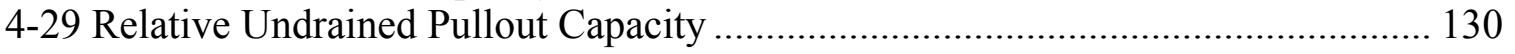


4-30 Comparison of Drained and Undrained Pullout Test Results for Clean Sand........ 131

4-31 Comparison of Drained and Undrained Pullout Test Results for 5\% Silty Sand ... 132

4-32 Comparison of Drained and Undrained Pullout Test Results for 10\% Silty Sand. 133

4-33 Comparison of Drained and Undrained Pullout Test Results for 15\% Silty Sand 134

4-34 Comparison of Drained and Undrained Pullout Test Results for 35\% Silty Sand. 135

4-35 Undrained to Drained Pullout Capacity Ratio.................................................. 136

4-36 Undrained Pullout Capacity versus Coefficients of Permeability ......................... 137

5-1 Minnow Creek Wall (After Runser, 1999) ........................................................... 149

5-2 Dimensions of the Model ............................................................................... 150

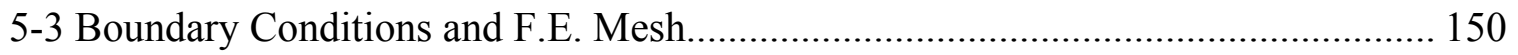

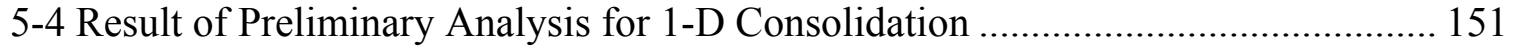

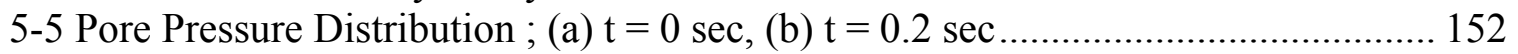

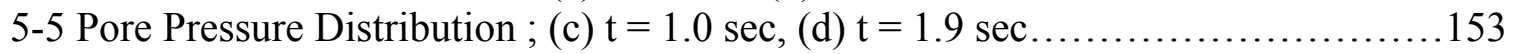

5-6 Results of Numerical Analysis; Effect of Permeability and Reinforcement Length 154 


\section{IMPLEMENTATION REPORT}

In the last three decades, the use of Mechanically Stabilized Earth (MSE) retaining walls has increased dramatically in civil engineering projects. MSE walls are used as design alternatives to traditional reinforced concrete retaining walls because of their capability to retain earth fills of significant height and sustain surface applied loads at lower cost than reinforced concrete walls.

The current design of MSE walls is based on limit state analyses where the ultimate strength of the soil and the pullout capacity of the reinforcement are incorporated. However, this applies only to drained conditions. For fully saturated conditions, there are no clear guidelines for the design of MSE walls. According to the Indiana DOT (INDOT) design guidelines, "For fully saturated conditions, site-specific field or laboratory pullout tests shall be performed". However, such tests are time-consuming and expensive. Because of that, MSE walls are avoided in many projects.

The stability of MSE walls may be compromised in undrained conditions such as during a heavy rain or during a rapid drawdown. Excess pore pressures in low permeability soils may not dissipate quickly enough, and thus may reduce the effective stresses inside the soil, which in turn may cause a reduction of the shear strength at the interface between the soil and the reinforcement. The study of MSE walls in undrained conditions is needed 
to determine the behavior of saturated MSE walls where rapid changes in pore pressures are anticipated. For this purpose, a series of laboratory pullout tests are performed under drained and undrained conditions for different soil types ranging from clean sand to $35 \%$ silty sand and, overburden pressures of 30, 100 and $200 \mathrm{kPa}$. Numerical analyses are also conducted to determine scale and permeability effects in the dissipation of excess pore pressures.

The following conclusions are obtained:

(1) Effect of silt: Drained and undrained pullout capacities decrease from clean sand to $5 \%$ silty sand, increase from $5 \%$ to $10 \%$, and then decrease from $10 \%$ to 15 and $35 \%$ silt. Pullout capacities change as the internal friction angle of the soil changes (i.e. pullout capacity increases as friction angle of the soil increases).

(2) Effect of overburden pressure: Pullout capacity increases as the overburden pressure increases. Larger displacements are required to reach the maximum pullout capacity for higher overburden pressure. Higher soil stiffness is observed for higher overburden pressure.

(3) Effect of drainage: The undrained pullout capacities are always smaller than the drained pullout capacities except for clean sand, that are equal. The ratio of undrained to drained pullout capacity changes with silt contents, but is the same for 100 and $200 \mathrm{kPa}$ overburden pressure. This ratio is one for clean sand, decreases to $0.67 \sim 0.69$ for $5 \%$ silty sand, increases to $0.77 \sim 0.78$ for $10 \%$ silt, decreases to $0.72 \sim 0.73$ for $15 \%$ and decreases again to $0.57 \sim 0.59$ for $35 \%$ silt. 
For $30 \mathrm{kPa}$ overburden, the ratio is one for clean sand, 0.5 for $5 \%$ silt, 0.67 for $10 \%$ silt, 0.78 for $15 \%$ silt and 0.72 for $35 \%$ silt.

(4) The dissipation of pore pressures is very rapid for permeabilities larger than $10^{-2}$ $\mathrm{cm} / \mathrm{sec}$. For permeabilities smaller than $10^{-3} \mathrm{~cm} / \mathrm{sec}$, dissipation of pore pressures is very slow and scale effects are extremely important in that the larger the reinforcement, the longer the time for pore pressures to dissipate.

The following recommendations are made:

Granular materials with even a small percentage of fines are not recommended as backfill in walls where undrained conditions may occur. This is because of the large reduction of pullout capacity observed, which can be as much as $60 \%$. An additional detrimental effect of fines is that they can be washed out of the backfill as the water level behind the wall changes; this may produce internal erosion and damage the wall. However, submerged or partially submerged MSE walls can be safely used if a clean granular backfill is used. Indiana DOT stone \# 8 material is appropriate for this situation because of the low percentage of fines, and large permeability.

The findings from this research also show that field tests under drained conditions are not appropriate to evaluate the undrained pullout capacity under undrained conditions. If for a particular project, the undrained pullout capacity of a reinforcement embedded in a soil matrix needs to be evaluated, laboratory tests similar to the ones performed in this research are recommended. As a lower bound, and thus on the safe side, the undrained shear strength of the soil could be used for stability calculations with a reasonable 
estimate of the interface friction between the soil and the reinforcement; note that the undrained shear strength depends on the overburden effective stress. 


\section{CHAPTER 1. INTRODUCTION}

In the last three decades, the use of Mechanically Stabilized Earth (MSE) retaining walls has increased dramatically in civil engineering projects since Vidal, a French engineer, developed the modern concept of MSE walls in the early 70's. MSE walls are used as design alternatives to traditional reinforced concrete retaining walls because of their capability to retain earth fills of significant height and sustain surface applied loads at lower cost than reinforced concrete walls. In general, MSE walls consist of a structural fill reinforced with tensile-resistant inclusions that are connected to facing elements. MSE walls are internally stabilized by mechanical interactions between the three components: backfill material, reinforcement, and facing.

The current design of MSE walls is based on limit state analyses where the ultimate strength of the soil and the pullout capacity of the reinforcement are incorporated. However, this applies only to drained conditions. For fully saturated conditions, there are no clear design guidelines for the design of MSE walls. According to the Indiana DOT (INDOT) design guidelines, "For fully saturated conditions, site-specific field or laboratory pullout tests shall be performed". However, such tests are time-consuming and expensive. Because of that, MSE walls are avoided in many projects. 
Although numerous investigations have been performed to improve the engineering properties of MSE walls, those investigations primarily focused on drained conditions. The working conditions of MSE walls in drained conditions and undrained conditions are quite different, especially when fine grain soils or granular soils with fines are used as backfill. The stability of MSE walls with such backfill may decrease in undrained conditions such as during heavy rain or during a rapid drawdown. Excess pore pressures in low permeability soils may not dissipate quickly enough, which may reduce the effective stresses inside the soil, which in turn may cause a reduction of the shear strength at the interface between the soil and the reinforcement. The study of MSE walls in undrained conditions is needed to determine the behavior of saturated MSE walls where rapid changes in pore pressures are anticipated.

In this research, a number of laboratory pullout tests are performed to determine the relation between drained and undrained pullout capacities for different soil types, overburden pressures, and drainage conditions. Those factors are fully examined to investigate their effect on pullout capacity.

The dissipation time of pore pressures varies depending on permeability and reinforcement length. These factors cannot be investigated in the laboratory pullout tests. Instead, numerical analyses, using a finite element (FE) program, are conducted. This report is divided in 5 chapters, in addition to this Introduction. 
In Chapter 2, a literature review of reinforced soil relevant to this research is presented. The basic theories of reinforced soil suggested by several engineers are introduced, which include mechanisms and behavior of reinforced soil. A number of full-scale tests and laboratory pullout tests are also presented in Chapter 2. Specifically, a study of several factors that may affect pullout capacity is performed. Next, a review of numerical analyses and analytical solutions is presented. Lastly, two case studies related to failure of MSE walls for undrained conditions, which are most relevant to this research, are summarized.

Chapter 3 describes the pullout test setup used in this research. It contains a detailed explanation of the pullout test machine and measuring devices. An introduction to the data acquisition system is also presented.

In Chapter 4, preliminary laboratory tests (Proctor tests, compaction tests, and permeability tests) and pullout tests are described. The test procedures and their results are presented and discussed.

In Chapter 5, scale effects are evaluated through a number of numerical tests where the effects of reinforcement length and permeability on excess pore pressure dissipation are investigated. 
Finally, Chapter 6 presents a summary and conclusions of this research. Based on the conclusions, recommendations for the design of MSE walls in undrained conditions are proposed. 


\section{CHAPTER 2. LITERATURE REVIEW}

\subsection{Introduction}

This chapter presents a review of the technical literature most relevant to this research. Section 2.2 describes the basic theory of MSE (Mechanically Stabilized Earth) walls first proposed by a French engineer, Vidal. It covers mechanisms of reinforced earth, behavior of reinforced soil, and introduction of pullout resistance; the emphasis is on MSE walls with inextensible reinforcement (i.e. steel), which is the focus of this investigation. Fullscale tests performed by several researchers are described in Section 2.3; in particular, a full-scale test performed by Runser (1999), is described in detail since the test was conducted for Indiana DOT. In Section 2.4, a number of laboratory pullout tests are introduced, especially tests performed by Palmeira (1989) who investigated the factors affecting pullout capacity. Section 2.5 presents numerical and analytical analyses of pullout tests, with focus on several parameters that may affect pullout capacity. Finally, Section 2.6 introduces two case studies regarding failure of MSE walls in undrained conditions, which are closely related to this research. 


\subsection{Reinforced Soil}

\subsubsection{Mechanisms of reinforced soil}

Reinforced soil has two components: soil and reinforcement. Each component has different properties, but the fundamental idea is that the reinforcement embedded in the soil provides tensile strength to the soil. In addition, a reinforced soil has higher shear strength and stiffness than an unreinforced soil.

A soil element extends horizontally and compresses vertically when a vertical load is applied to it. This deformation of the soil element is restrained by the reinforcement because of its higher stiffness; due to friction between the soil and the reinforcement, the movements of a particle of soil in contact with the reinforcement must be compatible with the movements of the reinforcement. There is a limit to the soil movement which depends on how much friction can be developed at the interface before sliding occurs. The shear stress at the interface produces tension in the reinforcement, and provides confinement to the soil, which in turn decreases the soil lateral deformations and increases the shear strength of the soil. This is the most important aspect of reinforced soil, which through tension in the reinforcement a stable composite mass with additional strength beyond that of the soil is obtained. 


\subsubsection{Concepts of reinforced soil}

Long et al. (1972) at the Laboratoire Central des Ponts et Chaussees (LCPC) carried out an experimental investigation to verify the mechanism of reinforced soil. Triaxial tests were conducted where cylindrical samples of reinforced sand were tested under axisymmetric stress conditions. The reinforcement in the sample was placed horizontally at a constant vertical spacing. Long et al. (1972) observed that there was an increase of the vertical stress required for failure in samples with reinforcement, and found that for a given confinement that was higher than approximately $100 \mathrm{kPa}$, the difference between the vertical stress at failure for reinforced and unreinforced soil was constant. They concluded that the failure envelopes of both reinforced and unreinforced soils were parallel to each other and had the same angle of internal friction, as shown in Figure 2-1 (a). The additional strength induced by the reinforcement was represented as 'anisotropic cohesion', c', which is the basis of the LCPC (Laboratoire Central des Ponts et Chaussees) cohesion theory; see Figure 2-1 (a).

The LCPC cohesion theory introduced a fictitious cohesion to explain the increase in shear strength, since the material tested was sand. A different explanation was proposed by Chapuis (1972), who introduced the 'enhanced confining stress' concept. The enhanced confining stress concept is based on the assumption that an additional confining stress is applied to the soil by the reinforcement. As shown in Figure 2-1 (b), the additional confinement shifts the Mohr circle of an element of the soil to the right. As a 
consequence, the point of failure is displaced from the original state, and thus the shear strength is increased.

\subsubsection{Design of mechanically stabilized earth retaining structures}

A Mechanically Stabilized Earth (MSE) wall has three components as shown in Figure 22: (1) the earth fill: usually granular material; (2) reinforcement: metal strips, strips or sheets of geotextiles or wire grids; and (3) facing: not necessary but generally used for aesthetic reasons or to prevent soil erosion at the face of the wall.

The primary functions of the MSE wall are: (1) support of the backfill through frictional resistance between reinforcement and soil; and (2) support of the facing panels.

The backfill on the one hand creates the lateral pressure that needs to be supported while on the other hand interacts with the reinforcements to resist such lateral pressure (Koerner, 1998). The grains of soil would behave as if they were tied by the reinforcement if the friction angle of the backfill soil was greater than the interface angle between soil and reinforcement (Vidal, 1969).

According to Schlosser and Long (1974), the reinforced soil is divided in two zones: active and passive, as shown in Figure 2-3. The active zone is the area between the failure plane and the front of the wall; within the active zone the soil tends to slip. The passive 
zone is the area where the shear stresses are mobilized to prevent sliding of the reinforcement and is located behind the failure plane. The shear stress on the reinforcement acts towards the face of the wall in the active zone and away from the wall face in the passive zone (See Figure 2-3).

The failure mechanisms of MSE walls are classified as internal and external. The internal failure modes include: (1) pullout of the reinforcement (adhesion failure); and (2) failure of the reinforcement (tension failure for an inextensible reinforcement). The external failure modes include: (1) sliding of the wall; (2) overturning of the wall; and (3) bearing capacity failure. Figure 2-4 shows schematic diagrams of the failure modes (Jones, 1996).

In terms of internal stability, MSE walls may fail by either pullout of the reinforcement out of the soil mass or by failure of the reinforcement itself. The pullout of the reinforcement occurs when the maximum frictional resistance developed along the surface of the reinforcement is attained. The factor of safety against pullout, $\mathrm{FS}_{(\mathrm{P})}$, is obtained using Equation 2-1.

$$
F S_{(P)}=\frac{2 l_{e} w \sigma_{v}^{\prime} \tan \phi_{u}}{\sigma_{a} S_{v} S_{h}}
$$

where, $1_{\mathrm{e}}$ : effective length as shown in Figure 2-5

w : width of the reinforcement

$\sigma_{\mathrm{v}}{ }^{\prime}$ : effective vertical pressure at a depth $\mathrm{z}$ 
$\Phi_{\mathrm{u}}$ : interface friction angle between the soil and the reinforcement

$\sigma_{\mathrm{a}}:$ active earth pressure at a depth $\mathrm{z}$, from Rankine theory

$\mathrm{S}_{\mathrm{v}}$ and $\mathrm{S}_{\mathrm{h}}$ : vertical and horizontal spacing of reinforcement

The numerator of Equation 2-1 is the maximum pullout force, which can be written also as:

$$
\mathrm{T}_{\max }=2 \mathrm{w} l_{\mathrm{e}} \sigma_{\mathrm{v}}{ }^{\prime} \mathrm{f}^{*}
$$

where, $f^{*}$ (i.e. $\tan \phi_{\mathrm{u}}$ in Equation 2-1) is an effective coefficient of friction at the interface between soil and reinforcement (Figure 2-6).

The coefficient of friction between soil and reinforcement, $\mathrm{f}^{*}$, is about 1.5 for a ribbed strip at the top of the wall and decreases linearly to a depth of $6 \mathrm{~m}$, as shown in Figure 26. Below this depth, the coefficient of friction is equal to $\tan \phi$, where $\phi$ is the internal friction angle of the backfill. The effective vertical stress due to the weight of the soil at this depth is about $100 \mathrm{kPa}$, which is considered as the threshold stress to restrain dilation of the soil. For a smooth strip, the coefficient of friction is 0.4 , constant. This is because the interface friction between the soil and the strip is smaller than the friction angle of the soil.

Failure of the reinforcement occurs when the pullout stress is larger than the yield stress of the material. The factor of safety against failure is obtained using Equation 2-3; a factor of safety about 2.5 3 is generally recommended (Das, 1995). 


$$
F S_{(B)}=\frac{w t f_{y}}{\sigma_{a} S_{v} S_{h}}
$$

where, $f_{y}$ is the yield strength of the reinforcement

$t$ is the thickness of the reinforcement

The design of an MSE wall, in terms of internal stability, is done as follows:

(1) determine geometry, soil and reinforcement properties: height of the wall, $\mathrm{H}$, unit weight of the backfill soil, $\gamma$, friction angle, $\Phi$, interface friction angle, $\Phi_{\mathfrak{u}}$, horizontal and vertical spacing of reinforcement, $S_{h}$ and $S_{v}$, width of reinforcement, $w$, and yield stress, $f_{\mathrm{y}}$

(2) determine the thickness of the reinforcement, $t$, required to prevent failure of the reinforcement from Equation 2-4; that is:

$$
t=\frac{\left(\sigma_{a} S_{v} S_{h}\right) F S_{(B)}}{w f_{y}}
$$

(3) determine the total length of reinforcement, L, at any depth Z (See Figure 2-5),

$$
\begin{aligned}
L=l_{r}+l_{e} & \\
\text { where, } \quad l_{r} & =\frac{(H-Z)}{\tan \left(45+\frac{\phi_{1}}{2}\right)} \\
l_{e} & =\frac{\left(\sigma_{a} S_{v} S_{h}\right) F S_{(P)}}{2 w \sigma_{v}^{\prime} \tan \phi_{u}}
\end{aligned}
$$


(4) determine the overall external stability against overturning, sliding, and bearing capacity. Koerner (1998) has suggested the following factors of safety: for sliding, FS $\geq 1.5$; for overturning, $1.5<\mathrm{FS}<2.0$; for bearing capacity FS $>3.0$.

\subsubsection{Soil behavior of MSE wall}

When a dense sand is sheared there is an increase in volume. This phenomenon is called dilatancy. In a direct shear test, the macroscopic shear plane is horizontal, but sliding of individual particles takes place along numerous microscopic planes that are at angle with the shear plane. This is because the particles move up and over neighboring particles (Craig, 1990), which causes an increase in volume.

Dilatancy of a granular soil is a function of the normal stress. Because inside a wall the soil is already confined, dilatancy results in an additional increase of confinement. As a consequence the interface shear strength increases, and the pullout capacity also increases.

Failure occurs either at the interface between the soil and reinforcement or inside the soil. Failure along the interface is usually associated with a smooth strip while failure through the soil occurs with a ribbed strip (i.e. higher frictional resistance). This is the reason why ribbed strips are usually used for MSE walls. 


\subsection{Full-Scale Tests}

Full-scale tests have been performed to evaluate and verify the reinforced soil theory. Since full-scale tests, however, are very expensive compared to laboratory tests, they are rarely performed. In spite of that, a number of full-scale tests have been performed after Vidal (1966) conducted the first test on an MSE wall.

A full-scale test was performed in 1968 at Incarville, France (Schlosser and Long, 1974). The wall was a $10 \mathrm{~m}$ high MSE wall, where strain gages were attached to steel reinforcements as the wall was built. It was found that the tension distribution along the reinforcement was not linear, and the maximum tension occurred at some distance from the face of the wall, as shown in Figure 2-3. It was also found that the location of maximum tension in each layer could be described as a parabolic curve; this curve separates the soil mass into active and passive zones (the curve is simplified as two planar failure surfaces in Figure 2-3).

The first American MSE wall was constructed in 1972, outside Los Angeles, California, on Cal-39 (Chang et al. 1972). Chang et al. reported the same tensile stress distribution as reported in the Incarville wall (i.e. the maximum tensile stress occurs at some distance away from the facing). They found that at the top of the wall the stresses in the soil close to the face of the wall followed Rankine's earth pressure theory, while at the middle of the reinforcement followed Jaky's at rest earth pressure theory. 
Another full-scale test was performed on a MSE wall by the Waterways Experiment Station (WES) in Vicksburg, Mississippi (Al-Hussaina and Perry, 1978). This 3.7m high MSE wall was surcharged to failure, with strain gages attached to the steel reinforcement and earth pressure cells embedded in the backfill. The data from the strain gages indicated that the tensile stress distribution in the reinforcement was similar to what had been previously reported. During construction tensile forces on the reinforcement near the facing were generally smaller than the theoretical values based on Rankine theory. However, the tensile force approached Rankine theory after the backfill was completed. Al-Hussaina and Perry (1978) assumed that the increased tensile force after completion was induced by post-construction settlements of the backfill.

Christopher (1993) and Christopher et al. (1994) investigated the behavior of MSE walls through full-scale tests. The tests were conducted varying reinforcement types (geogrid, steel bar mats and geotextiles), backfill types and surcharge loading. The results showed the importance of compaction; larger reinforcement stresses and smaller deformations were observed in MSE walls with a well-compacted dense backfill than in walls with a poorly compacted loose backfill. Very little deformation and no increase in reinforcement tension occurred in the MSE wall with a dense backfill when a surcharge was applied. This was so because the surcharge was not transferred to the reinforcement; instead it was supported by the residual stresses in the soil generated during compaction (Christopher, 1993). On the contrary, larger deformations were observed in the MSE wall with a loose backfill when a surcharge was applied. These large deformations occurred because the backfill was not sufficiently compacted and residual stresses in the soil were generated, 
and thus the surcharge load was transferred directly to the reinforcement (Christopher, 1993).

Bergado et al. (1993) performed full-scale tests on a $5.7 \mathrm{~m}$ high wall/embankment MSE system. The wall was constructed inside the campus of Asian Institute of Technology, 42 $\mathrm{km}$ north of Bangkok. The wall was composed of three different sections corresponding to three different backfill materials: clayey sand, lateritic soil, and weathered clay. The backfill was compacted to $95 \%$ of standard Proctor. The reinforcements used for the wall were two types of steel grids: (1) grids with only longitudinal ribbed bars (grid reinforcement 10); and (2) grids with both longitudinal and transverse bars (grid reinforcement 7 and 9). The purpose of these tests was to study the interaction between steel grid reinforcements and backfill soils through pullout tests on selected reinforcements. Figure 2-7 shows load-displacement curves for the field pullout test in clayey sand. The pullout resistance was mobilized at around $80 \mathrm{~mm}$ displacements for grid reinforcement 10. However, the pullout resistance for grid reinforcement 7 and 9 continued to increase; it was not fully mobilized even at a pullout displacement of 125 $\mathrm{mm}$. The authors concluded from these results that most of the pullout resistance was obtained from the transverse members of the grid, and that larger pullout displacements were needed to be mobilized for grids with both longitudinal and transverse bars. Bergado et al. (1993) also observed that the pullout resistance for a backfill compacted on the dry side of optimum was higher than compacted on the wet side. 
Runser (1999) instrumented a 17 m tall MSE wall with steel reinforcement in Minnow Creek near Logansport, Indiana. At the time, this was the tallest MSE wall built in Indiana. The wall was instrumented to observe reinforced soil behavior during and after construction, and to check the adequacy of the current design method for MSE walls. The instrumentation included strain gages, earth pressure cells, load cells and inclinometers. The strain gages, installed on the reinforcements, were used to identify the location of maximum tension and tension distribution. The earth pressure cells were installed on the foundation and reinforced zones to measure the coefficient of lateral earth pressure, lateral and vertical stress in the soil, the distribution of stresses in the facing elements, and compaction-induced stresses. Load cells, installed under the facing, were used to measure the vertical stress applied to the leveling pad panels: According to Runser (1999), this was one of the unique aspects of the test because only one other similar test had been reported (Christopher, 1993) before. The inclinometers were installed within the reinforced zone to measure lateral displacements of the wall.

It was observed that the maximum tensile stress occurred at some distance from the facing, as previously observed by others. The earth pressures, measured at the back of the facing, followed Jaky's at rest earth pressure theory in the upper one third of the wall, and Rankine theory in the rest of the wall (Runser, 1999). 


\subsection{Laboratory Tests}

Direct shear tests and pullout tests are the most common tests performed in the laboratory to observe interaction between soil and reinforcement. Figure 2-8 shows a typical setup for a shear test. In direct shear tests, the soil is sheared along the reinforcement while a vertical load is applied (Figure 2-8 (a)).

Pullout tests are performed literally pulling the reinforcement out of the soil while a vertical load is applied (Figure 2-8 (b)). From the tests, the coefficient of friction between soil and reinforcement is obtained.

The following factors affect the results of pullout tests: (1) boundary conditions; (2) dimensions of pullout box; and (3) embedded length of reinforcement. In this section, a number of tests are presented where the effects of some or all of the factors are investigated.

McGown et al. (1978) performed a number of plane strain tests with soil reinforcement at different angles with the direction of loading. The tests were conducted using dense, medium dense, and loose sand samples. The orientation of the reinforcement (steel strip) was varied from 0 to 90 degrees with the horizontal. It was observed that the tensile stresses in the inclusion decreased as the orientation increased from zero degrees until the orientation of zero extension, which is where the tensile strain in the reinforcement is zero. 
Palmeira and Milligan (1989) investigated the effects of boundary conditions: type of boundary at the top, frictional characteristics of the front wall, and the dimensions of the pullout box. Different tests were performed with two types of platens on the top boundary for the application of the vertical load: rigid platens, and flexible patens (a flexible bag filled with pressurized water). A steel grid reinforcement inclusion was used which was pulled out while the soil was loaded. Figure 2-9 is a plot of the interface friction with the two types of boundaries. As shown in the figure, a slightly higher coefficient of friction (i.e. higher pullout capacity) was obtained with a rigid than with a flexible top platen. The coefficient of friction was larger than the tangent of the internal friction angle of the soil (Palmeira et al., 1989), which was about 1.4. The difference was attributed to dilatancy of the soil since a $25 \mathrm{kPa}$ vertical stress was applied, which was well below the confinement stress that suppresses dilatancy.

During pullout, the lateral stress acting on the front wall of the pullout box increases and large shear stresses may develop at this location. Palmeira et al. (1989) investigated this phenomenon by performing pullout tests with different frictional characteristics of the front wall. The following conditions were investigated: rough wall, sand paper, plain metal, and lubricated wall. Figure 2-10 shows curves of interface friction between soil and inclusion with different front wall roughness. The highest interface friction was approximately 4.5 which was obtained with the rough wall; the lowest was about 2.0 obtained with the lubricated wall. Palmeira et al. (1989) performed additional pullout tests with a lubricated front wall to investigate the influence of the size of the pullout box. 
They found that the roughness of the front wall had a larger influence as the size of the box decreased. It was, therefore, concluded that the front wall of the pullout box should be lubricated to minimize the influence of wall friction.

Palmeira et al. (1989) also investigated the effects of reinforcement length. They conducted a number of tests with a fixed height of the pullout box, and different reinforcement lengths. Figure $2-11$ is a plot of interface friction between soil and reinforcement with different embedment lengths of the reinforcement in the soil. They found that the interface friction decreased as the embedment length of the reinforcement increased, and that the influence of the front wall and of the top and bottom boundaries increased with an increase of embedment length. Additional tests were performed to investigate the effects of the distance 'd' between the point of application of the pullout force and the front of the pullout box. Figure 2-12 shows a comparison of the interface friction measured from tests with tow values of ' $d$ ': $d=0$ (i.e. pullout load application on the front wall), and $\mathrm{d}=122.5 \mathrm{~mm}$ (pullout within the soil; a slot was used to separate the soil and the load connector). For the tests with $\mathrm{d}=0$, lubricated metal wall and nonlubricated metal wall were used; for $\mathrm{d}=122.5 \mathrm{~mm}$ a non-lubricated metal front wall was used. A lower pullout capacity was obtained for the reinforcement with $\mathrm{d}=122.5 \mathrm{~mm}$. Figure 2-12 also shows that for $\mathrm{d}=0$, the pullout capacity for the lubricated front wall was smaller than for the non-lubricated front wall.

Abramento et al. (1995) performed pullout experiments on a clean sand with steel sheet reinforcement and nylon 6/6 reinforcement, using a device referred to as the Automated 
Plane Strain Reinforcement (APSR) cell (Figure 2-13). The APSR cell, originally developed by Larson (1992), was designed to measure the tensile stress acting on the reinforcement during shearing of the soil. As recommended by previous researchers, a flexible top boundary was employed and the vertical stress was transmitted to the soil through waterbags. In addition, all contact surfaces of the cell were lubricated to minimize the influence of frictional resistance. A load cell was installed to measure the pullout capacity and four strain gages were attached to the inclusion to measure tensile stresses along the reinforcement. The data showed that the load-distribution along the inclusion was approximately linear for the steel inclusion and non-linear for the nylon inclusion. They also observed that the pullout capacity for the steel inclusion increased as the confining stress increased.

Bergado et al. (1993) performed laboratory pullout tests to investigate the behavior of different reinforcements in a cohesive soil. The tests were performed varying the type of reinforcement (steel, bamboo and polymer grids) and normal pressure (10, 50 and 90 $\mathrm{kPa}$ ). For an inextensible reinforcement such as steel and bamboo grids, it was found that: (1) the pullout resistance became constant after reaching the maximum pullout capacity; and (2) the pullout resistance significantly increased early in the test, but the increasing rate became smaller with pullout displacement. On the contrary, for extensible polymer grids, the pullout resistance continuously increased with pullout displacement.

Bergado et al. (1993) observed that the pullout capacity increased as the vertical stress increased, as shown in Figure 2-14. This is explained by Equation 2-2, since the pullout 
capacity increases as the effective vertical stress increases. However, the rate of increase of pullout capacity with pullout displacement was different for different reinforcements, with steel grids having the highest rate.

\subsection{Numerical and Analytical Analysis}

\subsubsection{Numerical analysis}

Bayoumi (2000) conducted a number of numerical analyses to investigate the pullout capacity of steel reinforcement in silty sands. The Finite Element (FE) code, ABAQUS, was used for the analyses. Figure 2-15 shows schematic diagrams of the FE model. The dimensions of the pullout box were $1.0 \mathrm{~m}$ in length and $0.2 \mathrm{~m}$ in height. The length and thickness of the reinforcement were $1.1 \mathrm{~m}$ and $0.003 \mathrm{~m}$, respectively (Figure 2-15 (a)). As shown in the figure, the steel reinforcement was extended beyond the box. Bayoumi explained that the extension of the reinforcement was an unavoidable choice because unrealistic results were obtained at the end of the reinforcement when the length of the reinforcement was shorter than that of the pullout box. In the FE analysis, horizontal displacements were restrained on the left side of the model and vertical displacements were restrained on the bottom of the model (Figure 2-15 (b)).

In the FE analysis, Bayoumi (2000) focused on the effects of several parameters: (1) silt percentage $(0,10$, and $20 \%)$; (2) coefficient of interface friction $(\mu=0.1,0.3$, and 0.5$)$; 
(3) vertical normal stress (30, 100, and $200 \mathrm{kPa})$; (4) drainage conditions (drained and undrained); (5) relative density of the soil (30 and $70 \%$ ); and (6) coefficient of lateral pressure $\left(\mathrm{k}_{0}, 0.33,0.5\right.$ and 1$)$.

Figures 2-16 to 2-20 show the conclusions of the analyses (Bayoumi, 2000). Figure 2-16 shows the pullout capacities for drained and undrained conditions with different vertical stresses and different silt percentages. As shown in the figure, both drained and undrained pullout capacities remained constant regardless of silt percentage. Failure occurred along the interface between the inclusion and the soil and thus it was mostly dependent on friction at the interface, rather than on the material properties.

Figure 2-17 shows the effects of the coefficient of interface friction for different vertical stresses. The drained pullout capacity increased linearly with the coefficient of interface friction. The undrained pullout capacity also increased, but it was no longer linear, due to the pore pressures generated. Figure 2-18 shows the effect of vertical normal stress on pullout capacity for different interface frictions. The pullout capacity increased linearly with the vertical stress for both drained and undrained conditions. This trend was expected because when the vertical stress increased the interface effective vertical stress, and consequently, the interface shear strength increased (Bayoumi, 2000).

Figure 2-19 shows the ratio of undrained and drained pullout capacities for different vertical stresses and coefficients of interface friction. The figure shows a significant reduction in undrained pullout capacity, compared to the drained pullout capacity. The 
following was observed: (1) the ratio ranged from 0.578 to 0.886 ; the smaller ratio occurred for higher interface friction while the larger ratio occurred for lower interface friction; and (2) the ratio was not influenced by the vertical stress. Figure 2-20 shows the effects of the coefficient of lateral earth pressure. As shown in the figure, Bayoumi (2000) observed that the effect of this coefficient was negligible for drained conditions. Although the undrained pullout capacity increased with an increase of the coefficient of lateral earth pressure, the magnitude of the increase was very small (approximately $5 \%$ ).

Bayoumi (2000) summarized his observations as follows; (1) the parameters that influence the most the pullout capacity are drainage conditions, coefficient of friction at the soil/reinforcement interface, and normal stress; and (2) the parameters that had no or negligible influence on the pullout capacity are silt percentage, relative density, and coefficient of lateral pressure.

Bergado et al. (1992) also performed numerical analyses of pullout tests. Results of the numerical analyses were compared with the results of laboratory pullout tests. Figure 221 shows the FE mesh used for the analyses. The dimensions of the model were $50 " \times 12^{\prime \prime}$ (approximately $1.27 \mathrm{~m} \times 0.3 \mathrm{~m}$ ). Triangular and quadrilateral elements were used for the soil elements with a nonlinear elastic material model (Duncan and Chang, 1970). Onedimensional joint elements were used for the interface between soil and reinforcement, and the reinforcement was modeled with one-dimensional bar elements. Unlike Bayoumi's model (2000), both vertical and horizontal displacements were restrained at the bottom of the model and only vertical displacements were allowed at the lateral sides. 
Weathered clay was used for the backfill material and three different vertical stresses (i.e. 30, 50, and $90 \mathrm{kPa}$ ) were applied. Figure 2-22 shows plots of pullout capacities from laboratory tests and numerical analyses. The agreement was considered satisfactory with a maximum difference of about $15 \%$ (Bergado et al., 1993).

\subsubsection{Analytical analysis: Shear-lag analysis}

The shear-lag analysis is an approximate analytical method to estimate the tensile stresses in a single planar reinforcement; the method is widely used for composite materials. Based on the shear-lag approximation, Abramento and Whittle (1993) and Abramento et al. (1995) proposed formulations that described the complete load-transfer behavior for pullout tests with extensible, planar reinforcements. The formulations were developed to predict the development and distribution of tensile stresses and interface tractions along the inclusion.

Figure 2-23 shows geometry and boundary conditions used in the derivation. The reinforcement has thickness $\mathrm{f}$, length $\mathrm{L}$, and is embedded in a soil box of overall vertical dimension $(\mathrm{m}+\mathrm{f})$. The soil mass is initially subjected to a uniform vertical stress $\left(\sigma_{1}\right)$ and horizontal stress $\left(\sigma_{3}\right)$. The soil is sheared in plane strain as the pullout load $\left(\sigma_{\mathrm{p}}\right)$ is applied at the active end of the inclusion $(\mathrm{x}=0)$. During shearing, tensile stresses $\left(\sigma_{x x}^{f}(x)\right)$ are generated along the reinforcement. The distributions of normal $\left(\sigma_{y y}^{i}\right)$ and shear tractions $\left(\sigma_{\mathrm{xy}}^{\mathrm{i}}\right)$ along the interface are indicated in Figure 2-23. In addition, normal 
stresses $\left(\sigma^{\mathrm{m}}{ }_{\mathrm{yy}}\right)$, horizontal stresses $\left(\sigma_{\mathrm{xx}}^{\mathrm{m}}\right)$ and shear stresses $\left(\sigma_{\mathrm{xy}}^{\mathrm{m}}\right)$ in the soil matrix can also be determined.

For the shear-lag analysis, Abramento et al. (1995) assumed the following: (1) the soil (properties: $G_{m}, v_{m}$ ) and reinforcement (properties: $E_{f}$, and $v_{f}$ ) are linear, isotropic, and elastic materials; (2) slippage along the interface is governed by the Coulomb friction law with friction angle ( $\delta$ ) (i.e. $\left|\sigma_{\mathrm{xy}}^{\mathrm{i}}\right| / \sigma_{\mathrm{yy}}^{\mathrm{i}} \leq \tan \delta$ ); (3) the end of the inclusion $(\mathrm{x}=\mathrm{L})$ is stress free; and (4) the axial stresses in the soil and in the inclusion are functions of $x$ only.

The shear-lag equations for the interface tractions $\left(\sigma_{x y}^{\mathrm{i}}, \sigma_{y y}^{\mathrm{i}}\right)$ were obtained as follows, (Abramento et al., 1995):

$$
\begin{array}{ll}
\sigma_{x y}^{i}=\frac{f}{2} \frac{d \sigma_{x x}^{f}}{d x} & (E q .2-6(a)) \\
\sigma_{y y}^{i}=\sigma_{1}+\frac{m f}{8} \frac{d^{2} \sigma_{x x}^{f}}{d x^{2}} & (E q .2-6(b))
\end{array}
$$

The interface tractions are related to the tensile stresses through Equation 2-6. Equation 2-7 describes the tensile stresses in the reinforcement, if there is no slippage at the interface. 
$\mathrm{C}_{1}, \mathrm{C}_{2}$ are constants to be determined from appropriate boundary conditions and subject to the constraints imposed by the local frictional resistance at the inclusion-soil interface (Abramento et. al., 1995).

In addition, $\mathrm{K}_{1}$, and $\mathrm{K}_{2}$ are constants defined in terms of the material properties and geometry (Equation 2-8).

$$
\begin{aligned}
& K_{1}=\frac{6}{m f} \frac{\left[\left(1-v_{m}\right) a+2 \frac{G_{m}}{E_{f}}\left(1+v_{f}\right)\left(1-v_{f}\right)\right]}{\left[\left(1+\frac{1}{4} v_{m}\right)-\frac{3}{2} \frac{G_{m}}{E_{f}}\left(1+v_{f}\right) v_{f}\right.} \quad(E q . \quad 2-8(a)) \\
& K_{2}^{1}=\frac{6}{m f} \frac{\left[v_{m}-2 \frac{G_{m}}{E_{f}}\left(1+v_{f}\right) v_{f}\right]}{\left[\left(1+\frac{1}{4} v_{m}\right)-\frac{3}{2} \frac{G_{m}}{E_{f}}\left(1+v_{f}\right) v_{f}\right.} \quad(E q . \quad 2-8(b)) \\
& K_{2}^{3}=-\frac{6}{m f} \frac{\left(1-v_{m}\right)(1+a)}{\left[\left(1+\frac{1}{4} v_{m}\right)-+\frac{3}{2} \frac{G_{m}}{E_{f}}\left(1+v_{f}\right) v_{f}\right.} \quad(E q . \quad 2-8(c))
\end{aligned}
$$

Abramento et. al (1995) found solutions for four phases during a pullout test: (1) no interface slippage; (2) active slipping front (one-way debonding); (3) active and passive slipping fronts (two-way debonding); and (4) full slippage. Equation 2-7 and 2-8 apply for phase (1); the solutions for other phases can be found in Abramento et. al. (1995). 


$$
\begin{aligned}
& \sigma_{x x}^{f}=C_{1} \cosh \left(\sqrt{K_{1} x}\right)+C_{2} \sinh \left(\sqrt{K_{1} x}\right)+K \quad(E q .2-7) \\
& \text { where, } K=\frac{K_{2} \sigma}{K_{1}} \text { and } K_{2} \sigma=K_{2}^{1} \sigma_{1}+K_{2}^{3} \sigma_{3}
\end{aligned}
$$

Figure 2-24 shows a comparison of the tensile stress distribution of the inclusion between the analytical solution and experiments (Abramento et. al., (1995)). The figure shows good agreement between predictions and measurements.

\subsection{Case Studies : Failure of MSE Walls}

Two case studies are analyzed: (1) a wall at the Barren River Plaza Shopping Center in Glasgow, Kentucky; and (2) a wall supporting an asphalt covered parking lot in Calgary, Alberta, Canada.

\subsubsection{Failure of a MSE wall in Glasgow, Kentucky (Barren River Plaza Shopping Center)}

A failure of a MSE wall with cohesive backfill material was investigated (Leonards et. al., 1994). A Keystone/Tensar geogrid MSE wall with a sloping backfill was built for a shopping center in Glasgow, Kentucky, in 1990. The average height of the wall was between 3 and $6 \mathrm{~m}$ with a maximum height of $6.4 \mathrm{~m}$. Figure 2-25 shows a typical cross section of the structure. It was determined that a slope was needed above the retaining 
wall system to meet existing grades. The height of the slope was designed between 3 and $8.2 \mathrm{~m}$ with the slope itself ranging between $1.7 \mathrm{H}: 1 \mathrm{~V}$ to $2 \mathrm{H}: 1 \mathrm{~V}$ (Figure 2-25).

The bedrock was found at a depth of approximately $12 \mathrm{~m}$ below the ground surface, overlain by silty clay and clayey silt with medium to high plasticity $(\mathrm{LL}=50 \sim 60, \mathrm{PL}=$ 25 35). The natural water content of the soil was at or slightly below the plastic limit.

The ground was excavated to permit placement of the geogrids in May, 1990. The construction of the MSE wall was planned after the excavation. However, a major failure of the soil behind the excavation occurred in June 1990. The material from this failure was included into the backfill. It was not certain that the material was recompacted to the requested density (i.e. $95 \%$ of Proctor density). Lateral drains were specified to be installed from the face of the wall, but they were not placed for unknown reasons. The reinforced section of the wall was constructed in August 1990 while the sloped portion of the backfill was not completed until October.

The first indication of post-construction problems occurred one month after completion of the wall, in November 1990, through slumping of the backfill. The slumping continuously increased after a heavy rainfall. On December 23, 1990, the retaining wall collapsed at the section where the slumping occurred.

Figure 2-26 shows the initial period of distress, especially (a) deformation rate of the wall, and (b) rainfall. At ground level, there was $27 \mathrm{~cm}$ (10.6 inches) of displacement 
over a 4 month period. The majority of the displacement occurred over two periods following a heavy rainfall (Figure 2-26 (a) and (b)). Major distress was also recorded in the backfill slope during and after the heavy rainfall.

Subsurface investigations were performed to determine the cause of the failure. They consisted of borings, soil tests, excavations, piezometers, and instrumentation of the wall. The groundwater table was located almost at the bottom of the reinforced zone. SPT results showed that for natural undisturbed soils the average $\mathrm{N}$ values above the groundwater table ranged between 15 and 30 while below the water table ranged between 10 and $15 . \mathrm{N}$ values as low as 2 or 3 with an average of 10 were obtained for the compacted fill behind the reinforced area. The results of compaction tests indicated that the backfill was compacted on the dry side of the optimum. In addition, it was later concluded that the soil outside the reinforced area was compacted at $86 \%$ of Proctor, lower than the specified $95 \%$. The excavation revealed that the top layer of reinforcement had been omitted, which explained why the top of the wall rotated.

A granular soil was specified in the original design for the backfill, but silty clay and clayey silt were used instead. Even with these soils, the backfill slope would have been stable if drainage systems had been installed. Because the backfill was not properly compacted, the clay absorbed water easily with a consequent loss of strength. This caused the soil to slump. The scarp created allowed water to penetrate to greater depths and further reduce the shear strength of the soil. 
In summary, the Barren River Plaza Shopping Center failure was caused by a series of errors throughout the design and construction process: (1) inappropriate backfill material and inadequate compaction control; and (2) omission of the top geogrid reinforcement.

\subsubsection{Failure of a geogrid reinforced wall in Calgary, Alberta (Parking lot)}

In Calgary in 1984, a $9 \mathrm{~m}$ tall geogrid reinforced retaining wall was constructed to support the parking lot. The retaining wall system was originally composed of separate soldier piles, timber lagging facings and anchors. The soldier piles (W250 $\times 49$ steel section) were placed in $600 \mathrm{~mm}$ diameter augered holes, which were about $3 \mathrm{~m}$ deep; the holes were then filled with concrete. The soldier piles were positioned at $2.2 \mathrm{~m}$ from center to center. Timber lagging was placed inside of the pile flanges with dimensions 75 $\mathrm{mm}$ thick and $150 \mathrm{~mm}$ wide.

The owners decided to use a high strength grid for support instead of anchors, because of the smaller cost of the solution, but still using the solider pile and timber lagging facings. Tensar SR2 geogrid was used for the wall reinforcement. Figure 2-27 shows the typical vertical section and design details of the wall. As shown in the figure, the geogrids were placed in 10 layers and the "wrap around" method was used.

A low plasticity clay till was used as the backfill material while a granular fill was placed close to the face of the wall and adjacent to the timber lagging to provide a drainage zone for the clay till. 
The wall operated satisfactorily after it was constructed in the spring of 1984. In September 1985, settlement and distress were noticed after a heavy rain. The wall was instrumented with a slope indicator on the wall face to monitor the movement of the wall. Conditions gradually deteriorated with time; the wall facing rotated continuously about its base. The top $3 \mathrm{~m}$ of the clay backfill softened, due to saturation of the fill.

Samples of the clay backfill were taken for triaxial tests (UU). It was found from the laboratory tests that the clay sample, compacted at $93 \%$ of Proctor at a water content of $10.5 \%$, had a compressive strength of $375 \mathrm{kPa}$. For a similar sample, the water content increased to $18.7 \%$ when saturated, and the compressive strength decreased down to 49 kPa (Burwash and Frost, 1991). The reason for the increase in water content was the absorption of water by the clay compacted at the dry side of optimum. The failure of the wall was caused by the loss in strength due to the increase in water content. The slope indicator showed that the wall facing was rotating about its base. It also showed that the outward movement of the wall greatly increased with time.

The failure of the wall was primarily caused by poor construction. Due to inappropriate compaction (i.e. compaction at dry side of optimum), the distress occurred in the retaining wall as the clay backfill became saturated after a heavy rain, and the strength was reduced as the clay absorbed water. As a consequence, the geogrids were subjected to large lateral strains to compensate for the loss of strength in the soil. Once the strength 
loss exceeded the capacity of the soldier piles, the deformations of the wall rapidly increased, eventually causing failure of the wall. 

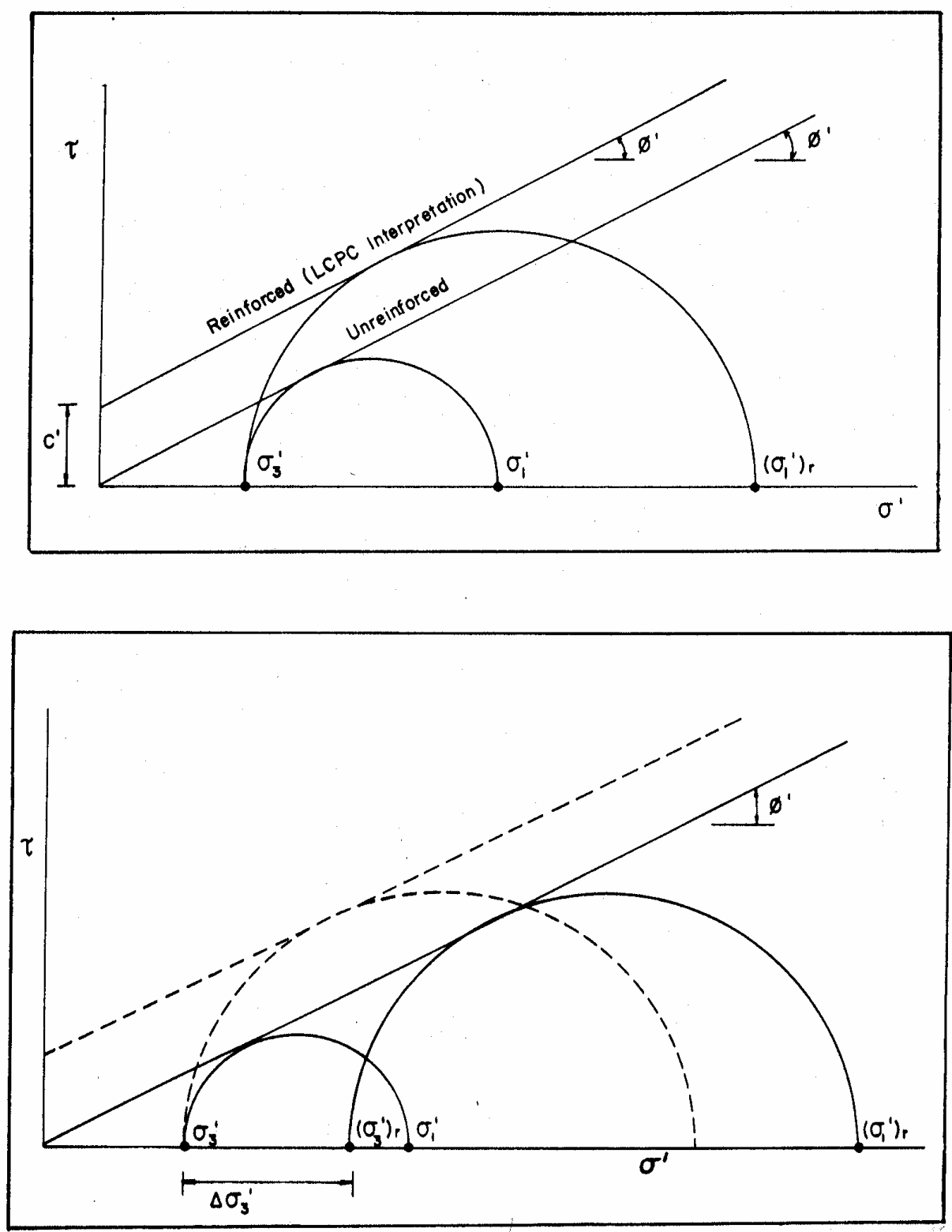

Figure 2-1 Mechanism of Reinforced Soil; (a) Anisotropic Cohesion Concept, and (b) Enhanced Confining Stress Concept (After Ingold, 1982) 


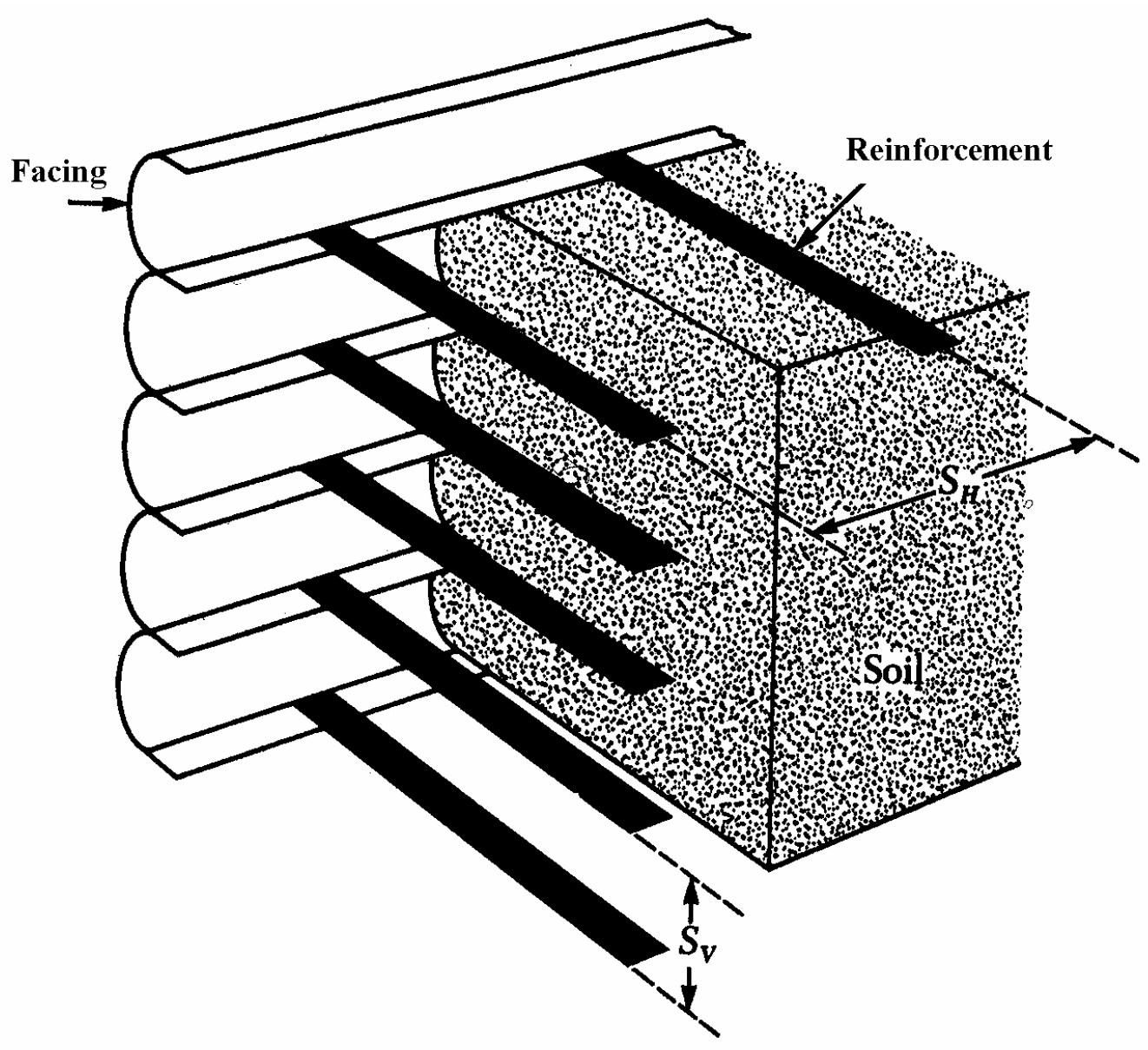

Figure 2-2 MSE Wall (After Das, 1995) 


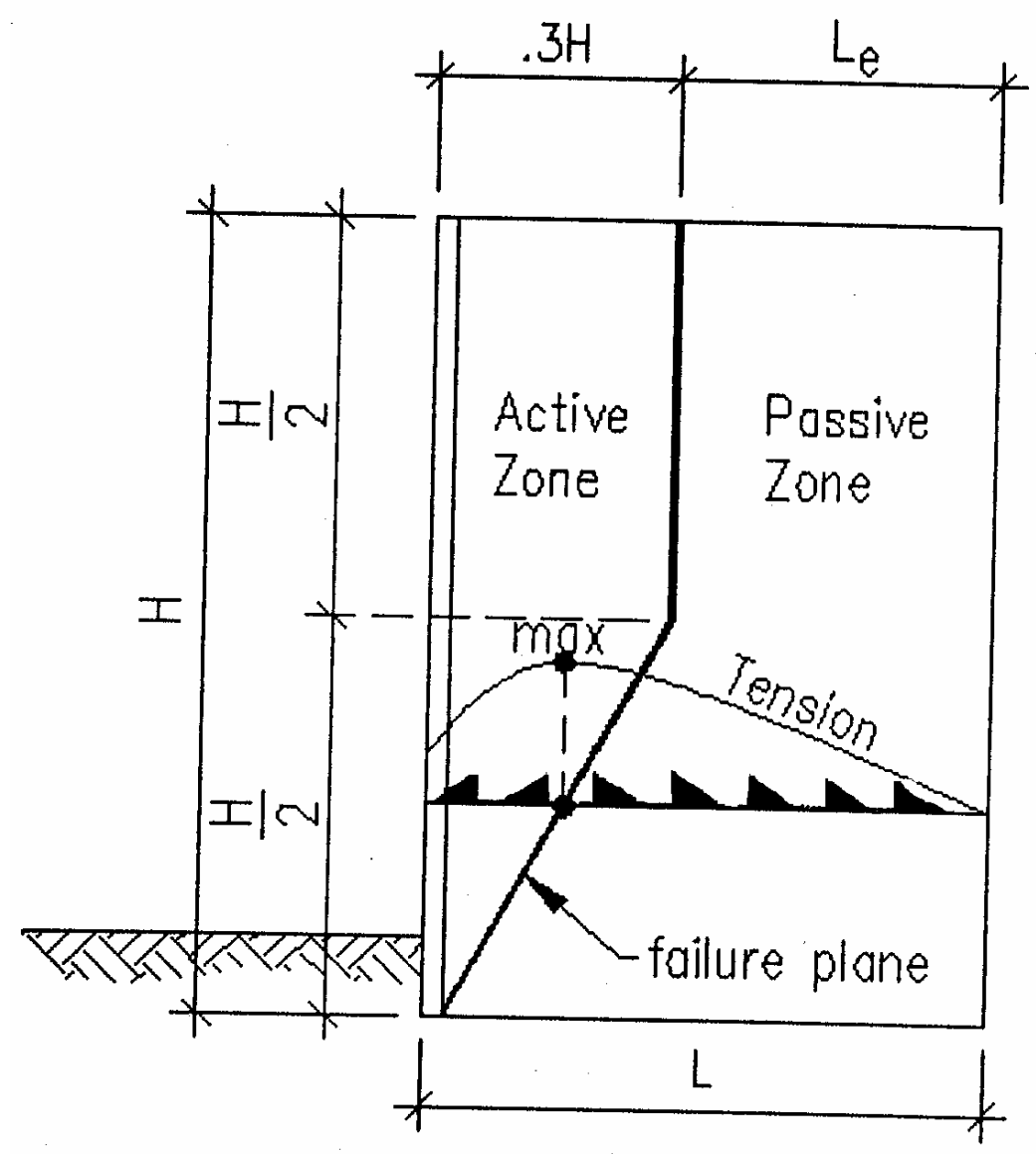

Figure 2-3 Location of the Failure Plane in MSE Wall with Steel Reinforcement (After Schlosser et. al., 1974) 


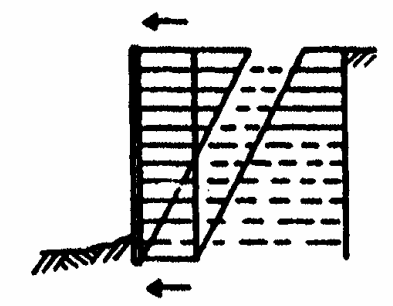

(a) Adhesion failure

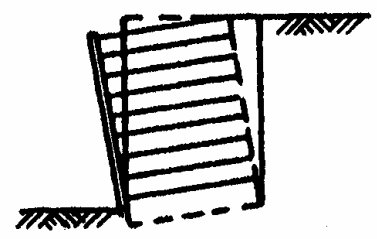

(d) Tilt/bearing failure

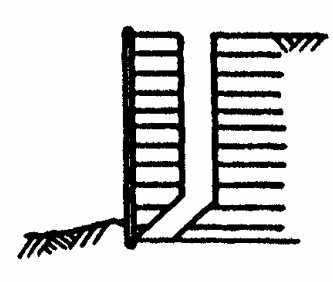

(b) Tension failure

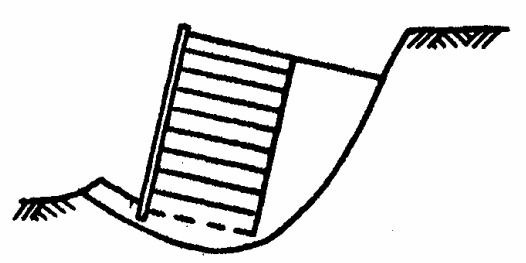

(e) Slip failure

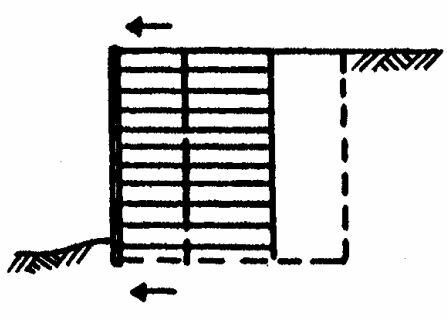

(c) Sliding

Figure 2-4 Failure Mechanisms of MSE Wall with Steel Reinforcement (After Jones, 1996) 


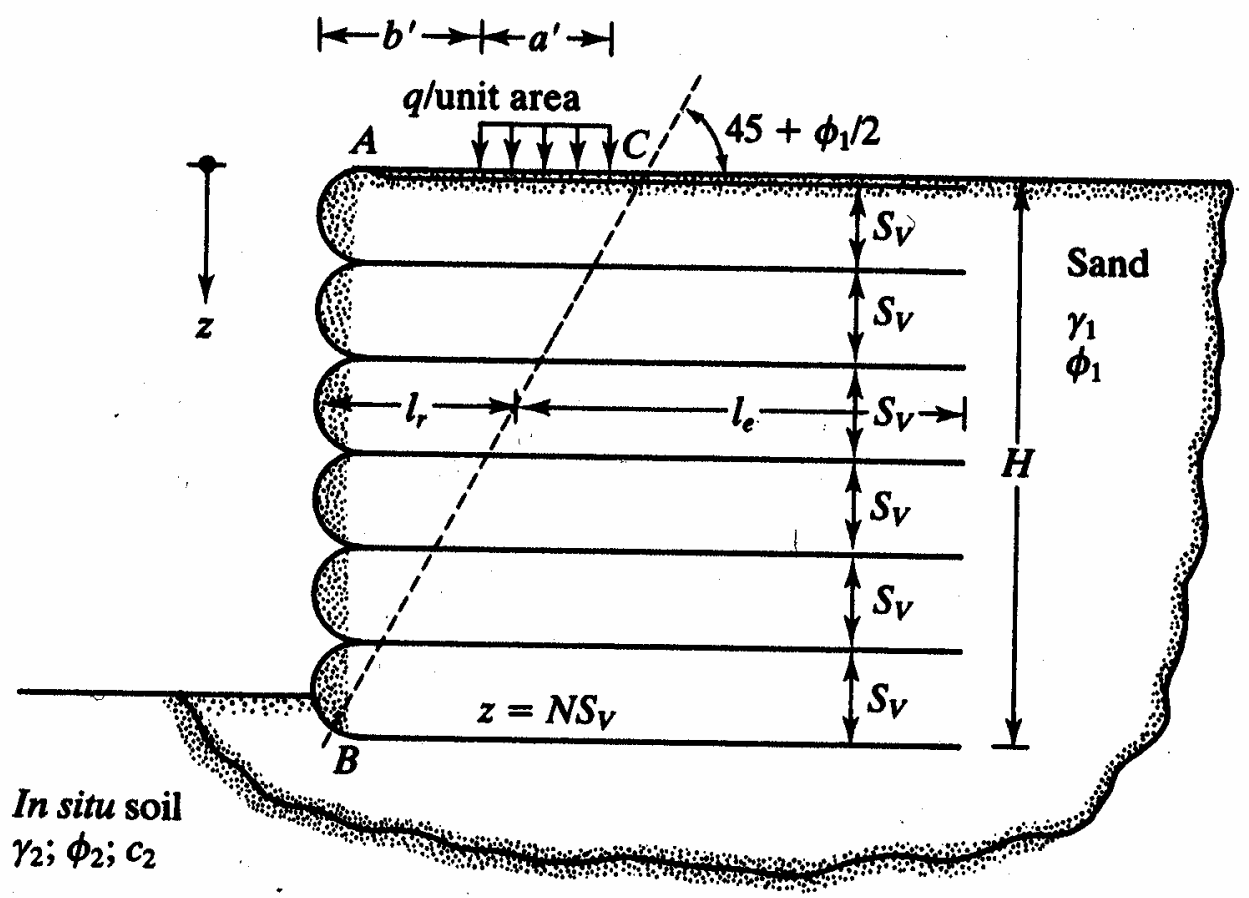

Figure 2-5 Analysis of a MSE Wall with Steel Reinforcement (After Das, 1995) 


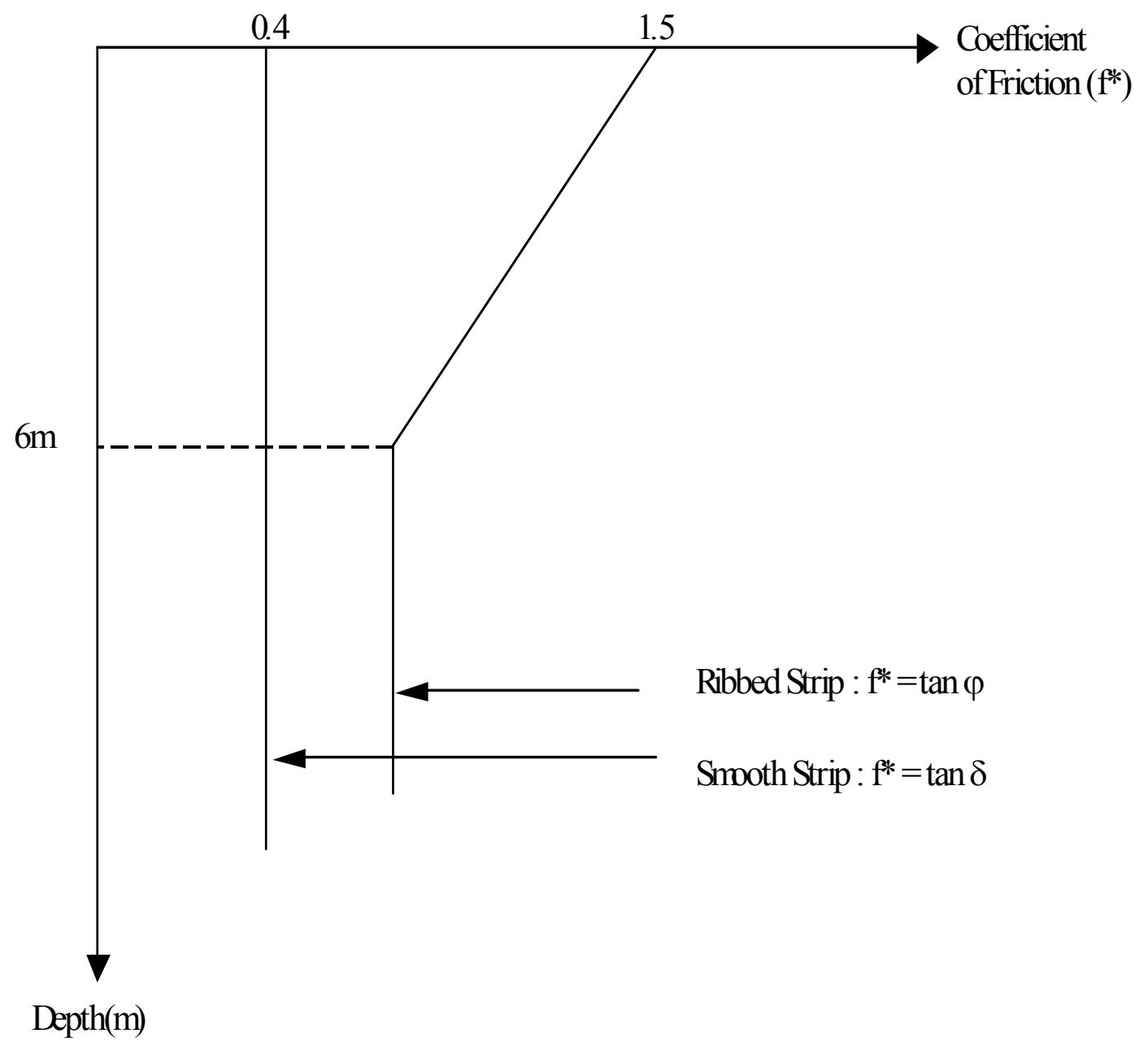

Figure 2-6 Coefficient of Friction for Steel Strip (After Bourdeau, 1999) 


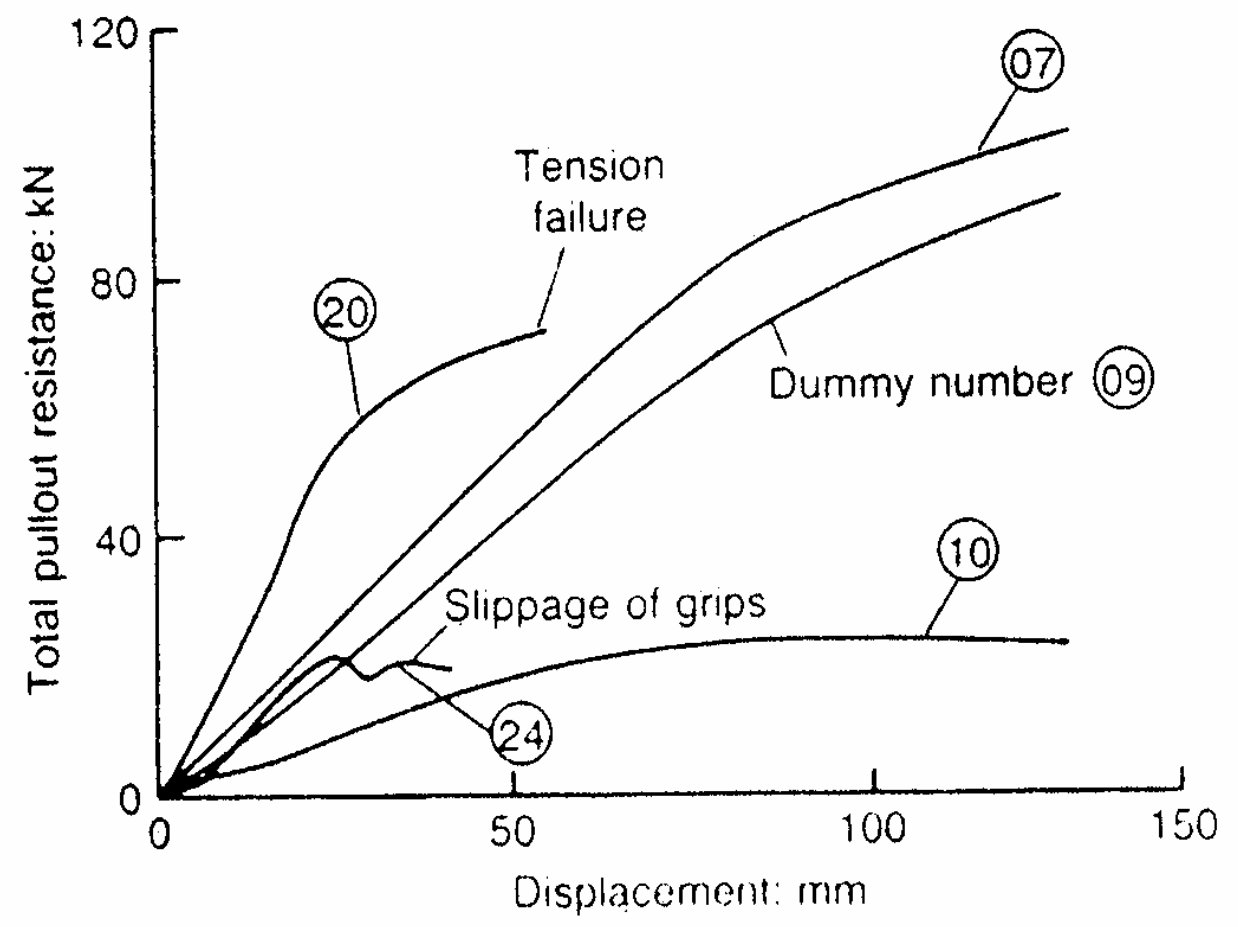

Figure 2-7 Load-Displacement Curves from Field Pullout Tests in Clayey Sand, Steel Grid (After Bergado et. al., 1993) 


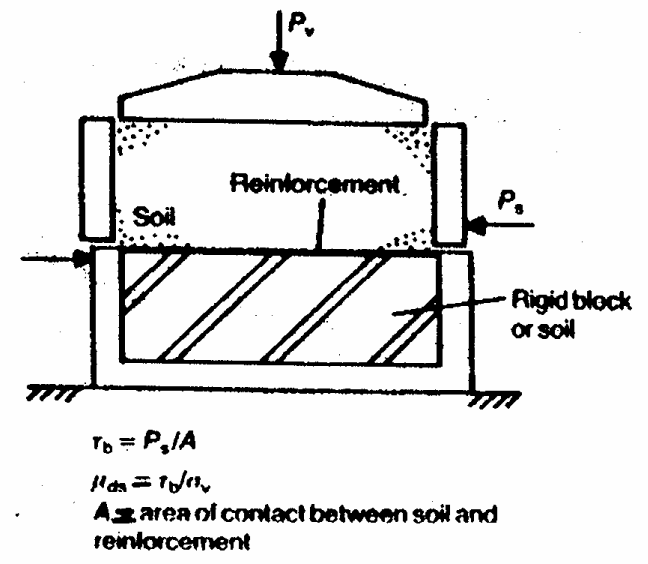

(a)

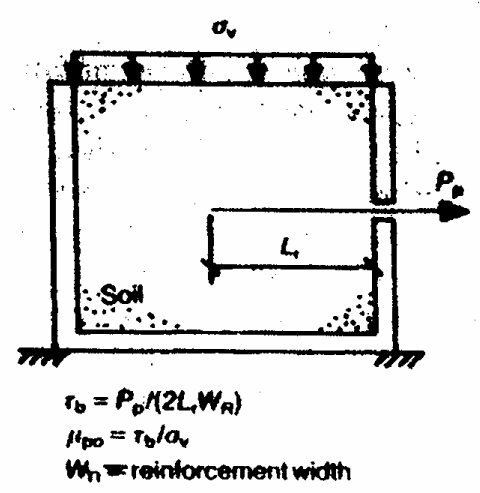

(b)

Figure 2-8 Determination of Friction Coefficient between Soil and Reinforcement;

(a) Direct Shear Test, and (b) Pullout Test (After Palmeira et. al., 1989) 


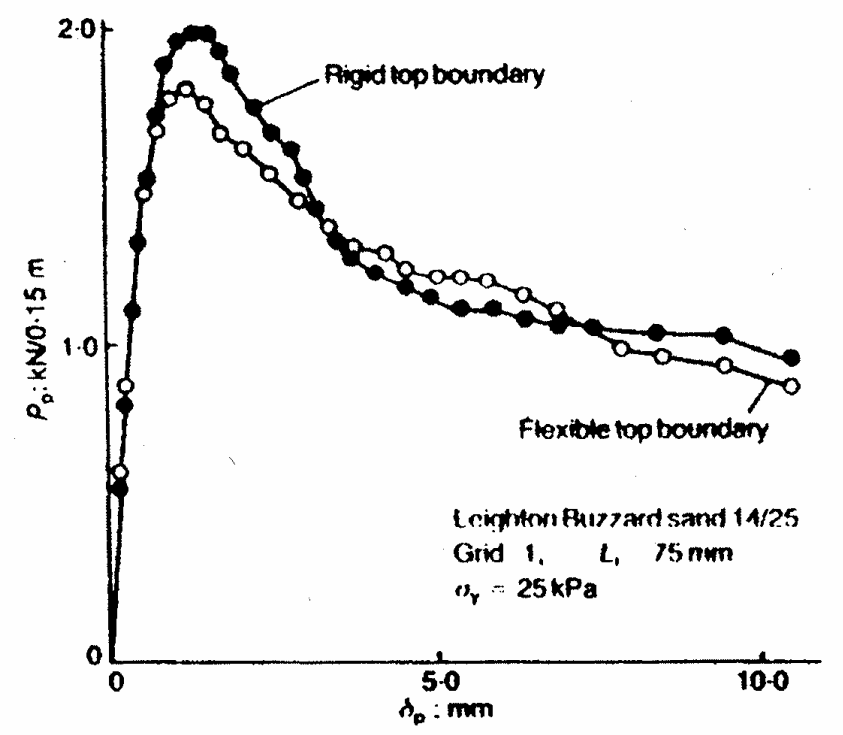

Figure 2-9 Effect of Top Boundary on Pullout Capacity, Steel Grid (After Palmeira et. al., 1989)

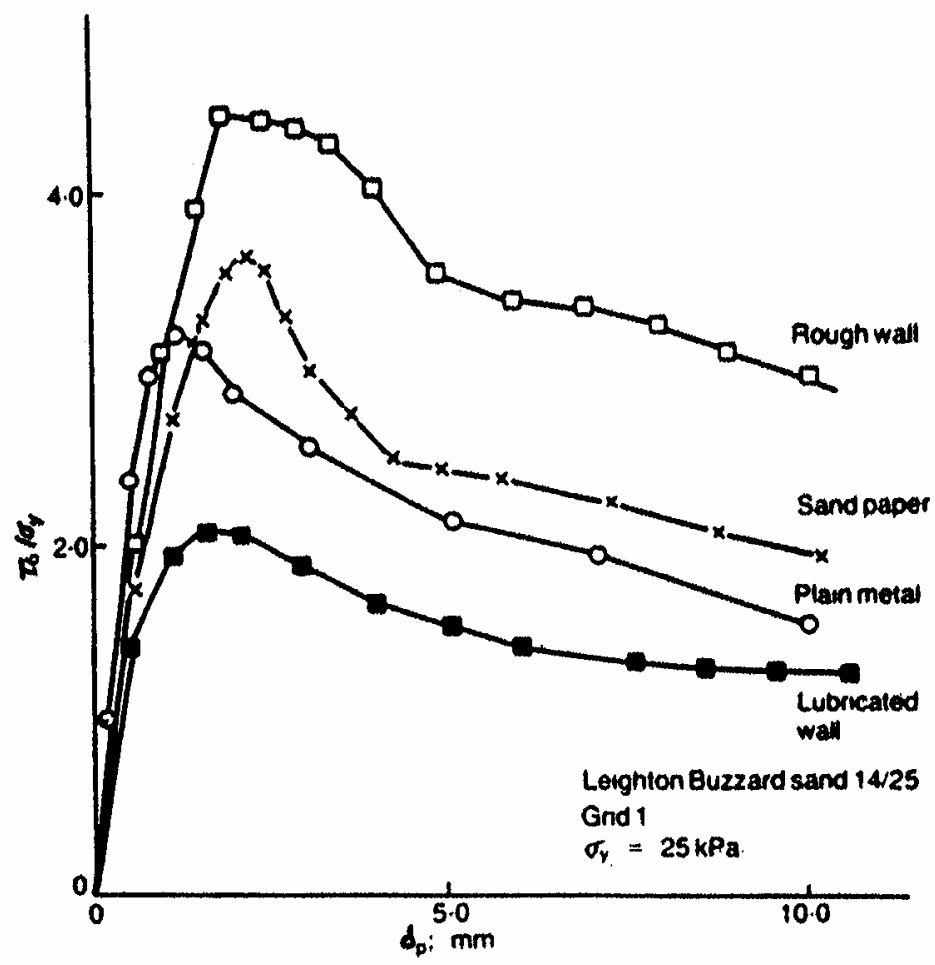

Figure 2-10 Effect of Roughness of Front Wall (After Palmeira et. al., 1989) 


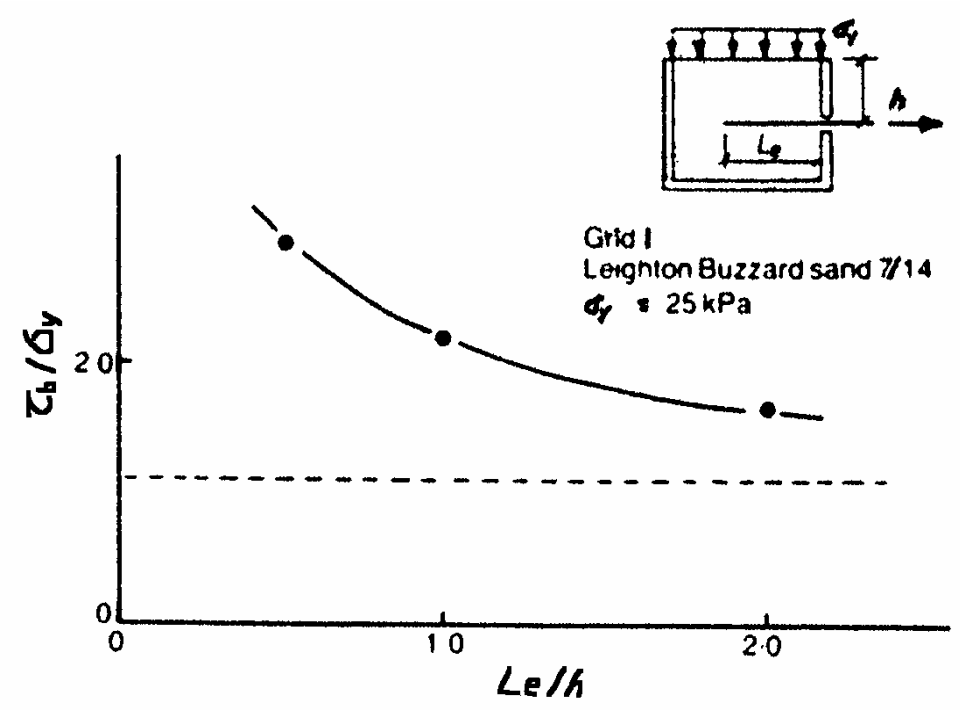

Figure 2-11 Effect of Embedment Length of Reinforcement (After Palmeira et. al., 1989)

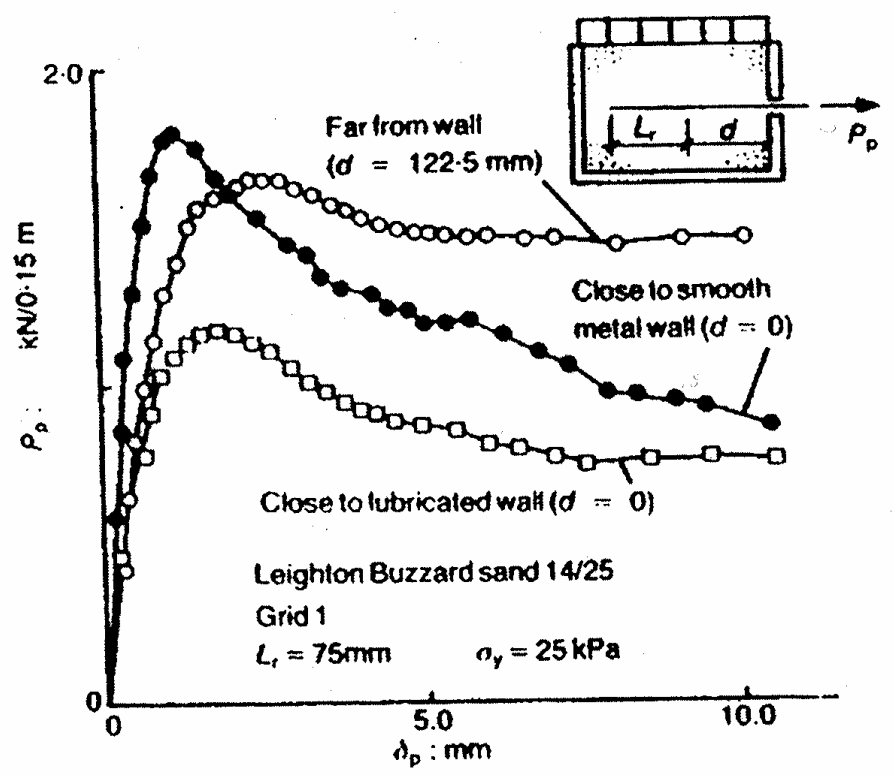

Figure 2-12 Comparison between Tests with Reinforcement Close to and Far from Front Wall (After Palmeira et. al., 1989) 


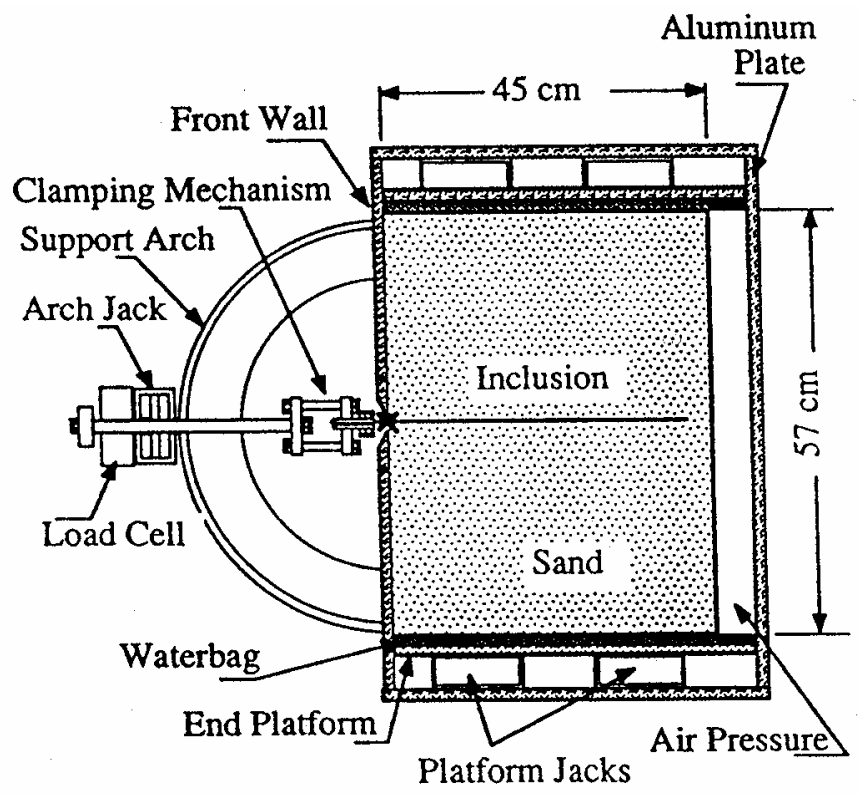

Figure 2-13 A Schematic Diagram of APSR Cell (After Abramento et. al., 1995)

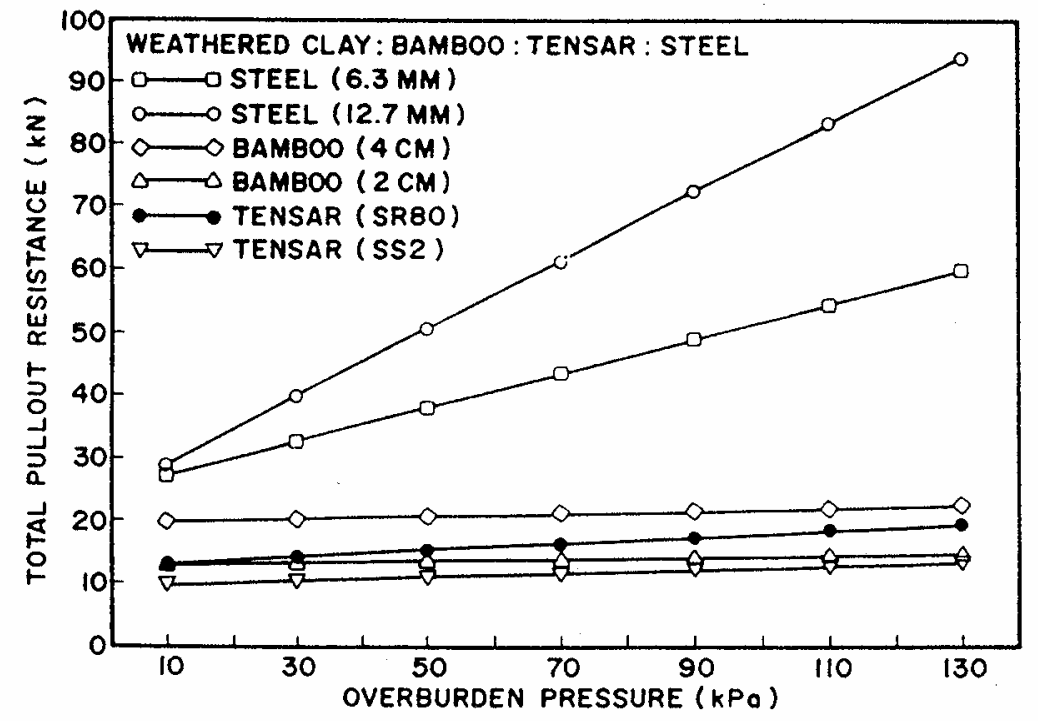

Figure 2-14 Comparison of Total Pullout Capacity of Bamboo, Tensar, and Steel Grids at $25 \mathrm{~mm}$ Pullout Displacement (After Bergado et. al., 1993) 


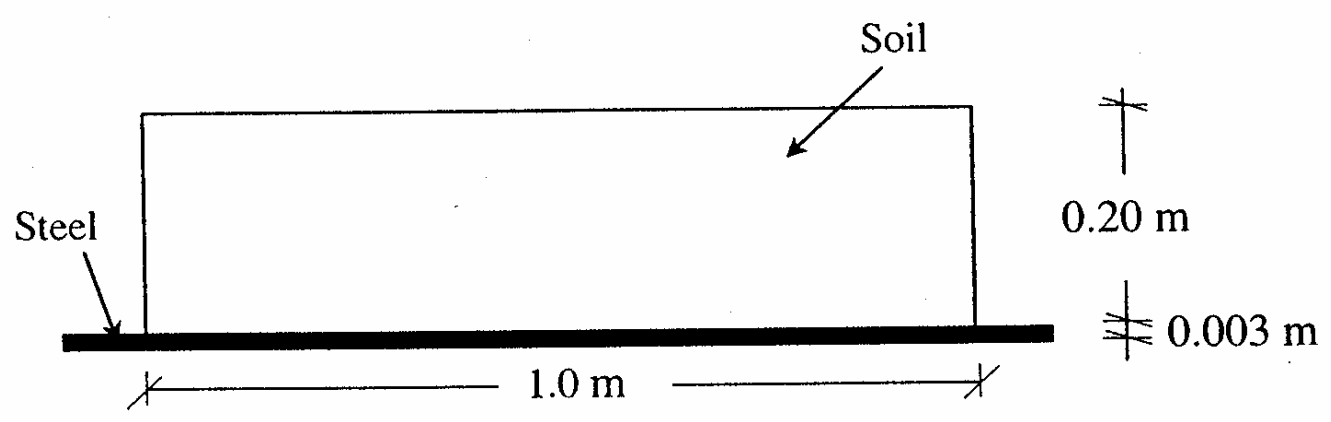

(a)

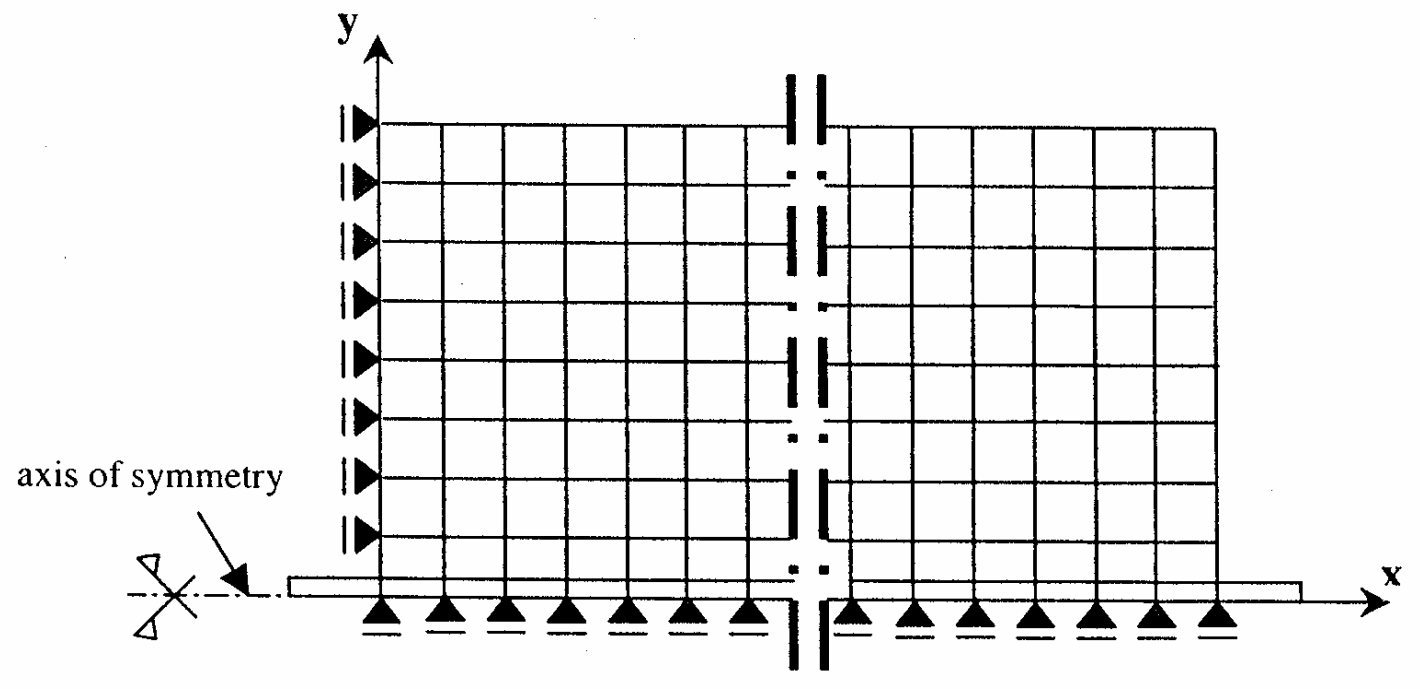

(b)

Figure 2-15 Modeling of Pullout Box; (a) Dimensions and Geometry, and (b) Boundary Conditions (After Bayoumi, 2000) 


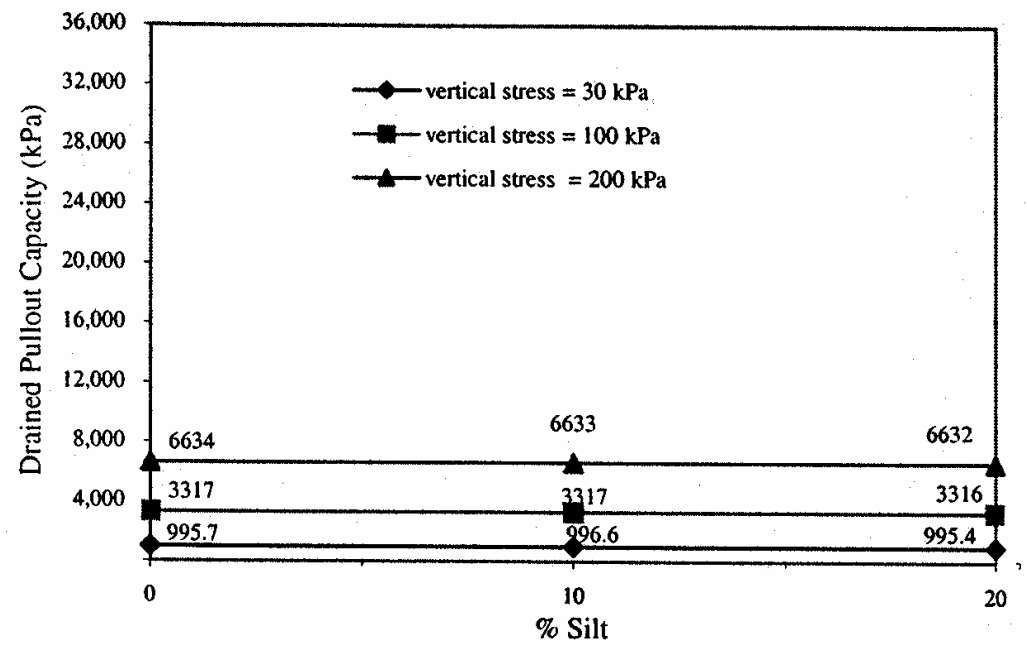

(a)

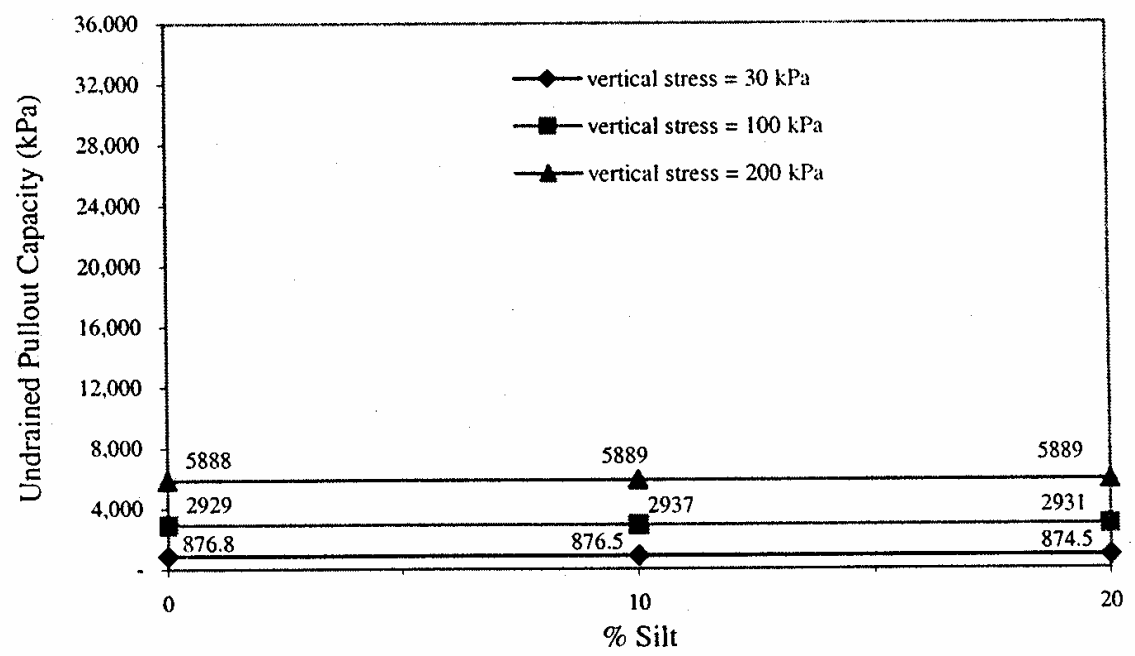

(b)

Figure 2-16 Effect of Silt Percentages $(\mu=0.1)$; (a) Drained, and (b) Undrained (After Bayoumi, 2000) 


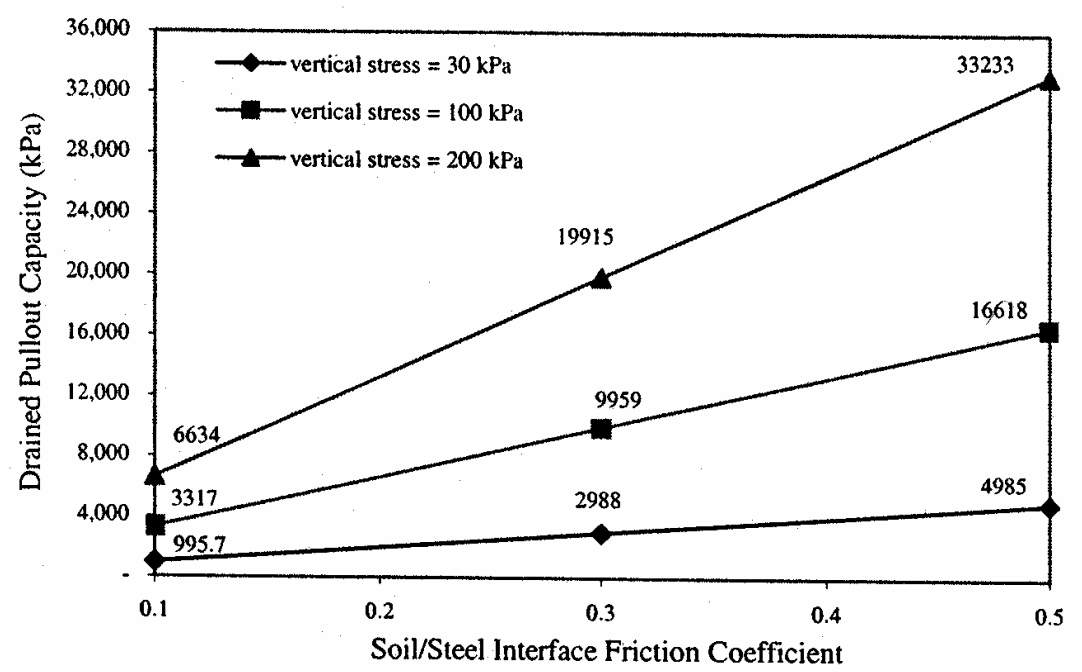

(a)

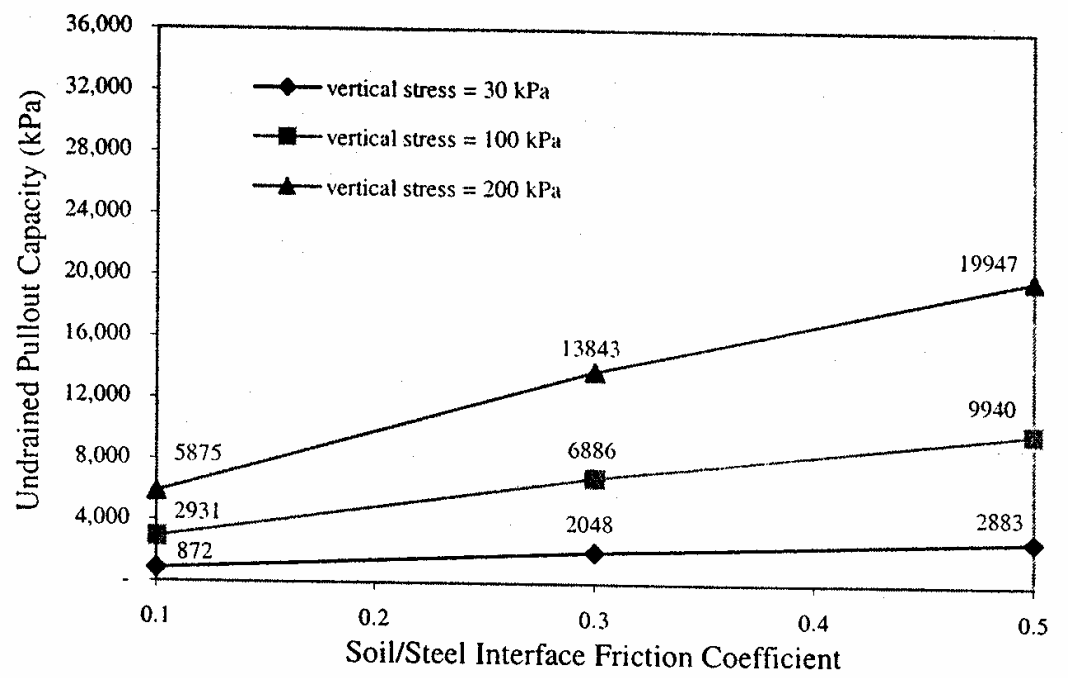

(b)

Figure 2-17 Effect of Interface Friction; (a) Drained, and (b) Undrained (After Bayoumi, 2000) 


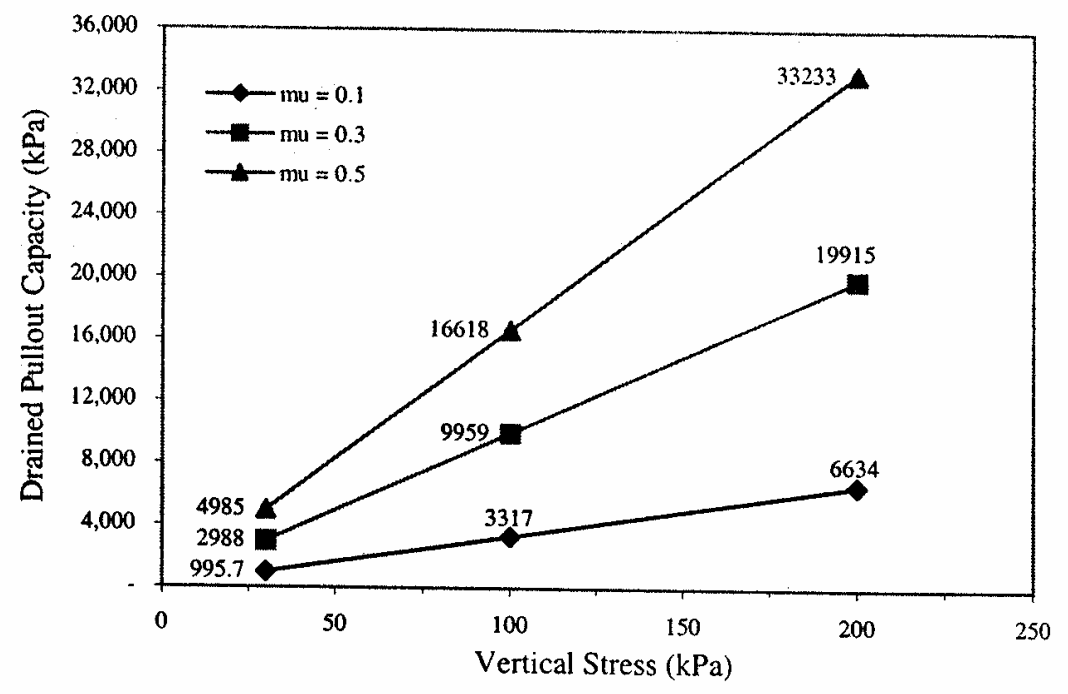

(a)

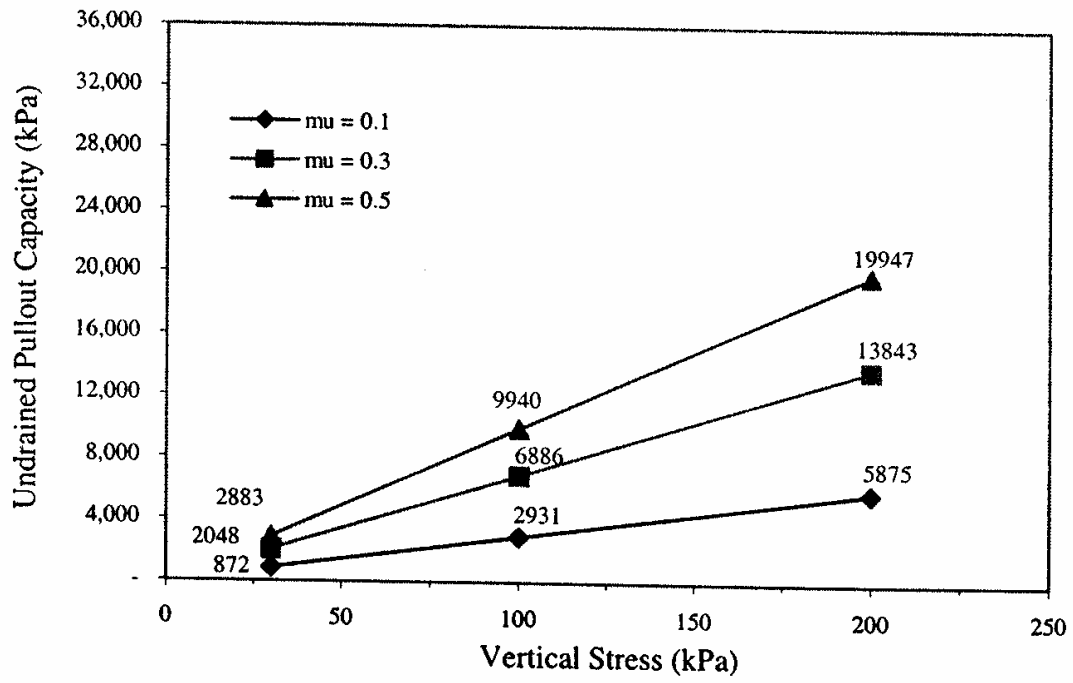

(b)

Figure 2-18 Effect of Vertical Stress $(\mathrm{mu}=\mu=$ Coefficient of Interface Friction);

(a) Drained, and (b) Undrained (After Bayoumi, 2000) 


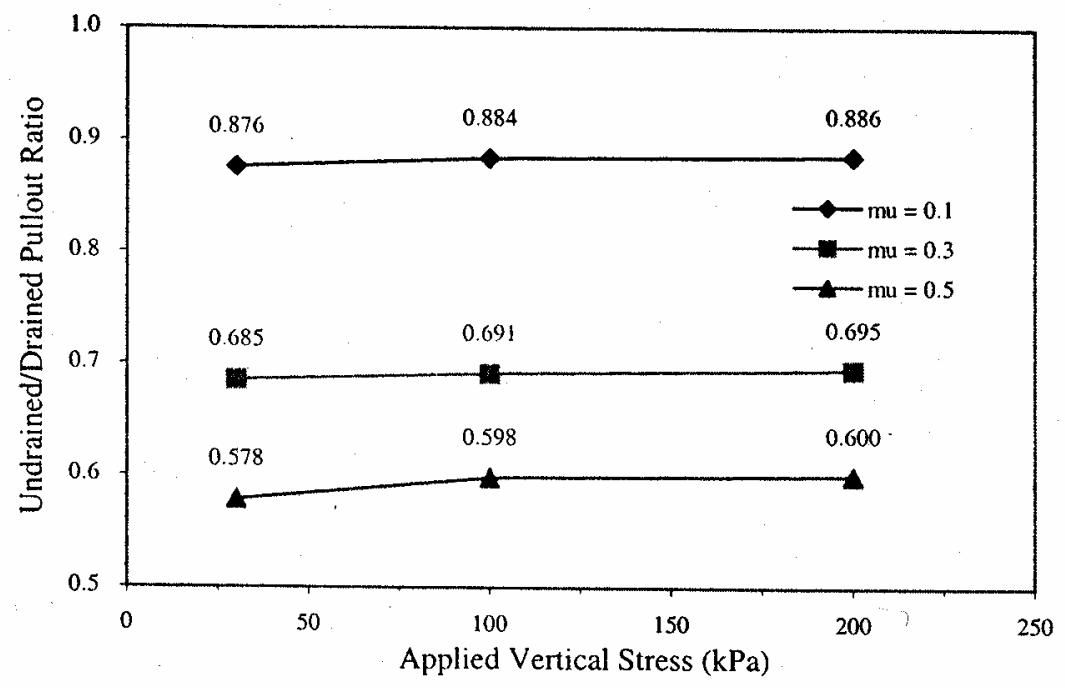

Figure 2-19 Effect of Drainage Condition with Respect to Vertical Stress (mu $=\mu=$ Coefficient of Interface Friction), (After Bayoumi, 2000)

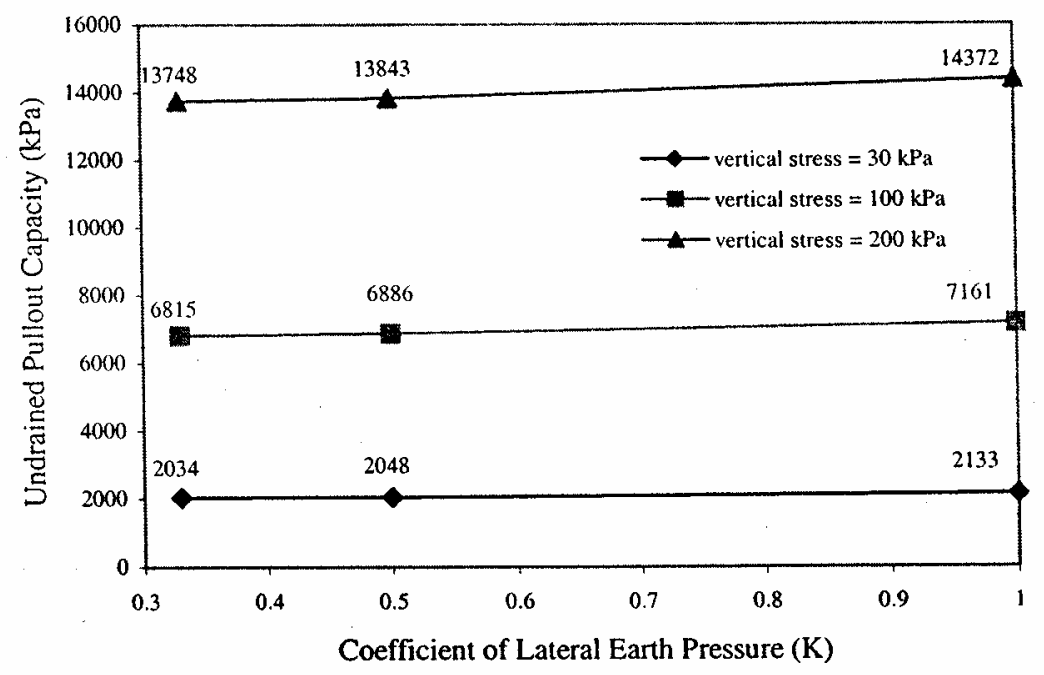

Figure 2-20 Effect of Lateral Pressure Coefficient for Undrained Condition (After Bayoumi, 2000) 


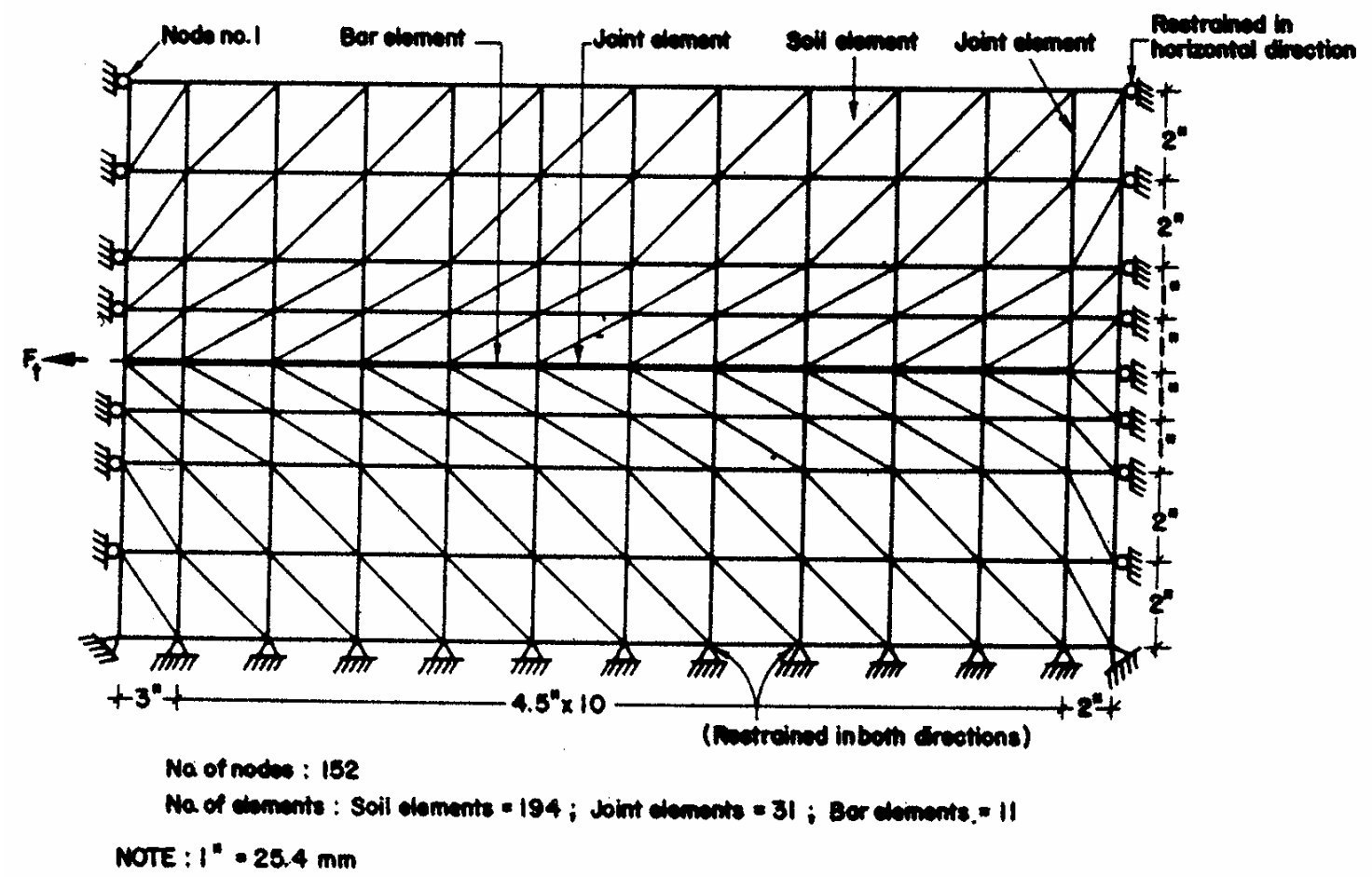

Figure 2-21 Modeling of Pullout Box for FE Analysis (After Bergado et. al., 1992) 


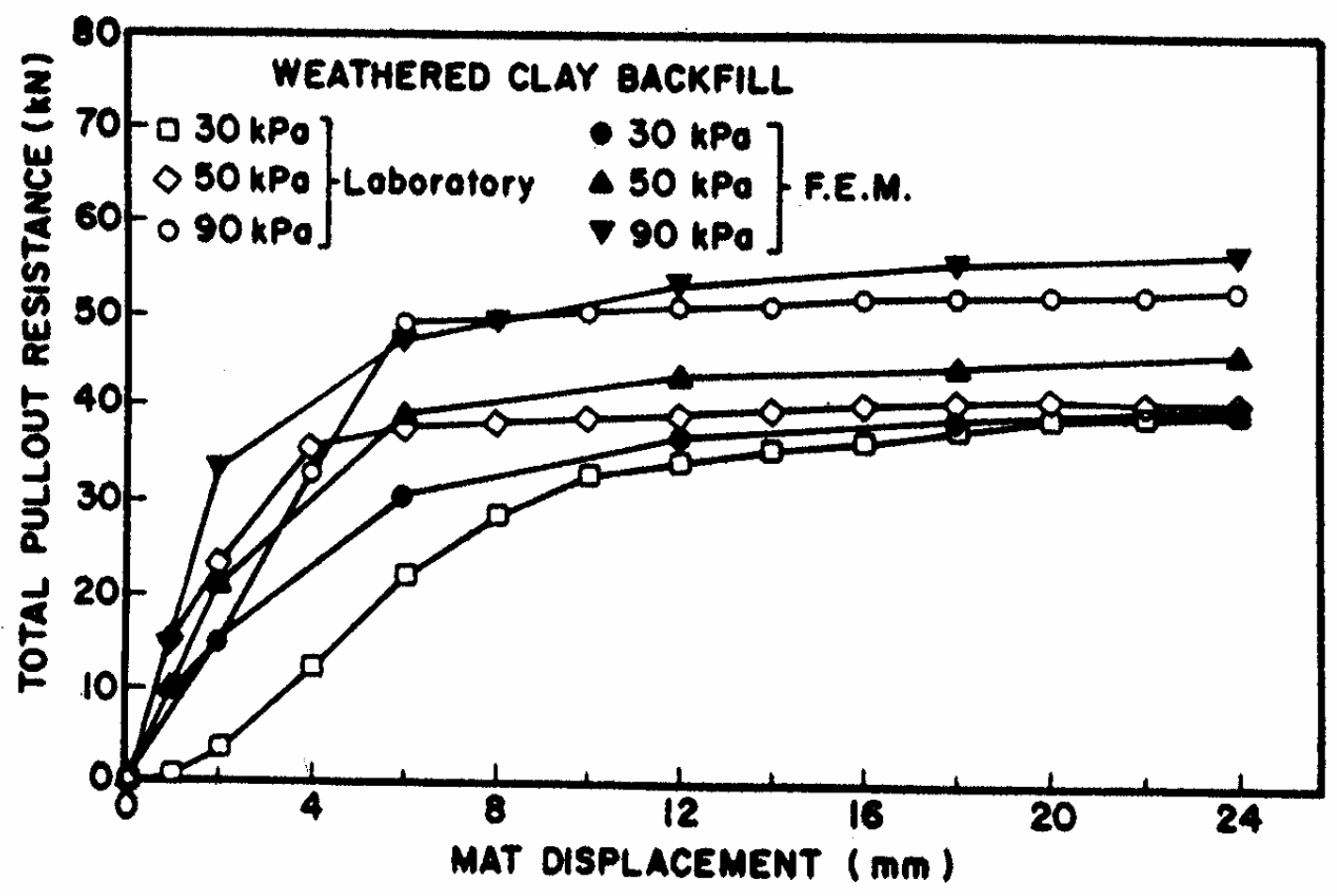

Figure 2-22 Comparison of Experimental and FEM Load-Displacement Curves (After Bergado et. al., 1992) 


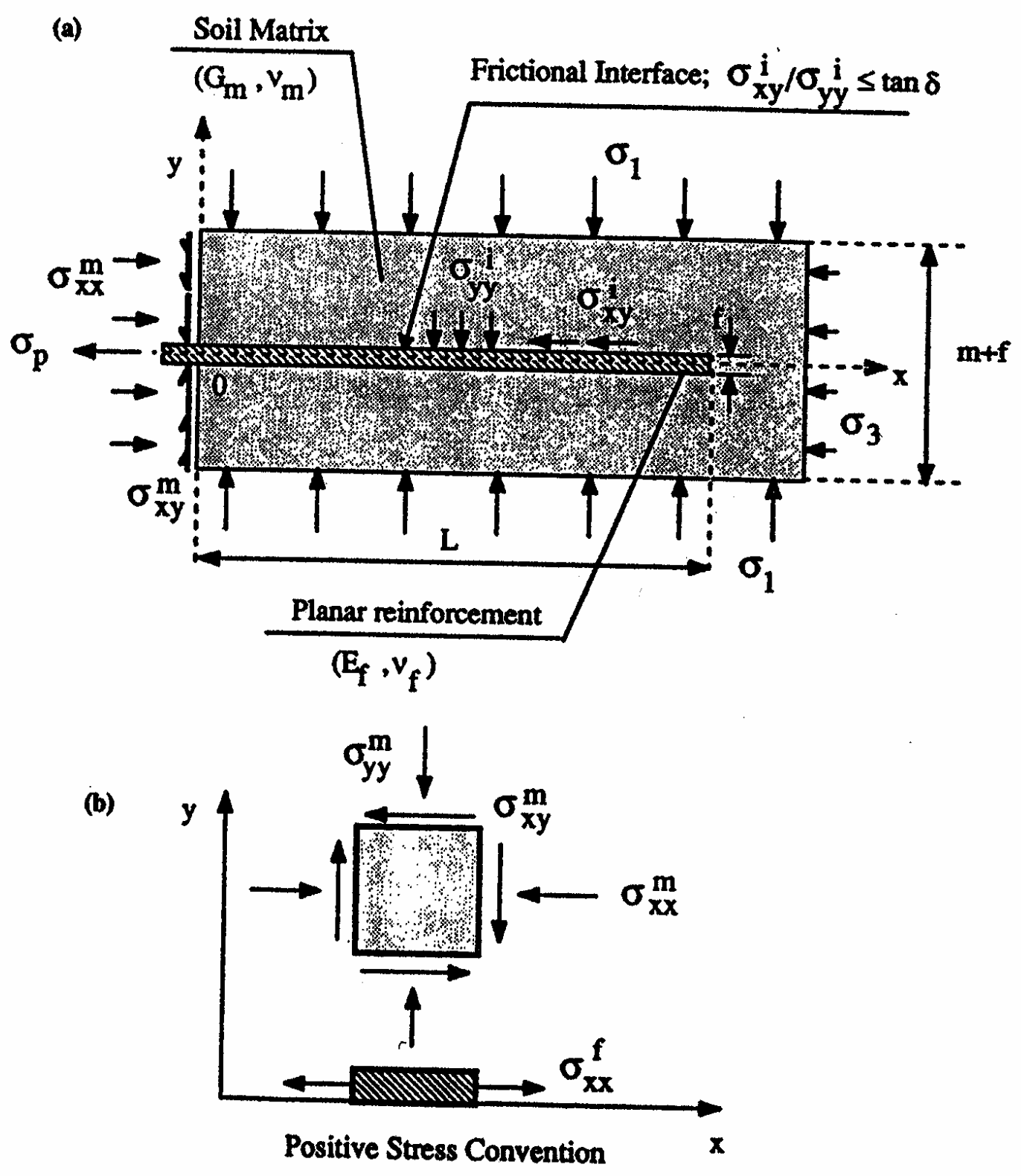

Figure 2-23 Geometry and Boundary Conditions of Pullout Tests for Planar Reinforcements (After Abramento et. al., 1995) 


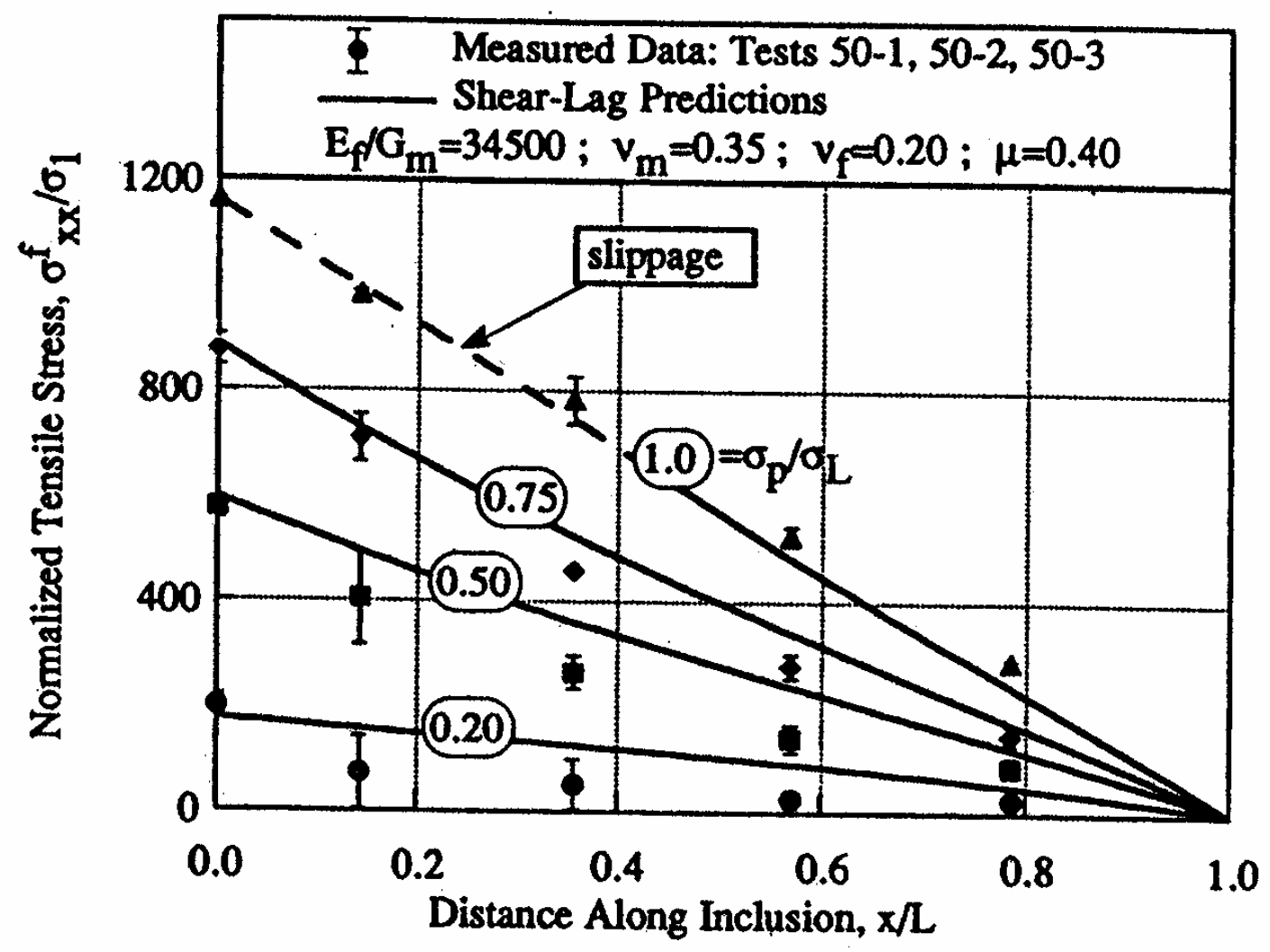

Figure 2-24 Comparison of Predicted and Measured Tensile Stress Distribution for Pullout Tests on Steel Sheet Inclusion (After Abramento et. al., 1995) 


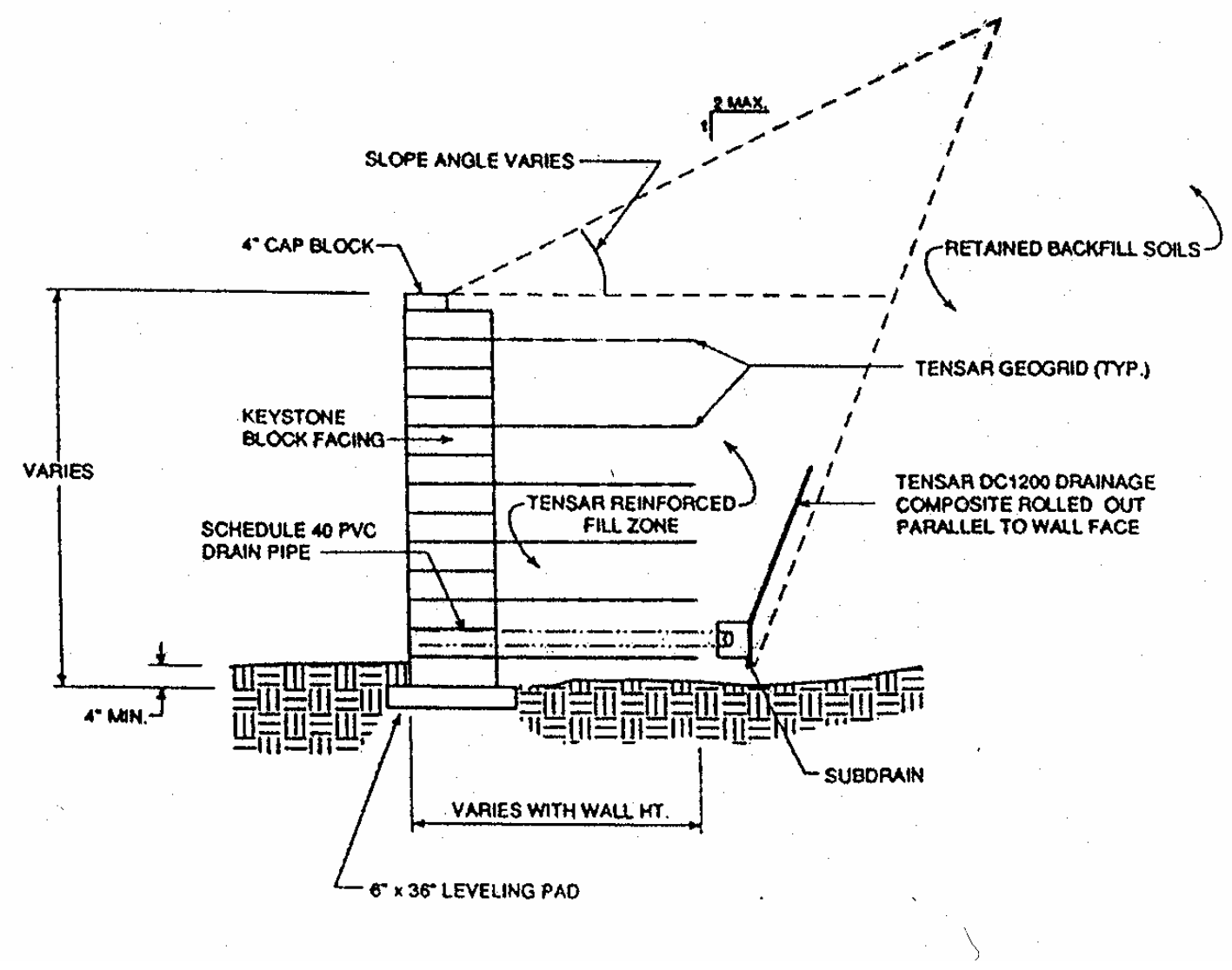

Figure 2-25 Typical Section of As-Designed Retaining Structure, Geogrid Reinforcement (After Leonards et. al., 1994) 


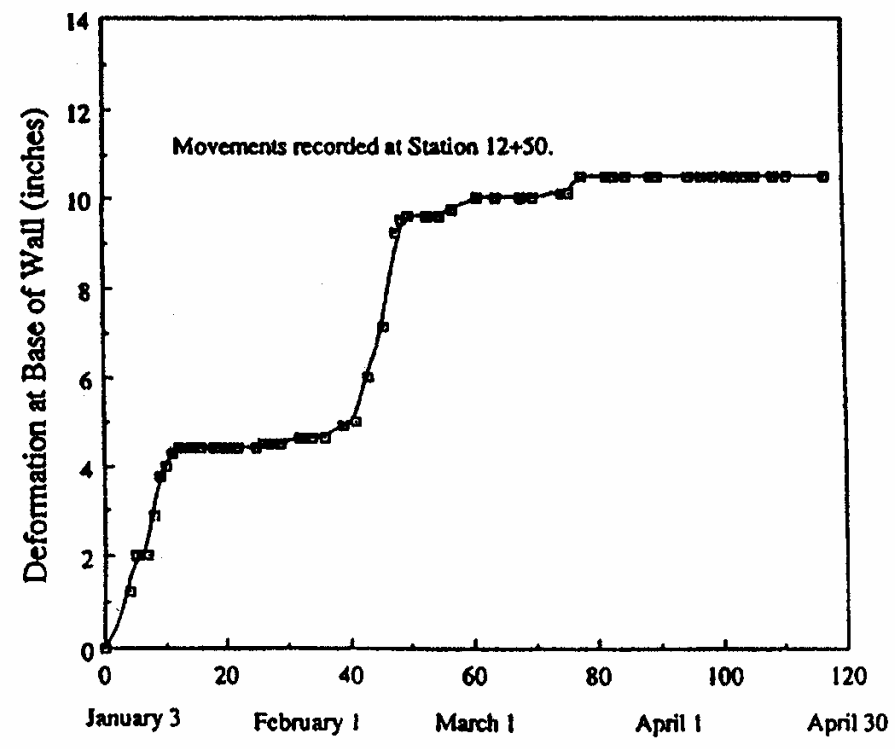

Day (January 3 to April 30, 1991)

(a)

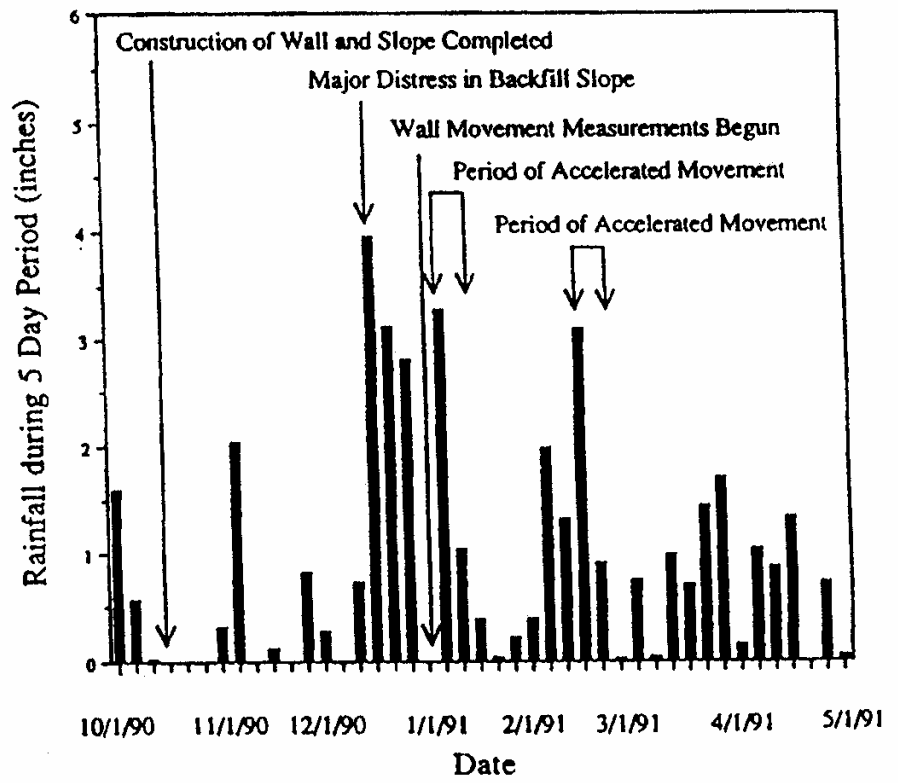

(b)

Figure 2-26 Initial Period of Distress; (a) Deformation Rate, and (b) Rainfall (After Leonards et. al., 1994) 

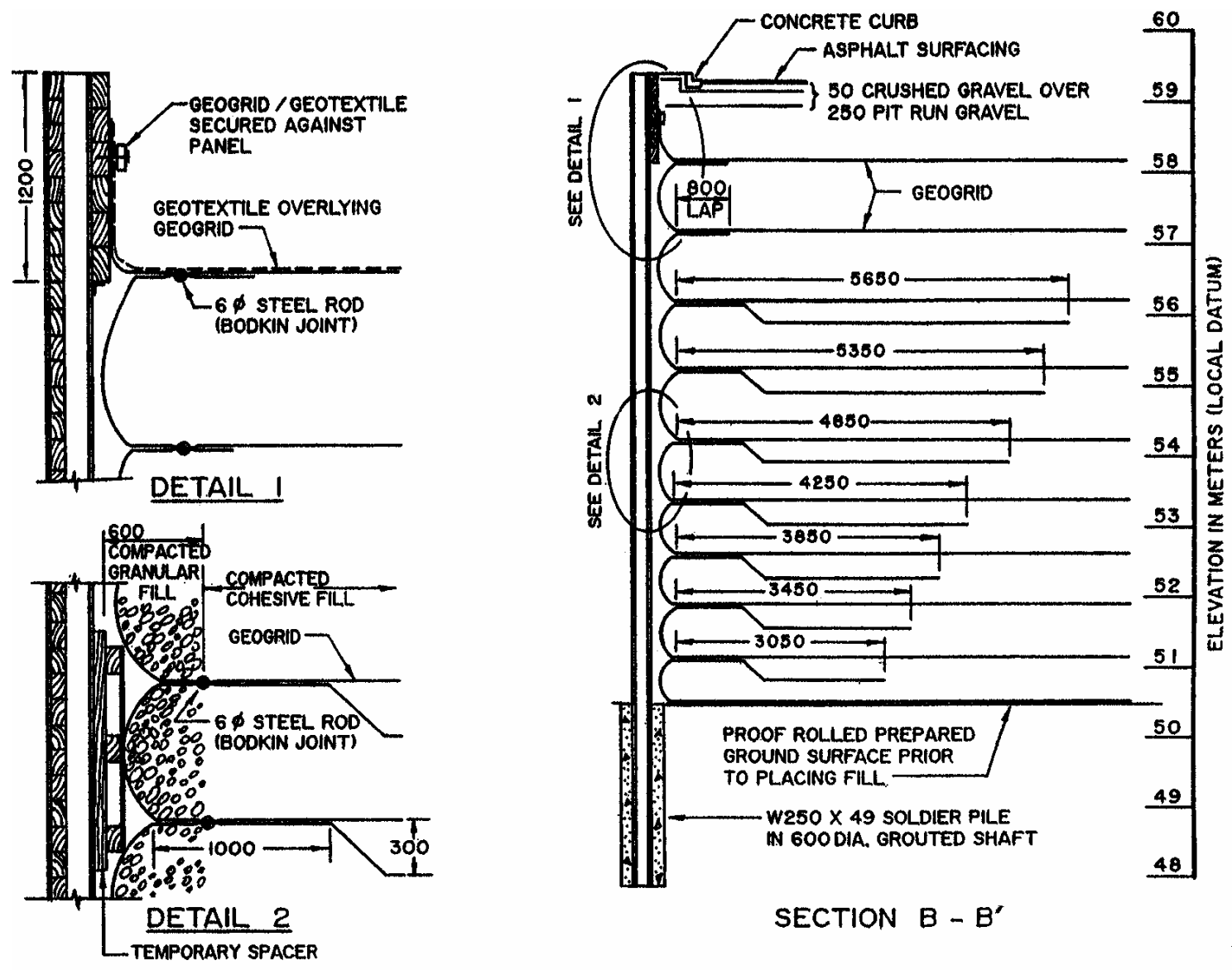

Figure 2-27 Typical Vertical Section and Design Details, Geogrid Reinforcement (After Burwash and Frost, 1991) 


\section{CHAPTER 3. TEST EQUIPMENT}

\subsection{Introduction}

Pullout tests are performed to determine the pullout capacity of a steel inclusion in a granular soil, and the associated pullout displacement under various conditions, which include different overburden pressures, different materials, and different drainage conditions. The pullout tests are performed with combinations of these conditions. A pullout test machine is designed for this purpose, and measuring devices such as load cell, LVDT and pressure transducers are employed to complete the pullout test setup. A data acquisition system is also used to record the test results.

This chapter presents the pullout test machine and the measuring devices. It covers the design of the pullout test machine and the function of the measuring devices. The setup of the pullout tests is also introduced in this chapter. Lastly, the data acquisition system is discussed. 


\subsection{Pullout Test Machine}

The pullout test system consists of four parts: (1) pullout test machine, (2) measuring devices, (3) two external water chambers and a pressure regulator system, and (4) data acquisition system.

The laboratory pullout test machine consists of two parts: (1) pullout box, and (2) pullout system. The pullout box is made of steel plates and consists of two parts, as shown in Figures 3-1 (a) and (b): (1) the soil chamber; (2) the water chamber. The soil chamber is where the soil is placed; the water chamber is filled with water. The pullout tests are either drained or undrained tests. Drained tests are performed without water (i.e. the soil is dry) while undrained tests are performed with the pullout box completely filled with water. Figures 3-1(a) and (b) show the longitudinal section and an overall view of the pullout box. The dimensions of the soil chamber are $1.0 \mathrm{~m}$ long, $0.4 \mathrm{~m}$ wide and $0.5 \mathrm{~m}$ high, and the dimensions of the water chamber are $0.5 \mathrm{~m}$ long, $0.4 \mathrm{~m}$ wide and $0.5 \mathrm{~m}$ high. Therefore, the total dimensions of the pullout box are $1.5 \mathrm{~m}$ long, $0.4 \mathrm{~m}$ wide and $0.5 \mathrm{~m}$ high.

The soil is compacted in the soil chamber and a steel reinforcement is inserted in the middle of the soil. A grip system holds the steel reinforcement, and it is connected to a load cell located in the water chamber. The load cell is attached to a steel bar connected inside the pullout box to the pullout system, which is part of the large direct shear machine built by P. J. Fox (1997), who used the pullout machine for strength testing of 
geosynthetic clay liners (GCLs). The pullout system is powered by two stepper motors, which provide a large range of pullout displacement rates from virtually zero to 10 $\mathrm{mm} / \mathrm{min}$. Each motor is connected to a double reduction gear box that drives a lead screw that has a diameter of $57.1 \mathrm{~mm}$ and a pitch of $12.7 \mathrm{~mm}$. Since the gear boxes have a very high displacement ratio (i.e. 900:1) to increase the available torque to the screws, the test can be performed at very small displacements rates. Each lead screw is capable of applying a pullout force of up to $93 \mathrm{kN}$; the total capacity of the machine is then $186 \mathrm{kN}$. The pullout rate and the pullout displacement are controlled by a computerized system.

The pullout system developed by Fox has been modified for this research. In Fox's tests, a movable pullout plate located between GCLs was sheared. Since steel reinforcement is employed for this research instead of the pullout plate, a new grip system and connection to the cross beam of the pullout system has been added. The overall frame and pullout mechanism were not changed. The grip system, located in the water chamber, is composed of two grips bolted together with the steel strip placed between the grips. A submersible load cell is attached to the grips. The cylinder connected to the motor and gear is made of stainless steel to prevent corrosion, and passes the wall of the pullout box through a circular orifice, which is sealed with an O-ring to prevent water leakage. Because the O-ring introduces friction between the cylinder and the wall, the load cell is placed inside the water chamber to obtain accurate measurements.

The water chamber is necessary to ensure that the soil behind the front wall will be saturated and that no water flow (and thus no change in volume during undrained tests) 
occurs. Because during pullout the stainless steel shaft is pulled out of the box, there is a decrease in volume inside the water chamber (i.e. a volume equal to the cross section of the shaft times the pullout capacity). This decrease in volume, if not replaced by an equal volume of water, would decrease the pore pressure in the water chamber and thus cause flow of water from the soil chamber to the water chamber. The volume is replaced in the box by a supply of water at the desired pressure from two small external water chambers, as shown in Figure 3-2. Thus as the shaft is pullout, the volume is replaced by water and the level in the water chambers decreases. Care has been taken to ensure that at the beginning of the test there is enough volume in the external water chambers to replace the volume lost.

There are three openings on the lid of the pullout box as shown in Figure 3-1 (a) and (b). These are openings for air pressure, water pressure and drainage. As mentioned before, the air pressure is used to apply overburden pressure to the soil, and the water pressure is applied to saturate the specimen. Two pressure regulators control the magnitude of these pressures. The drainage opening is necessary to check that saturation is complete. Once the water reaches the top of the box, it flows out through the drainage opening, which ensures that the soil is fully saturated. To ensure that the soil will remain saturated during testing, a backup pressure is applied to the water (Figure 3-2).

The steel strip used has dimensions identical to commercial galvanized ribbed strips that are $5 \mathrm{~cm}$ wide and $3 \mathrm{~mm}$ thick. The total length of the reinforcement is $1.0 \mathrm{~m}$, of which 
$0.75 \mathrm{~m}$ are embedded into the soil. Epoxy is placed at three places on the surface of the reinforcement to increase interface friction.

A perforated steel plate and a filter are placed on the bottom of the soil chamber to allow water to flow free from the water chamber into the soil. By placing the perforated steel plate and the filter, the water flows to the end of the soil chamber easily facilitating a uniform upward movement of the water through the soil. Figure 3-3 shows a schematic diagram of the porous steel plate and the filter in the soil chamber.

\subsection{Measuring Devices}

Measurements of pullout load and pullout displacement are taken in each test by a load cell and a Linear Variable Differential Transducer (LVDT), respectively. The load cell is located inside the water chamber, and the LVDT is placed on top of the cross beam of the pullout system. In addition, the overburden pressure applied is monitored by a pressure transducer attached to the pressure. A backup water pressure is required to saturate the specimen for undrained tests. The pressure is applied from the central laboratory air pressure system through the pressure regulator and external water chambers. A pressure transducer is attached to the pressure regulator to measure the backup water pressure. The pore water pressure inside the soil is measured by a pressure transducer installed on one of the sidewalls of the pullout box; this measurement is needed to check if the internal 
pore pressure is equal to the backup water pressure applied to ensure that full saturation is accomplished and thus the test can start.

All measuring devices are properly calibrated except the load cell, since a calibration chart is provided by the manufacturer.

\subsubsection{Load cell}

The pullout load is measured by a submersible Load Cell located inside the water chamber, as shown in Fig. 3-1(a). The load cell is a Load Cell Model 3100 UniversalTension \& Compression made by HSI - Houston Scientific International Inc. Its capacity is $133 \mathrm{kN}(30,000 \mathrm{lb})$ that covers all expected pullout loads. The load cell is submersible to prevent water from infiltrating inside the cell during undrained tests, once the pullout chamber is filled with water.

\subsubsection{LVDT}

The pullout displacement is monitored by a Linear Variable Differential Transducer (LVDT), Model LD600-100 made by Omega. The maximum stroke is $\pm 125 \mathrm{~mm}$, which is enough to monitor the pullout displacements until residual friction is obtained. The LVDT is firmly mounted to the cross beam of the pullout box. The tip of the rod of the 
LVDT always touches the front wall of the pullout box during the pullout tests. The pullout displacement is measured as the cross beam moves backward (as the reinforcement is pulled out).

\subsubsection{Pressure transducer}

Three pressure transducers are used to measure: (1) the air pressure applied to the air bag, (2) the outside backup water pressure, and (3) the inside pore water pressure. A pressure transducers model AB with capacity $1379 \mathrm{kPa}$ (200 psi), made by Data Instruments Inc. is used for the air bag pressure; a model PX102 pressure transducer with capacity 138 $\mathrm{kPa}$ (20 psi), made by Omega, for the outside water pressure, and a model AB pressure transducer with capacity $3447 \mathrm{kPa}$ (500 psi), made by Omega, for the inside pore water pressure. The air pressure and the outside water pressure transducers are attached to the pressure regulator while the inside pore water pressure transducer is installed on the sidewall of the pullout box. A hollow pipe with the pressure transducer attached to one end is inserted to measure the water pressure inside the soil. The tip of the pipe is covered with a filter to prevent soil from entering into the pipe. Since the water enters the box from the water chamber, the water pressure should be checked at a point far from the water chamber. The pressure transducer is, therefore, located close to the other end of the soil. The pressure transducer for the inside pore water pressure is required for undrained tests to compare the inside pore water pressure with the outside water pressure, as previously explained. 


\subsection{Test Procedure}

The test procedure for drained and undrained tests is the same except that the soil is saturated and water pressure is applied in the undrained tests. Palmeira and Milligan (1989) have pointed out that the apparent bond resistance between the soil and the pullout box could be increased up to $100 \%$ by the wall roughness for pullout tests with steel grid reinforcements in dense sand. All contact surfaces (i.e. front wall, sidewalls and end wall) are lubricated with silicon grease before the soil is placed in the chamber to minimize boundary shear tractions (Abramento et. al., 1995).

The drained tests are performed as follows: (1) the soil is placed in the soil chamber in four layers approximately $10 \mathrm{~cm}$ thick and each layer is suitably compacted; (2) the steel reinforcement is installed between layer two and layer three; (3) the air bag is placed on top of the soil after the compaction is complete; (4) the lid is then closed and bolted to the frame; (5) air pressure is applied to the air bag; the pressure transducer attached to the pressure regulator measures the applied air pressure; (6) the test starts: the steel reinforcement is pulled out after the air pressure reaches the target value. The load cell in the water chamber measures the pullout load and a LVDT on the reaction beam measures the pullout displacement. A data acquisition system records all signals from the measuring devices.

For undrained tests, the test procedure is basically the same as for drained tests. The soil is saturated with water after step (2), which is supplied to the water chamber. The upward 
movement of the water inside the soil prevents air bubbles from being trapped inside the soil. Steps (3), (4) and (5) follow after the entire soil is saturated. In step 6, backup water pressure is applied to the box. At the same time, the water pressure inside the soil is measured by the pressure transducer installed on the sidewall of the chamber; (7) the test starts when the inside water pressure is equal to the outside water pressure; and (8) measurements of pullout load, pullout displacement, air pressure to the air bag, outside water pressure, and inside water pressure are taken during the test.

For undrained tests, the saturation process is as follows: water flows into the soil chamber through four channels carved on the bottom of the pullout box. Water also flows into the soil chamber through the reinforcement opening when the water level reaches the opening. The water continues to move upwards to saturate the soil and fills the water chamber. When the water is observed at the top of the soil, an air bag is placed on top of the soil and the lid of the pullout box is placed and bolted to the frame. However, the pullout box is not fully saturated yet because there is still an empty space between the air bag and the lid. Additional water from the external water chambers is supplied to the pullout box to fill the empty space.

For both drained and undrained tests, additional reaction beams are placed on the lid and bolted to the frame to provide reaction and limit the deformation of the air bag as the air pressure is increased. An O-ring between the lid and the frame prevents water leaks. Various overburden pressures are achieved by applying different air pressures to the air 
bag, which are applied from the central laboratory air pressure system, and are controlled by a pressure regulator.

The pullout rates are $1 \mathrm{~mm} / \mathrm{min}$ and $10 \mathrm{~mm} / \mathrm{min}$ for drained tests and undrained tests, respectively. The pullout rate is important especially for undrained tests because of dissipation of excess pore water pressures. The pullout rate is not critical for drained tests because drained tests are performed without water (i.e. dry condition). The faster pullout rate is employed for undrained tests in order to prevent dissipation of excess pore water pressures during the tests.

\subsection{Data Acquisition System}

A PC-based data acquisition system and plug-in data acquisition board (DAQ board) are used to read and store the following data: (1) pullout load of the reinforcement; (2) pullout displacement; (3) outside water pressure; (4) inside pore water pressure; and (5) overburden pressure.

Fig. 3-4 shows the layout of the data acquisition system. Signals from measuring devices are transferred to SCXI terminal blocks. The terminal blocks are connected to SCXI modules, which are located inside a SCXI chassis. The electric signals are conditioned in the SCXI modules and then transferred to the DAQ board, installed in the computer. 
Four SCXI terminal blocks, model SCXI 1321, with four channels per block (i.e. total 16 channels), provide connections between the signals and the data acquisition system. Each channel consists of four connectors for positive and negative excitations, and positive and negative signals. Strain-relief clamps inside the terminal blocks firmly and safely hold lead wires from the measuring devices. Four SCXI modules, model SCXI 1000, are used to condition the electric signals. The SCXI chassis, model SCXI 1000, is used to house, power and control the SCXI modules and the conditioned signals. The chassis is capable of housing four SCXI modules. A PCI-MIO-16XE-50 is the data acquisition board and is installed in a computer. It can receive up to 16 analog inputs.

Signals generated by sensors and transducers are conditioned before the data acquisition system acquires the signal. This includes signal amplification, filtering, electrical isolation and multiplexing. Signals (i.e. output voltages) from sensors are too small to read, compared to input voltages. They are amplified for reading. This is called signal amplification, and is controlled by adjusting the gain. Setting of the gain is done in SCXI modules, by plugging small chips, called jumpers, into different positions. Different gains are used for each device to display the electric signals efficiently. Unwanted signals come with wanted signals due to noise, which originates from external sources (i.e. AC power line, motors, transformers, computers and electrical storms) and internal sources (i.e. digital clocks and microprocessors). The filtering is a digital algorithm that selectively removes noise from a signal, or emphasizes certain frequency ranges and de-emphasizes others. Proper filtering for the devices is also accomplished by controlling jumpers in SCXI modules. The electrical isolation is a technique that transfers data without electrical 
continuity, accomplished in SCXI modules automatically. The multiplexing is a process that permits the selection of one of many channels at a time, and is performed in the DAQ board. Signal conditioning is suitably done for each measuring device manually or automatically.

A commercial software, LabView 5.1 by National Instruments, periodically reads electric signals from the measuring devices and stores them in the hard drive. Twelve channels can be simultaneously read with the available data acquisition system. Three channels are used for the load cell, the LVDT, and the air bag pressure; two additional channels are needed in undrained tests for the outside water pressure and the inside pore water pressure. A code has been written to perform the actual data acquisition and includes creation of channels, selection of data reading frequency, and pattern of output display. The code also has been written to plot data on the computer screen as the test is performed and the results can be checked as the test is conducted. The actual code for LabView has been written with help from Jorge Casana, a former Purdue University graduate student in civil engineering and Donald Peacock, a technician from National Instruments.

The data reading rate can be controlled by the program. The rate is 1 reading per second per channel for drained tests and 4 readings per second per channel for undrained tests. More frequent readings are taken for undrained tests because the testing time is shorter than for drained tests. 


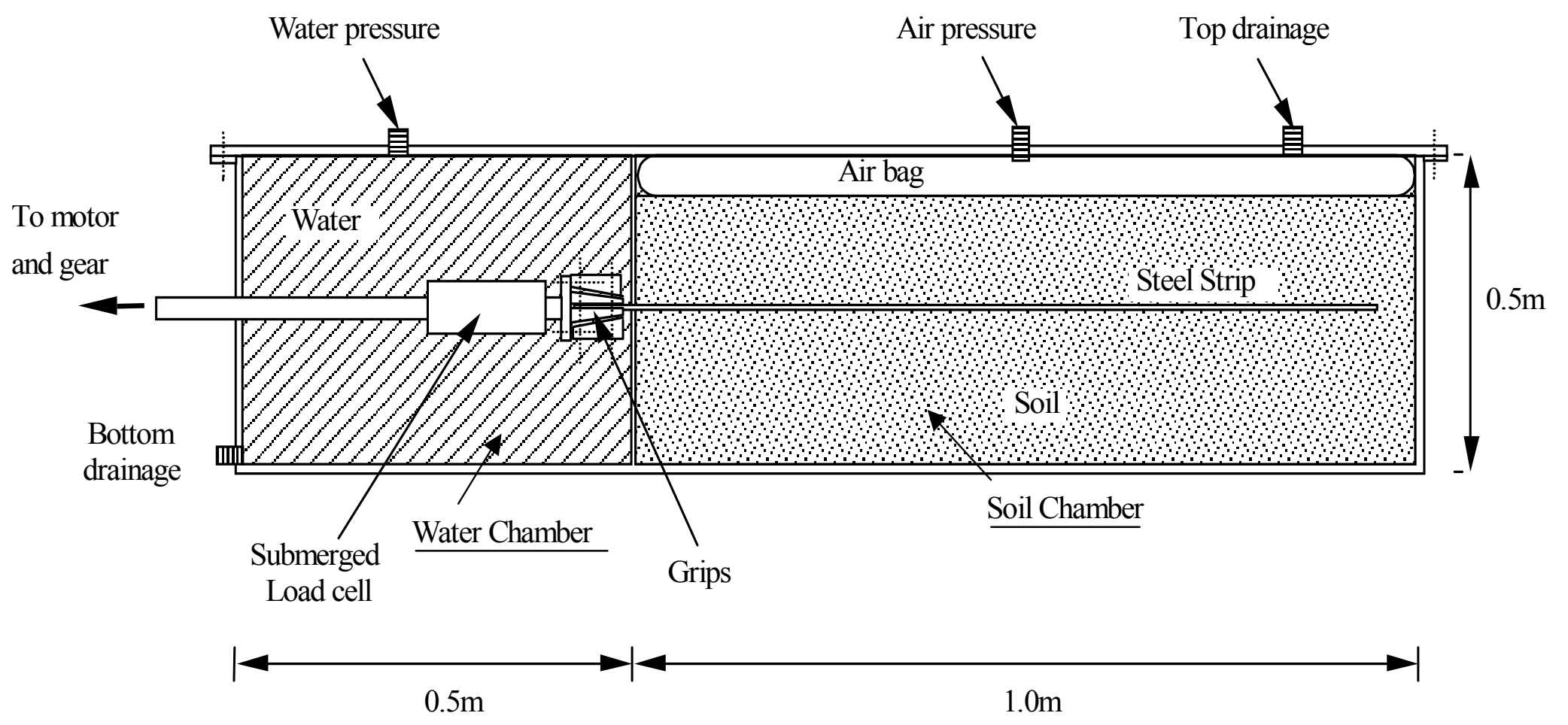

Figure 3-1(a) A Schematic Diagram of the Longitudinal Section of the Pullout Box 


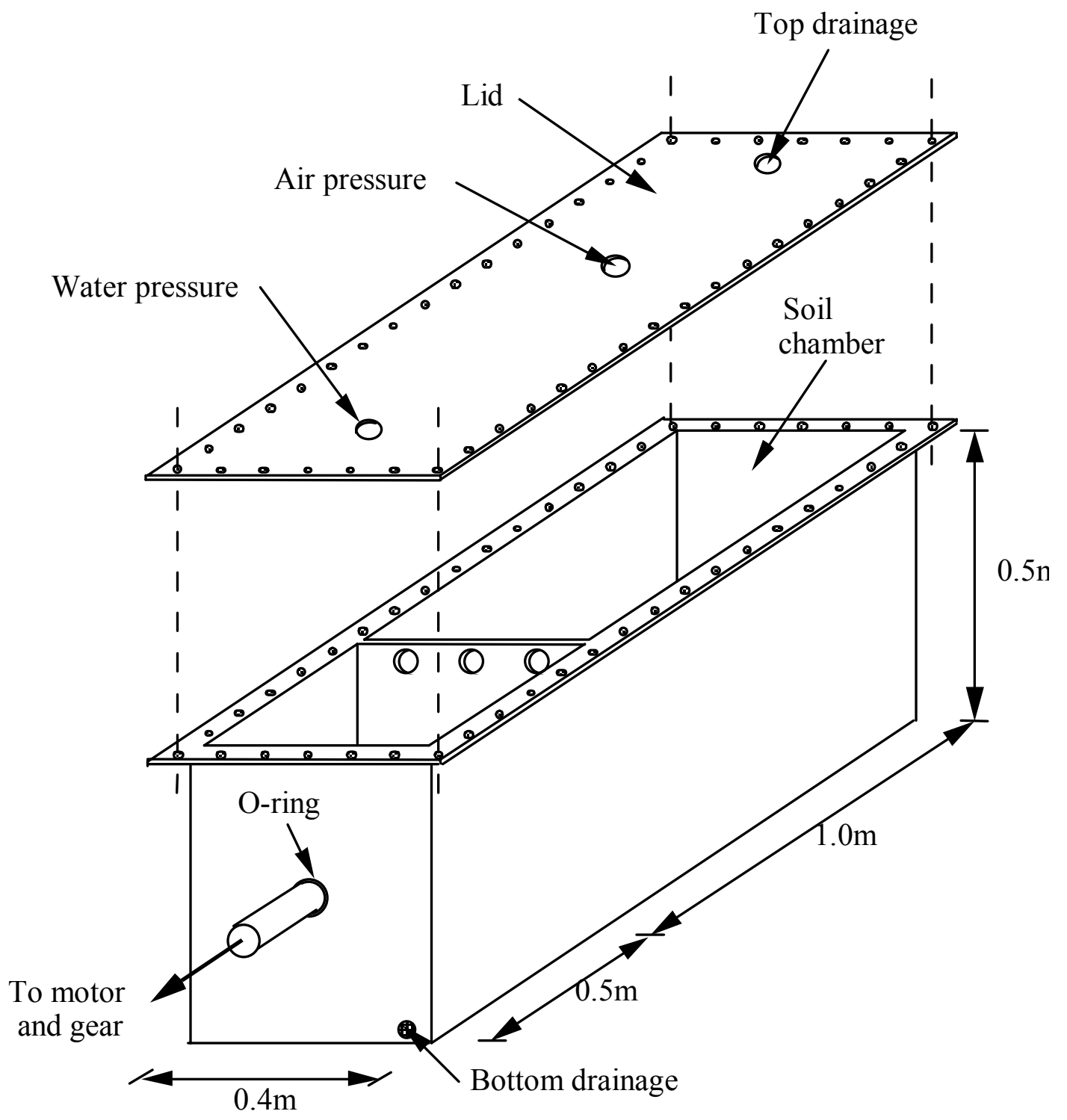

Figure 3-1(b) A Schematic Diagram of the Pullout Box 


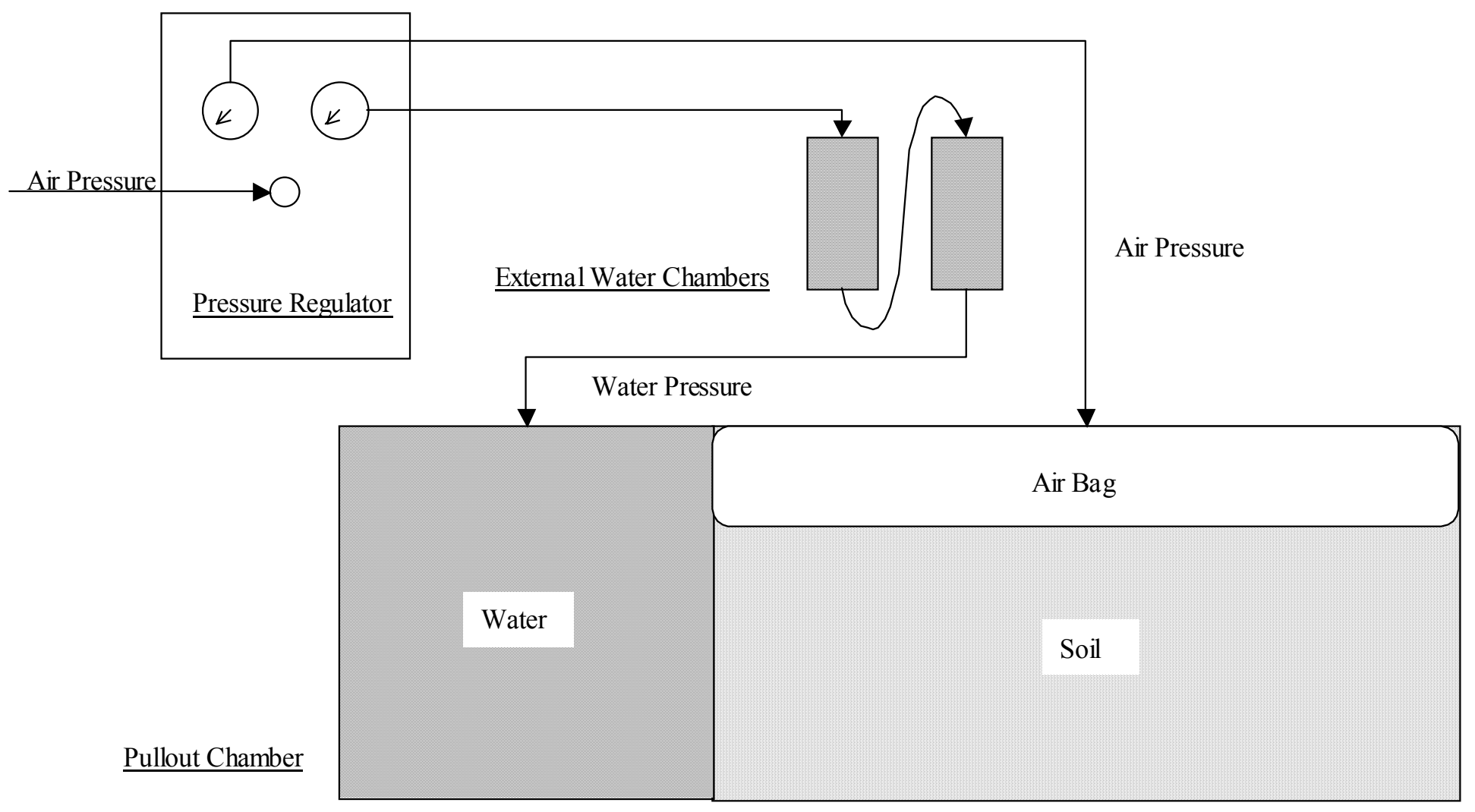

Figure 3-2 A Schematic Diagram of Pullout Test Setup 


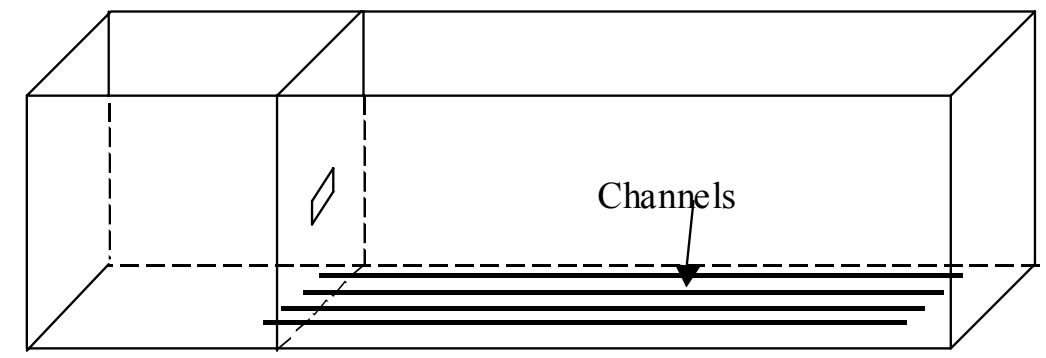

(a)

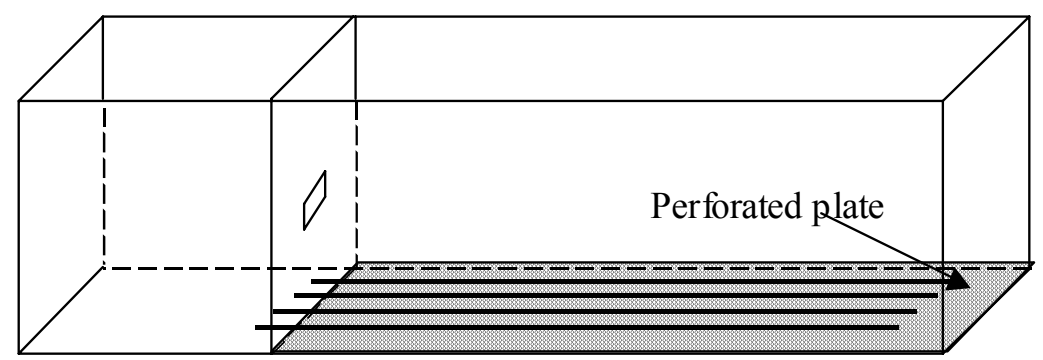

(b)

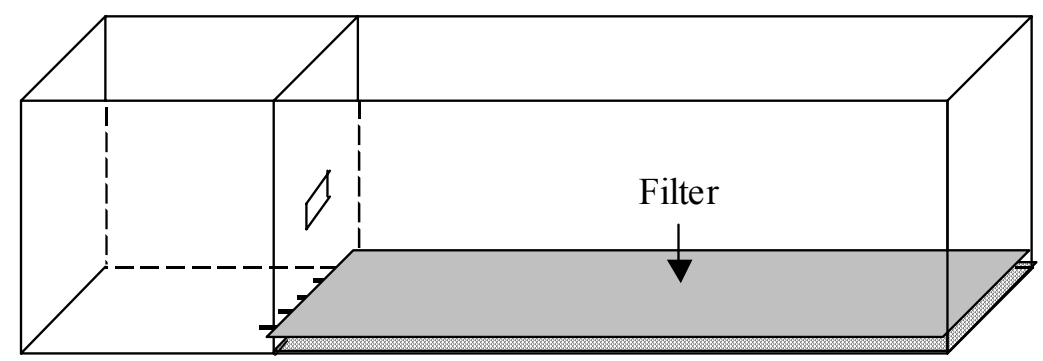

(c)

Figure 3-3 A Schematic Diagram of the Water Flow System at the Bottom of the Soil Chamber 


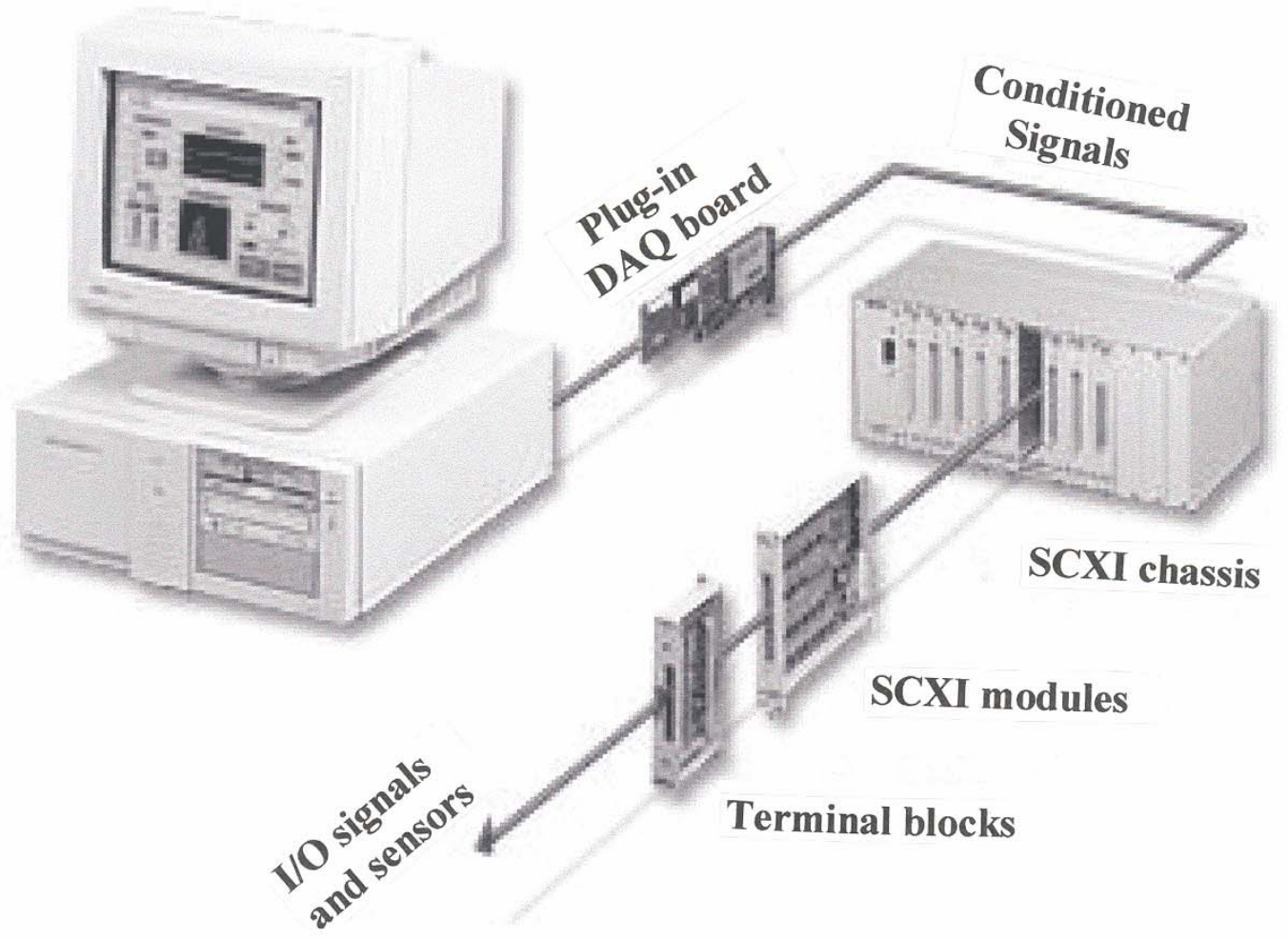

Figure 3-4 Layout of Data Acquisition System (from National Instruments Web Page) 


\section{CHAPTER 4. LABORATORY TESTS AND RESULTS}

\subsection{Introduction}

A series of laboratory tests are conducted prior to the pullout test, and include soil property tests, proctor tests, compaction tests and permeability tests. These tests are necessary to determine material properties, to decide compaction degree and compaction method, and to support pullout test results. Sections 4.2 and 4.3 present the need, the procedure and the results for these tests. Section 4.4 covers the pullout tests with the procedure and the results. Finally, conclusions obtained from all tests are introduced in Section 4.5 .

Pullout tests are performed varying the following conditions: (1) different soils; (2) different overburden pressures; and (3) different drainage conditions. The analysis and comparison of the pullout test results are discussed based on these three different conditions. 


\subsection{Material}

The soils used are clean sand and silty sands. Silty sands are prepared by mixing clean sand with silt. The following percentages of silt, measured by weight of clean sand, are used: 5,10,15 and 35\%. The sand and silt used are Ottawa sand and \#106 Sil-Co-Sil ground silica from U.S. Silica Company, respectively.

According to Salgado et al. (2000), Ottawa sand can be classified, after the Unified Soil Classification, as a SP soil. The diameter of the sand particles ranges from $0.1 \mathrm{~mm}$ to $0.6 \mathrm{~mm}$, with the grain size distribution shown in Figure 4-1. The maximum and minimum void ratios $\left(\mathrm{e}_{\max }\right.$ and $\left.\mathrm{e}_{\min }\right)$ of Ottawa sand are 0.78 and 0.48 , respectively. The grain size distribution of the silt is also shown in Figure 4-1. The maximum and minimum void ratios for the clean sand and silty sands used in the experiments are shown in Table 4-1.

Table 4-1 The Minimum and Maximum Void Ratios for Clean and Silty Sand (Salgado et al., 2000)

\begin{tabular}{|c|c|c|}
\hline Silt Percentage (\%) & $\mathrm{e}_{\min }$ & $\mathrm{e}_{\max }$ \\
\hline 0 & 0.48 & 0.78 \\
\hline 5 & 0.42 & 0.70 \\
\hline 10 & 0.36 & 0.65 \\
\hline 15 & 0.32 & 0.63 \\
\hline
\end{tabular}




\subsection{Preliminary Tests}

Some preliminary tests are conducted to determine the characteristics of the soil before the pullout tests are performed. They include proctor tests, compaction tests, and permeability tests. Proctor tests are performed to find out the relationship between the dry unit weight of the soil and the water content. Compaction tests are performed to determine how much energy is required to obtain the desired density of the material. The coefficients of permeability for each material are obtained from permeability tests.

\subsubsection{Proctor test}

The proctor tests performed follow the standard ASTM D-698. The soil in the mold is compacted in three equal layers by dropping a hammer of certain weight from a defined height. The hammer weighs $2.5 \mathrm{~kg}$ and it drops 25 times on each layer from a height of $30.5 \mathrm{~cm}$. The applied compaction energy is about $600 \mathrm{kN}-\mathrm{m} / \mathrm{m}^{3}$. The test is repeated several times for different water contents until sufficient data are obtained. Afterwards, the dry unit weight and water content are plotted and the maximum dry unit weight of the soil is obtained. In the pullout tests, the silty sands are compacted at $95 \%$ of the maximum dry unit weight obtained from the proctor tests except clean sand which is compacted at $100 \%$ of the maximum dry unit weight. The choice of compaction degree is supported by the fact that the backfill material for MSE walls is usually compacted at a certain degree of compaction that is usually higher than $90 \%$ of Proctor. 
The proctor test results for clean sand are shown in Figure 4-2. The figure shows that the maximum dry density is obtained for complete dry conditions (i.e. water content, $\omega=$ $0 \%$ and slightly lower densities are obtained as water is added. It is also noted in the figure that there is an abrupt decrease of dry unit weight for a small increase in water content from the dry state. The lower density that is obtained at low water contents is due to capillary forces resisting rearrangement of the sand grains. This phenomenon is known as bulking (Lambe, 1969). For larger water contents, the dry density is almost constant which denotes that the compaction of clean sand is not influenced by the water content. However, Foster(1962) has observed that the dry density of a cohesionless soil increases again as the water content further increases so that the dry density at complete saturation is the same or slightly larger than the dry density obtained at zero water content. The maximum dry unit weight for clean sand is $17.1 \mathrm{kN} / \mathrm{m}^{3}$ and the desired value for pullout test is $100 \%$ of the maximum dry unit weight; that is $17.1 \mathrm{kN} / \mathrm{m}^{3}$.

Figure $4-2$ also shows proctor test results for $2 \%$ silty sand. Although the $2 \%$ silty sand is not used in pullout tests, the proctor and permeability tests are also performed. The proctor test shows that the results for clean sand and $2 \%$ silty sand are the same.

Figures 4-3 to $4-6$ show proctor test results for $5 \%, 10 \%, 15 \%$ and $35 \%$ silty sands, respectively. Unlike clean sand, the dry unit weight of silty sands increases as the water content increases up to the so-called optimum water content where the maximum dry unit weight is obtained. The dry unit weight decreases as the water content increases beyond the optimum water content. The optimum water contents for the silty sands tested in this 
research lye between 9 and 12\%. The maximum dry unit weights obtained from each test are; 16.7, 17.1, 17.9 and $19.3 \mathrm{kN} / \mathrm{m}^{3}$ for $5 \%, 10 \%, 15 \%$ and $35 \%$ silt content, respectively, as shown Figures 4-3 to 4-6. The maximum dry unit weight increases as the silt percentage increases because the silt particles fill the sand voids. The $95 \%$ values of the maximum dry unit weights are $15.9,16.2,17.0$ and $18.3 \mathrm{kN} / \mathrm{m}^{3}$ for $5,10,15$ and $35 \%$ silty sand, respectively. Table 4-2 summarizes the proctor test results.

Table 4-2 Proctor Test Results

\begin{tabular}{|c|c|c|l|}
\hline Material & $\begin{array}{c}\text { Maximum } \\
\text { Dry Unit Weight } \\
\left(\mathrm{kN} / \mathrm{m}^{3}\right)\end{array}$ & $\begin{array}{c}\text { 95\% of Maximum } \\
\text { Dry Unit Weight } \\
\left(\mathrm{kN} / \mathrm{m}^{3}\right)\end{array}$ & Remarks \\
\hline $\begin{array}{c}\text { Clean sand } \\
2 \% \text { Silty Sand }\end{array}$ & 17.1 & $17.1(100 \%)$ & $\begin{array}{l}\text { The max. dry unit } \\
\text { weight is used for } \\
\text { pullout test }\end{array}$ \\
\hline $5 \%$ Silty sand & 16.7 & 15.9 & \\
\hline $10 \%$ Silty sand & 17.1 & 16.2 & \\
\hline $15 \%$ Silty sand & 17.9 & 17.0 & \\
\hline $35 \%$ Silty sand & 19.3 & 18.3 & \\
\hline
\end{tabular}




\subsubsection{Compaction tests}

As stated earlier, compaction tests are performed to determine how much compaction energy is required to obtain $95 \%$ of the proctor test for the soil placed in the soil chamber of the pullout box.

Sand mixed with water is placed in four layers in the soil chamber of the pullout box. Three small containers in each of the four layers (i.e. 12 containers total) are placed inside each layer before compaction, as shown in Figure 4-7. The compaction energy is delivered by dropping a hammer that weighs $4 \mathrm{~kg}$, from a given height from the top of the soil layer and for a number of times. The containers are taken out after the compaction is complete to measure the dry unit weight. The measured dry unit weights are used to find out if the delivered energy is sufficient to obtain the desired unit weight and to ensure that a uniform density is obtained in each layer and from layer to layer. The compaction energy is a function of the weight of the hammer, the drop height, the number of drops, the number of layers, and the volume of compacted material. The following equation gives the energy delivered per unit volume. 


$$
E=\frac{W \cdot h \cdot n \cdot N}{V}
$$

$$
\begin{aligned}
& \text { where }=\text { hammer weight } \\
& \qquad \begin{array}{l}
\mathrm{h}=\text { drop height } \\
\mathrm{n}=\text { number of blows per layer } \\
\mathrm{N}=\text { number of layers } \\
\mathrm{V}=\text { volume of material }
\end{array}
\end{aligned}
$$

Using a rule of thumb, the first compaction is performed with a given height, a selected number of drops and with a selected water content. The 12 containers are taken out after the compaction is complete and put in an oven at $110^{\circ} \mathrm{C}$, and kept there overnight, following ASTM D2216. The dry unit weight of the compacted material is obtained from each container by dividing the dry weight of the soil by the volume of the container, which is measured prior to the test. Based on this result, a new attempt is made by varying the water content, the drop height, or the number of drops per layer until the desired dry unit weight is obtained. This compaction test is performed for clean sand and for each silty sand.

The compaction test results are plotted with dry unit weight vs. compaction energy. The results show that different dry unit weights are obtained with different water content as well as with different compaction energy. Figure 4-8 shows the results of the compaction test for $5 \%$ silty sand. The target dry unit weight for the $5 \%$ silty sand is $15.9 \mathrm{kN} / \mathrm{m}^{3}$ (i.e. $95 \%$ of the proctor). The first trial is done with $5 \%$ water content and relatively low value of the compaction energy; the obtained dry unit weight is much lower than required. Two 
more attempts still with $5 \%$ water content are then made by increasing the compaction energy but the results are still too low. The water content is then increased from $5 \%$ to $10 \%$. The results show that the obtained dry unit weights bracket the target value.

Figure 4-9 shows the compaction test results for $10 \%$ silty sand. The target dry unit weight, $15.9 \mathrm{kN} / \mathrm{m}^{3}$, falls within the range of the compaction test results, and the compaction energy required can be obtained by interpolation. Figure 4-10 shows the results of the compaction tests for $15 \%$ silty sand. The obtained dry unit weight is about $17.5 \mathrm{kN} / \mathrm{m}^{3}$, which is similar to the target dry unit weight, $17.0 \mathrm{kN} / \mathrm{m}^{3}$. The compaction tests for $35 \%$ silty sand are shown in Figure $4-11$. With a $10 \%$ water content, the target dry unit weight, $18.3 \mathrm{kN} / \mathrm{m}^{3}$, is obtained at relatively low compaction energy.

To check if the target dry unit weight is achieved during actual pullout tests, some soil containers are placed within the soil and retrieved after completion of each test. The results show that the dry unit weight is indeed the target unit weight within a $2 \%$ error.

\subsubsection{Permeability tests}

Permeability tests are performed following ASTM D 2434. The constant head test is used for $0,2,5,10$ and $15 \%$ silty sand while the falling head test is used for $35 \%$ silty sand due to its relatively low permeability. As mentioned before, additional permeability tests 
for $2 \%$ silty sand have been performed to evaluate the change of permeability between $0 \%$ and $5 \%$ silty sand.

The soil specimen is prepared at the same density used for the pullout tests. The permeability tests are performed after the specimen becomes saturated. The constant head tests are performed at three different heads and the amount of flow of water through the specimen for a given period of time is measured three times per each head. The coefficient of permeability is taken as the average of the results. An additional test is performed for each material to ensure repeatability. The falling head tests are also performed at three different head differences. The elapsed time for a certain drop of height is measured and the average permeability is obtained. A repeatability test is also performed.

The permeability decreases as the silt content increases as shown in Table 4-3 and Figure 4-12. The coefficient of permeability decreases from clean sand to $35 \%$ silt with increasing silt content. Figure 4-12 shows that there is a dramatic reduction of permeability from clean sand to $10 \%$ silty sand. 
Table 4-3 Coefficient of Permeability

\begin{tabular}{|c|c|}
\hline Material & Coefficient of Permeability, $k$ \\
\hline Clean Sand & $2.27 \times 10^{-2} \mathrm{~cm} / \mathrm{sec}$ \\
\hline $2 \%$ Silty Sand & $1.74 \times 10^{-2} \mathrm{~cm} / \mathrm{sec}$ \\
\hline $5 \%$ Silty Sand & $1.12 \times 10^{-2} \mathrm{~cm} / \mathrm{sec}$ \\
\hline $10 \%$ Silty Sand & $3.89 \times 10^{-3} \mathrm{~cm} / \mathrm{sec}$ \\
\hline $15 \%$ Silty Sand & $2.28 \times 10^{-3} \mathrm{~cm} / \mathrm{sec}$ \\
\hline $35 \%$ Silty Sand & $1.75 \times 10^{-4} \mathrm{~cm} / \mathrm{sec}$ \\
\hline
\end{tabular}

\subsection{Pullout Test}

Clean granular soils are expected to be the most appropriate backfill materials for MSE walls. Since the permeability of clean granular soils is high enough so that no excess pore pressures remain during loading, the pullout capacity for both drained and undrained conditions is expected to be similar. Unfortunately, such good backfill materials are not always available in practice, and a percentage of fines is usually present. As a result, the permeability of the material decreases as the percentage of fines increases. In low permeability soils, excess pore pressures may not dissipate quickly enough and, as a consequence, the effective stress may decrease and the pullout capacity may be reduced. 
Drained pullout tests are performed to compare the pullout capacities for different percentage of fines and overburden pressures. Undrained pullout tests are performed to investigate the effect of excess pore pressures, and to compare the results with drained pullout test results. Clean sand and silty sand soils are used for the experiments. Silty sands are obtained by mixing Ottawa Sand with silt with the following fines content: 0,5 , 10, 15 and $35 \%$. The $35 \%$ of fines content is not practical as a backfill material. However, it is used as an extreme case to evaluate the decrease of pullout capacity with fines. Effective overburden pressures of 30,100 and $200 \mathrm{kPa}$ are applied, which correspond to soil overburdens of $1.5,5.0$ and $10.0 \mathrm{~m}$, respectively, which are representative of the typical range of wall heights.

The pullout tests are performed varying the following conditions: (1) material: clean sand, $5 \%, 10 \%, 15 \%$ and $35 \%$ silty sand, (2) effective overburden pressure: 30,100 and $200 \mathrm{kPa}$, and (3) drainage condition: drained and undrained. The total number of tests is 30 but some additional tests are performed for repeatability. Repeatability is checked by performing two identical tests and by comparing the results. One repeatability test is performed for each material, for each drainage condition, and for a selected overburden pressure. For clean sand, all tests for drained conditions are repeated. This is done because of the relevance of clean granular materials in MSE walls. For clean sand and undrained conditions, no repeatability tests are performed because the results, as expected, are equal to those for drained conditions. Consequently, a total of 11 repeatability tests are performed. Table 4-4 shows the different testing conditions. 
Table 4-4 Pullout Test Conditions

\begin{tabular}{|c|c|c|}
\hline $\begin{array}{c}\text { Material : } \\
\text { Ottawa sand } \\
(\% \text { of silt })\end{array}$ & $\begin{array}{c}\text { Effective Overburden } \\
\text { Pressure }(\mathrm{kPa})\end{array}$ & Drainage Condition \\
\hline 0 & 30 & Drained \\
5 & 100 & Undrained \\
10 & 200 & \\
15 & & \\
35 & & \\
\hline
\end{tabular}

Both drained and undrained pullout tests are performed following the procedure stated in section 3.4. The total pullout length is about $20 \mathrm{~mm}$, which is large enough to obtain post peak behavior of the reinforced soil.

In undrained tests, a backup water pressure of 40 to $70 \mathrm{kPa}$ is applied to the soil. The magnitude of the backup water pressure does not influence the pullout capacity, and it is applied to maintain saturated conditions during the test. Since the effective overburden pressure should be the same for drained and undrained tests, the air pressure to the air bag for undrained tests is 30,100 or $200 \mathrm{kPa}$ plus the backup water pressure.

The drained and undrained pullout test results are presented in section 4.4.1. The evaluation of the results, based on the effect of overburden pressure, material (i.e. different fines contents) and drainage conditions, is discussed in the following sections. 


\subsubsection{Pullout test results}

Figure 4-13 shows the drained pullout test results for clean sand. As previously mentioned, drained tests are performed twice for clean sand to ensure repeatability. The figure shows that the tests are repeatable. For clean sand, the pullout capacity increases as the overburden pressure increases. This is an expected result since the pullout capacity is governed by the effective normal stress, as mentioned in Chapter 2. The figure also shows that the pullout capacity rapidly increases with pullout displacement until a peak or a maximum value is obtained. However, the post peak behavior changes with overburden pressure. A peak is clearly observed for $200 \mathrm{kPa}$ overburden pressure; after the peak the pullout capacity decreases. In contrast, the pullout capacity for $30 \mathrm{kPa}$ becomes almost constant once it reaches the maximum pullout capacity. A somewhat less clear peak occurs for $100 \mathrm{kPa}$, with pullout capacity gradually decreasing afterwards. Figure 4-13 also shows that the initial stiffness of the material increases with overburden pressure. It is also observed that the peak occurs at a larger displacement as overburden pressure increases.

Figure 4-14 shows the undrained test results for clean sand for all effective overburden pressures. The figure shows a quite similar behavior to the drained test, as expected. In fact, the drained and undrained behavior of clean sand is identical. More detailed comparisons of the drained and undrained test results are presented in section 4.4.4. 
The drained pullout test results for 5\% silty sand are shown in Figure 4-15. All test results for $5 \%$ silty sand, regardless of overburden pressure, show that the pullout capacity quickly increases with displacement up to a certain value. Afterwards, large displacements are observed for a small increase of pullout capacity. As with clean sands, the higher the overburden pressure, the higher the pullout capacity. Higher stiffness occurs for higher overburden pressure similar to what occurs for clean sand. In contrast to clean sands, no peak load is observed in the tests; the pullout capacity continues to increase slowly with displacements. Two repeatability tests are performed for 30 and 200 $\mathrm{kPa}$, respectively, which show very good agreement; the test with $200 \mathrm{kPa}$ stops earlier because the air bag ruptured.

Undrained pullout test results for 5\% are shown in Figure 4-16. The higher pullout capacity occurs for higher overburden pressure. Similar to the drained pullout capacity, undrained pullout capacity quickly increases up to a certain value and shows little increase or becomes constant for large displacements. The point of the graph of maximum curvature (this is the point taken as the pullout capacity) occurs at larger displacements as overburden pressure increases; with increasing overburden pressure, the stiffness also increases. Repeatability tests are performed for 100 and $200 \mathrm{kPa}$ and they show good agreement.

Drained test results for $10 \%$ silty sand are shown in Figure $4-17$. The pullout capacity is larger than for $5 \%$ silty sand. It is observed again that higher pullout capacity and higher stiffness occur as the overburden pressure increases. A peak and post-peak softening 
behavior is observed, similar to clean sands but less pronounced. The peak for lower overburden pressures occurs at smaller displacements. A repeatability test is performed at $100 \mathrm{kPa}$ overburden pressure, which shows good agreement. Figure 4-18 shows the undrained pullout test results for $10 \%$ silty sand. For $200 \mathrm{kPa}$ overburden pressure, the undrained pullout capacity rapidly increases with displacement and it reaches a peak; afterwards it decreases quickly with increasing displacements. A similar trend is shown for $100 \mathrm{kPa}$ overburden pressure but the post-peak pullout capacity decreases relatively slowly compared to that for $200 \mathrm{kPa}$ overburden pressure. For $30 \mathrm{kPa}$ overburden pressure, the undrained pullout capacity becomes almost constant after it reaches a maximum. As with other tests an increase in overburden pressure increases the pullout capacity, the displacement at where peak occurs, and the stiffness of the system. There is a reduction in the undrained pullout capacity compared to the drained tests. Again, more detailed comparisons of the drained and undrained test results are presented in section 4.4.4.

The drained and undrained pullout test results for 15\% silty sand are shown in Figures 419 and 4-20. The drained pullout test results for $200 \mathrm{kPa}$ overburden pressure shows a clear peak while the other test results do not. As with previous test results, the following is observed; (1) the higher the overburden pressure, the higher the pullout capacity; (2) the higher the overburden pressure, the stiffer of the pullout response; and (3) the higher the overburden pressure, the larger the displacement at which the peak pullout load occurs. The repeatability tests performed at $100 \mathrm{kPa}$ overburden pressure with drained conditions and at $30 \mathrm{kPa}$ with undrained conditions show good agreement. The peak is 
clearly observed at 100 and $200 \mathrm{kPa}$ overburden pressure while it is not clear at $30 \mathrm{kPa}$ overburden pressure.

The drained pullout test results for 35\% silty sand are shown in Figure 4-21. The pullout test result for $200 \mathrm{kPa}$ overburden pressure shows the largest stiffness and the largest pullout capacity. As before, pullout capacity and stiffness increase with overburden pressure. The displacement at which peak loads are observed decrease as the overburden pressure decreases from $200 \mathrm{kPa}$ to $100 \mathrm{kPa}$; for $30 \mathrm{kPa}$ overburden pressure the displacement at peak load is similar to $100 \mathrm{kPa}$ overburden pressure. Figure 4-22 shows the undrained test results for 35\% silty sand. All the tests show peaks for all overburden pressures. The peaks occur at smaller displacements for smaller overburden pressures. As with other tests, the pullout capacity and initial stiffness increase with overburden pressure. What is most significant from a comparison of results between Figures 4-21 and 4-22, i.e. drained vs. undrained tests, is the dramatic reduction in pullout capacity of undrained tests compared to drained tests.

\subsubsection{Effect of overburden pressure}

Table 4-5 and Figure 4-23 summarize the drained pullout test results. The values shown are the maximum pullout capacities obtained from each test. When the pullout test shows a peak followed by a softening, the pullout capacity has been taken as the value of the 
peak. For cases that show no definite peak, the pullout capacity has been taken as the value of the load at the point of maximum curvature of the load-displacement curve.

As seen in Table 4-5 and Figure 4-23, the drained pullout capacity increases as the overburden pressure increases for all the soils tested. The pullout capacity for $100 \mathrm{kPa}$ overburden pressure is about twice the pullout capacity for $30 \mathrm{kPa}$ overburden pressure, and the pullout capacities for $200 \mathrm{kPa}$ overburden pressure are also about twice those for $100 \mathrm{kPa}$. The results indicate that the pullout capacity increases almost proportionally with overburden pressure from $100 \mathrm{kPa}$ to $200 \mathrm{kPa}$, but not from $30 \mathrm{kPa}$ to $100 \mathrm{kPa}$.

Table 4-5 Maximum Drained Pullout Capacity (in kN)

\begin{tabular}{|c|c|c|c|}
\hline \multirow{2}{*}{ Soil } & \multicolumn{3}{|c|}{ Overburden Pressure } \\
\cline { 2 - 4 } & $30 \mathrm{kPa}$ & $100 \mathrm{kPa}$ & $200 \mathrm{kPa}$ \\
\hline Clean Sand & 2.12 & 4.24 & 8.19 \\
\hline $5 \%$ Silty Sand & 1.92 & 4.09 & 7.6 \\
\hline $10 \%$ Silty Sand & 2.51 & 4.66 & 8.61 \\
\hline $15 \%$ Silty Sand & 1.92 & 3.48 & 6.79 \\
\hline $35 \%$ Silty Sand & 1.02 & 2.2 & 4.37 \\
\hline
\end{tabular}


The undrained pullout test results are summarized in Table 4-6 and Figure 4-24. Similar to drained tests, the undrained pullout capacity also increases with overburden pressure. The undrained pullout capacity for $200 \mathrm{kPa}$ effective overburden pressure is about twice that for $100 \mathrm{kPa}$ effective overburden pressure. However, no proportionality is observed between $30 \mathrm{kPa}$ and $100 \mathrm{kPa}$ effective overburden pressures.

Table 4-6 Maximum Undrained Pullout Capacity (in kN)

\begin{tabular}{|c|c|c|c|}
\hline \multirow{2}{*}{ Soil } & \multicolumn{3}{|c|}{ Overburden Pressure } \\
\cline { 2 - 4 } & $30 \mathrm{kPa}$ & $100 \mathrm{kPa}$ & $200 \mathrm{kPa}$ \\
\hline Clean Sand & 2.12 & 4.24 & 8.19 \\
\hline $5 \%$ Silty Sand & 0.96 & 2.75 & 5.23 \\
\hline $10 \%$ Silty Sand & 1.69 & 3.59 & 6.74 \\
\hline $15 \%$ Silty Sand & 1.5 & 2.52 & 4.99 \\
\hline $35 \%$ Silty Sand & 0.73 & 1.29 & 2.5 \\
\hline
\end{tabular}

\subsubsection{Effect of material}

Figure 4-25 shows the drained pullout capacity for all soils tested. The pullout capacity is shown in Table 4-5. The drained pullout capacity decreases from clean sand to $5 \%$ silty sand, increases for $10 \%$ silty sand, where the drained pullout capacity is the highest, and 
decreases from $10 \%$ silty sand as the silt content increases. This trend is observed for all overburden pressures.

Table 4-7 and Figure 4-26 show the relative drained pullout capacity. The values are obtained by dividing the maximum pullout capacity of each soil at a given overburden pressure by the maximum pullout capacity of clean sand at the same overburden pressure. The pullout capacity ratio decreases from 1.0 (clean sand) to $0.91 \sim 0.96$ for $5 \%$ silty sand and increases to $1.05 \sim 1.18$ for $10 \%$ silty sand and then decreases to $0.82 \sim 0.91$ and $0.48 \sim 0.53$, for $15 \%$ and $35 \%$ silty sand, respectively.

Table 4-7 Relative Drained Pullout Capacity

\begin{tabular}{|c|c|c|c|}
\hline \multirow{2}{*}{ Soil } & \multicolumn{3}{|c|}{ Overburden Pressure } \\
\cline { 2 - 4 } & $30 \mathrm{kPa}$ & $100 \mathrm{kPa}$ & $200 \mathrm{kPa}$ \\
\hline Clean Sand & 1 & 1 & 1 \\
\hline $5 \%$ Silty Sand & 0.91 & 0.96 & 0.93 \\
\hline $10 \%$ Silty Sand & 1.18 & 1.10 & 1.05 \\
\hline $15 \%$ Silty Sand & 0.91 & 0.82 & 0.83 \\
\hline $35 \%$ Silty Sand & 0.48 & 0.52 & 0.53 \\
\hline
\end{tabular}

This trend can be understood by analyzing the peak friction angle of each material. The peak friction angle is the factor that governs the pullout capacity, but changes with fines content, relative density, and confinement. The pullout capacity should increase as the 
peak friction angle increases since higher friction angles provide stronger frictional resistance at the soil-steel interface.

Salgado et. al. (2000) have performed triaxial tests on Ottawa sand with 0, 5, 10, 15 and $20 \%$ silt contents, for different void ratios (i.e. different relative densities) and different mean effective stresses. Results from the triaxial tests are very useful to evaluate the pullout test results performed in this research.

Table 4-8 shows the triaxial test results from Salgado et al. (2000), which include the peak friction angle for different mean effective stresses, different fines contents, and different relative densities. A direct comparison between results from the triaxial tests and the pullout tests is not possible because the type of test (triaxial vs. plain strain), the mean effective stress, and the relative densities are not the same. However, an estimate of the peak friction angle is possible by interpolation and extrapolation from the data of Table 4-8. The triaxial test results with $100 \mathrm{kPa}$ mean effective stress are used to obtain the peak friction angle for each silty sand with the actual relative density of the pullout tests. This is done because for pullout tests with $100 \mathrm{kPa}$ overburden pressure, the mean effective stress is about $70 \mathrm{kPa}$, which is similar to the $100 \mathrm{kPa}$ mean effective stress of the triaxial tests.

The values of the peak friction angle are $35.8^{\circ}$ for clean sand, $35.5^{\circ}$ for $5 \%$ silty sand, $36^{\circ}$ for $10 \%$ silty sand, $35.6^{\circ}$ for $15 \%$ silty sand. There is no data from the triaxial tests for $35 \%$ silty sand. Results from Table $4-7$ show that the peak friction angle for $35 \%$ silt 
would be smaller than for $15 \%$ silty sand. As already indicated, the actual peak friction angle for the pullout test will be different than that from Table 4-8 because the friction angles in triaxial compression are smaller than in plain strain. However, the trend will be similar, and the peak friction angles obtained can be used as indicators of the relative magnitude of the pullout tests. 
Table 4-8 Static Triaxial Test Results (After Salgado et. al., 2000)

\begin{tabular}{|c|c|c|c|c|c|c|}
\hline Test & $\begin{array}{c}\text { Fines } \\
\text { content } \\
(\%)\end{array}$ & e & $\begin{array}{c}D_{R} \\
(\%)\end{array}$ & $\begin{array}{c}\sigma_{3}^{\prime} \\
(\mathrm{kPa})\end{array}$ & $\phi_{\mathrm{p}}$ & $\underset{(\mathrm{kPa})}{\mathrm{p}_{\mathrm{p}}^{\prime}}$ \\
\hline A1 & 0 & 0.633 & 49.1 & 200 & 32.4 & 359 \\
\hline $\mathrm{A} 2$ & 0 & 0.590 & 63.3 & 400 & 34.7 & 756 \\
\hline A3 & 0 & 0.643 & 45.8 & 100 & 31.0 & 173 \\
\hline A4 & 0 & 0.674 & 35.3 & 100 & 30.1 & 167 \\
\hline A5 & 0 & 0.635 & 48.4 & 200 & 32.0 & 352 \\
\hline A6 & 0 & 0.632 & 49.3 & 200 & 31.1 & 346 \\
\hline A7 & 0 & 0.678 & 33.9 & 100 & 31.4 & 177 \\
\hline A8 & 0 & 0.662 & 39.3 & 200 & 30.9 & 342 \\
\hline A9 & 0 & 0.674 & 35.2 & 300 & 31.2 & 523 \\
\hline A10 & 0 & 0.659 & 40.2 & 200 & 32.4 & 357 \\
\hline A11 & 0 & 0.610 & 56.7 & 100 & 33.3 & 181 \\
\hline A12 & 0 & 0.586 & 64.6 & 100 & 34.0 & 185 \\
\hline A13 & 0 & 0.537 & 80.9 & 100 & 36.5 & 198 \\
\hline A14 & 0 & 0.558 & 74.1 & 100 & 35.9 & 195 \\
\hline A15 & 0 & 0.645 & 44.9 & 400 & 31.2 & 687 \\
\hline A16 & 0 & 0.665 & 38.3 & 400 & 31.5 & 692 \\
\hline A17 & 0 & 0.699 & 27.1 & 400 & 30.2 & 669 \\
\hline B1 & 5 & 0.660 & 14.4 & 150 & 33.8 & 275 \\
\hline B2 & 5 & 0.581 & 42.3 & 200 & 36.8 & 402 \\
\hline B3 & 5 & 0.661 & 14.0 & 250 & 33.2 & 456 \\
\hline B4 & 5 & 0.495 & 73.4 & 200 & 38.7 & 426 \\
\hline B5 & 5 & 0.630 & 24.9 & 200 & 34.5 & 379 \\
\hline B6 & 5 & 0.587 & 40.4 & 250 & 36.8 & 501 \\
\hline B7 & 5 & 0.657 & 15.3 & 200 & 33.2 & 366 \\
\hline B8 & 5 & 0.634 & 23.7 & 300 & 33.6 & 549 \\
\hline B9 & 5 & 0.609 & 32.5 & 200 & 35.6 & 390 \\
\hline B10 & 5 & 0.475 & 80.3 & 100 & 40.4 & 133 \\
\hline B11 & 5 & 0.502 & 70.8 & 100 & 40.8 & 225 \\
\hline B12 & 5 & 0.612 & 31.4 & 300 & 33.7 & 554 \\
\hline B13 & 5 & 0.632 & 24.3 & 400 & 32.5 & 709 \\
\hline
\end{tabular}




\begin{tabular}{|c|c|c|c|c|c|c|}
\hline $\mathrm{C} 1$ & 10 & 0.583 & 23.1 & 250 & 35.9 & 489 \\
\hline $\mathrm{C} 2$ & 10 & 0.564 & 29.6 & 100 & 37.0 & 201 \\
\hline C3 & 10 & 0.569 & 28.0 & 250 & 37.0 & 504 \\
\hline C4 & 10 & 0.581 & 23.9 & 350 & 35.8 & 685 \\
\hline C5 & 10 & 0.571 & 27.2 & 300 & 37.0 & 607 \\
\hline C6 & 10 & 0.447 & 69.9 & 150 & 39.0 & 317 \\
\hline C7 & 10 & 0.567 & 28.8 & 200 & 35.6 & 393 \\
\hline $\mathrm{C} 8$ & 10 & 0.500 & 51.7 & 200 & 37.3 & 408 \\
\hline C9 & 10 & 0.447 & 70.0 & 100 & 40.5 & 224 \\
\hline C10 & 10 & 0.420 & 79.3 & 100 & 41.3 & 230 \\
\hline C11 & 10 & 0.563 & 30.2 & 400 & 33.7 & 733 \\
\hline C12 & 10 & 0.560 & 31.0 & 400 & 34.1 & 741 \\
\hline Test & $\begin{array}{c}\text { Fines } \\
\text { content } \\
(\%)\end{array}$ & $\mathrm{e}$ & $\begin{array}{l}D_{R} \\
(\%)\end{array}$ & $\begin{array}{c}\sigma_{3}^{\prime} \\
(\mathrm{kPa})\end{array}$ & $\phi_{\mathrm{p}}$ & $\begin{array}{c}\mathrm{p}_{\mathrm{p}}^{\prime} \\
(\mathrm{kPa})\end{array}$ \\
\hline D1 & 15 & 0.500 & 41.9 & 100 & 35.8 & 199 \\
\hline D2 & 15 & 0.512 & 37.9 & 200 & 34.9 & 382 \\
\hline D3 & 15 & 0.363 & 86.1 & 100 & 44.7 & 258 \\
\hline D4 & 15 & 0.410 & 70.9 & 100 & 39.5 & 217 \\
\hline D5 & 15 & 0.390 & 77.5 & 100 & 42.4 & 238 \\
\hline D6 & 15 & 0.366 & 85.1 & 100 & 43.1 & 244 \\
\hline D7 & 15 & 0.412 & 70.4 & 100 & 41.9 & 235 \\
\hline D8 & 15 & 0.375 & 82.4 & 100 & 42.1 & 235 \\
\hline D9 & 15 & 0.392 & 76.8 & 100 & 44.4 & 256 \\
\hline D10 & 15 & 0.320 & 100.0 & 100 & 45.5 & 265 \\
\hline D11 & 15 & 0.607 & 7.4 & 100 & 32.4 & 179 \\
\hline D12 & 15 & 0.587 & 13.7 & 200 & 33.9 & 376 \\
\hline D13 & 15 & 0.588 & 13.5 & 200 & 33.2 & 364 \\
\hline D14 & 15 & 0.551 & 25.6 & 100 & 35.0 & 191 \\
\hline D15 & 15 & 0.533 & 31.2 & 100 & 33.0 & 182 \\
\hline D16 & 15 & 0.530 & 32.1 & 400 & 34.9 & 754 \\
\hline D17 & 15 & 0.522 & 34.8 & 400 & 33.8 & 738 \\
\hline E1 & 20 & 0.423 & 59.8 & 500 & 37.5 & 408 \\
\hline E2 & 20 & 0.384 & 71.5 & 350 & 38.4 & 524 \\
\hline E3 & 20 & 0.402 & 66.0 & 450 & 38.8 & 428 \\
\hline E4 & 20 & 0.470 & 45.4 & 200 & 34.5 & 380 \\
\hline E5 & 20 & 0.494 & 38.3 & 100 & 35.2 & 198 \\
\hline E6 & 20 & 0.535 & 25.9 & 300 & 35.0 & 572 \\
\hline E7 & 20 & 0.448 & 52.2 & 450 & 37.4 & 305 \\
\hline E8 & 20 & 0.531 & 27.0 & 500 & 34.7 & 280 \\
\hline E9 & 20 & 0.484 & 41.2 & 400 & 34.5 & 747 \\
\hline E10 & 20 & 0.476 & 43.5 & 400 & 34.7 & 754 \\
\hline E11 & 20 & 0.487 & 34.4 & 400 & 34.3 & 744 \\
\hline
\end{tabular}


Table 4-9 and Figure 4-27 show the relative pullout capacity for $100 \mathrm{kPa}$ overburden pressure and the interpolated peak friction angles from Salgado et al. (2000). As seen in the table and the figure, the drained pullout capacity follows the trend of the peak friction angle, $\phi_{\mathrm{p}}{ }^{\prime} \cdot \phi_{\mathrm{p}}$ ' slightly decreases from clean sand to $5 \%$ silty sand, increases for $10 \%$ silty sand and then decreases for higher silt contents.

Table 4-9 Correlation between Peak Friction Angle and Relative Drained Pullout Capacity

\begin{tabular}{|c|c|c|}
\hline \multirow{2}{*}{ Soil } & $\begin{array}{c}\text { Relative Pullout Capacity } \\
(100 \mathrm{kPa} \text { overburden pressure })\end{array}$ & $\left(\phi_{\mathrm{p}}{ }^{\prime}\right)$ \\
\hline Clean Sand & 1 & 35.8 \\
\hline $5 \%$ Silty Sand & 0.96 & 35.5 \\
\hline $10 \%$ Silty Sand & 1.10 & 36.0 \\
\hline $15 \%$ Silty Sand & 0.82 & 35.6 \\
\hline $35 \%$ Silty Sand & 0.52 & \\
\hline
\end{tabular}

Figure 4-28 shows the undrained pullout capacity for all tests. The values are shown in Table 4-6. The undrained pullout capacity decreases as the silt content increases from clean sand to $5 \%$ while it increases as silt content increases from 5\% to $10 \%$. Afterwards, it decreases again as the silt content increases. The undrained pullout capacity for 200 $\mathrm{kPa}$ overburden pressure decreases much faster with increasing silt content than for 
smaller overburden pressures. Table 4-10 and Figure 4-29 show the relative undrained pullout capacity. The relative undrained pullout capacity is the capacity obtained by dividing the undrained pullout capacity of each soil by the undrained pullout capacity of clean sand. It significantly decreases for 5\% and increases from 5\% to $10 \%$; afterwards it decreases as the silt content increases. This is the same trend observed in drained pullout capacity.

Table 4-10 Relative Undrained Pullout Capacity

\begin{tabular}{|c|c|c|c|}
\hline \multirow{2}{*}{ Soil } & \multicolumn{3}{|c|}{ Overburden Pressure } \\
\cline { 2 - 4 } & $30 \mathrm{kPa}$ & $100 \mathrm{kPa}$ & $200 \mathrm{kPa}$ \\
\hline Clean Sand & 1 & 1 & 1 \\
\hline $5 \%$ Silty Sand & 0.45 & 0.65 & 0.64 \\
\hline $10 \%$ Silty Sand & 0.80 & 0.85 & 0.82 \\
\hline $15 \%$ Silty Sand & 0.71 & 0.59 & 0.61 \\
\hline $35 \%$ Silty Sand & 0.35 & 0.31 & 0.31 \\
\hline
\end{tabular}

\subsubsection{Effect of drainage condition}

The undrained pullout capacity is not only influenced by the internal friction angle of the soil but also by the excess pore pressures generated during shearing (i.e. during pullout). The excess pore pressures generated when the soil is sheared reduce the effective normal 
stress, which in turn decreases the pullout capacity. One would expect, and it is confirmed by the results, that as the fines in the soil increase, permeability would decrease and excess pore pressures would increase and cause a reduction of effective stresses and consequently of pullout capacity.

Figure 4-30 shows the comparison of drained and undrained test results for clean sand. As expected, the pullout capacity for both drained and undrained tests is the same for all overburden pressures. The trend of the pullout capacity from both drained and undrained tests are virtually undistinguishable.

It is observed for $5 \%$ silty sand that there is a large reduction from drained pullout capacity to undrained pullout capacity, as shown in Figure 4-31. Drained pullout tests shows a stiffer slope at small displacements than undrained pullout tests. Also, the maximum pullout capacity, taken at a point of maximum curvature, is observed at smaller displacements for undrained pullout tests. The drained pullout capacity continues to slightly increase after the peak is reached while the undrained pullout capacity becomes constant after the peak except for $200 \mathrm{kPa}$ overburden pressure, where a slight increase is observed after the peak.

The comparison between drained and undrained pullout tests for $10 \%$ silty sand is presented in Figure 4-32. A reduction of pullout capacity occurs for all overburden pressures. The initial stiffness for the drained tests is higher than for the undrained tests, except for perhaps $100 \mathrm{kPa}$ overburden pressure where the difference is not noticeable. 
As with 5\% silty sand, the maximum pullout capacity occurs at smaller displacements for undrained than for drained tests. The post-peak behavior for $30 \mathrm{kPa}$ overburden pressure undrained test is similar to the drained test, and both of them do not show a clear peak. What it is interesting for $100 \mathrm{kPa}$ and $200 \mathrm{kPa}$ overburden pressure tests is that the drained tests do not show a clear peak, which the undrained tests do, with quite a noticeable reduction after the maximum capacity is reached. This is a fundamental difference in post-peak behavior from a "strain hardening" response to a "strain softening" response.

Figure 4-33 shows the comparison of drained and undrained tests for $15 \%$ silty sand. The drained test results show higher stiffness than for undrained tests for all overburden pressures. The trends observed in Figure 4-33 are similar to those discussed for $10 \%$ silty sand. For $30 \mathrm{kPa}$ overburden pressure, no clear peak is observed for both drained and undrained tests, with both tests showing a slightly "strain hardening" behavior: this is not the case for larger overburden pressures, where a clear softening is observed after peak for undrained tests. It is also observed in Figure 4-33 that the maximum pullout capacity is achieved at smaller displacements for undrained tests than for drained tests.

Figure 4-34 shows the comparison for $35 \%$ silty sand. The pullout capacity considerably decreases for 100 and $200 \mathrm{kPa}$ overburden pressures, but not so much for $30 \mathrm{kPa}$. The initial stiffness of drained tests is higher than undrained tests for 100 and $200 \mathrm{kPa}$ overburden pressure; however, the stiffness of the undrained test for $30 \mathrm{kPa}$ is higher than the drained test. All undrained tests show a peak with a post-peak softening behavior; this 
is only observed in drained tests for $100 \mathrm{kPa}$ and $200 \mathrm{kPa}$ overburden pressures. As with all previous tests the maximum pullout capacity is reached at smaller displacements for undrained tests than for drained tests.

Table 4-11 and Figure 4-35 show the undrained to drained pullout capacity ratio. The ratio is obtained by dividing the maximum undrained pullout capacity for a given overburden pressure by the maximum drained pullout capacity from each soil.

The undrained to drained (UD/D) pullout capacity ratio for clean sand is 1 , since both drained and undrained pullout capacities are the same. The UD/D pullout capacity ratio significantly decreases for $5 \%$ silt, where a larger reduction is observed for $30 \mathrm{kPa}$ than for 100 and $200 \mathrm{kPa}$ overburden pressure. The ratio increases from $5 \%$ to $10 \%$ silt, with a similar value for 100 and $200 \mathrm{kPa}$, and a comparatively smaller value for $30 \mathrm{kPa}$. As the silt content increases from $5 \%$ to $10 \%$, two different trends are observed; (1) for $30 \mathrm{kPa}$ overburden pressure, the ratio increases; and (2) for $100 \mathrm{kPa}$ and $200 \mathrm{kPa}$ the ratio decreases, with a similar value for both overburden pressures. For $35 \%$ silt content the ratio decreases from $15 \%$ silt in all cases.

Figure 4-36 shows the evolution of undrained pullout capacity with permeability. As already discussed the pullout capacity increases with overburden pressure. For each of the three overburden pressures, the general trend is a decrease of capacity as the permeability decreases. There is a recovery of pullout capacity between permeabilities of 0.01 and $0.07 \mathrm{~cm} / \mathrm{sec}$ (which correspond to silt contents of 5\% and 10\%, respectively); 
this is due to a lower void ratio of the soil. Figure 4.36 is similar to Figure 4.28 since silt content and permeability are related. As discussed earlier an increase of silt content beyond $5 \%$ has a positive influence on the internal friction angle of the soil as the silt fills the voids of the sand. This is reflected in Figure 4.36 where both the effects of permeability and silt content are included. On the one hand as the permeability decreases the undrained pullout capacity decreases; on the other hand an increase of silt content may increase the internal friction angle of the soil and produce the opposite effect: an increase of pullout. It is expected that for two soils with the same internal friction angle, and for the same pullout rate, the pullout capacity will decrease with decreasing permeability (perhaps to a minimum pullout which may not decrease further with smaller permeabilities).

In summary, the undrained to drained pullout capacity ratio is always similar for 100 and $200 \mathrm{kPa}$ overburden pressure for all soils tested. The ratio decreases as the silt content increases except from 5\% to $10 \%$ silt. However, the ratio for $30 \mathrm{kPa}$ overburden pressure decreases from clean sand to $5 \%$, increases from $5 \%$ to $15 \%$, and decreases again to $35 \%$ silty sand. In addition, the ratio for $30 \mathrm{kPa}$ is smaller than the ratio for 100 and $200 \mathrm{kPa}$ overburden pressure with $5 \%$ and $10 \%$ silty sand while it is larger with $15 \%$ and $35 \%$ silty sand. 
Table 4-11 Undrained to Drained Pullout Capacity Ratio

\begin{tabular}{|c|c|c|c|}
\hline \multirow{2}{*}{ Soil } & \multicolumn{3}{|c|}{ Overburden Pressure } \\
\cline { 2 - 4 } & $30 \mathrm{kPa}$ & $100 \mathrm{kPa}$ & $200 \mathrm{kPa}$ \\
\hline Clean Sand & 1.00 & 1.00 & 1.00 \\
\hline $5 \%$ Silty Sand & 0.50 & 0.67 & 0.69 \\
\hline $10 \%$ Silty Sand & 0.67 & 0.77 & 0.78 \\
\hline $15 \%$ Silty Sand & 0.78 & 0.72 & 0.73 \\
\hline $35 \%$ Silty Sand & 0.72 & 0.59 & 0.57 \\
\hline
\end{tabular}

\subsection{Conclusions}

This section summarizes material properties and conclusions obtained from all tests performed in this research, which include proctor tests, compaction tests, permeability tests and pullout tests.

\subsubsection{Material}

(1) The soils used are clean (Ottawa) sand and silty sands with silt content of 5, 10,15 and $35 \%$.

(2) The minimum and maximum void ratios for the soils are presented in Table 4-

1. The grain size distribution is shown in Figure 4-1 (Salgado et. al. (2000)). 


\subsubsection{Proctor tests}

(1) Proctor tests are performed to determine the maximum dry unit weight of the soil samples and the results are presented in Table 4-2 and Figures from 4-2 to 4-6.

(2) The target dry unit weights for pullout tests are obtained from the proctor tests, and are the maximum dry unit weight for clean sand and $95 \%$ of Proctor for silty sands.

\subsubsection{Compaction tests}

(1) Compaction tests are performed to determine the compaction energy required to obtain the target dry unit weight for pullout tests.

(2) Figures 4-8 to 4-11 show the results of the compaction tests, and the appropriate compaction energy required for each soil.

\subsubsection{Permeability tests}

(1) Permeability tests are performed to determine the relationship between the permeability (i.e. dissipation time of excess pore pressure) and the undrained pullout capacity.

(2) Table 4-3 and Figure 4-12 show the result of permeability tests. Permeability decreases as the silt content increases. 


\subsubsection{Pullout tests}

(1) Pullout tests are performed with the following conditions: sands with different silt contents $(0,5,10,15$ and $35 \%)$, different overburden pressures (30, 100 and $200 \mathrm{kPa}$ ), and different drainage conditions (drained and undrained).

(2) Figures 4-13 to 4-22 show the results of both drained and undrained pullout tests for all the soils tested. Both drained and undrained pullout capacities decrease from clean sand to $5 \%$ silty sand, increase to $10 \%$ silty sand and decrease to 15 and $35 \%$ silty sand for all the overburden pressures.

(3) Effect of overburden pressure

- Pullout capacity increases as the overburden pressure increases.

- The higher the overburden pressure, the stiffer soil response.

- The displacement at maximum pullout capacity increases with overburden pressure.

(4) Effect of material

- The pullout capacity is governed by the internal friction angle of the soil, and increases as the peak friction angle increases.

- Table 4-9 and Figure 4-27 show the correlation between the peak friction angle and the relative drained pullout capacity.

(5) Effect of drainage condition

- There is a reduction of pullout capacity in undrained tests compared to drained tests. 
- The initial stiffness of the pullout response is higher in drained tests than in undrained tests.

- The undrained to drained pullout capacity ratio for 100 and $200 \mathrm{kPa}$ overburden pressure is similar and decreases from clean sand to $5 \%$, increases to $10 \%$ and decreases to $35 \%$ silt.

- The undrained to drained pullout capacity ratio for $30 \mathrm{kPa}$ decreases from clean sand to $5 \%$, increases from $5 \%$ to $15 \%$, and decreases to $35 \%$ silt. 


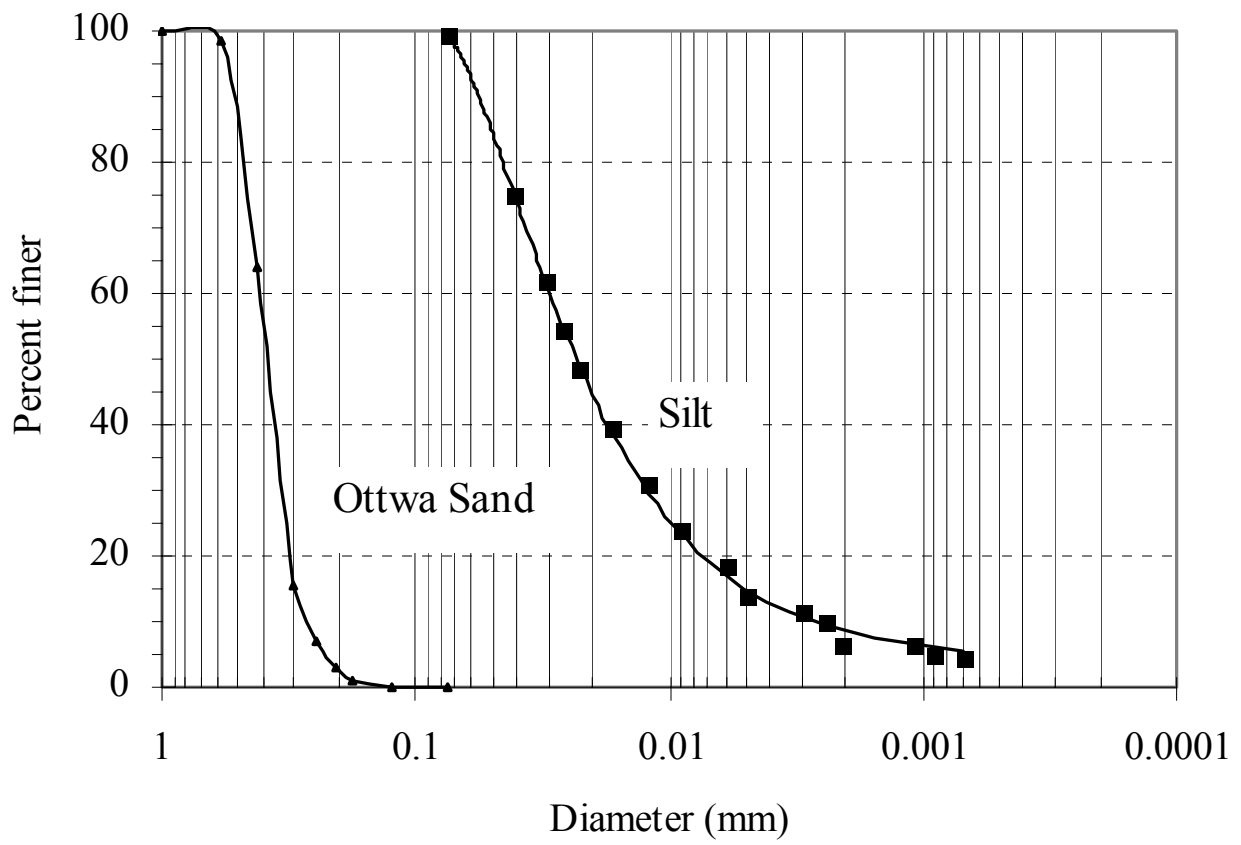

Figure 4-1 Grain Size Distribution (After Salgado et. al., 2000) 


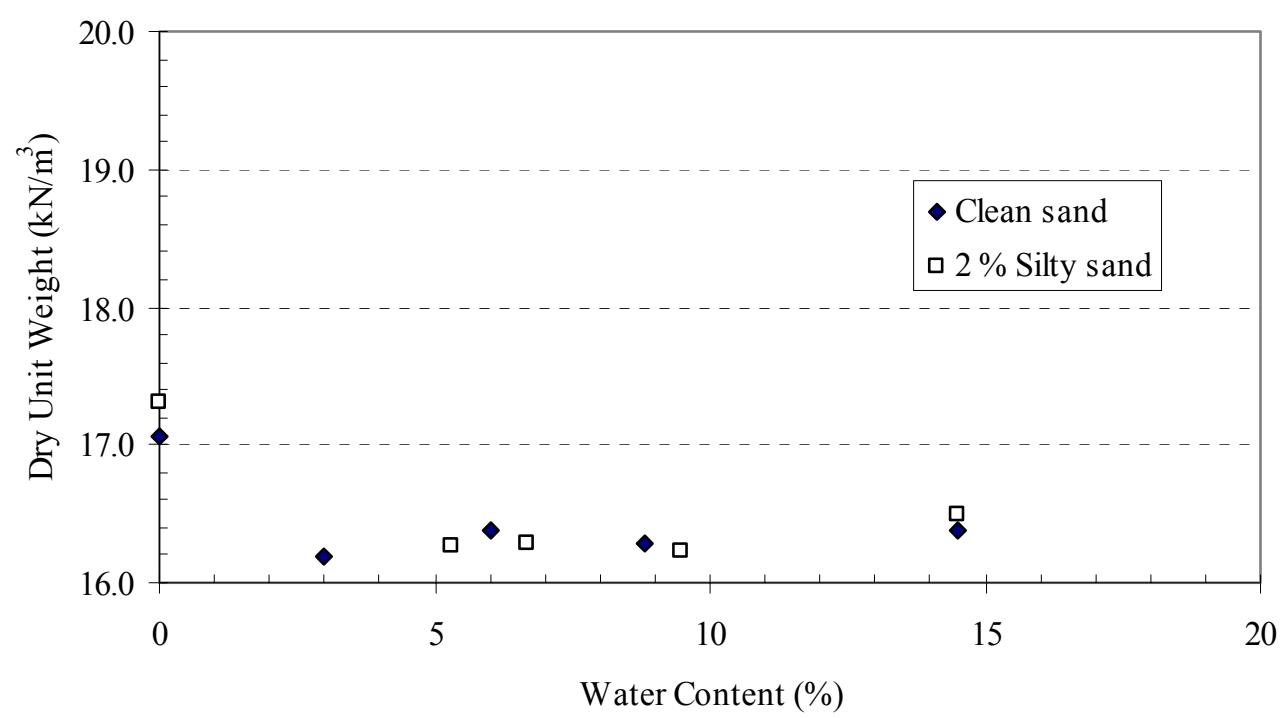

Figure 4-2 Standard Proctor Test Results for Clean Sand and 2\% Silty Sand

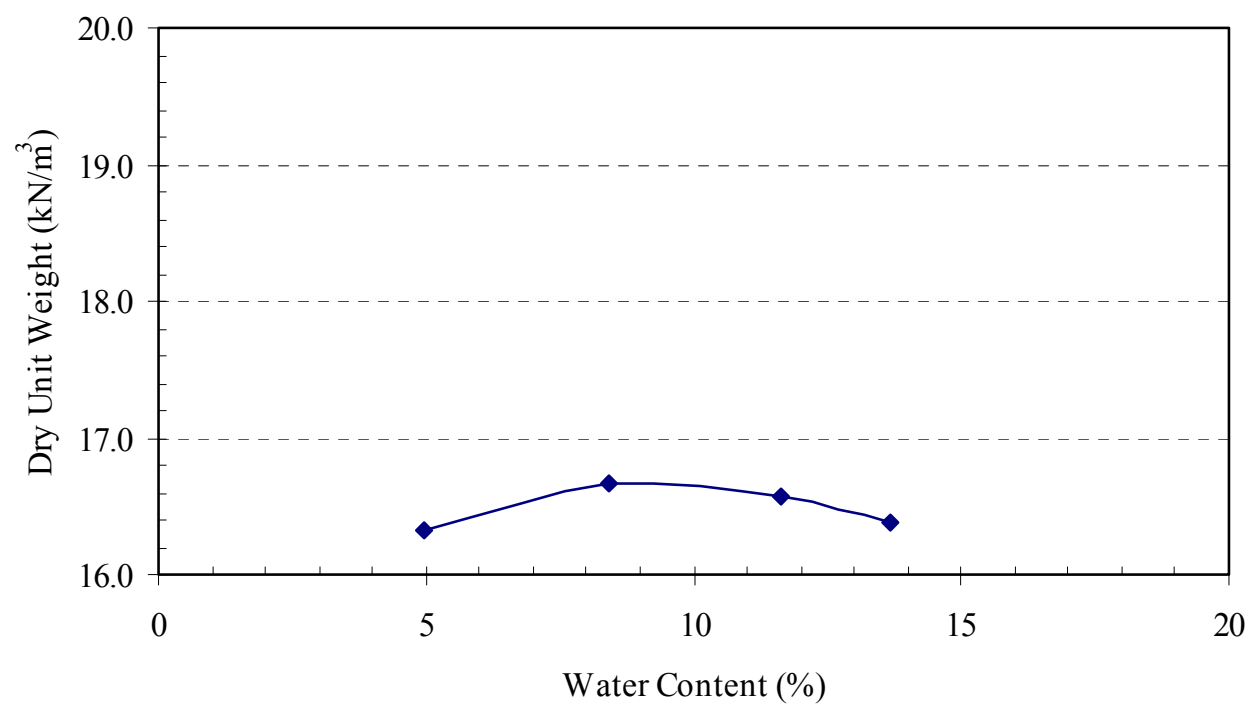

Figure 4-3 Standard Proctor Test Results for 5\% Silty Sand 


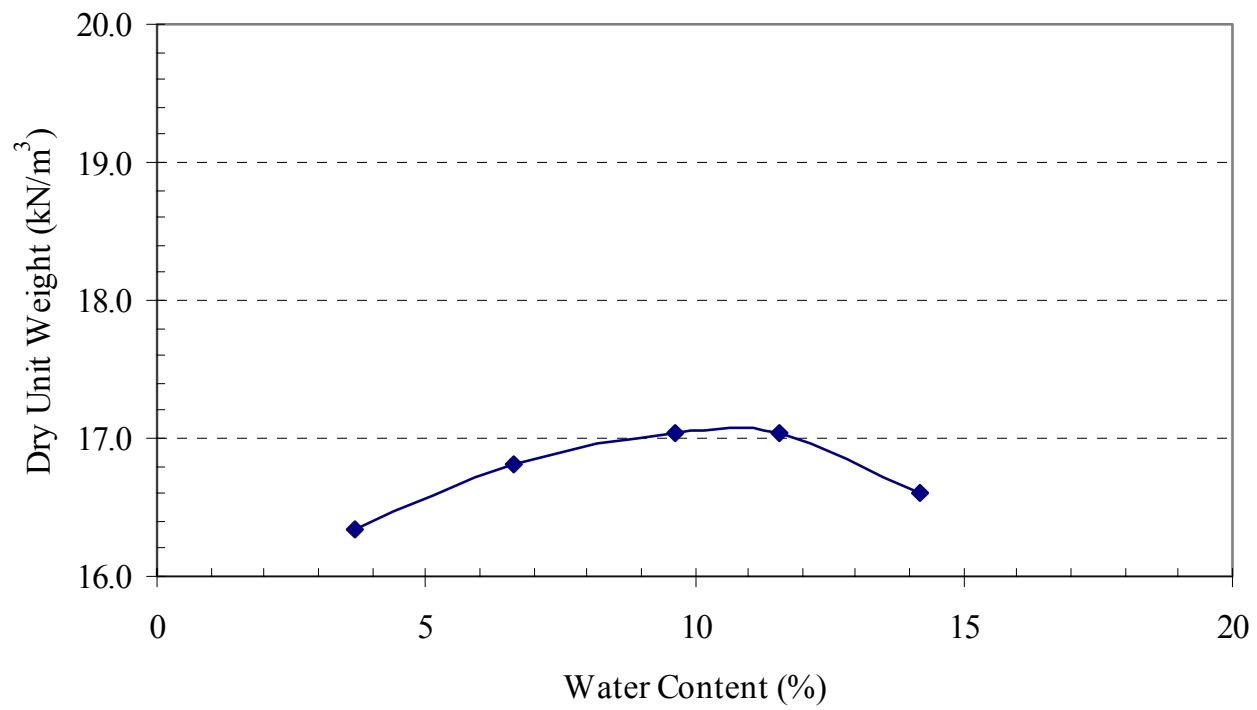

Figure 4-4 Standard Proctor Test Results for 10\% Silty Sand

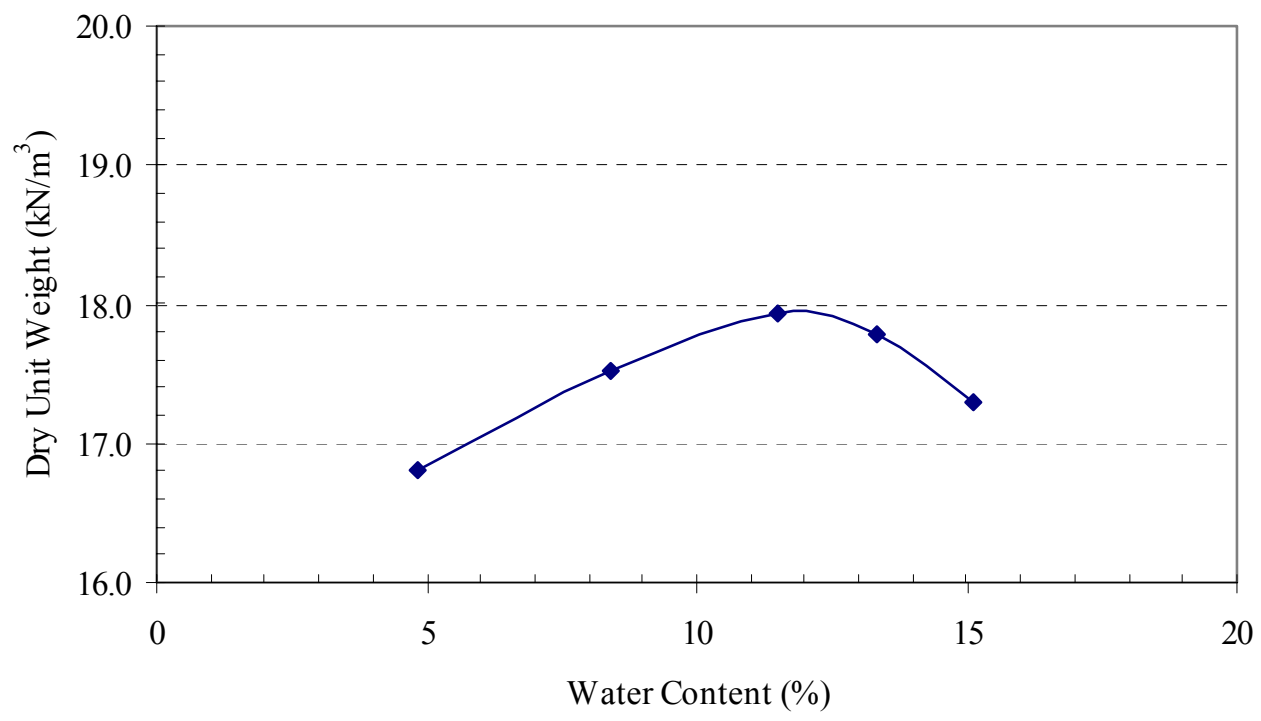

Figure 4-5 Standard Proctor Test Results for 15\% Silty Sand 


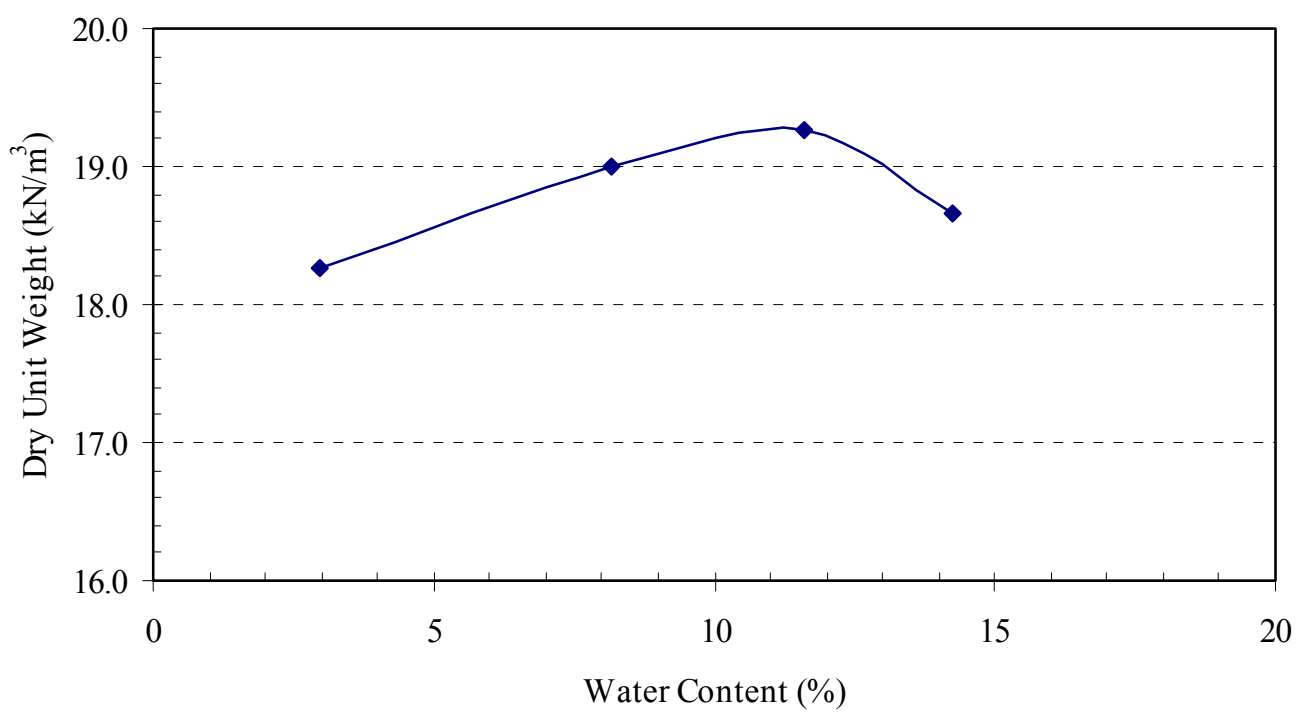

Figure 4-6 Standard Proctor Test Results for 35\% Silty Sand 


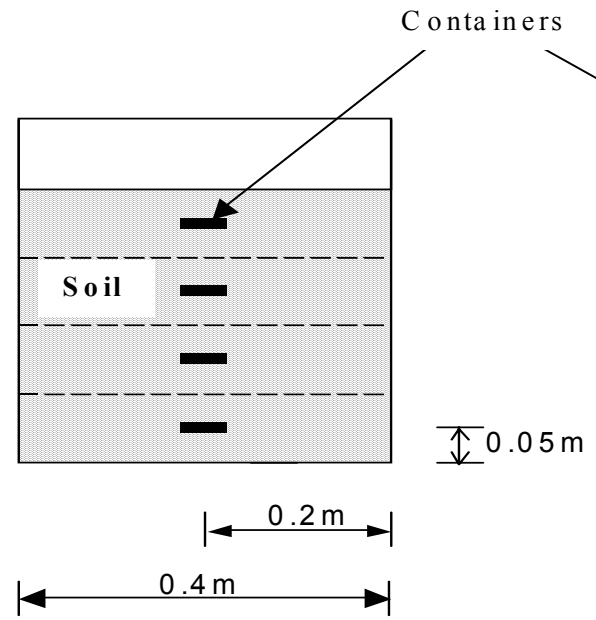

C ross section

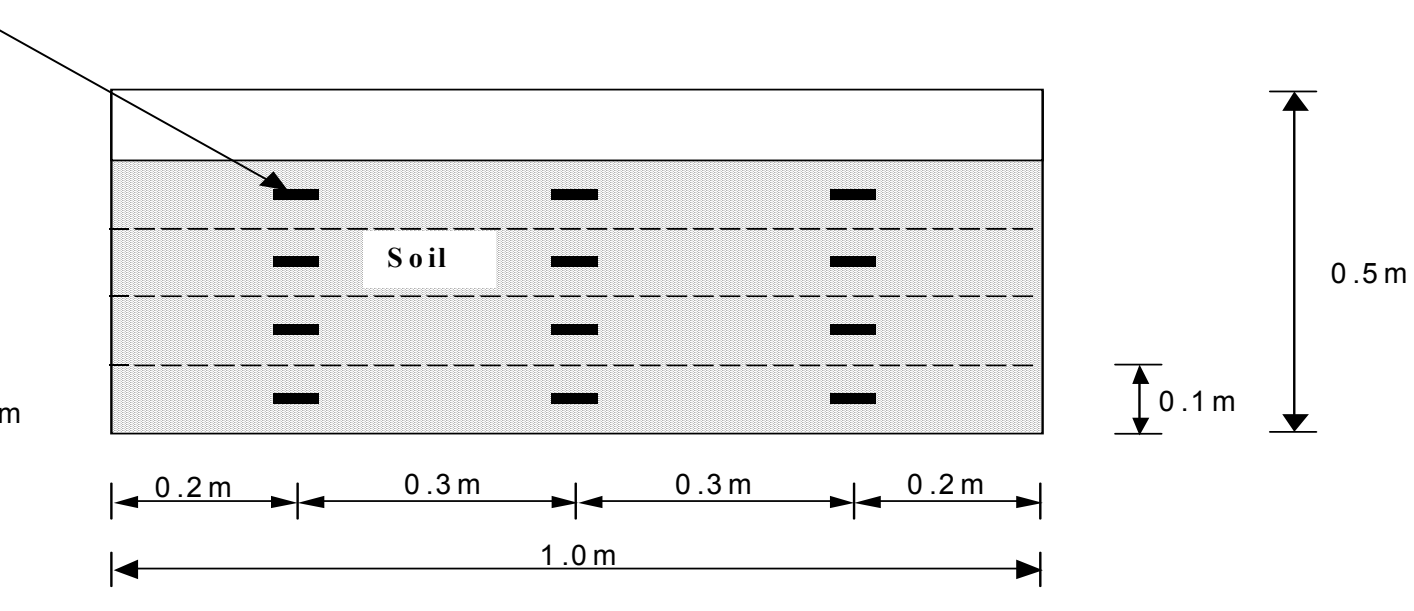

Longitudina 1 section

Figure 4-7 Location of Soil Sample Containers in Compaction Tests 


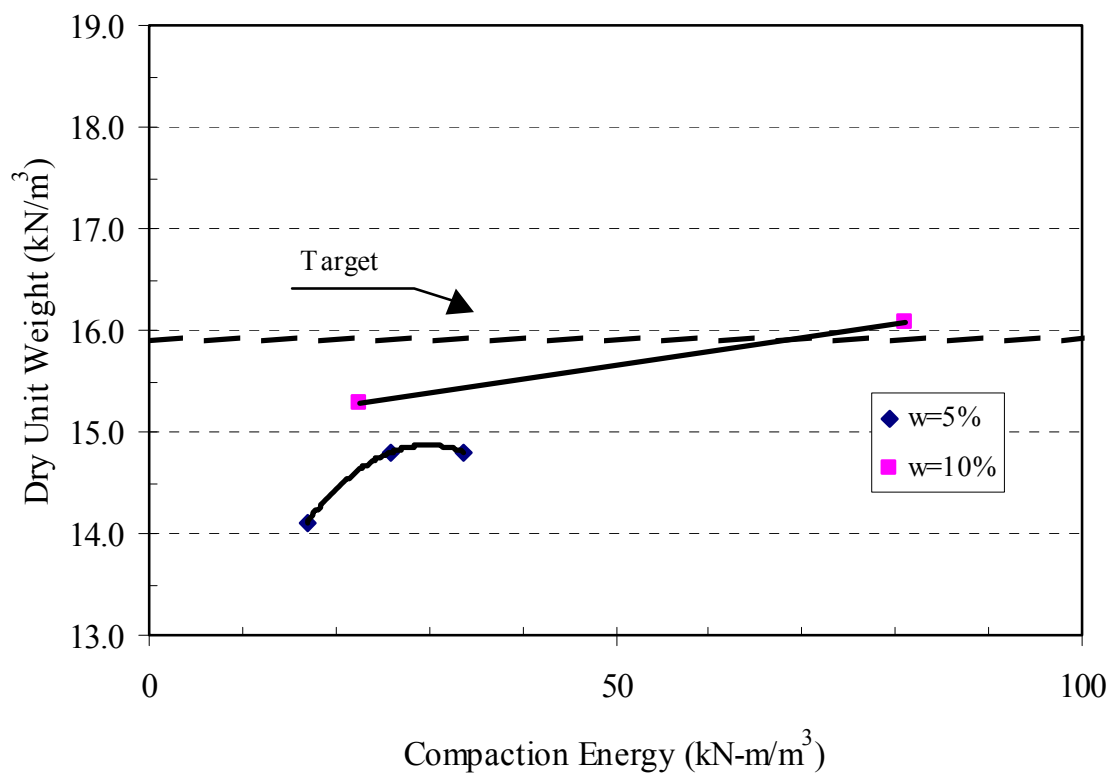

Figure 4-8 Compaction Test Results for 5\% Silty Sand

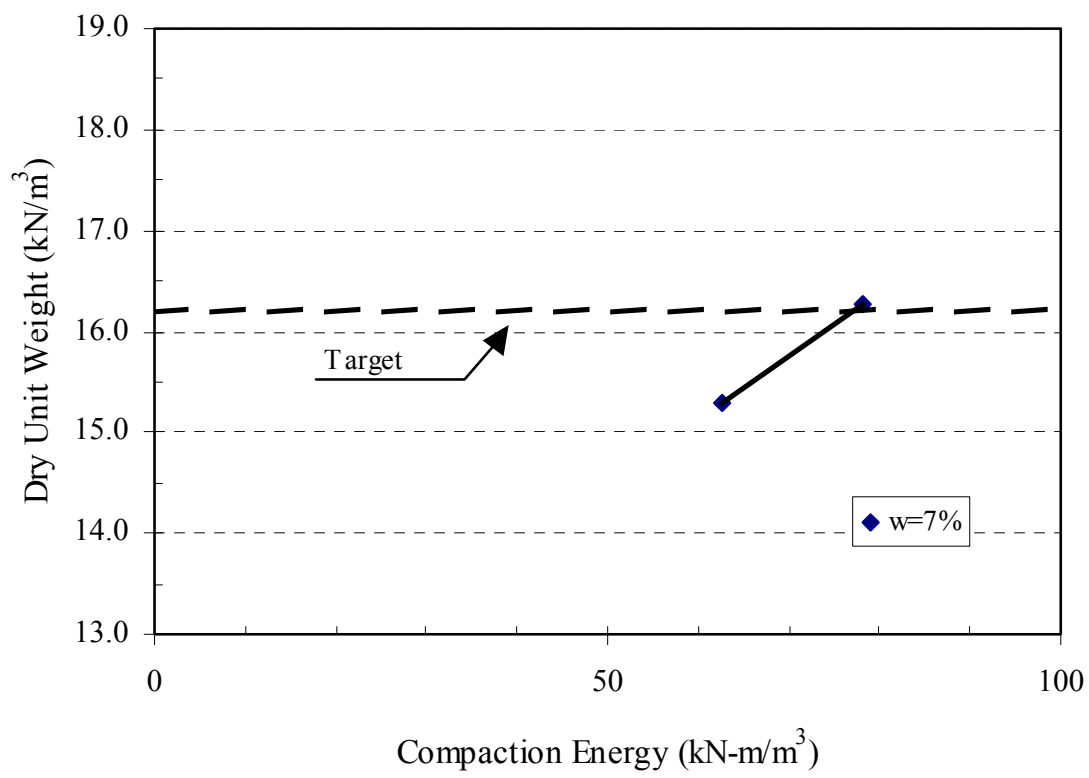

Figure 4-9 Compaction Test Results for 10\% Silty Sand 


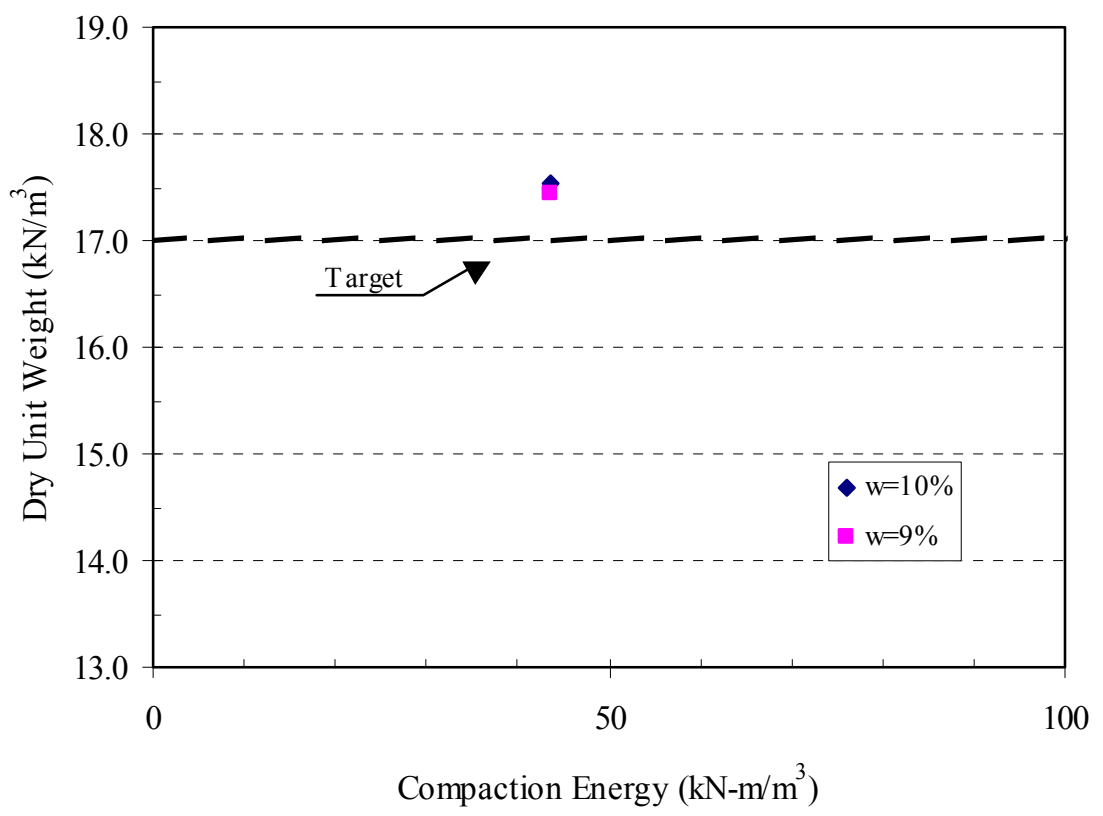

Figure 4-10 Compaction Test Results for 15\% Silty Sand

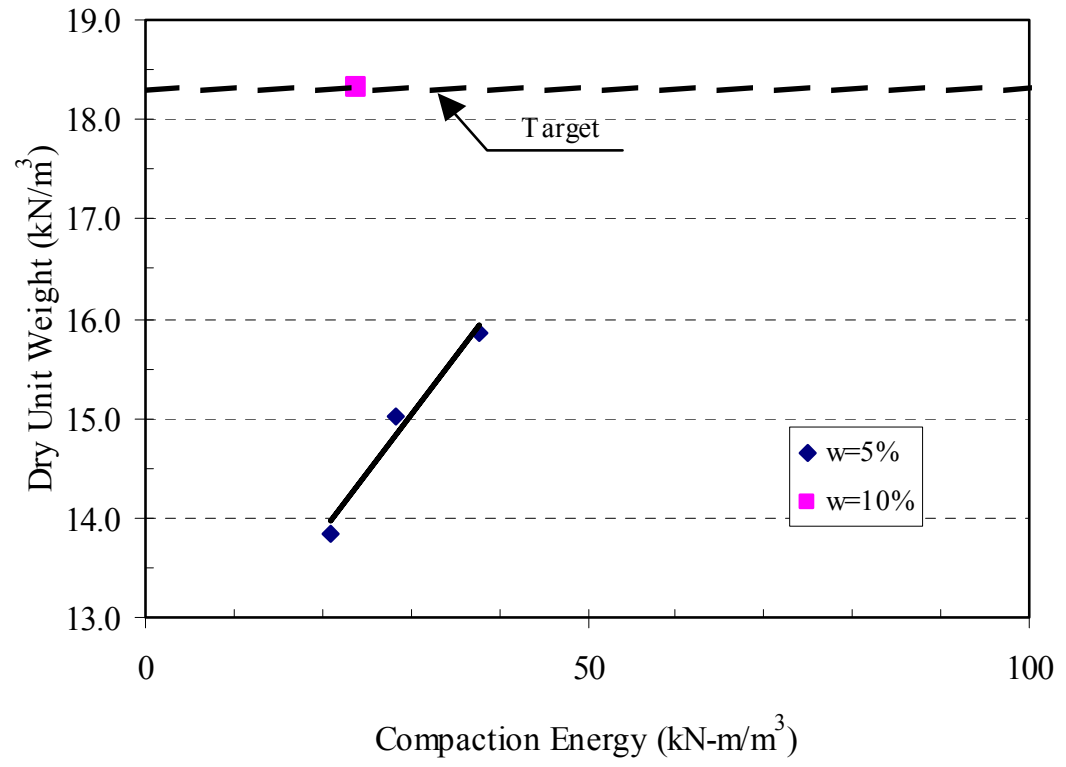

Figure 4-11 Compaction Test Results for 35\% Silty Sand 


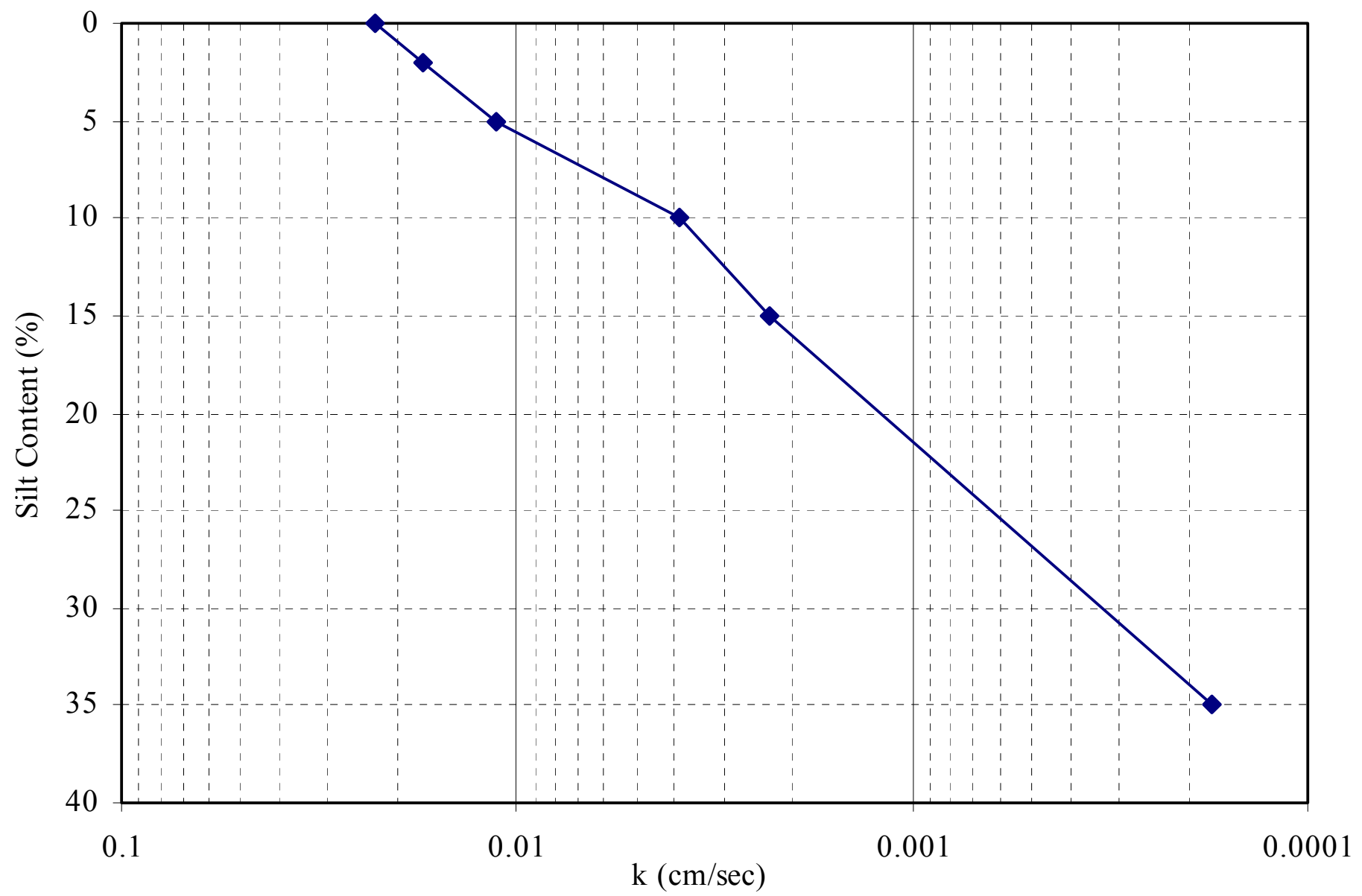

Figure 4-12 Coefficient of Permeability with Silt Content 


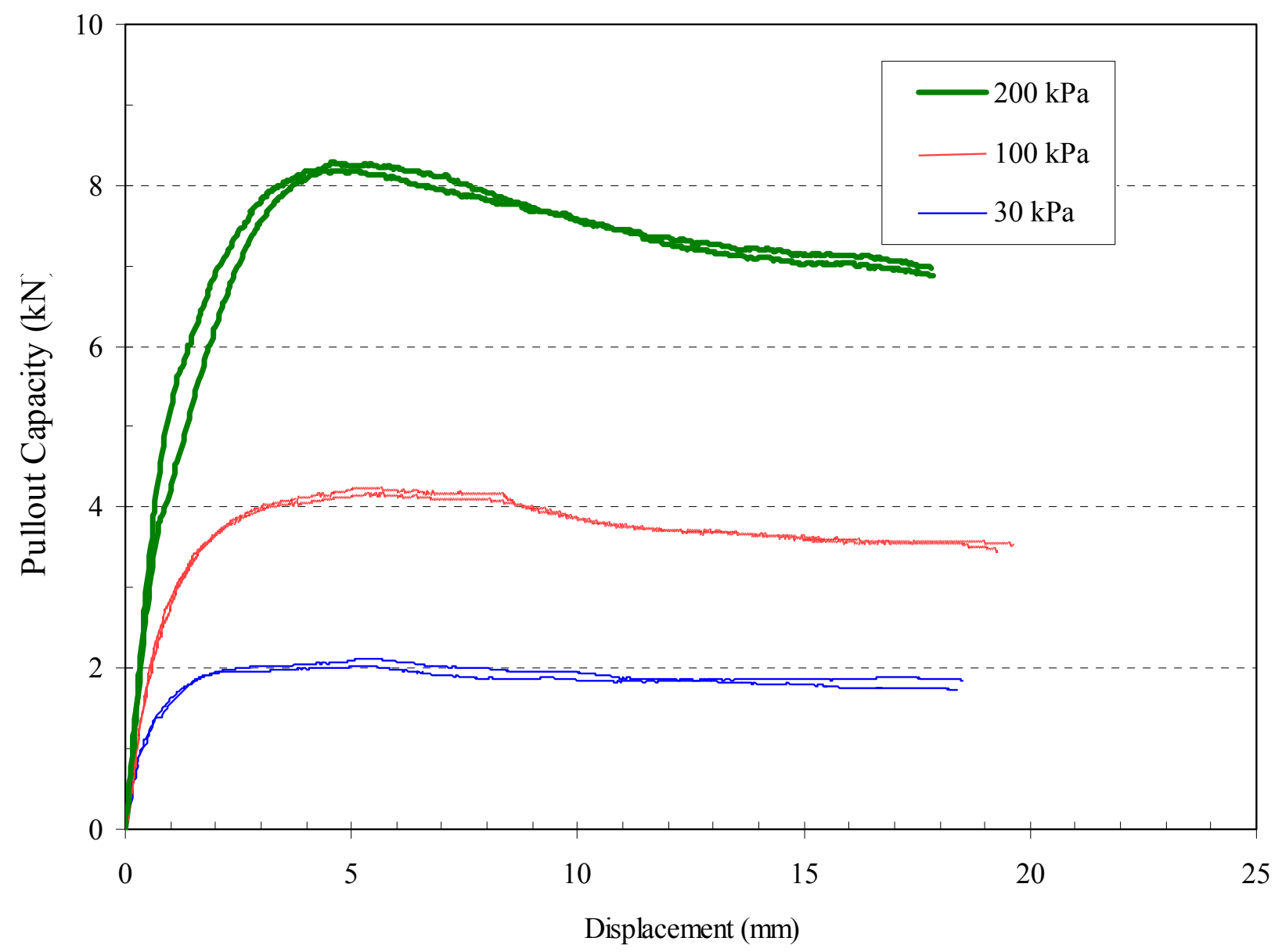

Figure 4-13 Drained Pullout Test Results for Clean Sand 


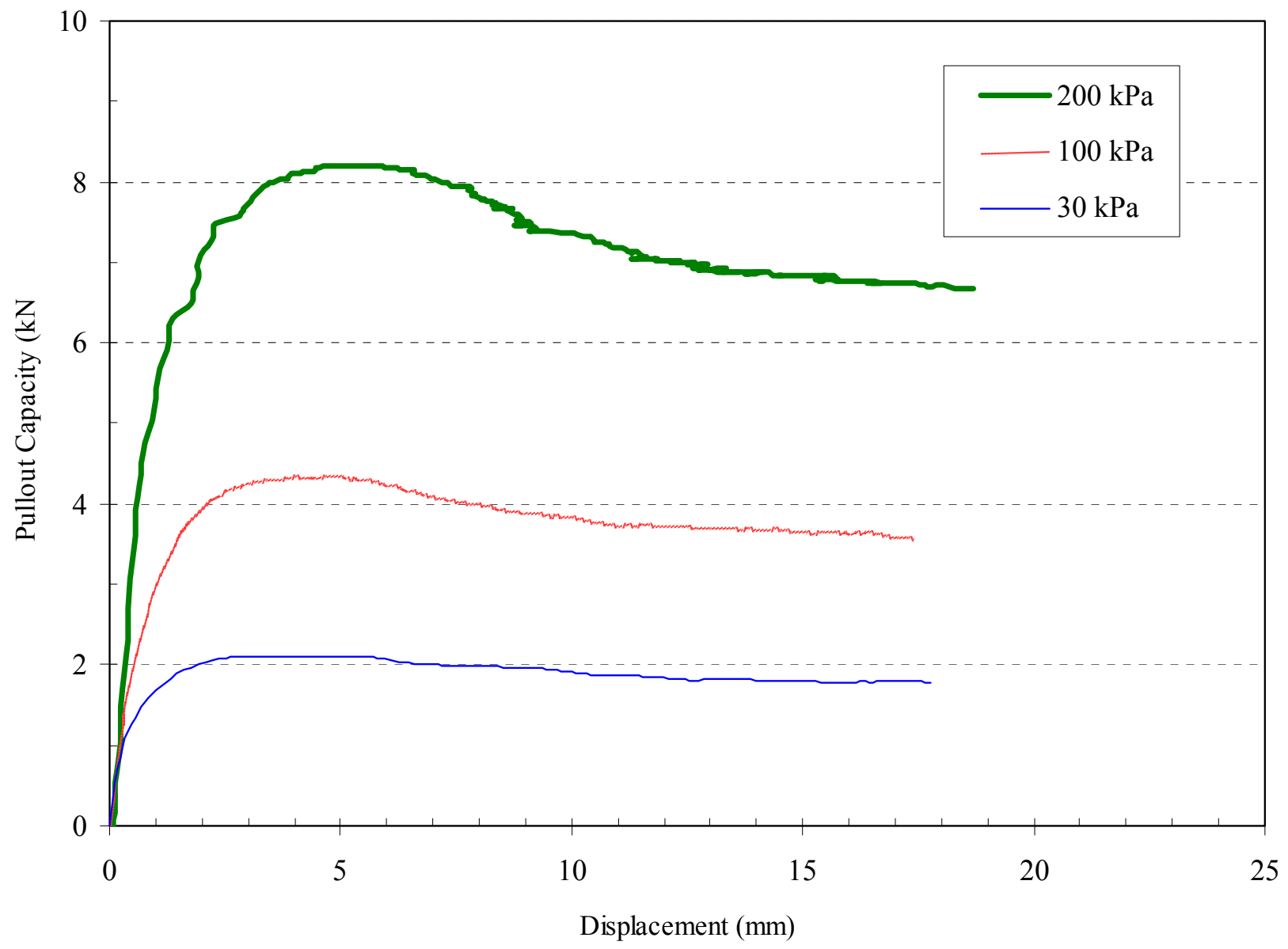

Figure 4-14 Undrained Pullout Test Results for Clean Sand 


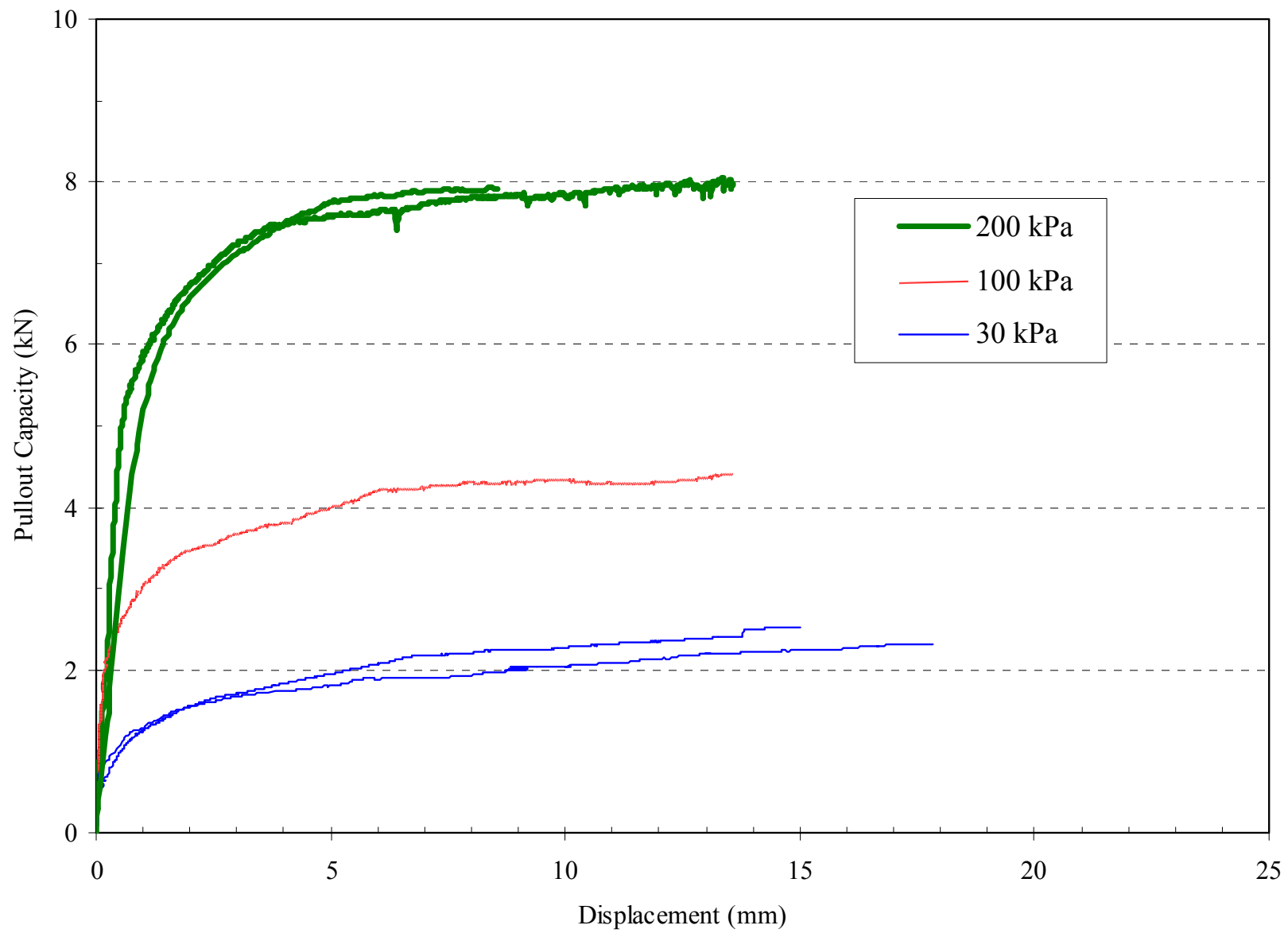

Figure 4-15 Drained Pullout Test Results for 5\% Silty Sand

Б゙ 


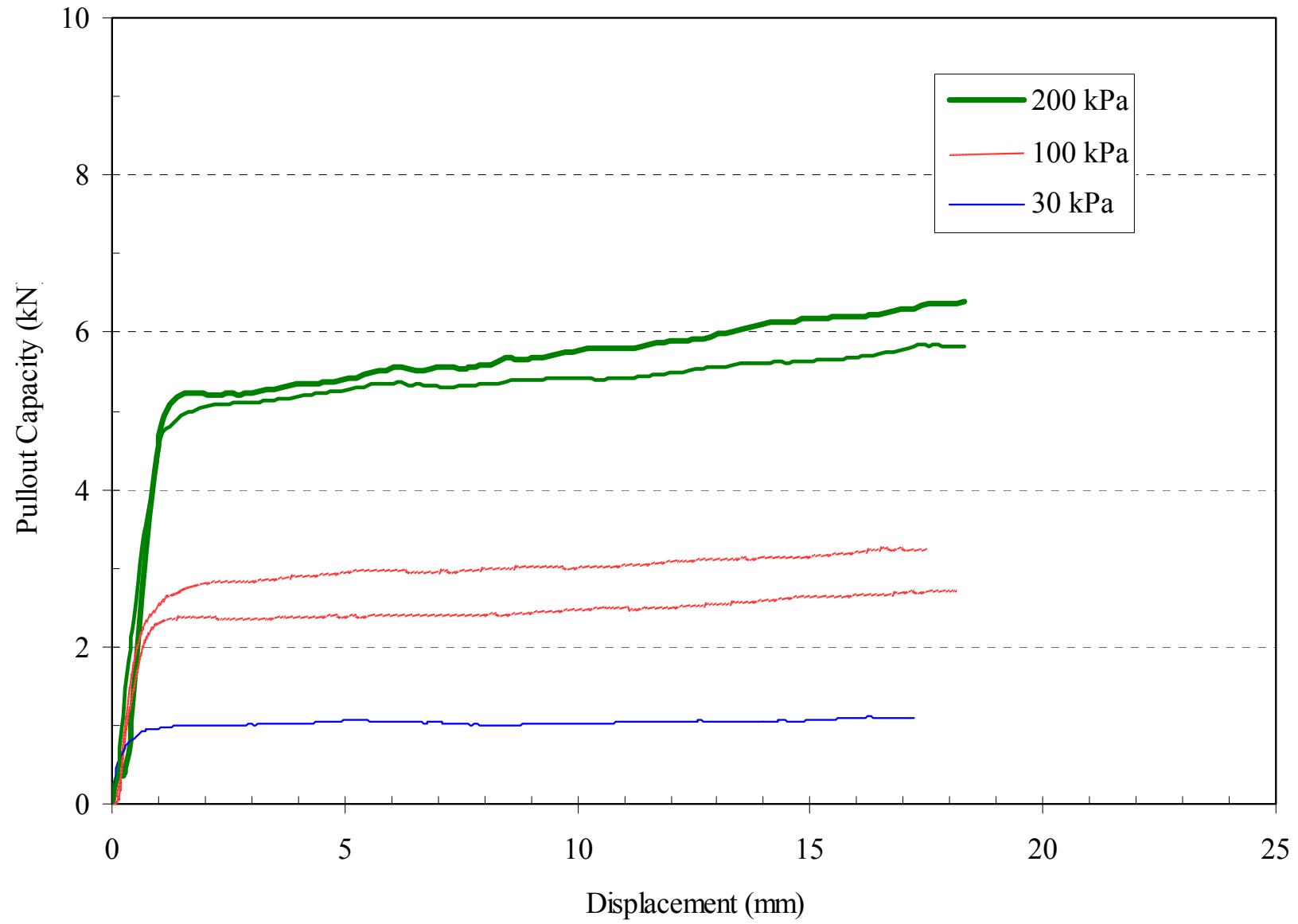

Figure 4-16 Undrained Pullout Test Results for 5\% Silty Sand 


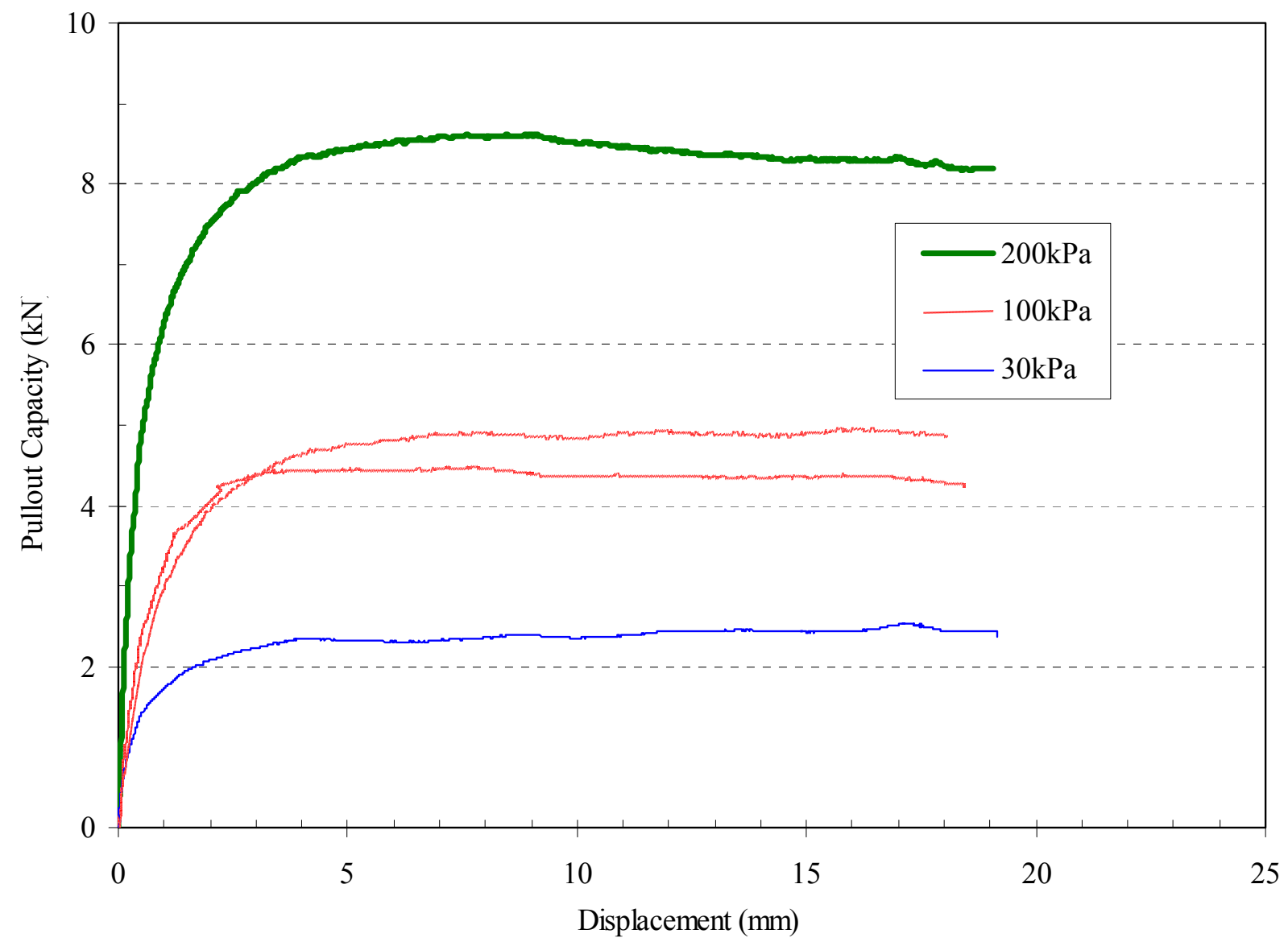

Figure 4-17 Drained Pullout Test Results for 10\% Silty Sand 


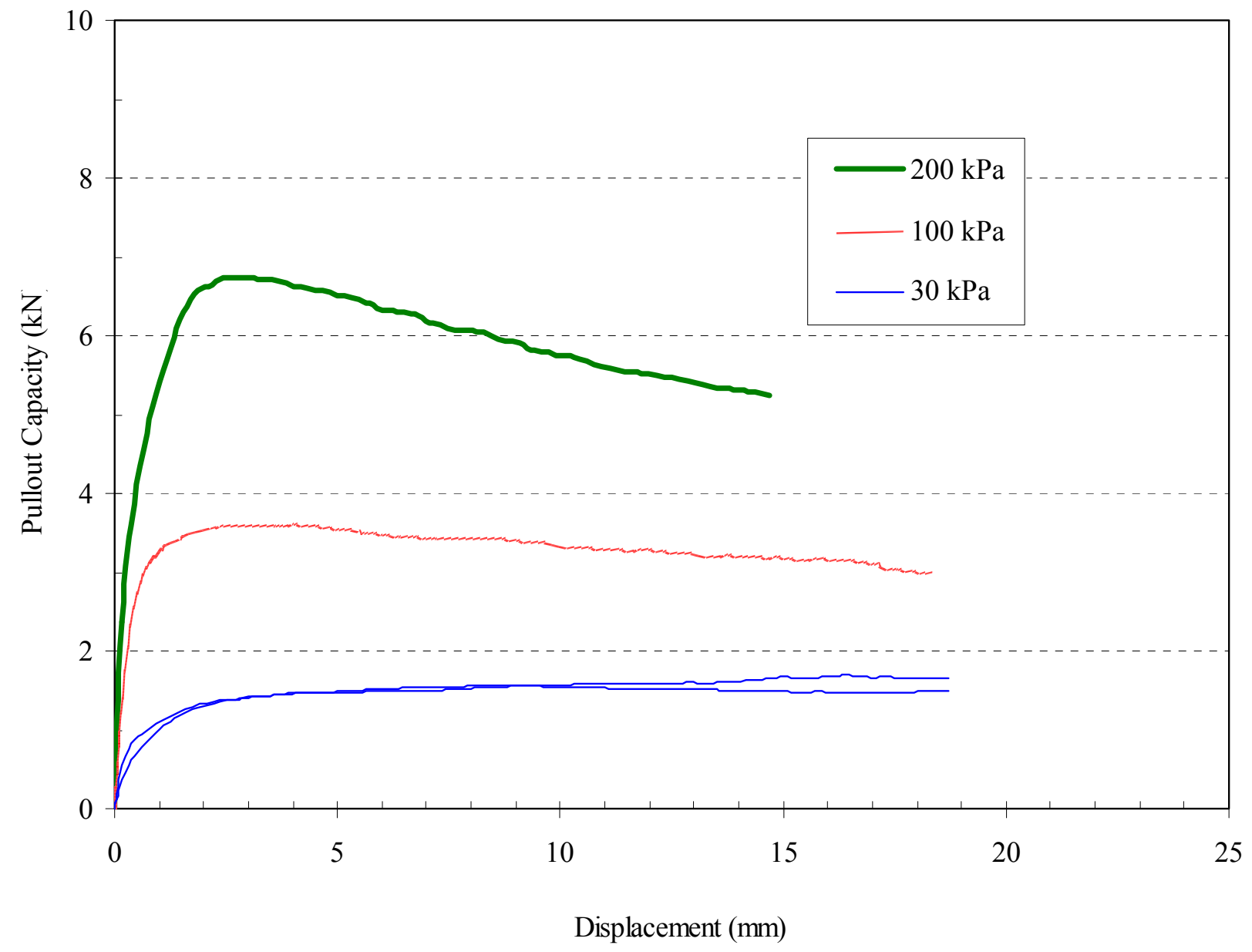

Figure 4-18 Undrained Pullout Test Results for 10\% Silty Sand 


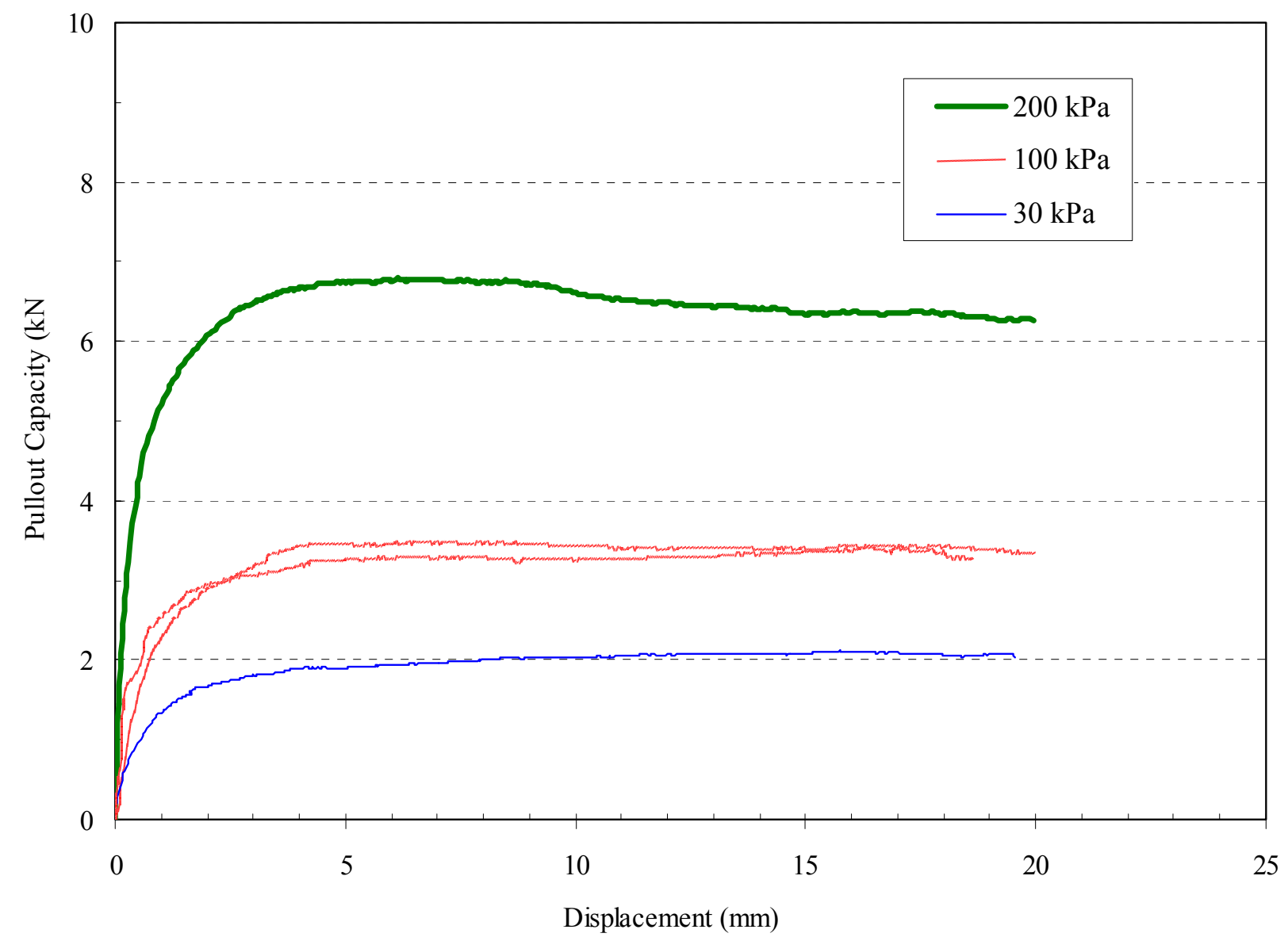

Figure 4-19 Drained Pullout Test Results for 15\% Silty Sand 


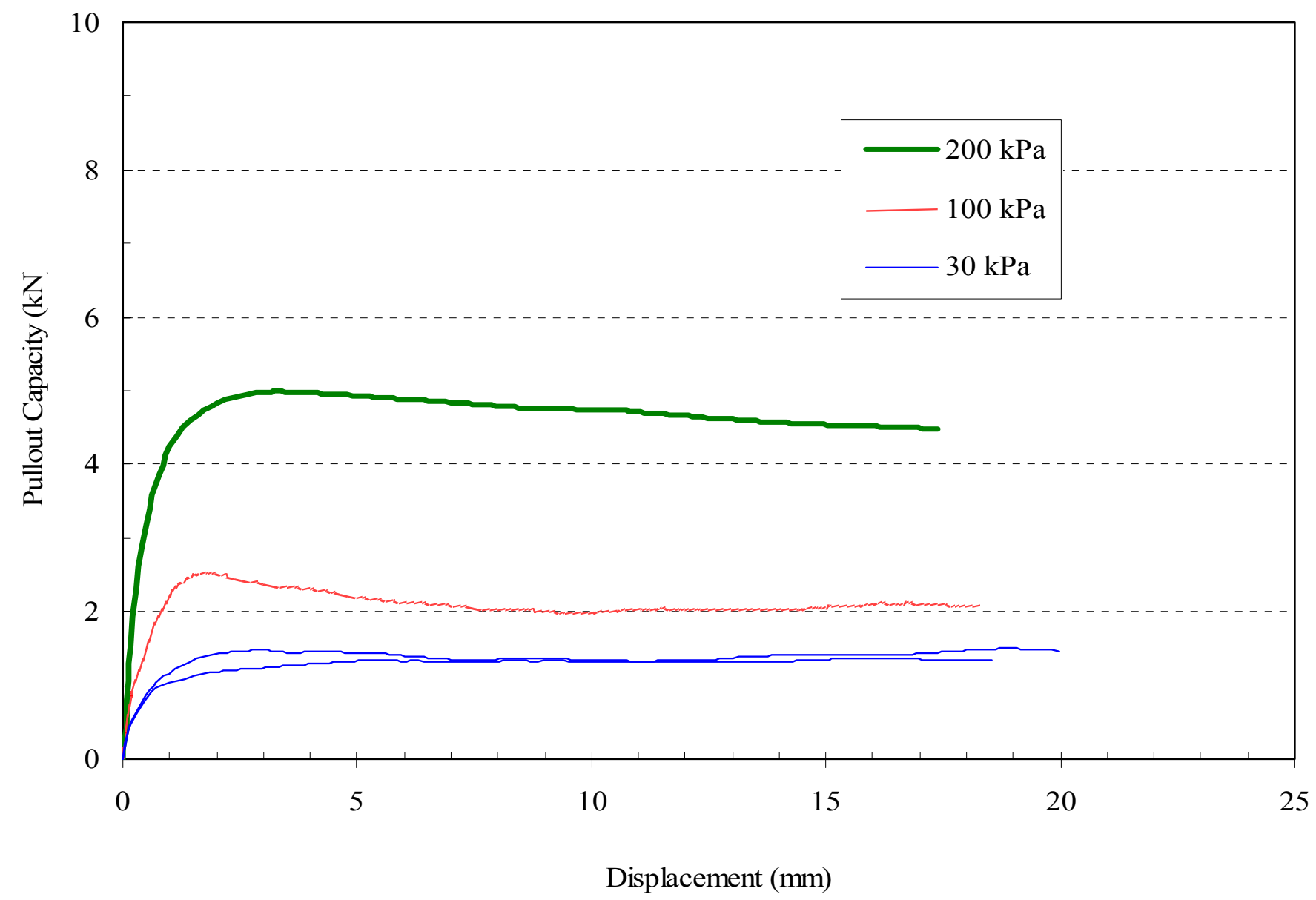

Figure 4-20 Undrained Pullout Test Results for 15\% Silty Sand 


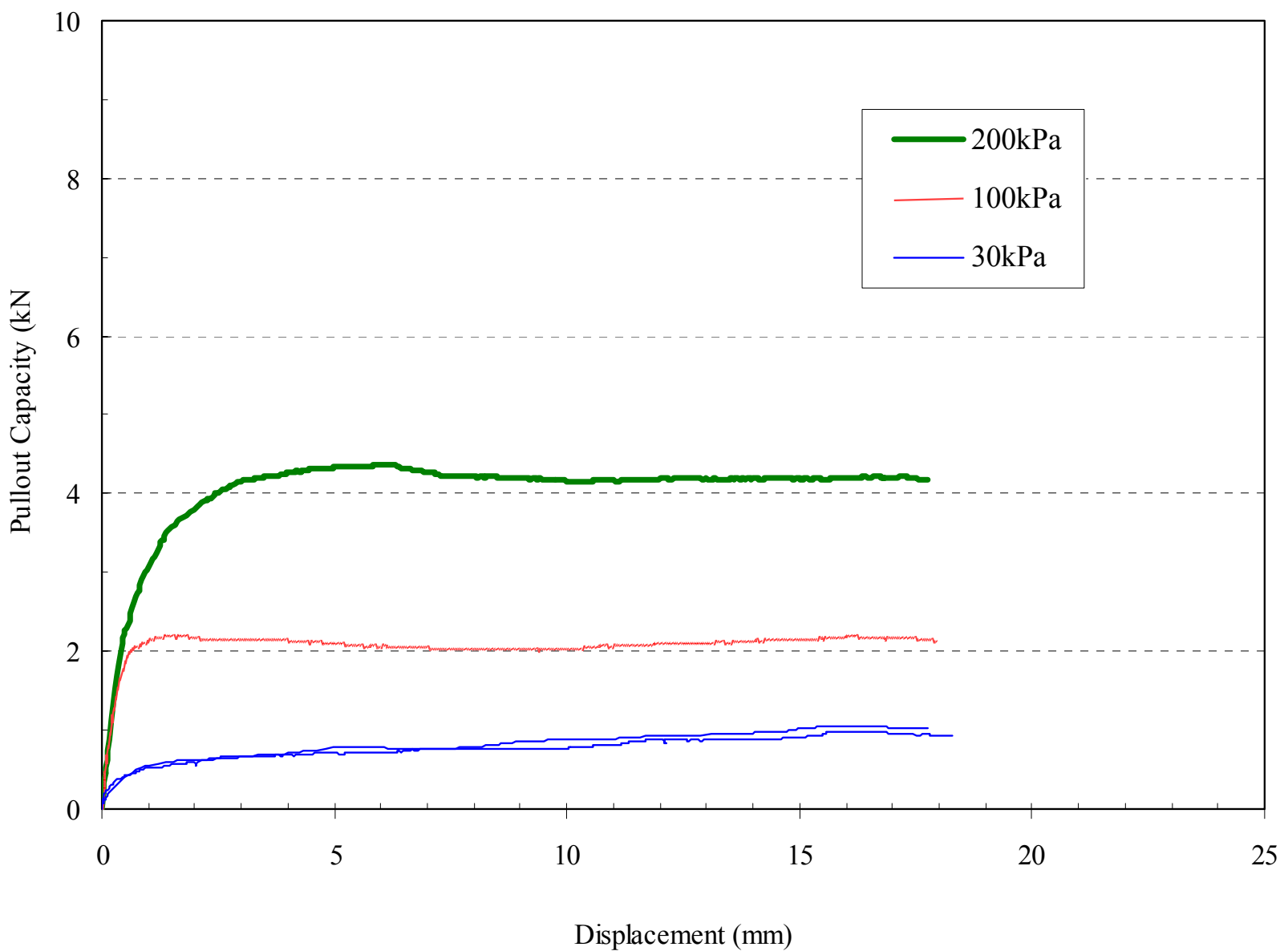

Figure 4-21 Drained Pullout Test Results for 35\% Silty Sand 


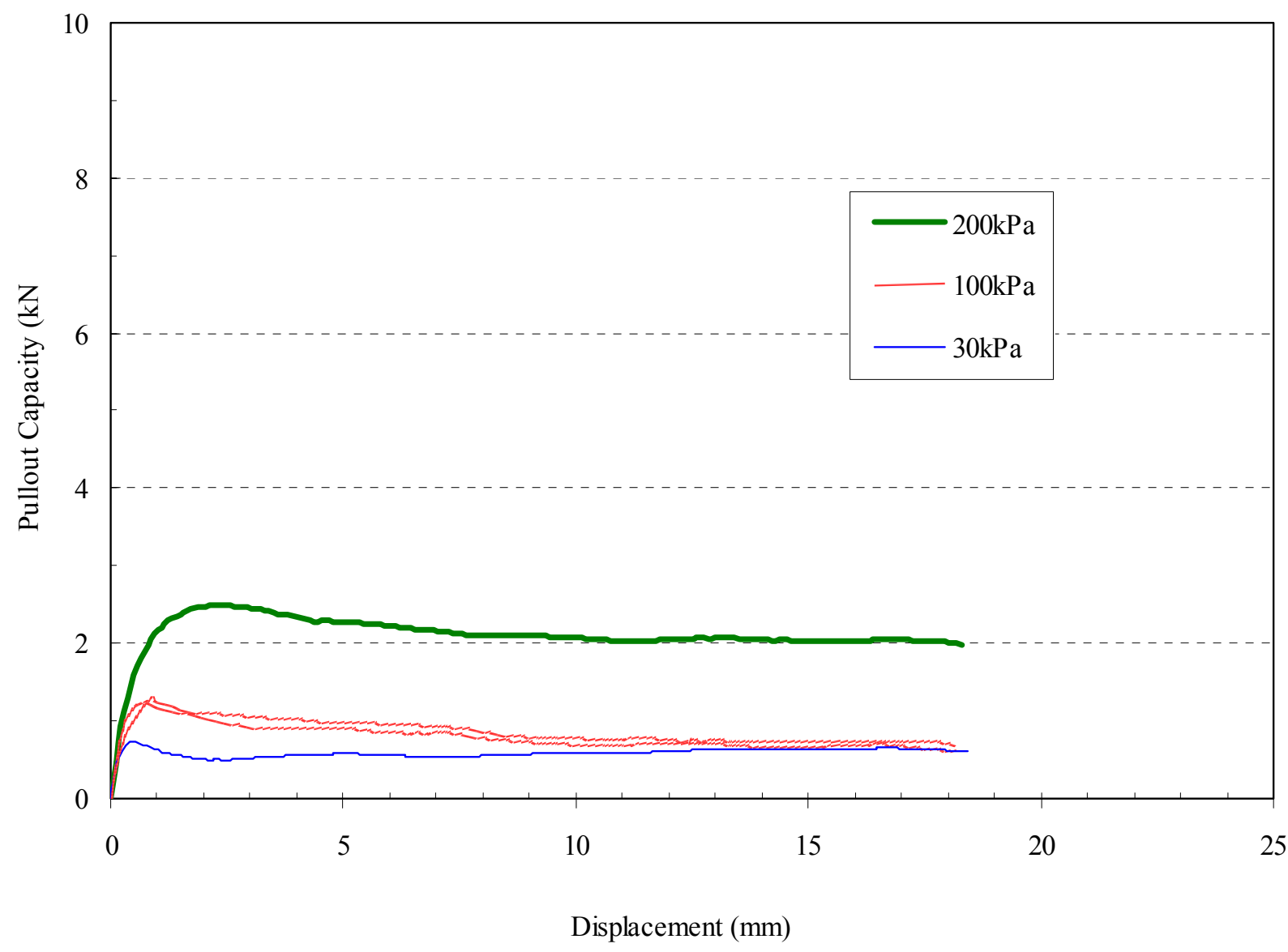

Figure 4-22 Undrained Pullout Test Results for 35\% Silty Sand 


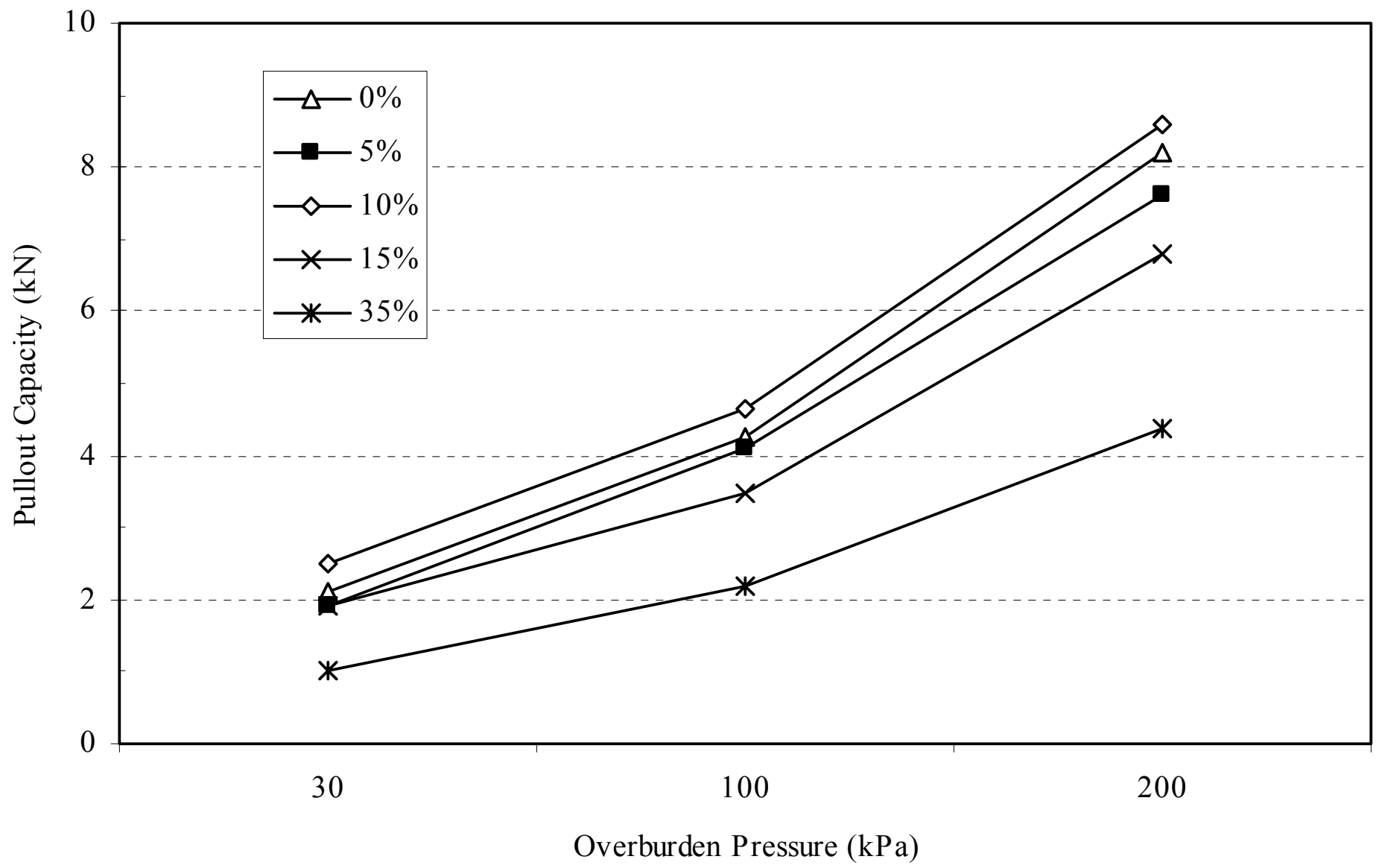

Figure 4-23 Drained Pullout Capacity 


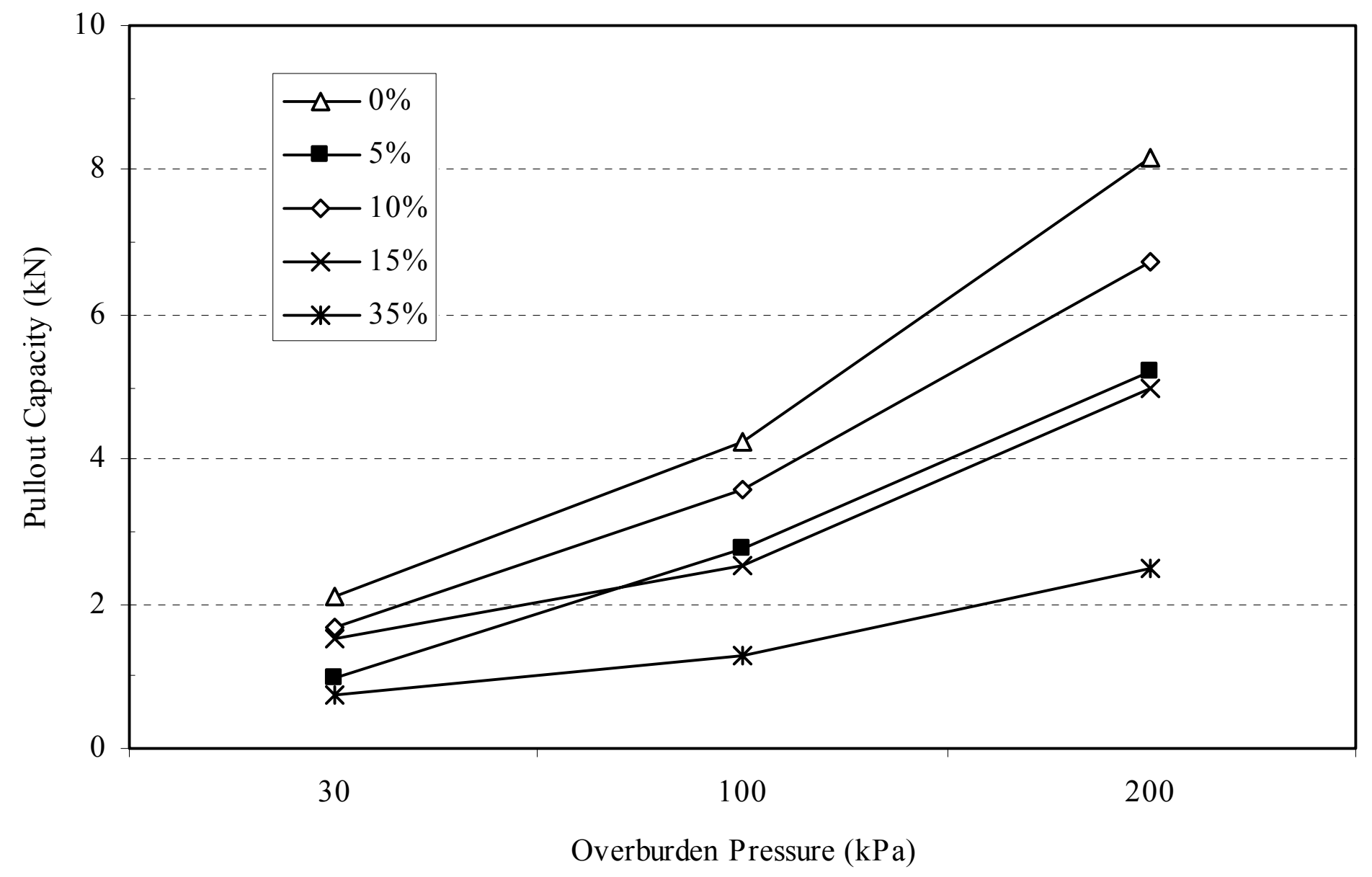

Figure 4-24 Undrained Pullout Capacity 


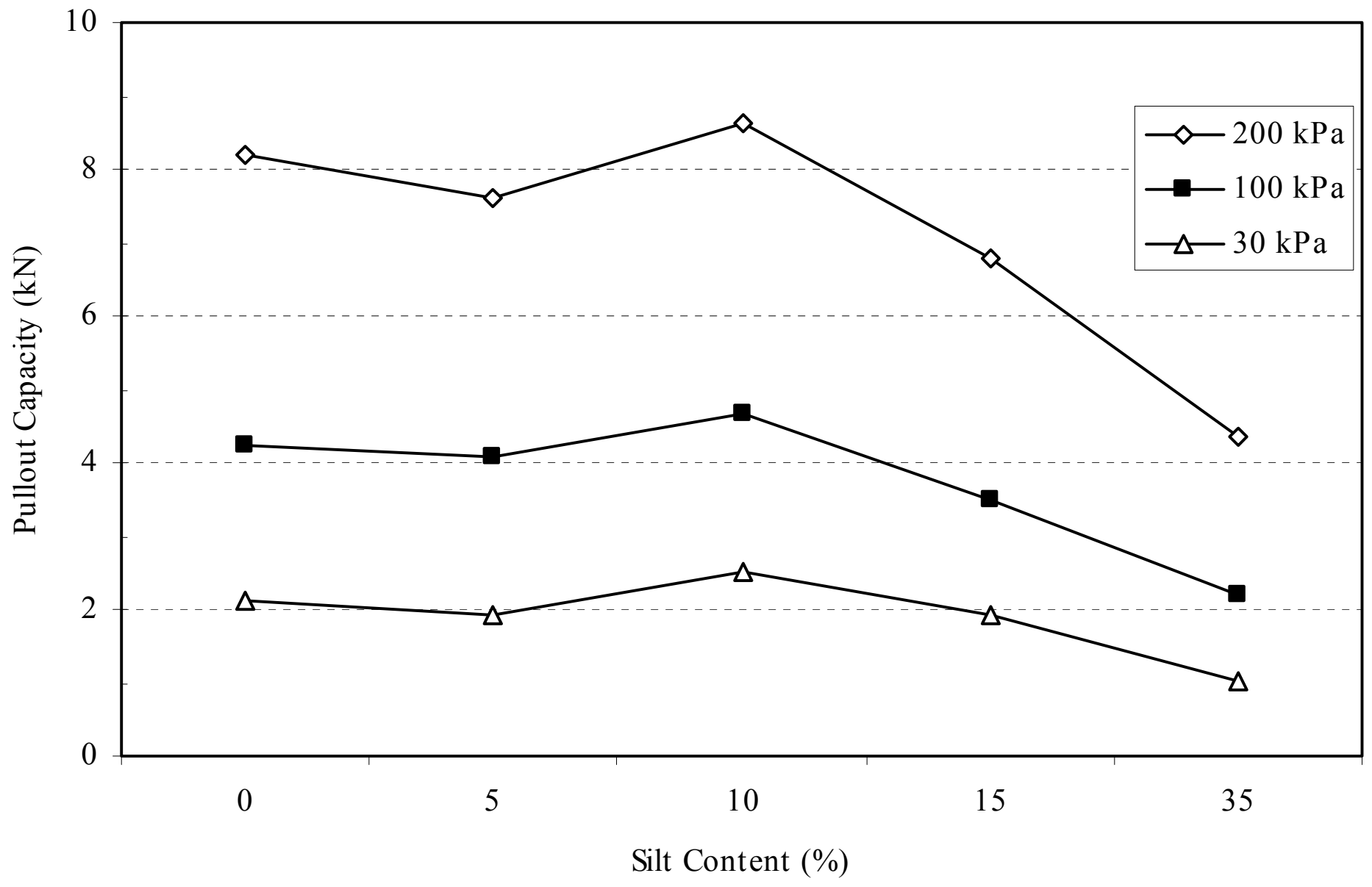

Figure 4-25 Drained Pullout Capacity 


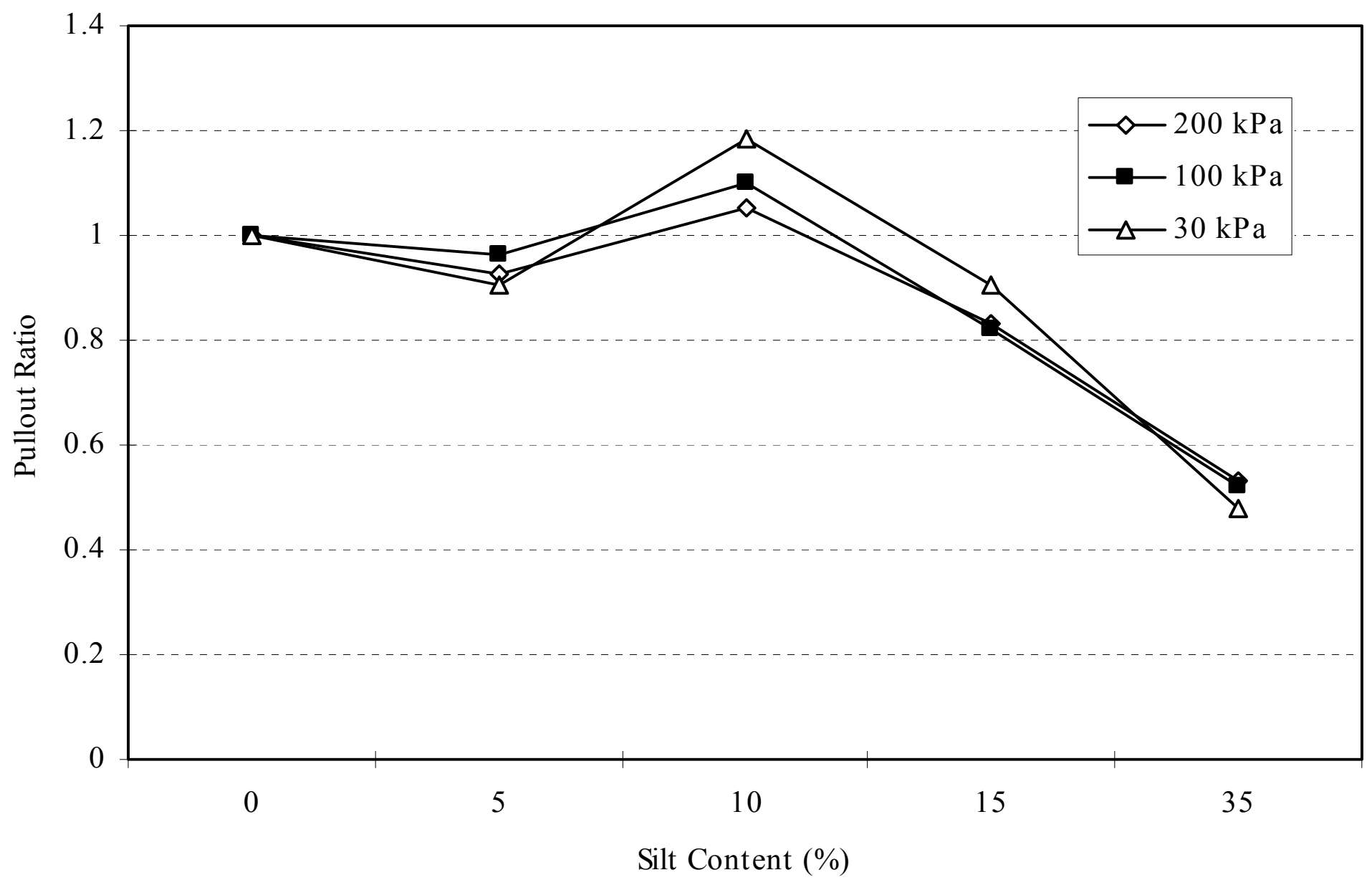

Figure 4-26 Relative Drained Pullout Capacity 


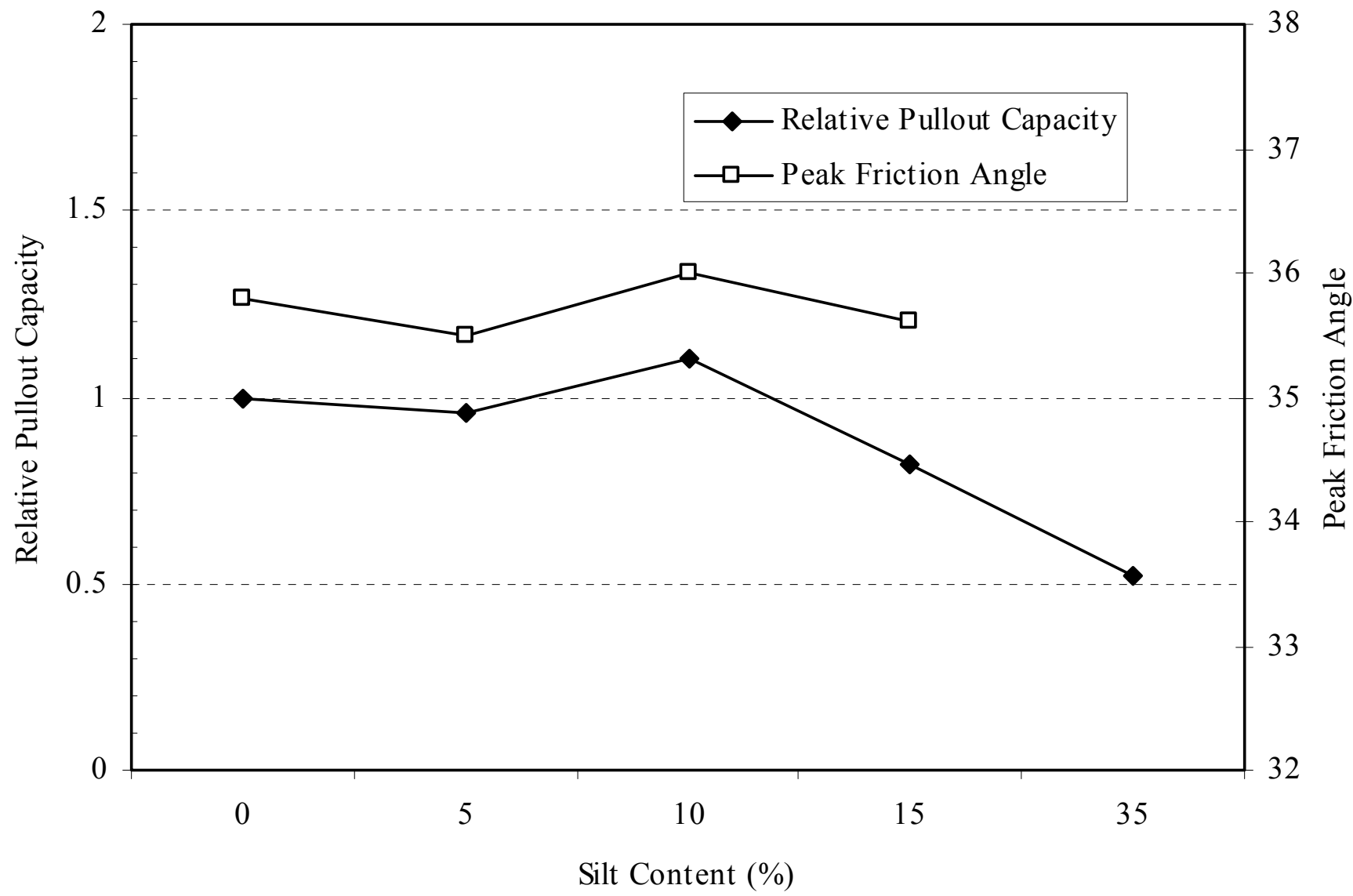

Figure 4-27 Correlation between Peak Friction Angle and Relative Drained Pullout Capacity 


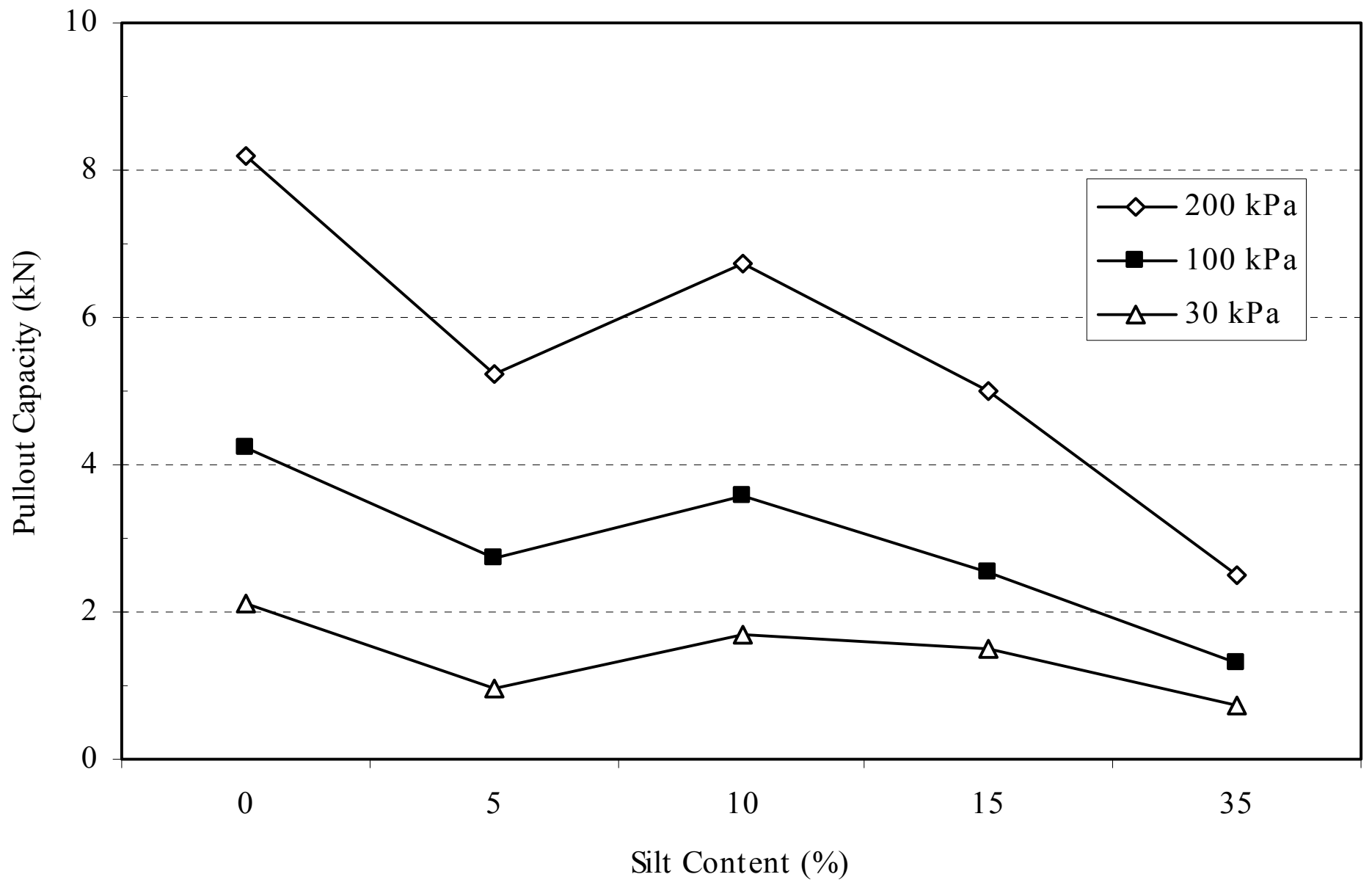

Figure 4-28 Undrained Pullout Capacity 


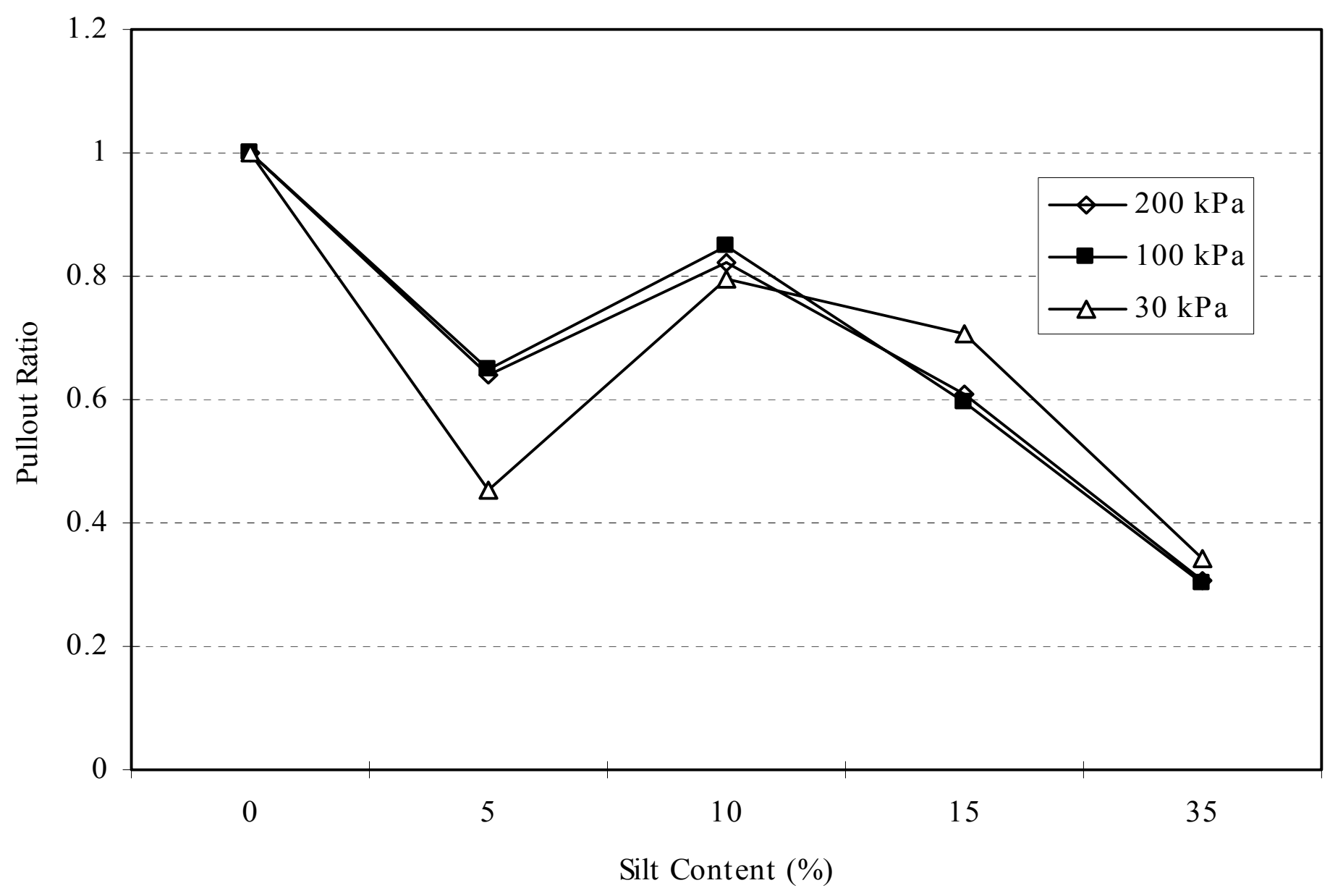

Figure 4-29 Relative Undrained Pullout Capacity 


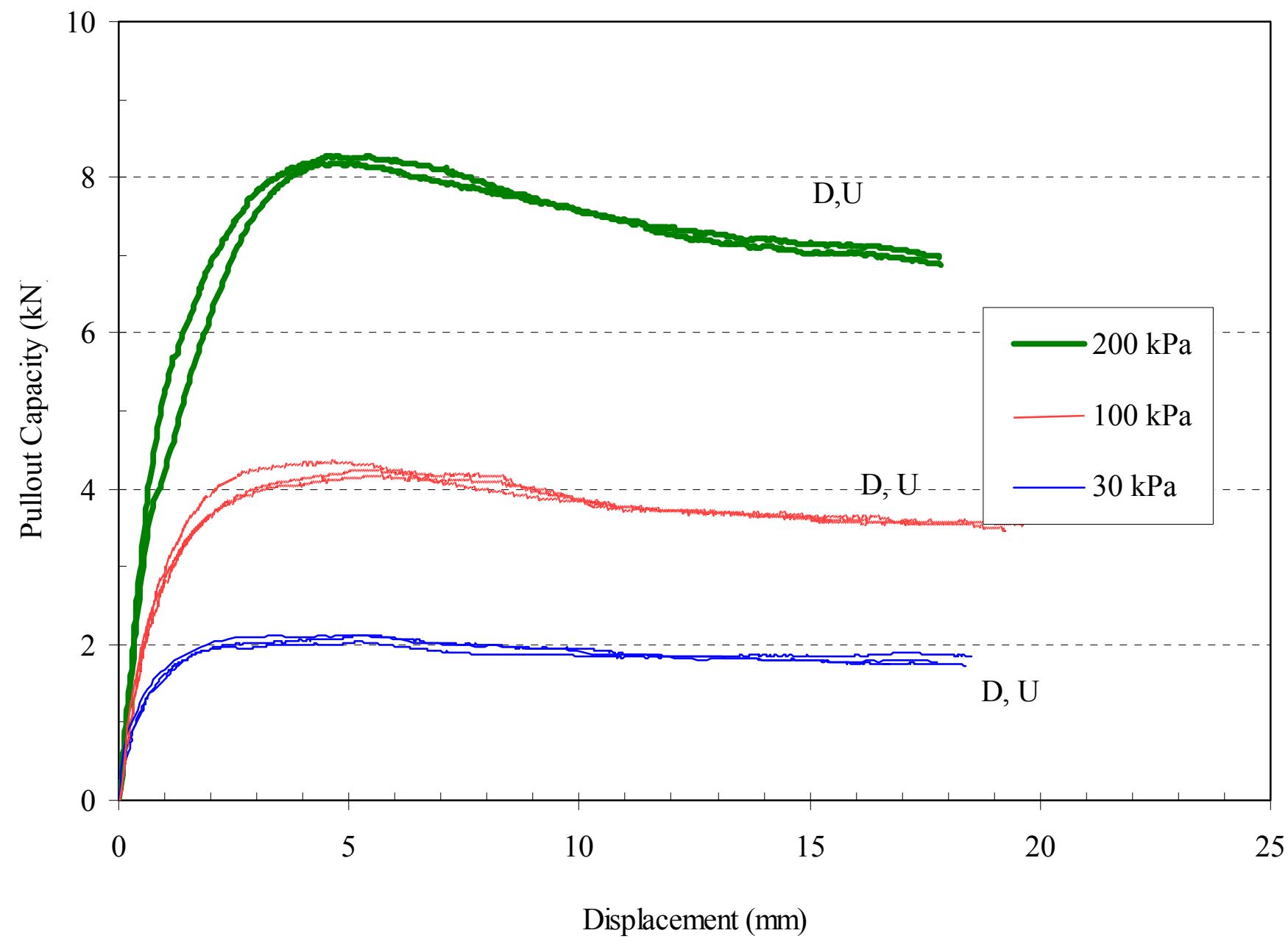

Figure 4-30 Comparison of Drained and Undrained Pullout Test Results for Clean Sand 


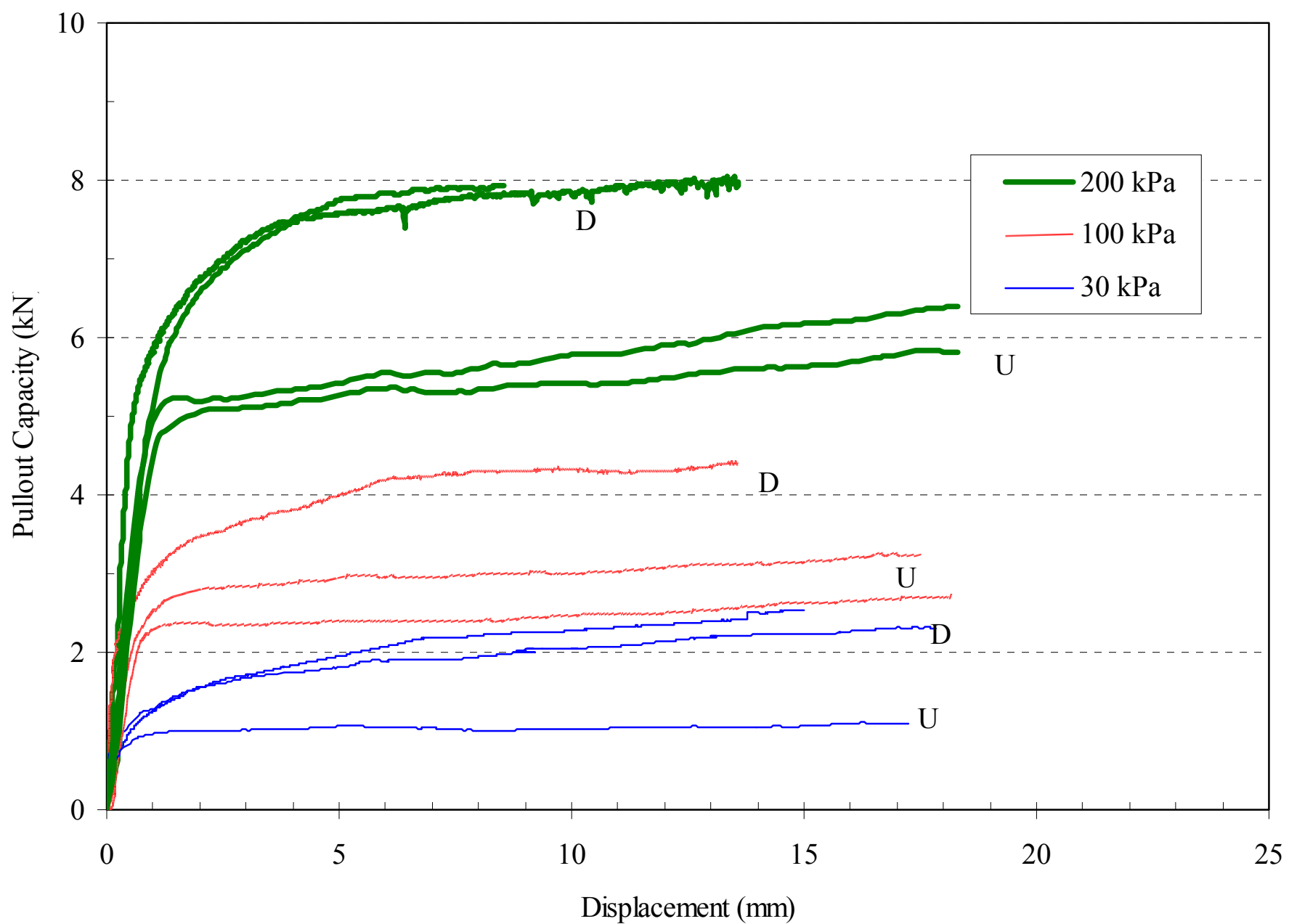

Figure 4-31 Comparison of Drained and Undrained Pullout Test Results for 5\% Silty Sand 


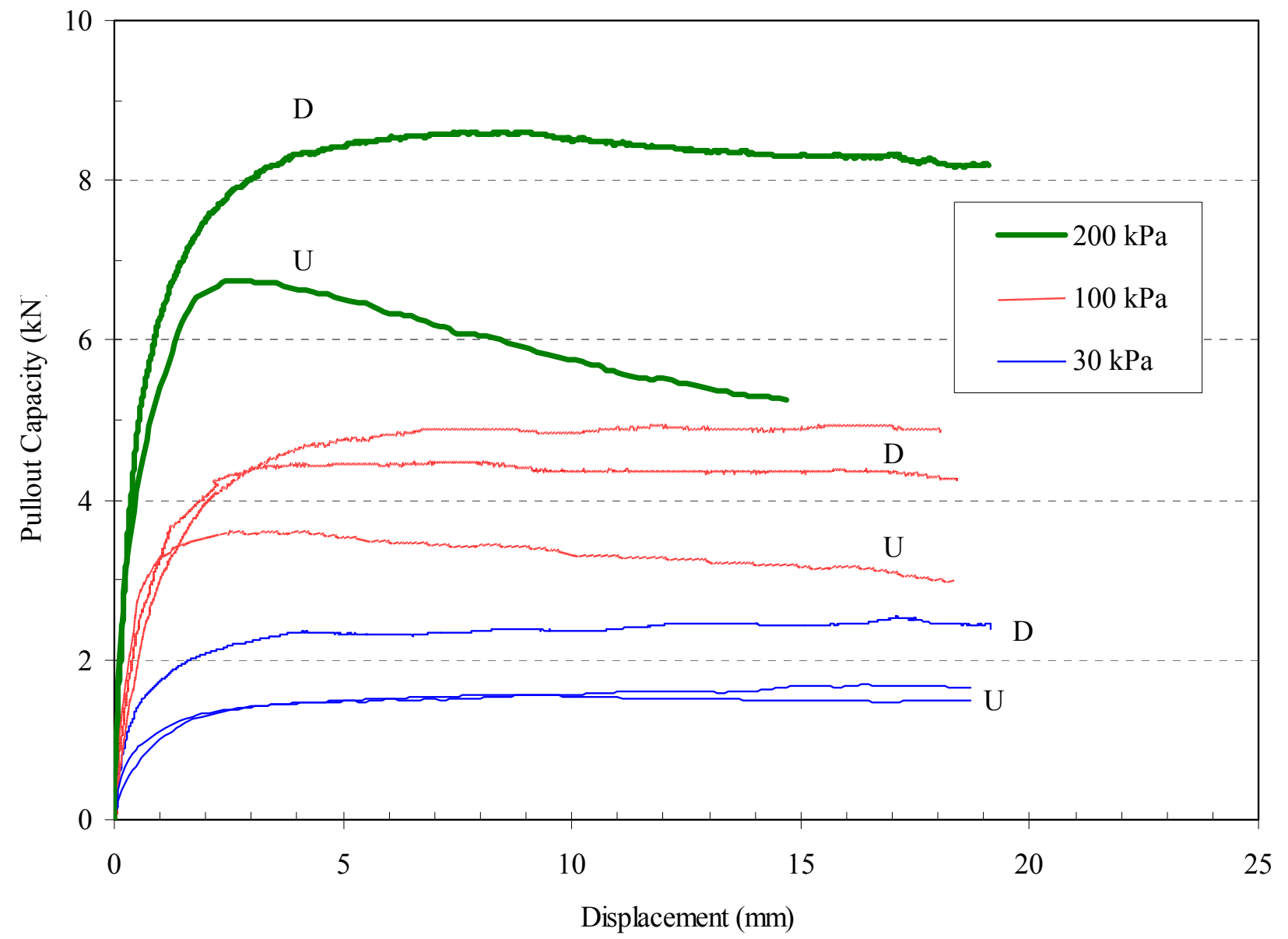

Figure 4-32 Comparison of Drained and Undrained Pullout Test Results for 10\% Silty Sand 


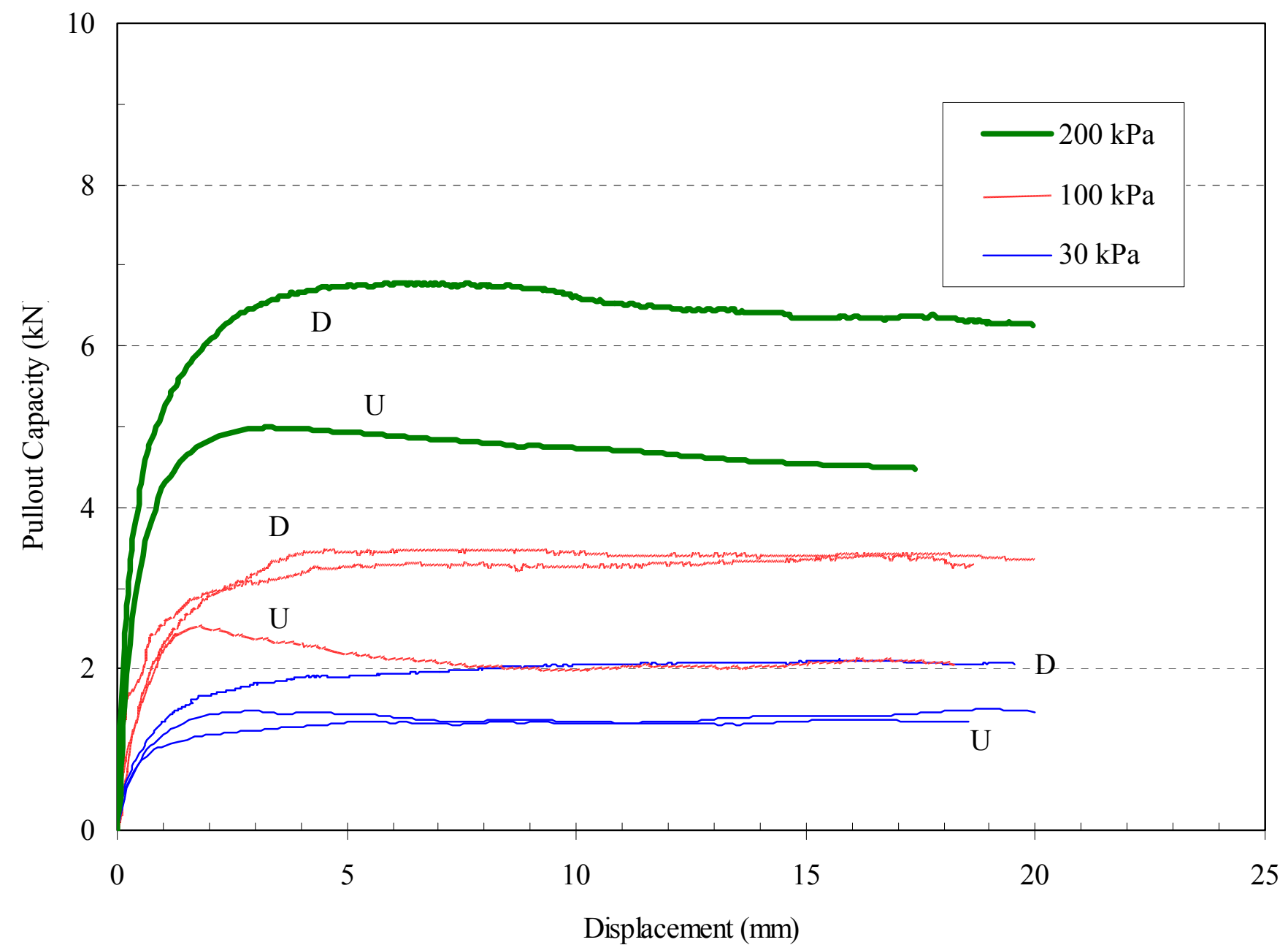

Figure 4-33 Comparison of Drained and Undrained Pullout Test Results for 15\% Silty Sand 


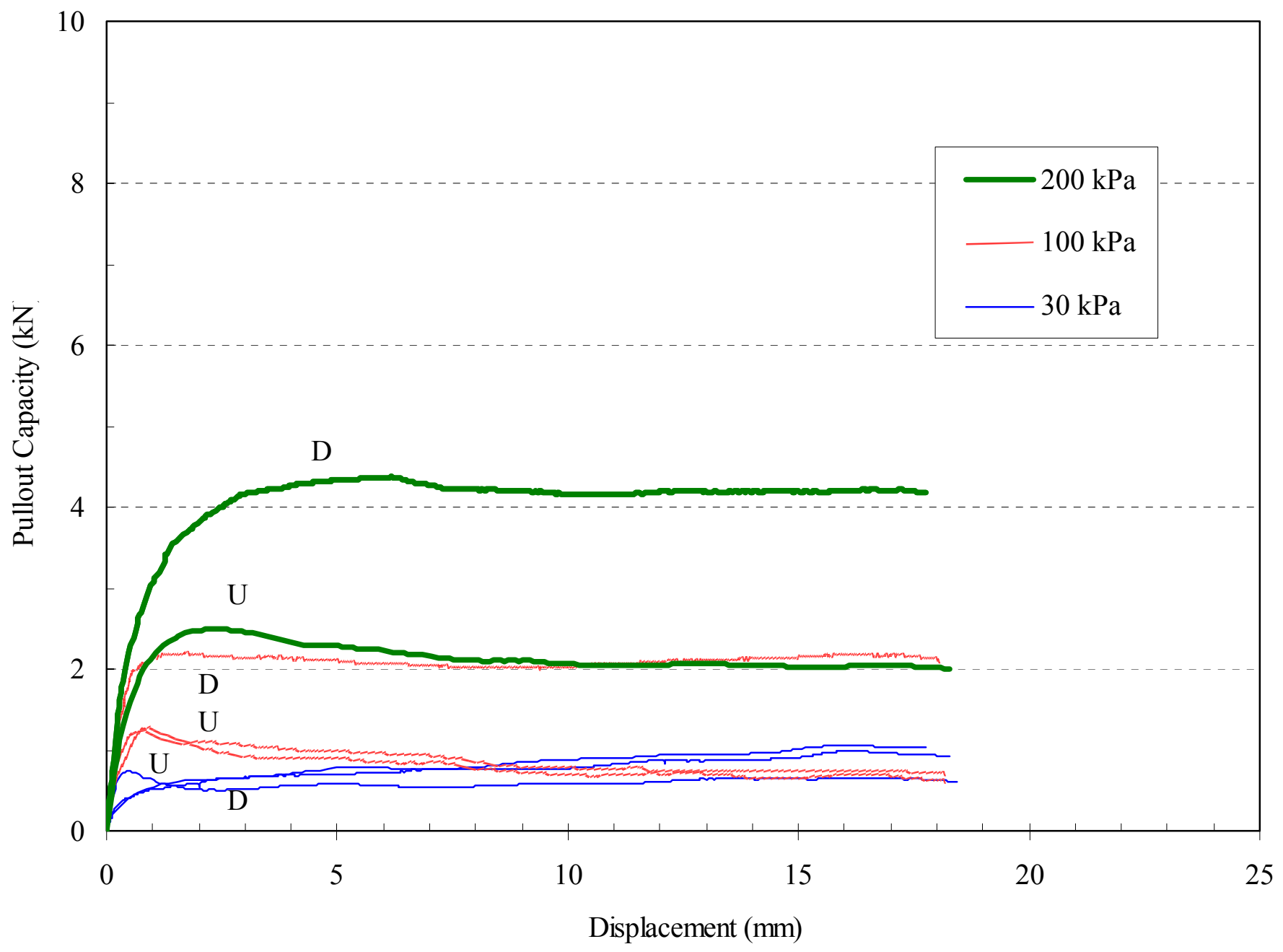

Figure 4-34 Comparison of Drained and Undrained Pullout Test Results for 35\% Silty Sand 


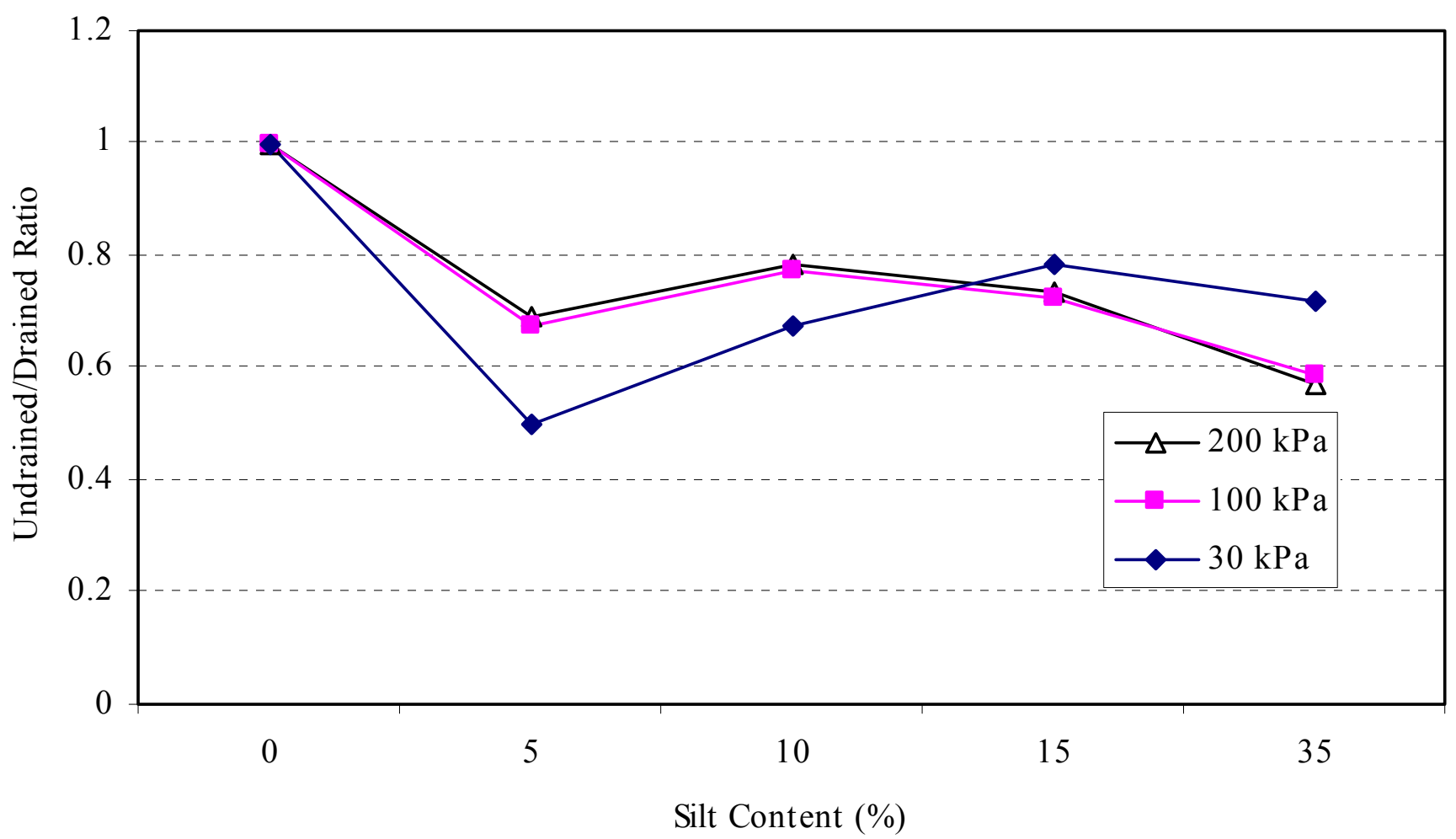

Figure 4-35 Undrained to Drained Pullout Capacity Ratio 


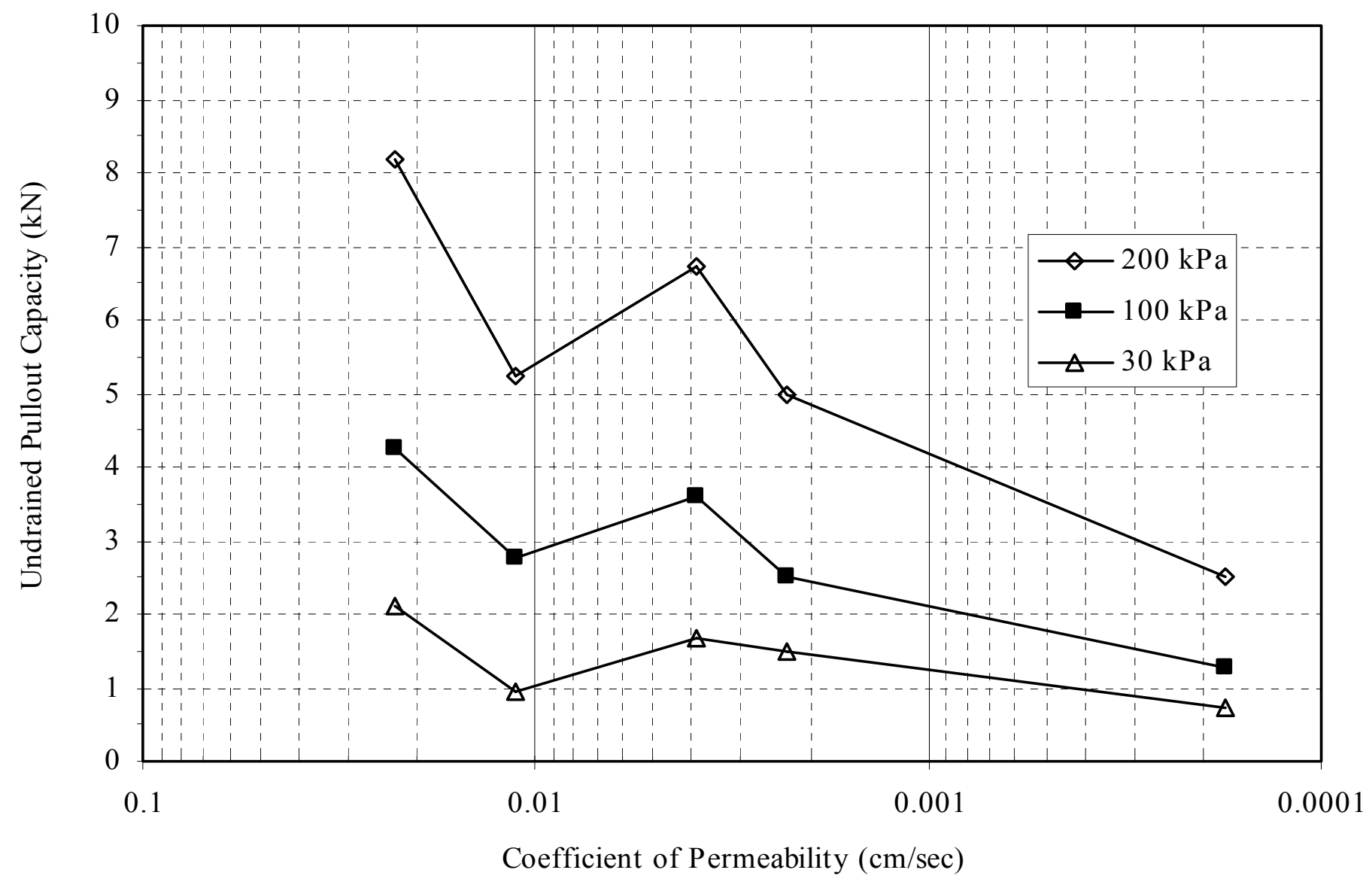

Figure 4-36 Undrained Pullout Capacity versus Permeability 


\section{CHAPTER 5. NUMERICAL ANALYSIS}

\subsection{Introduction}

The pullout capacity of a steel inclusion in silty sand for drained and undrained conditions is presented in Chapter 4. For undrained conditions, pore pressures are generated within the soil as it is sheared during pullout. The pullout capacity of the steel reinforcement depends on the friction at the interface with the soil, which in turn depends on the normal effective stress acting on the inclusion. With increasing pore pressures, the normal effective stress decreases and the pullout capacity decreases. As the pore pressures generated dissipate, the effective stress increases and the pullout capacity increases; thus the dissipation rate of pore pressures is an important factor. The permeability and the distance from a given point in the soil to the closest drainage boundary govern the time that will take for the pore pressures to dissipate. The time for pore pressure dissipation defines whether drained or undrained conditions occur. For example, if a section of the wall is submerged during flooding, undrained conditions within the soil will be generated if the water level decreases at a rate faster than the pore pressures inside the wall are dissipated; similarly, drained conditions will be attained if the water level drawdown occurs at a rate slower than pore pressure dissipation. 
The size of the pullout box used for the experiments is quite small compared to the actual size of a MSE wall. The difference in size will require different times for pore pressure dissipation. In the experiments the drainage distance from any point within the soil to a drainage boundary (top and front in the pullout box) is much smaller than in a MSE wall (top and front also), and thus dissipation of excess pore pressure will occur faster. Undrained conditions may be maintained close to the end of the reinforcement while drained conditions are obtained near the facing.

The effect of the two factors: permeability and reinforcement length, is investigated in this chapter. The Finite Element (FE) code, ABAQUS (1999) is used for the investigation. ABAQUS is a general-purpose FE software that is very well suited for this analysis since it can incorporate a coupled mechanical analysis with pore pressure dissipation in poroelastic materials.

\subsection{Finite Element Modeling}

\subsubsection{Dimensions of the model}

The dimensions of the model used for the numerical analysis have been obtained from the Minnow Creek Wall (Runser, 1999), which is $17 \mathrm{~m}$ tall, so far the tallest MSE wall built in Indiana (see Figure 5-1). As shown in the figure, the longest reinforcement is $15.55 \mathrm{~m}$, which is placed at the bottom of the wall. The reinforcements are spaced vertically at 
$0.75 \mathrm{~m}$. With a rapid drawdown, dissipation of pore pressures occurs both upwards and towards the facing of the wall.

Because of the constant spacing of the reinforcement, the volume of wall that is modeled is the one comprised between two layers of reinforcement. Based on the wall dimensions and drainage conditions, a basic model for the analysis is taken as $16 \mathrm{~m}$ long and $0.75 \mathrm{~m}$ high with a vertical load corresponding to the weight of the $17 \mathrm{~m}$ backfill, as shown in Figure 5-2. In addition, the length of the reinforcement is varied to investigate the effect of wall size; this is discussed later in Section 5.2.7.

\subsubsection{Boundary conditions}

Figure 5-3 shows the boundary conditions of the finite element model. Both left and right sides of the model are supported by rollers allowing vertical displacements. Horizontal displacements are not allowed on the sides of the model to reproduce the initial geostatic, $\mathrm{k}_{\mathrm{o}}$, loading conditions. Horizontal displacements are allowed at the bottom of the model by rollers and vertical displacements are constrained. 


\subsubsection{Meshing}

Since the purpose of the analysis is to investigate the dissipation rate of pore pressures, only the soil is modeled. The size of the soil element ranges from $0.075 \mathrm{~m}$ to $0.25 \mathrm{~m}$ horizontal, and $0.075 \mathrm{~m}$ vertical depending on the total length of the model. The total number of elements is about 2000. The finite element mesh is shown in Figure 5-3.

\subsubsection{Element selection}

Retaining walls are structures that can be considered very long in the dimension perpendicular to the cross section; thus plane strain conditions can be assumed. Because of that, all elements in the model are 8-node biquadratic plane strain elements, with pore pressure at the corner nodes (CPE8P, from the ABAQUS element library). All nodes have two degrees of freedom: horizontal translation and vertical displacements; the corner nodes have pore pressures as an additional degree of freedom.

\subsubsection{Initial stresses}

The numerical analysis is composed of two stages. In the first stage, the initial loading conditions are applied. This is done by imposing a vertical stress to the top of the mesh, corresponding to the self-weight of the $17 \mathrm{~m}$ backfill. In this stage, $\mathrm{k}_{\mathrm{o}}$ conditions are 
reached since lateral movements are prevented and no excess pore pressures are generated (i.e. the vertical, $\sigma_{\mathrm{v}}$, and horizontal stresses, $\sigma_{\mathrm{h}}=\mathrm{k}_{\mathrm{o}} \sigma_{\mathrm{v}}$ are effective stresses). The soil is fully saturated and the water level is at the top of the mesh. In the second stage, the pore pressures at the top and left hand side of the mesh are set to zero (i.e. rapid drawdown with drainage along these two sides), and pore pressures begin to dissipate as drainage of the water occurs through the top and left side of the model. Consolidation is allowed until 95\% of dissipation of pore pressure is obtained within the entire mesh.

\subsubsection{Material properties}

The soil is modeled as an elastic material, with the properties of the clean sand used in the pullout tests. Among them, Young's Modulus and Poisson's ratio are estimated 30 $\mathrm{MPa}$ and 0.25 , respectively. The coefficient of lateral earth pressure is 0.4 and the initial void ratio is 0.52 . Table $5-1$ summarizes the material properties.

Table 5-1 Material Properties of the Soil

\begin{tabular}{|c|c|c|c|}
\hline $\begin{array}{c}\text { Young's Modulus } \\
(\mathrm{MPa})\end{array}$ & Poisson's Ratio & Coefficient of & Initial Void Ratio \\
\hline 30 & & Lateral Earth Pressure & \\
\hline & 0.25 & 0.4 & 0.52 \\
\hline
\end{tabular}




\subsubsection{Factors investigated}

Two factors are investigated in this analysis: (1) permeability; and (2) length of reinforcement. The coefficients of permeability selected for the analysis range from $10^{-1}$ $\mathrm{cm} / \mathrm{sec}$ to $10^{-4} \mathrm{~cm} / \mathrm{sec}$, which cover the range of permeabilities of the material tested (See Chapter 4). A total of 5 permeabilities are analyzed: $10^{-1}, 2.27 \times 10^{-2}, 10^{-2}, 10^{-3}$, and $10^{-4}$ $\mathrm{cm} / \mathrm{sec}$, and six reinforcement lengths: $0.75,2,4,8,12$, and $16 \mathrm{~m}$. The height of the wall is kept constant at $0.75 \mathrm{~m}$, which is the standard reinforcement spacing used in practice. Table 5-2 shows the values of the factors investigated.

Table 5-2 Factors Investigated

\begin{tabular}{|c|c|}
\hline Coefficient of Permeability $(\mathrm{cm} / \mathrm{sec})$ & Length of Reinforcement $(\mathrm{m})$ \\
\hline $10^{-1}$ & 0.75 \\
$2.27 \times 10^{-2}$ & 2 \\
$10^{-2}$ & 4 \\
$10^{-3}$ & 8 \\
$10^{-4}$ & 12 \\
& 16 \\
\hline
\end{tabular}




\subsection{Preliminary Analysis}

A preliminary analysis is performed to verify the model. A comparison between a 1-D analysis with ABAQUS and closed-form solutions is made. The FE model is the same model described in previous sections, except that the model has a unit width and dissipation of pore pressure occurs through the top boundary only.

The closed-form solution is based on Terzaghi's theory of 1-D consolidation. The time factor $\left(\mathrm{T}_{\mathrm{v}}\right)$ for a certain degree of consolidation $(\mathrm{U})$ is obtained using Equation 5-1. For the analysis, the target degree of consolidation is $95 \%$, and consequently, the time factor is 1.129 ( i.e. $\mathrm{T}_{\mathrm{v}}=1.129$ ).

$$
T_{v}=1.781-0.933 \log (100-U \%) \quad \text { for } U>60 \%
$$

Equation 5-2 is used to obtain $t_{95}$, the time required for $95 \%$ of consolidation. With the material properties, $\mathrm{c}_{\mathrm{v}}=3.67 \mathrm{~m} / \mathrm{sec}^{2}$, and with the model geometry, $\mathrm{H}_{\mathrm{dr}}=0.75 \mathrm{~m}$. This results in $t_{95}=0.17$ seconds.

$$
\begin{aligned}
& T_{95}=\frac{c_{v} \cdot t_{95}}{H_{d r}{ }^{2}}(\text { Eq. } 5-2) \\
& \text { where, } \mathrm{c}_{\mathrm{v}}=\text { coefficient of consolidation } \\
& \mathrm{t}_{95}=95 \% \text { consolidation time } \\
& \mathrm{H}_{\mathrm{dr}}=\text { average longest drainage path during consolidation }
\end{aligned}
$$


With ABAQUS 0.185 seconds are needed for 95\% consolidation, as shown in Figure 5-4. The difference is about $10 \%$, which is small enough for practical purposes.

\subsection{Analysis of Consolidation Time}

The pore pressures will dissipate at different rates throughout the model depending on the distance to a drainage boundary; the nearer to the boundary, the more quickly the pore pressures dissipate. The point at the bottom right corner of the mesh (Figure 5-3) is taken as a reference to evaluate the dissipation of the pore pressures. This is the farthest point from the drainage boundaries, and thus if $95 \%$ of pore pressures have dissipated at this point, the dissipation of excess pore pressures will be smaller in the rest of the model.

\subsubsection{Pore pressure distribution}

To investigate the dissipation and distribution of pore pressures throughout the model, detailed plots are presented for one particular case. The case corresponds to a soil with permeability $10^{-2} \mathrm{~cm} / \mathrm{sec}$ and reinforcement length $4 \mathrm{~m}$. Figure 5-5 (a) shows the pore pressure distributions at the beginning of the analysis (i.e. end of stage 1 or initial/geostatic conditions). As one can observe in the figure, the pore pressure distribution is linear with depth (i.e. hydrostatic), with a maximum of $7.36 \mathrm{kPa}$, which corresponds to a column of water of $0.75 \mathrm{~m}$. Figures 5-5 (b) to (d) show the pore pressure 
distribution with time. Note that in the figures the top and left boundaries are drainage boundaries where the pore pressures are zero. The plots show that dissipation occurs very rapidly on the left hand side and quickly progresses to the bottom and right sides of the model. After only 0.2 seconds, $60 \%$ of consolidation has already occurred at the reference point (bottom right corner of the mesh). $95 \%$ of pore pressure dissipation occurs at 1.9 seconds. The plots also show how the pore pressure contours adapt to the shape of the boundaries: the vertical contours are parallel to the left side and the horizontal are parallel to the top. This indicates how dissipation progresses towards the drainage boundaries.

\subsubsection{Effect of permeability}

Consolidation time increases as the permeability decreases. Figure 5-6 shows results of 95\% consolidation time for different reinforcement lengths and permeabilities. Permeability has a dramatic effect on the time it takes for the pore pressures to dissipate. For permeabilities larger than $10^{-2} \mathrm{~cm} / \mathrm{sec}$ dissipation of pore pressures is almost immediate. As the permeability decreases below $10^{-2} \mathrm{~cm} / \mathrm{sec}$, the time required for $95 \%$ consolidation increases dramatically. 


\subsubsection{Effect of reinforcement length}

Figure 5-6 shows that the length of reinforcement does not affect much the time for consolidation for permeabilities above $10^{-2} \mathrm{~cm} / \mathrm{sec}$. For permeabilities between $10^{-2}$ $\mathrm{cm} / \mathrm{sec}$ and $10^{-3} \mathrm{~cm} / \mathrm{sec}$ the results are independent of the reinforcement length except for the case of reinforcement length $0.75 \mathrm{~m}$. This indicates that for larger reinforcements the drainage path is mostly towards the upper boundary, which is located $0.75 \mathrm{~m}$ above the reference point. As expected, the consolidation time decreases as drainage increases in the two directions. For permeabilities lower than $10^{-3} \mathrm{~cm} / \mathrm{sec}$, the consolidation time increases and the influence of the reinforcement length is larger.

\subsection{Conclusions}

It has been found from the numerical analyses that the dissipation of pore pressures is very fast for permeabilities larger than $10^{-2} \mathrm{~cm} / \mathrm{sec}$. Because of the quick dissipation, it is expected that the pullout capacity for soils with permeability larger than $10^{-2} \mathrm{~cm} / \mathrm{sec}$ will not change much with drainage conditions. Among the soils tested (Chapter 4), only clean sand and $5 \%$ silty sand have higher or similar permeabilities. For permeability $10^{-3}$ $\mathrm{cm} / \mathrm{sec}$, which corresponds to $10 \%$ and $15 \%$ silty sand (Chapter 4 ), the dissipation of pore pressures becomes slower, and it significantly becomes very slow for permeability $10^{-4}$ $\mathrm{cm} / \mathrm{sec}(35 \%$ silty sand, Chapter 4$)$. Thus for soils with permeability lower than $10^{-3}$ 
$\mathrm{cm} / \mathrm{sec}$ the undrained pullout capacity should be much smaller than the drainage pullout capacity.

It has been observed in Chapter 4 that the undrained pullout capacities for the clean sand are the same as the drained pullout capacities, which indicates that excess pore pressures do not have any influence. As the silt percentage increases, the permeability decreases, and the time for pore pressure dissipation increases; it is expected then, and it is confirmed by the experiments, that as the silt percentage increases the undrained pullout capacity decreases relative to the drained pullout capacity. 


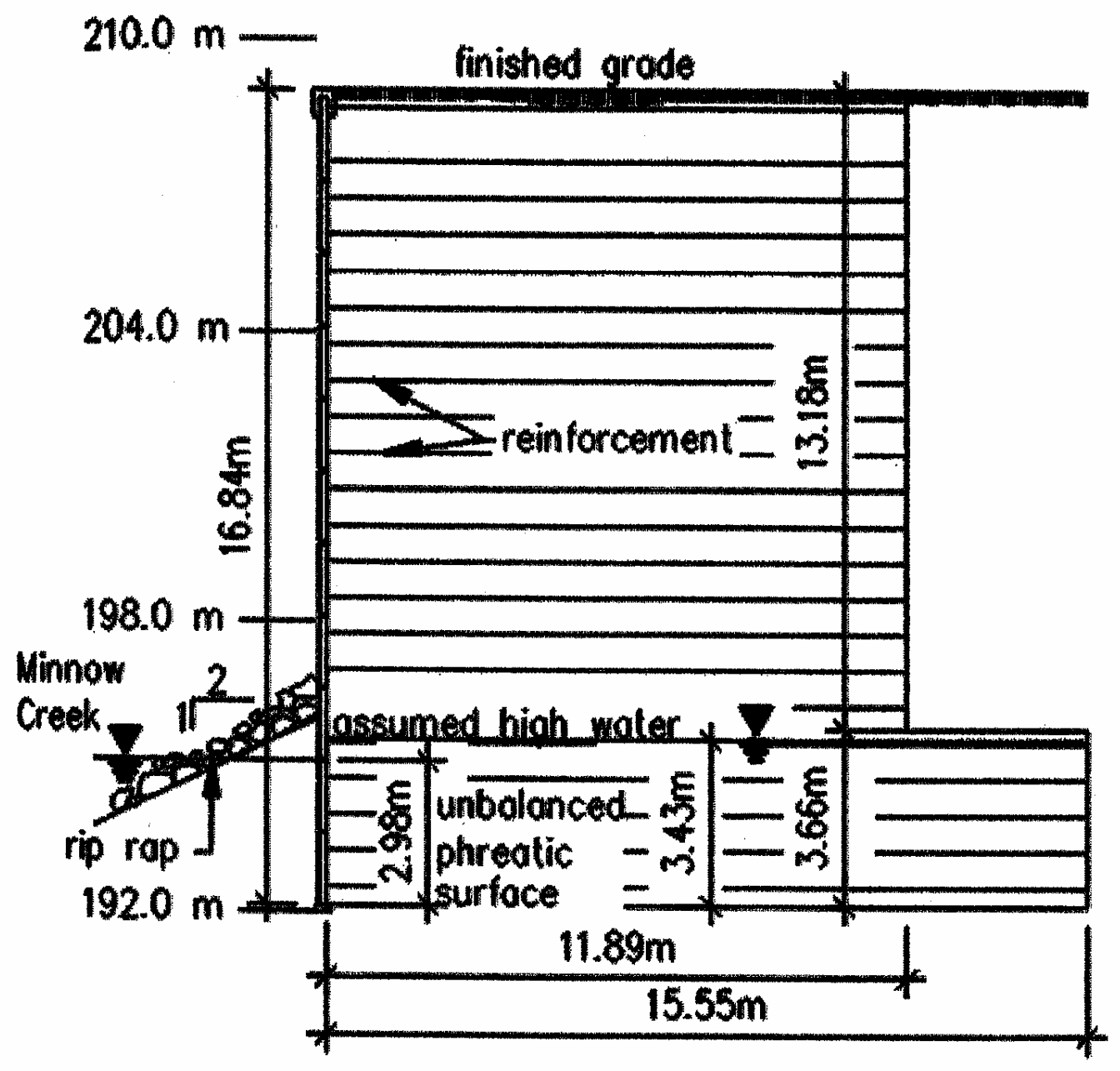

Figure 5-1 Minnow Creek Wall (After Runser, 1999) 


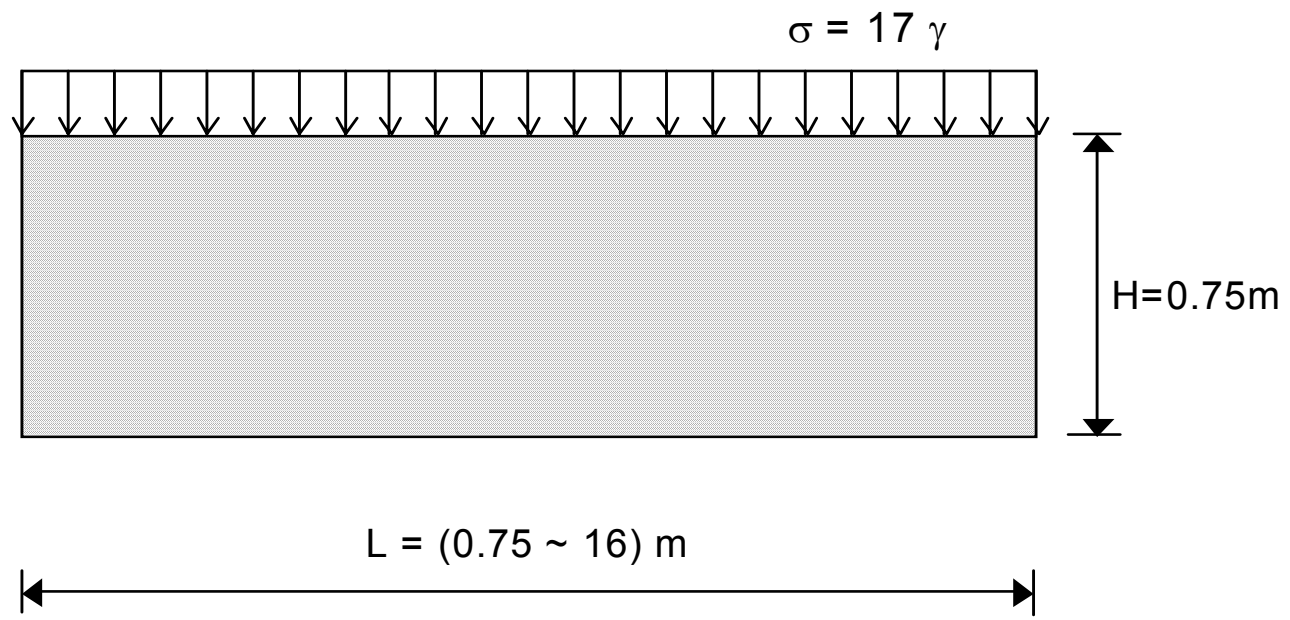

Figure 5-2 Dimensions of the Model
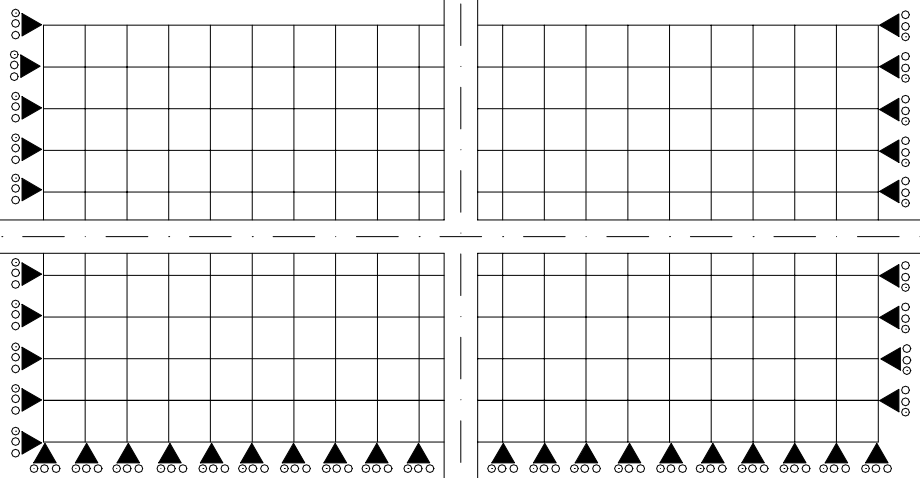

Figure 5-3 Boundary Conditions and F.E. Mesh 


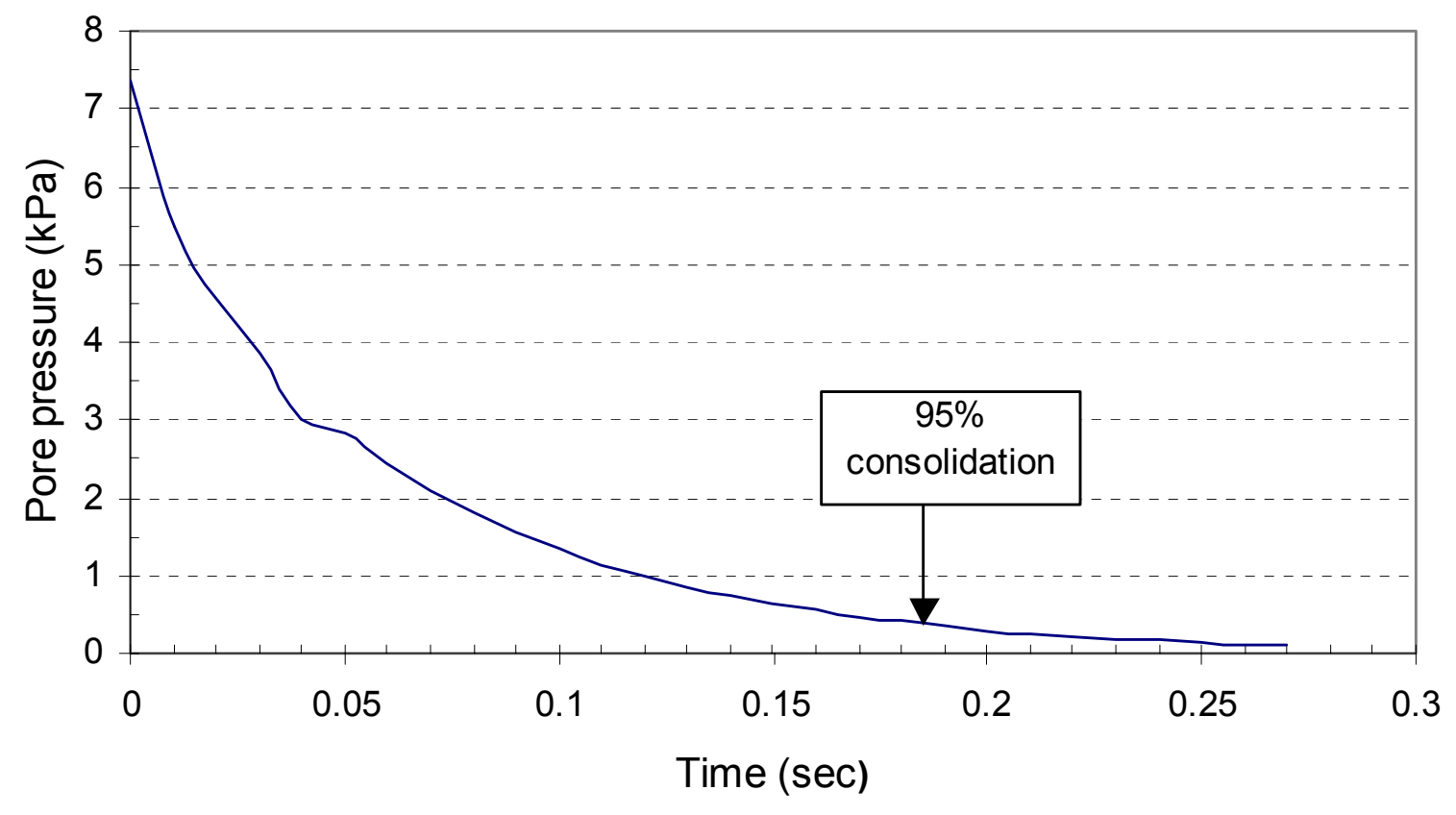

Figure 5-4 Result of Preliminary Analysis for 1-D Consolidation 


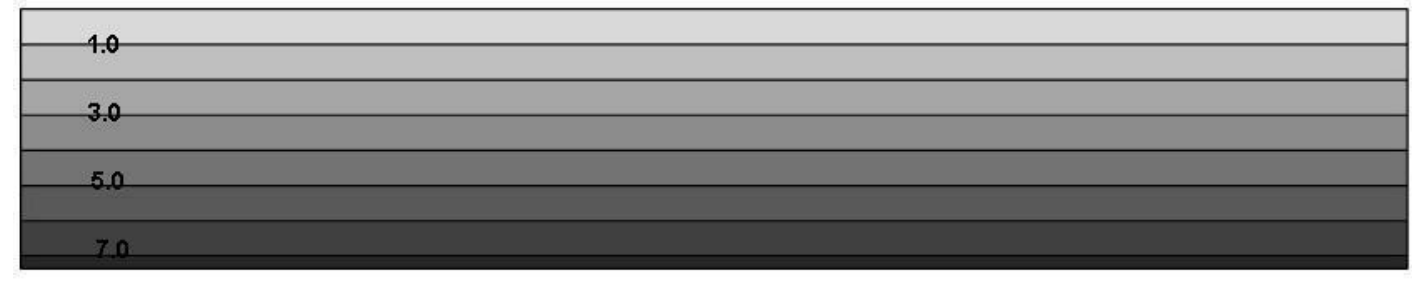

(a)

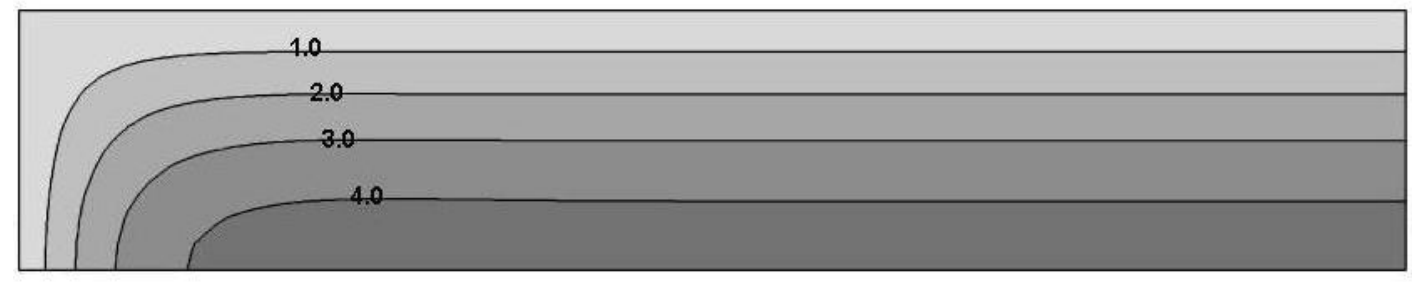

(b)

Figure 5-5 Pore Pressure Distribution; (a) $t=0 \mathrm{sec}$, (b) $t=0.2 \mathrm{sec}$ 


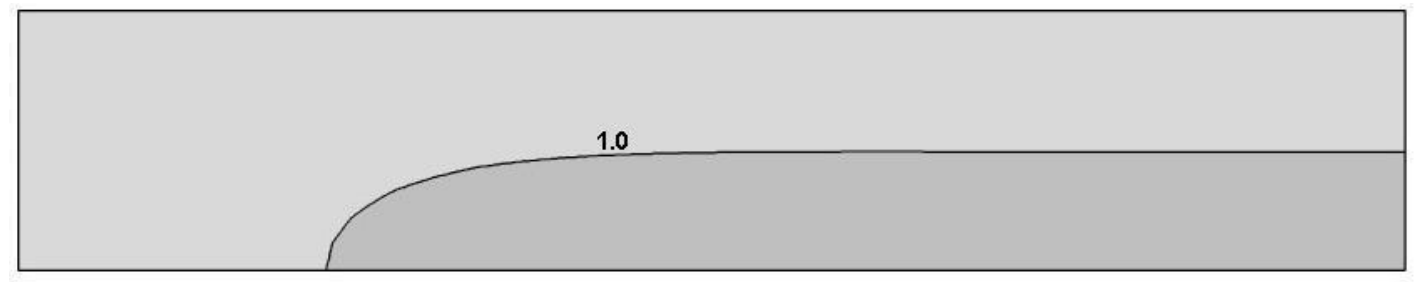

(c)

(d)

Figure 5-5(Cont'd) Pore Pressure Distribution; (c) $t=1.0 \mathrm{sec},(d) t=1.9 \mathrm{sec}$ 


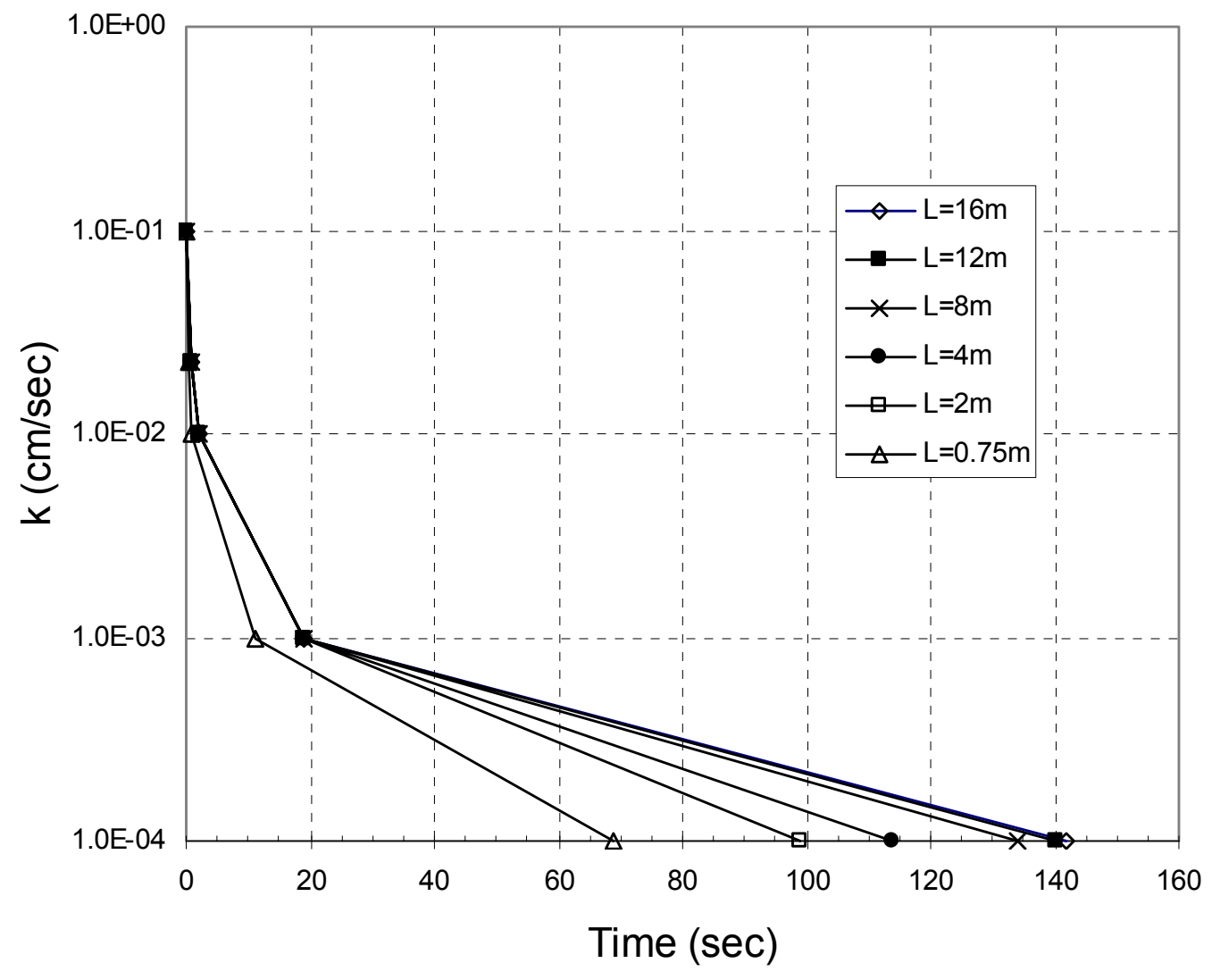

Figure 5-6 Results of Numerical Analysis;

Effect of Permeability and Reinforcement Length 


\section{CHAPTER 6. CONCLUSIONS AND RECOMMENDATIONS}

The main purpose of this research is to define how pullout capacity of reinforced soil is affected by drainage conditions. A series of laboratory pullout tests are performed with granular soil and a steel inclusion, varying material type, overburden pressure, and drainage conditions: drained undrained. In addition, a series of preliminary laboratory tests such as proctor tests, compaction tests and permeability tests are performed prior to the pullout tests. Numerical analyses are also conducted to investigate effects of reinforcement length and permeability on the undrained pullout capacity. This chapter presents a summary of the findings, conclusions drawn from the test results, and recommendations. 


\subsection{Summary}

\subsubsection{Test equipment}

The test setup for the pullout tests is as follows:

(1) A soil chamber and water chamber. The dimensions of the soil chamber are $1.0 \mathrm{~m}$ long, $0.4 \mathrm{~m}$ wide, and $0.5 \mathrm{~m}$ high and the water chamber is $0.5 \mathrm{~m}$ long, $0.4 \mathrm{~m}$ wide and $0.5 \mathrm{~m}$ high. The dimensions of the entire pullout box are $1.5 \mathrm{~m}$ long, $0.4 \mathrm{~m}$ wide and $0.5 \mathrm{~m}$ high (Figure 3-1). The interior walls of the pullout box are lubricated with grease to minimize frictional resistance.

(2) Two external water chambers supply water to the pullout box to maintain full saturation conditions inside the soil chamber.

(3) An air bag placed on top of the soil is pressurized to apply the desired confinement stress to the soil.

(4) A steel inclusion, $1.0 \mathrm{~m}$ long, $5 \mathrm{~cm}$ wide, and $3 \mathrm{~mm}$ thick is embedded $(0.75 \mathrm{~m}$ of embedment) in the middle of the soil. The steel inclusion is connected to the loading frame through a shaft. A load cell placed inside the water chamber is attached to the shaft and to the steel inclusion grip system.

(5) The pullout tests are performed by pulling out the steel inclusion embedded in the compacted soil while the overburden pressure is applied. Different overburden pressures are achieved by applying different air pressures to the air bag. For the 
undrained tests the soil is saturated with water. The inclusion is pulled out relatively slowly for the drained tests $(1 \mathrm{~mm} / \mathrm{min})$, and relatively rapidly for the undrained tests $(10 \mathrm{~mm} / \mathrm{min})$.

(6) A data acquisition system is used to read and store the following data: pullout load, pullout displacement, outside water pressure, inside pore water pressure, and overburden pressure.

\subsubsection{Preliminary laboratory tests}

A series of laboratory tests are performed to investigate the properties of the soil and include: Proctor tests, compaction tests, and permeability tests.

(1) The types of soil used in this research are sand (Ottawa sand) and silty sands with silt contents: 5, 10, 15, and $35 \%$. The peak friction angles of the soils are (Salgado et. al., 2000): $35.8^{\circ}$ (clean sand), $35.5^{\circ}(5 \%), 36.0^{\circ}(10 \%)$, and $35.6^{\circ}$ (15\% silty sand).

(2) Proctor tests are performed on every soil to determine the maximum dry density. The soil in the pullout tests are compacted to $95 \%$ Proctor density except clean sand, which is compacted to $100 \%$ Proctor. The results are presented in Table 4-2 and Figures 4-2 to 4-6.

(3) Compaction tests are performed to define how much compaction energy is required to obtain the target density of the soil (95\% Proctor density). The results are presented in Figures 4-8 to 4-11. 
(4) Permeability tests are performed to determine the correlation between permeability and undrained pullout capacity based on dissipation of excess pore pressures. The coefficients of permeability range from $2.27 \times 10^{-2}$ (clean sand) to $1.75 \times 10^{-4} \mathrm{~cm} / \mathrm{sec}$ (35\% silty sand). The results are shown in Table 4-3 and Figure 4-12.

\subsubsection{Pullout tests}

The pullout tests are performed for different material (clean sand, 5, 10, 15, and $35 \%$ silty sand), different overburden pressures $(30,100$, and $200 \mathrm{kPa})$, and different drainage conditions (drained and undrained). The following is observed:

(1) Effect of silt: Drained and undrained pullout capacities decrease from clean sand to 5 $\%$ silty sand, increase from $5 \%$ to $10 \%$, and then decrease from $10 \%$ to 15 and $35 \%$ silt. Pullout capacities change as the internal friction angle of the soil changes (i.e. pullout capacity increases as friction angle of the soil increases).

(2) Effect of overburden pressure: Pullout capacity increases as the overburden pressure increases. Larger displacements are required to reach the maximum pullout capacity for higher overburden pressure. Higher soil stiffness is observed for higher overburden pressure.

(3) Effect of drainage: The undrained pullout capacities are always smaller than the drained pullout capacities except for clean sand, that are equal. The ratio of undrained to drained pullout capacity changes with silt contents, but is the same for 100 and 200 
$\mathrm{kPa}$ overburden pressure. This ratio is one for clean sand, decreases to $0.67 \sim 0.69$ for $5 \%$ silty sand, increases to $0.77 \sim 0.78$ for $10 \%$ silt, decreases to $0.72 \sim 0.73$ for $15 \%$ and decreases again to $0.57 \sim 0.59$ for $35 \%$ silt. For $30 \mathrm{kPa}$ overburden, the ratio is one for clean sand, 0.5 for $5 \%$ silt, 0.67 for $10 \%$ silt, 0.78 for $15 \%$ silt and 0.72 for $35 \%$ silt.

(4) The results and comparisons of the pullout tests are presented in Tables 4-5 to 4-11 and Figures 4-13 to 4-34.

\subsubsection{Numerical analyses}

Numerical analyses are conducted to determine scale and permeability effects in the dissipation of excess pore pressures. The analyses are performed with the Finite Element (FE) program, ABAQUS. The analyses are performed for different coefficients of permeability $\left(10^{-1}, 2.27 \times 10^{-2}, 10^{-2}, 10^{-3}\right.$, and $\left.10^{-4} \mathrm{~cm} / \mathrm{sec}\right)$ and reinforcement lengths $(0.75,2,4,8,12$, and $16 \mathrm{~m})$. The following observations are made:

(1) The dissipation of pore pressures is very rapid for permeabilities larger than $10^{-2}$ $\mathrm{cm} / \mathrm{sec}$. For smaller permeabilities the dissipation becomes slower. For permeability smaller than $10^{-3} \mathrm{~cm} / \mathrm{sec}$, it takes a very long time for the pore pressures to dissipate.

(2) Results from the numerical analyses correlate well with experiments in that for clean sand, with permeability larger than $10^{-2} \mathrm{~cm} / \mathrm{sec}$, pullout capacity does not change with drainage conditions; the undrained pullout capacity of the silty sands, with 
permeabilities smaller than $10^{-2} \mathrm{~cm} / \mathrm{sec}$ is reduced with undrained tests. The largest reduction occurs for $35 \%$ silty sand that has a permeability of $1.75 \times 10^{-4} \mathrm{~cm} / \mathrm{sec}$.

(3) For larger permeabilities, the reinforcement length does not influence the time for pore pressure dissipation unless the reinforcement length is equal to the vertical drainage length. However, for smaller permeabilities, it is clearly noticeable that the longer the reinforcement, the larger the time for pore pressure dissipation

\section{2 $\underline{\text { Recommendations }}$}

This investigation shows that for drained tests the pullout capacity of granular materials may increase with the addition of a small percentage of non-plastic fines. This is directly correlated with an increase of the internal friction angle of the material, which in turn increases because the void ratio of the soil decreases as the fines occupy pore space. Once the percentage of fines reaches a threshold value (10\% for this investigation, it depends on the particular material under consideration) the addition of fines is detrimental and the internal friction angle and consequently the pullout capacity decrease. This may be caused by the fines preventing the granular particles to be in contact with each other, and thus reducing the shear stress required to mobilize the grains. It is expected that as the size of the granular material increases, and thus the pore space increases, the threshold value of fines that will decrease the pullout capacity will increase. 
These conclusions change substantially under undrained conditions. Even a small percentage of fines $(5 \%)$ may reduce the pullout capacity by $50 \%$ to $70 \%$. This reduction depends on the overburden stress and on the percentage of fines. This reduction in pullout capacity under undrained conditions is caused by a decrease of effective normal stresses at the interface between the soil and the reinforcement, which in turn is caused by the generation of excess pore pressures produced as the soil is sheared. The reduction appears to be more significant at lower overburden stresses where the added benefit of dilation in drained tests disappears. Clean sand is the only soil where no reduction is observed. This is because of the large permeability of the soil (about $10^{-2}$ $\mathrm{cm} / \mathrm{sec}$ ) compared to the other soils. This finding is supported by results from the numerical model that indicate that excess pore pressures take a long time to dissipate for permeabilities smaller than $10^{-2} \mathrm{~cm} / \mathrm{sec}$. This is particularly significant in the field where the length of the reinforcement is much larger. Thus, granular materials with even a small percentage of fines are not recommended as backfill in walls where undrained conditions may occur. A review of the literature supports this conclusion since a number of walls with a low permeability backfill failed after a heavy rain. An additional detrimental effect of fines is that they can be washed out of the backfill as the water level behind the wall changes; this may produce internal erosion and damage the wall. 


\subsection{Implementation}

For practical reasons, it is not recommended to use granular materials with fines content larger than 5 to $10 \%$ even on walls above the water table. The reasons for that are the potential for segregation of the fines, and that the material may be sensitive to changes in water content. As a general recommendation the fines should be non-plastic. For each project, the adequacy of a particular granular material as a backfill for a wall that will not experience undrained conditions can be evaluated by running triaxial tests on the material compacted to the specified density in the field.

Submerged or partially submerged MSE walls can be used if a clean granular backfill is employed. Indiana DOT stone \# 8 material is appropriate for this situation because of the low percentage of fines and large permeability. Both experiment and numerical tests show that with a clean material the time required for pore pressure dissipation is so small that for any practical purposes, no excess pore pressures are generated and the stability of the wall can be assessed through conventional calculations where effective stresses are used.

The findings from this research also show that field tests under drained conditions are not appropriate to evaluate the undrained pullout capacity under undrained conditions. If for a particular project, the undrained pullout capacity of a reinforcement embedded in a soil matrix needs to be evaluated, laboratory tests similar to the ones performed in this research are recommended. As a lower bound, and thus on the safe side, the undrained 
shear strength of the soil could be used for stability calculations with a reasonable estimate of the interface friction between the soil and the reinforcement; note that the undrained shear strength depends on the overburden effective stress. 
LIST OF REFERENCES 


\section{LIST OF REFERENCES}

Abaqus Manual (1999). Hibbit, Karlson \& Sorenson, Inc.

Abramento, M. and Whittle, A.J. (1993). Shear-Lag Analysis of a Planar Soil Reinforcement in Plane Strain Compression, Journal of Engineering Mechanics, ASCE, 119(2), pp. 270-291.

Abramento, M. and Whittle, A.J. (1995). Experimental Evaluation of Pullout Analyses for Plannar Reinforcements, Journal of Geotechnical Engineering, June, pp. 486-492.

Al-Hussaina, M., and Perry, E. B. (1978). Filed Experiment of Reinforced Earth Wall, Proceedings of the ASCE Symposium on Earth Reinforcement, Pittsburgh, pp. 127-157.

Bayoumi, A. (2000). Evaluation of Pullout Capacity of Reinforced Ottawa Sand under Drained and Undrained Conditions, MS thesis, Purdue University.

Bergado, D.T., Lo, K-H, Chai, J-C, Shivashankar, R, Alfaro, M. C., and Anderson, L. R. (1992). Pullout Tests using Steel Grid Reinforcements with Low- Quality Backfill, Journal of Geotechnical Engineering, Vol. 118, No. 7, July, pp. 1047-1063.

Bergado, D.T., Hardiyatimo, H. C., Cisneros, C. B., Chai, J-C., Alfaro, M. C., Balasubramaniam, A.S., and Anderson, L. R. (1992). Pullout Resistance of Steel Geogrids with Weathered Clay as Backfill Material, American Society for Testing and Materials, pp.33-46.

Bergado, D.T., Shivashankar, R., Alfaro, M.C., Chai, J-C. and Balasubramaniam, A.S. (1993). Interaction Behavior of Steel Grid Reinforcements in a Clayey Sand, Geotechnique 43. No.4, pp. 589-603.

Bergado, D.T., Chai, J. C., Abiera, H. O., Alfaro, M. C., and Balasubramaniam, A.S. (1993). Interaction between Cohesive-Frictional Soil and Various Grid Reinforcements, Geotextiles and Geomembranes 12, pp. 327-349.

Bourdeau, P. (1999). Class Note, Slopes and Retaining Structures, Purdue University. 
Burwash, W. J., and Frost, J. D. (1991). Case History of a $9 \mathrm{~m}$ High Geogrid Reinforced Retaining Wall Backfilled with Cohesive Soil, Proceedings, Geosynthetics '91 Conference, Atlanata, GA, Vol. 2, pp. 485-493.

Chang, J., Forsyth, R., Smith, T. (1972). Reinforced Earth Highway Embankment - Road 39, Highway Focus, Vol. 4, No.1, Federal Highway Administration, .S. Department of Transportation, Washington, D.C., Jan., 1972.

Chapuis, R. (1972). Rapport de recherché de DEA, Institute de Mecanique de Grenoble (unpublished internal report)

Christopher, B. R. (1993). Deformation Response and Wall Stiffness in Relation to Reinforced Soil Wall Design, Doctoral Thesis, Purdue University

Christopher, B. R., Bonczkiewicz, C., and Holtz, R. D. (1994). Design, Construction, and Monitoring of Full Scale Test of Reinforced Soil Walls and Slopes, Recent Case Histories of Permanent Geosynthetic-Reinforced Soil Retaining Walls, Balkema, Rotterdam, pp. 45-49.

Christopher, B. R., Gill, S.A., Giroud, J. P., Juran, I., Mitchell, J. K., Schlosser, F. and Dunnicliff, J. (1989). Reinforced Soil Structures, Design and Construction Guidelines Vol I, FHWA Report No. RD-89-043.

Craig, R. F. (1990). Soil Mechanics $4^{\text {th }}$, Chapman and Hall.

Das, B. M. (1995). Principles of Geotechnical Engineering $3^{\text {rd }}$, PWS publishing company.

Duncan, J. M. and Chang, C. Y. (1970). Nonlinear Analysis of Stress-Strain in Soils, Journal of Soil Mechanics and Foundations Division, ASCE, Vol. 96, No. SM5, pp. $1629-1653$.

Foster, C.R. (1962). Field Problems: Compaction, Foundation Engineering, G.A. Leonards (ed.), McGraq-Hill, New York

Fox, P.J., Rowland, M.G., Scheithe, J.R., Davis, K.L., Supple, M.R. and Crow, C.C. (1997). Design and Evaluation of a Large Direct Shear Machine for Geosynthetic Clay Liners, American Society for Testing and Materials

Ingold, T. S. (1982). Reinforced Earth, Thomas Telford Ltd, London

Jones, C. J. (1996). Earth Reinforcement and Soil Structures, New York, Thomas Telford publishing. 
Koerner, R. M. (1998). Designing with Geosynthetics, Upper Saddle River, NJ, Prentice Hall.

Lambe, T.W. and Whitman, R.V. (1969). Soil Mechanics, John Wiley \& Sons.

Larson, D. G. (1992). A Laboratory Investigation of Load-Transfer in Reinforced Soil, ph. D thesis, MIT.

Leonards, G. A., Frost, J. D., and Bray, J. d. (1994). Collapse of Geogrid-Reinforced Retaining Structure, Journal of Performance of Constructed Facilities, Vol. 8, No. 4, Nov., pp. 274-292.

Long, N. T., Guegan, Y. \& Legeay, G. (1972). Étude de la terre armée a l'appareil triaxial, Rapp. de Recherche, No. 17, LCPC

Mcgown, A., Andrawes, K. Z., and Al-Hasani, M. M. (1978). Effect of Inclusion Properties on the Behavior of Sand, Geotechnique 28, No. 3, pp. 327-346.

National Instruments INC. Product Catalog Web Page at www.ni.com.

Palmeira, E.M. (1987). The Study of Soil-Reinforcement Interaction by means of Large Scale Laboratory Tests, Ph.D thesis, University of Oxford, U.K.

Palmeira, E.M. and Milligan, G.W.E. (1989). Scale and other Factors Affecting the Results of Pullout Tests of Grids Buried in Sand, Geotechnique, London, pp. 511-524.

Runser, D. J., (1999). Instrumentation and Experimental Evaluation of a $17 \mathrm{~m}$ tall Reinforced Earth Retaining wall, MS thesis, Purdue University

Salgado, R., Bandini, P. and Karim, A (2000). Shear Strength and Stiffness of Silty Sand, Journal of Geotech and Geoenvironmental Eng. Div. ASCE

Schlosser, F. and Elias, V. (1978). Friction in Reinforced Earth Proceedings of the ASCE Symposium on Earth Reinforcement, Pittsburgh

Schlosser, F. and Long, N. (1974). Recent Results in French Research on Reinforced Earth, Journal of the Construction Division, ASCE, 100 (CO3), pp. 223-237

Vidal, H. (1969). The Principle of Reinforced Earth, Transportation Research Record, 282, pp. 1-16. 